\title{
VIGILÂNCIA DE POPULAÇÃO EXPOSTA A CHUMBO NO MUNICÍPIO DE BAURU - SÃO PAULO: INVESTIGAÇÃO DE FATORES DE RISCO DE EXPOSIÇÃO E AVALIAÇÃ̃O DA DINÂMICA INSTITUCIONAL
}

CLARICE UMBELINO DE FREITAS

Tese apresentada na área de concentração de Saúde Ambiental da Faculdade de Saúde Pública da Universidade de São Paulo para obtenção do Grau de Doutor em Saúde Pública.

Área de concentração: Saúde Ambiental

ORIENTADOR: PROF. DR. NELSON GOUVEIA

São Paulo

2004

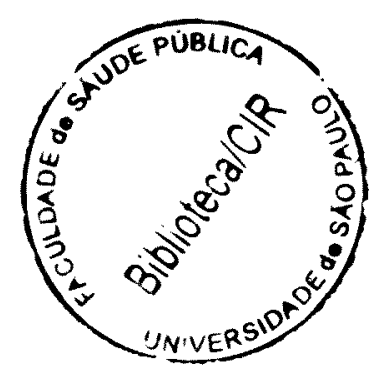




$$
4544812005 \text { doc }
$$

Autorizo, exclusivamente para fins acadêmicos e científicos, a reprodução total ou parcial desta tese, por processos fotocopiadores.

Assinatura:

Data: 
O consenso não é mais que a supressão da política.

Jacques Rancière

Aos meus familiares que me deram as bases para crescer e prosseguir.

Especialmente a Joana por suportar minhas ausências e falta de atenção e a Luzia pelo incentivo constante. 


\section{AGRADECIMENTOS}

A imprensa noticia: existe excesso de tireoidite de Hashimoto no Pólo Petroquímico de Capuava, as DIR e municipios pedem uma postura do CVE. A população está em polvorosa, como sempre. Santa Gertrudes precisa ser avaliada quanto à exposição da população a cádmio, chumbo e boro; o cádmio é cancerígeno e os ventos das cerâmicas tomam a direção da cidade. Explodem casos de anencefalia em Guaira. Os níveis de meta-hemoglobina na população estão elevados. As pessoas não tomam mais água do sistema público de abastecimento porque esta é a causa da enfermidade. Desespero geral. $\mathrm{O}$ municipio e a DIR cobram respostas. Reunião com o orientador, levantamento bibliográfico... Aumento de $60 \%$ do numero de cânceres em Cajobi, dizem os jomais. A causa são os agrotóxicos. O Estuário de Santos está parado. Faz-se necessário prosseguir o estudo de consumo de animais aquáticos. Preciso escrever a introdução da tese, tenho reunião com o orientador. A população de Ribeirão Pires está consumindo moluscos contaminados por manganês, chumbo e cádmio. A Promotoria Pública de Jacareí pede resultados da avaliação da exposição a chumbo na população, e tem mais: o programa de agrotóxicos precisa ter uma definição de laboratório de referência. O programa de Vigilância em Saúde e qualidade do ar carece de rumos mais claros. Curso de especialização no Rio. As reuniões em Brasília ... foi lá!, sei que não sou uma aluna aplicada. Aliás, meu orientador já me perguntou porquê sou tão diferente. Sei lá, respondi, já perguntei até para minha mãe. Coordeno a Divisão de Doenças Ocasionadas pelo Meio Ambiente do CVE e lá "caem" os problemas ou vamos atrás deles, mas foi em Brasília ... estávamos no aeroporto, após uma reunião do grupo assessor do VIGIAR. Esperávamos o vôo que só sairia duas horas depois. Resolvemos tomar um café e conversar. Um pequeno grupo, umas seis pessoas. Conversávamos sobre coisas amenas, quando de repente alguém perguntou: Clarice, e a sua tese? O orientador fazia parte do grupo e respondeu sem pestanejar: "já entreguei para Deus". Ele não imaginava o peso desta resposta. Senti-me queimando 
eternamente no fogo do inferno. Rearrumei a vida na medida do possível, mudei as prioridades e acabou saindo alguma coisa. Esta que você tem em mãos.

A orientação do Nelson Gouveia é suave, mas segura. Teve uma grande disponibilidade. Faria outro doutorado com ele, apesar de ter certeza de que ele não cometeria o mesmo erro duas vezes..

Este foi sobretudo um trabalho de equipe, ou melhor, equipes interinstitucionais e multidisciplimares. Todo o mérito é devido à integração e cooperação entre os grupos, desde o município, passando pelos niveis regionais da Diretoria Regional de Saúde de Bauru e Regional da CETESB, até o nível central das duas instituições de Saúde e Ambiente (Estado e Federação). Menção especial deve ser feita aos especialistas em toxicologia e neuropediatria, que prestaram assessoria e estiveram sempre à disposição de nossas dúvidas e questionamentos.

Durante o desenrolar das atividades em Bauru, tivemos dois diretores no Centro de Vigilância Epidemiologica. O José Cássio de Moraes enfrentou toda a investigação de exposição e discussão interinstituicional e o Carlos Magno C. B. Fortaleza, que nos deu efetivo apoio na conclusão da tese.

Aos meus colegas, amigos de trabalho, pela compreensão e ajuda nas discussões, dúvidas e revisão do texto, bem como pela cobertura nas minhas ausências, tirando férias e licenças para concluir o trabalho. Minha gratidão a Rosária, Mirta, Fátima, André, Estela, Angélica, Cida e Roque.

À minha filha e amiga Joana, à Elizame, à Dulce e Marília por me suportarem nas crises e dúvidas frente às prioridades entre o trabalho e a academia que para mim deveriam ser interligados.

No processo de trabalho, vamos encontrando companheiros, parcerias, cúmplices e até amigos. A conjunção destas coisas é mais rara, mas aconteceu. Foi com a Márcia Simonetti, diretora da Vigilância Epidemiológica de Bauru. A sintonia era completa e, em alguns momentos, não sabia de quem era a idéia. Começamos por um respeito mútuo, depois amizade que persistiu. Sem a Márcia não teria acontecido Bauru. 


\section{RESUMO}

Freitas CU. Vigilância de população exposta a chumbo no município de Bauru São Paulo: investigação de fatores de risco de exposição e avaliação da dinâmica institucional. São Paulo; 2004. [Tese de Doutorado - Faculdade de Saúde Pública da Universidade de São Paulo].

Introdução: Por requisição da Secretaria de Meio Ambiente realizou-se estudo de exposição em população de área contaminada por chumbo no município de Bauru.

Objetivos: Realizar diagnóstico de exposição de crianças residentes no entorno da empresa contaminadora para propor medidas de controle, avaliar o impacto destas medidas e descrever a dinâmica institucional entre os atores envolvidos, buscando dar subsídios para casos similares.

Métodos: Estudo transversal com aplicação de questionário aos genitores e dosagem de chumbo no sangue $(\mathrm{PbS})$ em todas as crianças menores de 13 anos no raio de $1 \mathrm{~km} \mathrm{da}$ empresa. Foram feitas comparações das médias de chumbo antes e após as medidas de controle e regressão logística para identificação de fatores de risco. Analisaram-se as funções e atividades das instituições a partir do arcabouço legal da intersetorialidade, noções de redes e governança.

Resultados: Das 850 crianças investigadas, 311 apresentaram níveis de plumbemia acima do estabelecido pela Organização Mundial de Saúde. Os fatores de risco identificados foram: morar em área não asfaltada, genitor trabalhar na empresa, distância da fonte, brincar na terra, comer terra, tomar leite local, número de crianças no domicílio. Após as medidas de controle houve queda de $46 \%$ nas médias de $\mathrm{PbS}$, considerando 241 crianças reavaliadas, das 311 com $\mathrm{PbS} \geq$ a $10 \mu \mathrm{g} / \mathrm{dL}$. A análise da dinâmica institucional levanta a necessidade do estabelecimento de formas mistas de gerenciamento.

Conclusões: $O$ estudo subsidiou a tomada de decisões relativas à remediação e a abordagem utilizada indica novas formas de gerenciamento de áreas contaminadas no Estado de São Paulo.

Descritores: chumbo, criança, áreas contaminadas, vigilância, epidemiologia, intersetorialidade. 


\section{SUMMARY}

Freitas, CU. Vigilância de população exposta a chumbo no município de Bauru - São Paulo: investigação de fatores de risco de exposição e avaliação da dinâmica institucional. [Surveillance of lead exposure in the city of Bauru SP: investigating risk factors and evaluating the institutional dynamics]. São Paulo (BR): 2004. [PhD Thesis - Faculdade de Saúde Pública da Universidade de São Paulo, Brazil].

Introduction: the Secretary of Environment of the State of São Paulo demanded an evaluation of lead exposure in an area of Bauru.

Objectives: to ascertain the lead exposure of children to propose control measures, evaluate the impact of these measures, and to describe the institutional dynamics among the partners invoved in order to advise other similar cases.

Methods: cross-sectional study of all children $<13$ years old in a radius of $1 \mathrm{~km}$ from the plant responsible for the contamination. Blood Lead Levels (BLL) were determined for each child and questionnaires were applied to their parents. Mean BLL were compared before and after the control measures. Logistic regression identified risk factors of lead esposure. The role and activities of the partners were described and analyzed through the legal framework of intersectoral approaches, and the concepts of networks and governance.

Results: of the 850 investigated children, 311 presented BLL above the limits established by the World Health Organization. The risk factors identified were: to live in unpaved areas, parent working in the plant, distance from the plant, to play on the ground, to eat earth, and to drink local milk. After control measures a reduction of $46 \%$ in BLL was identified considering 241 re-evaluated children with BLL $\geq 10 \mu \mathrm{g} / \mathrm{dL}$. The analysis of the institutional dynamics points towards a need to establish hybrid forms of management.

Conclusions: this study informed the decision-making process regarding management of contaminated areas. The institutional dynamics point towards new arrangements for the different actors irivolved.

Key Words: lead, child, contaminated areas, epidemiology, surveillance, intersectorial approaches. 


\section{SIGLAS USADAS}

AAP - American Academy of Pediatrics

ALA - Ácido aminolevulínico

ALAD - Ácido aminolevulínico desidratase

ANP - Agência Nacional de Petróleo

CDC - Centers for Diseases Control

CENEPI - Centro Nacional de Epidemiologia

CETESB - Companhia de Tecnologia e Saneamento Ambiental

CGVAM - Coordenação Geral de Vigilância Ambiental em Saúde

CMMAD - Comissão Mundial sobre o Meio Ambiente e o Desenvolvimento

CNUMAD - Conferência das Nações Unidas sobre o Meio Ambiente e

Desenvolvimento

CONAMA - Comissão Nacional de Meio Ambiente

COPASAD - Conferência Pan-Americana sobre Saúde e Ambiente no

Desensolvimento Humano Sustentável

CVE - Centro de Vigilância Epidemiológica

CVS - Centro de Vigilância Sanitária

DIR X - Direção Regional, com sede em Bauru, da Secretaria Estadual da Saúde

DOMA - Divisão de Doenças Ocasionadas pelo Meio Ambiente/CVE

ECLAMC - Estudo Colaborativo Latino Americano de Malformações Congênitas

FDA - Food and Drug Administration

FIESP - Federação das Indústrias do Estado de São Paulo

FUNASA - Fundação Nacional da Saúde

FUNDACENTRO - Fundação Centro de Segurança e Medicina do Trabalho

GSP - Grande São Paulo

HCM - Hemoglobina Corpuscular Média

IAL - Instituto Adolfo Lutz

IARC - International Agency for Research on Cancer

IBAMA - Instituto Brasileiro do Meio Ambiente 
IBGE - Instituto Brasileiro de Geografia e Estatistica

IMC - Índice de Massa Corpórea

MP - Ministério Público

MS - Ministério da Saúde

NHANES - National Health and Nutrition Examination Survey

OMS - Organização Mundial da Saúde

OPAS - Organização Pan-americana de Saúde

QI - Quociente de Inteligência

PEL - Probable Effect Level

$\mathrm{Pb}-$ Chumbo

$\mathrm{PbS}$ - Chumbo no Sangue

RMGSP - Região Metropolitana da Grande São Paulo

SABESP - Companhia de Saneamento Básico do Estado de São Paulo

SAMA - Divisão de Ações sobre o Meio Ambiente/CVS

SEADE - Fundação Sistema Estadual de Análise de Dados

SES - Secretaria de Estado da Saúde de São Paulo

SINVAS - Sistema Nacional de Vigilância Ambiental em Saúde

SMA - Secretaria Estadual do Meio Ambiente

SUS - Sistema Único de Saúde

SUSAM - Superintendência de Saneamento Ambiental

UNESP - Universidade Estadual Paulista

UNICAMP - Universidade de Campinas

USEPA - United States Environmental Protection Agency

VCM - Volume Corpuscular Médio

VIDÁGUA - ONG localizada na cidade de Bauru

VIGISUS - Projeto de Estruturação do Sistema Nacional de Saúde

WHO - World Health Organization

ZPP - Zincoprotoporfirina 


\section{ÍNDICE}

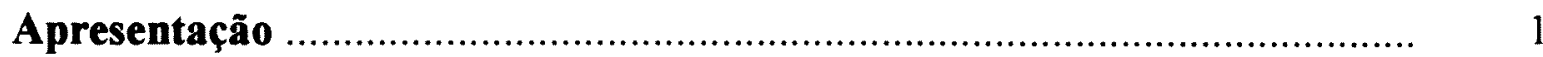

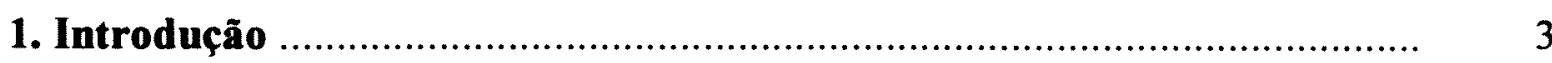

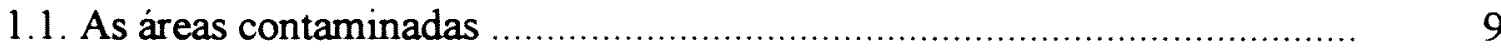

1.2. A industrialização em São Paulo ............................................................ 11

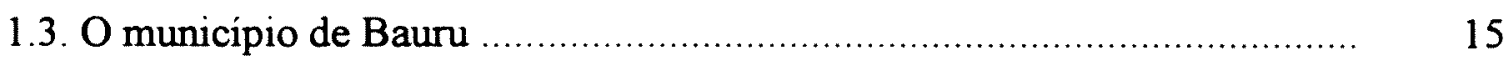

1.3.1. Indústria em Bauru................................................................... 18

1.4. Arcabouço legal do setor saúde …….................................................... 20

1.5. O chumbo no ambiente ....................................................................... 26

1.6. Fontes de exposição humana ……............................................................ 33

1.6.1. O ar como fonte de exposição ........................................................ 36

1.6.2. Exposição por ingestão ................................................................... 41

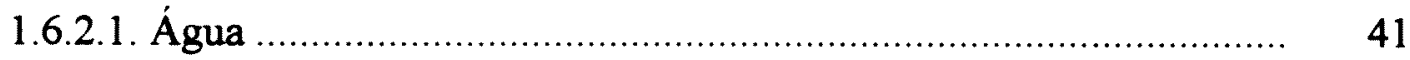

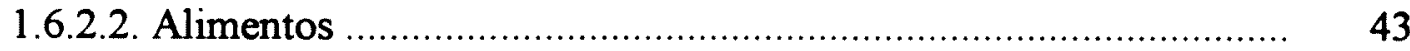

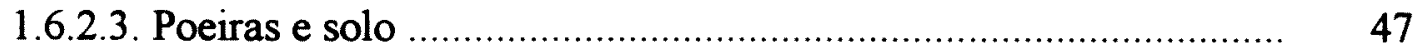

1.6.2.4. Outras fontes de exposição …………………………………..... 49

1.7. O chumbo no organismo ……............................................................. 53

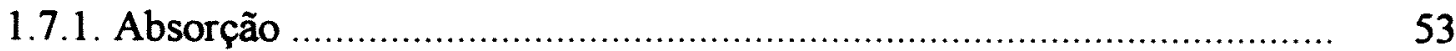

1.7.1.1. Absorção pela via respiratória .................................................. 53

1.7.1.2. Absorção pela via oral ............................................................ 54

1.7.1.3. Absorção pela pele ….............................................................. 54

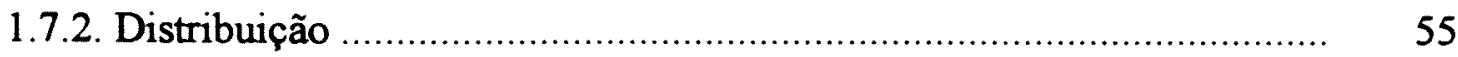

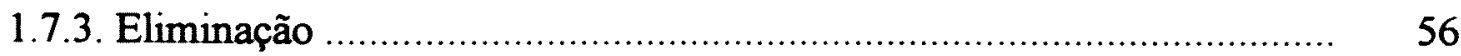

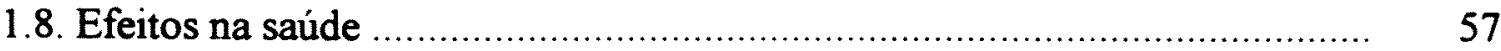

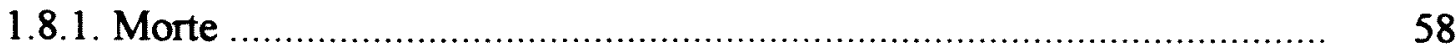

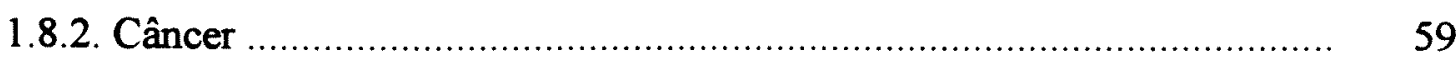

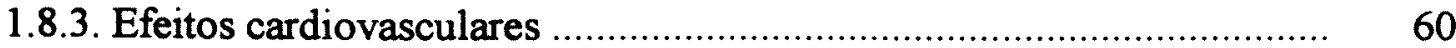




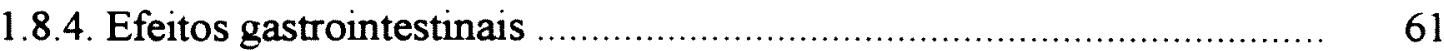

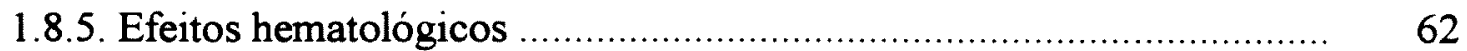

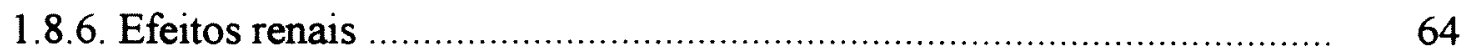

1.8.7. Efeitos endócrinos e no desenvolvimento físico .............................. 65

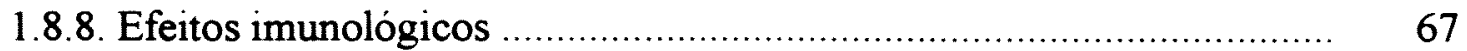

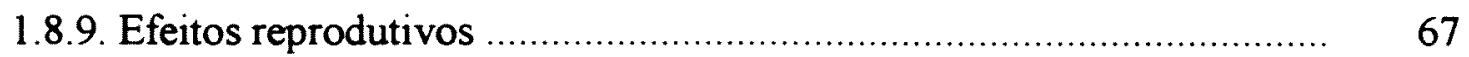

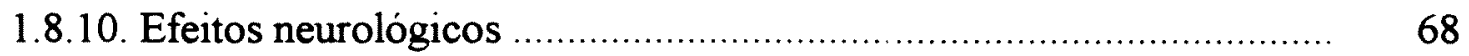

1.9. Biomarcadores de exposição a chumbo ................................................... 72

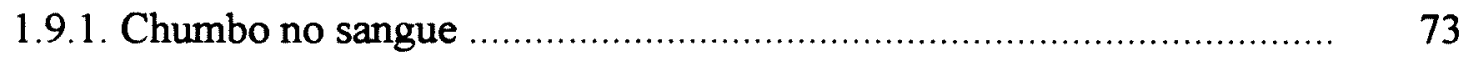

1.9.2. Chumbo no plasma ............................................................ $\quad 74$

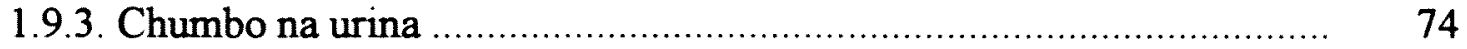

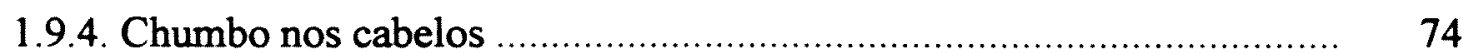

1.9.5. Chumbo nos dentes .......................................................... 75

1.9.6. Chumbo nos ossos .................................................................... 75

1.10. Niveis de plumbemia em crianças no mundo......................................... 76

1.11. Estudos de populações expostas a fontes fixas de emissão de chumbo ..... 81

2. Objetivos ....................................................................................... 90

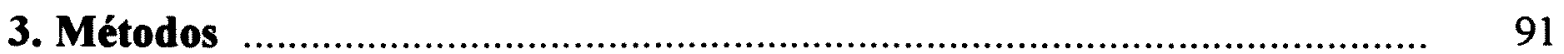

3.1. O problema e as primeiras ações ........................................................ 92

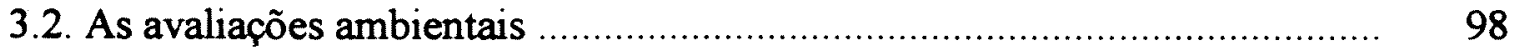

3.3. A avaliação da exposição humana ................................................... 101

3.4. Análise dos fatores de risco de exposição ......................................... 106

3.5. Avaliação do impacto das medidas de controle .................................... 108

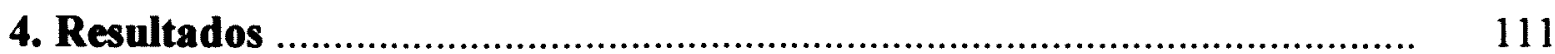

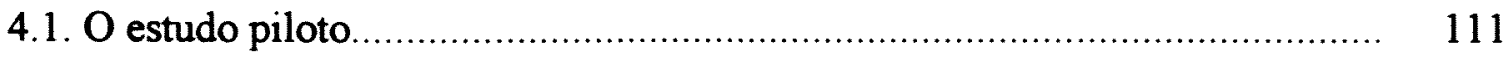

4.2. O reconhecimento preliminar da área................................................. 113

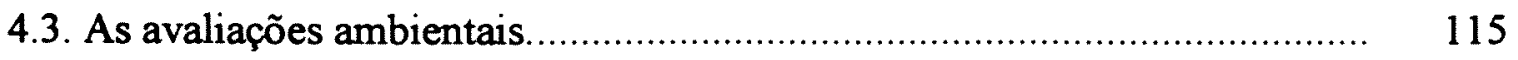

4.3.1. As avaliações da CETESB....................................................... 115 


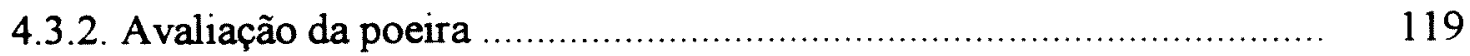

4.3.3. Avaliação dos produtos da horta e animais......................................... 121

4.4. Avaliação epidemiológica de exposição a chumbo.................................... 121

4.4.1. Variáveis ligadas à pessoa ........................................................... 123

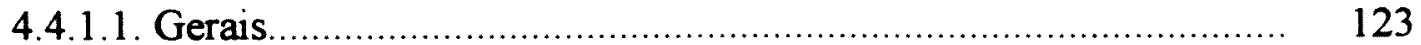

4.4.1.2. Hábitos das crianças........................................................... 125

4.4.1.3. Ocupação dos pais ................................................................ 127

4.4.2. Variáveis relacionadas ao lugar.................................................. 128

4.4.2.1. Fatores internos à residência................................................. 128

4.4.2.2. Fatores externos à residência ................................................ 129

4.4.3. Características ligadas ao tempo ................................................ 132

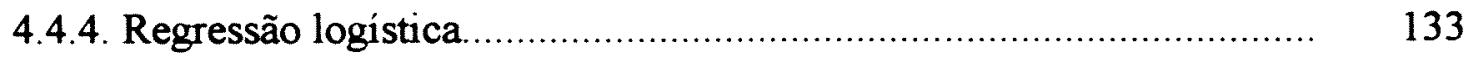

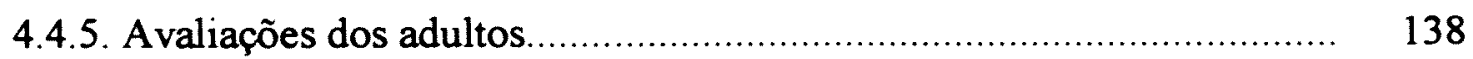

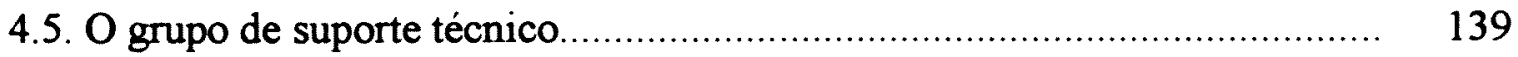

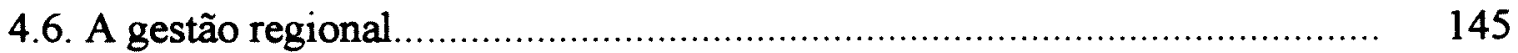

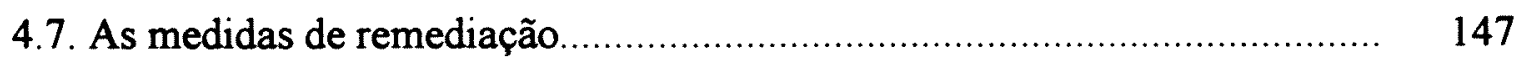

4.8. As reavaliações de plumbemia das crianças ............................................. 150

4.8.1. Avaliação antes da remediação....................................................... 150

4.8.2. Reavaliação após as medidas de controle .......................................... 151

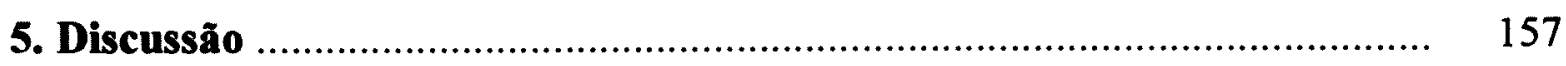

5.1. Intersetorialidade: fundamentos jurídico-legais …................................. 158

5.2. As noções de redes e a experiência de Bauru ........................................... 169

5.3. Aspectos de governança na experiência de Bauru .................................. 175

5.4. A avaliação das crianças ...................................................................... 193

5.5. As reavaliações das crianças ................................................................ 201

6. Conclusões .................................................................................. 211

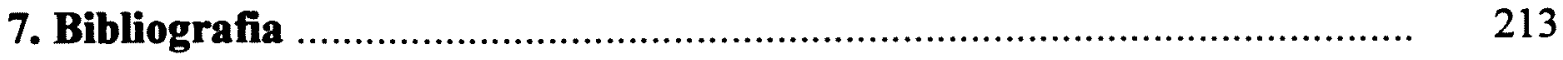

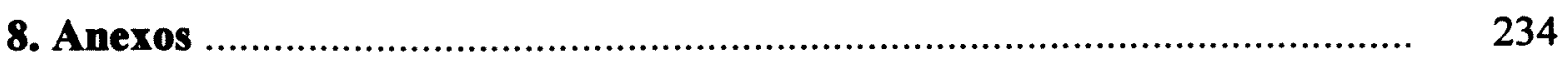


Anexo 1: Entrevista com o gestor do processo …………........................... 235

Anexo 2: Termo de permissão dos responsáveis ........................................... 246

Anexo 3: Questionário de investigação aplicado na área ................................ 247

Anexo 4: Análise de alimentos ............................................................ 249

Anexo 5: Primeira reunião do grupo de suporte técnico ................................... 251

Anexo 6: Segunda reunião do grupo de suporte técnico ………...................... 255

Anexo 7: Percentual de perdas entre os grupos de crianças segundo realização 258

dos exames de plumbemia antes e após as medidas de remediação 


\section{APRESENTAÇÃO}

O desenvolvimento deste estudo envolveu grupos interinstitucionais e multidisciplinares. Este tipo de trabalho exige arranjos que são diferenciados de acordo com a experiência dos integrantes e, no caso de Bauru, foram consensuados a cada etapa.

A experiência do municipio de Bauru contou com uma teia de relações complexa, envolvendo desde o nivel local, regional e universidades, que compunham, acordavam e tomavam decisões orientadas por um grupo, denominado nesta tese como grupo de suporte técnico, sediado no Centro de Vigilância Epidemiológica. Uma vez tomadas as decisões, as instituições participantes se responsabilizavam por encaminhá-las, executando-as de acordo com as peculiaridades próprias. Assim, coube ao município executar as atividades de campo, o que foi realizado pelos profissionais da Vigilância em Saúde, tendo-se designado um coordenador. À Diretoria Regional de Saúde de Bauru coube a orientação e supervisão das atividades de campo e orientação técnica ao municipio, construção e controle do banco de dados de crianças. A CETESB se responsabilizou pela avaliação ambiental e o Centro de Vigilância Sanitária pela coleta para análise dos produtos de consumo humano, com as análises laboratoriais efetuadas no Instituto Adolfo Lutz. 
Os arranjos foram variados, tendo em alguns momentos pessoas responsáveis pelos encaminhamentos e tarefas e em outros grupos, como foi o caso das avaliações clínico-neurológica e neurocomportamental dos menores.

O desenho do estudo e análise dos dados de exposição humana, produção de relatórios da área da saúde para o Ministério Público e coordenação do grupo de suporte técnico ficaram a cargo da Divisão de Doenças Ocasionadas pelo Meio Ambiente do Centro de Vigilância Epidemiológica e foram executadas pela autora da presente tese. A autora conta com autorização do Município e Regional de Saúde de Bauru para divulgar todo o trabalho realizado.

Portanto, esta tese é resultado de um trabalho de análise de dados e de avaliação da dinâmica institucional, sendo o autor participante do processo e não apenas um observador externo.

Estas particularidades e arranjos em Bauru, não descaracterizam um trabalho interinstitucional e multidisciplinar, na medida em que todas as produções efetuadas eram apresentadas ao grupo de suporte técnico, tendo este a função de julgar sua pertinência e adequação, decidindo quanto aos encaminhamentos pertinentes a cada caso. 


\section{1 - INTRODUÇÃO}

Em $1^{\circ}$ de fevereiro de 2002, foi protocolada na Direção Regional de Saúde de Bauru correspondência da Companhia de Tecnologia e Saneamento Ambiental CETESB comunicando a interdição de uma indústria de acumuladores, ocorrida em 29/01/02, motivada pela constatação de emissão de chumbo - Pb na atmosfera, oriundo do processo industrial da empresa, em valores superiores aos padrões estabelecidos. A correspondência solicitava “... pesquisa epidemiológica, para avaliação da saúde das pessoas envolvidas". Este trabalho pretende avaliar a exposição da população do entorno dessa indústria; identificar fatores de risco para niveis elevados de chumbo no sangue para orientação de medidas de controle; verificar se essas medidas tiveram impacto na população e, a partir do relato das atividades dos diversos setores envolvidos, descrever a dinâmica institucional do processo.

O setor metalúrgico da indústria, interditado por contaminação atmosférica por chumbo, teve início de suas atividades em 1974 (Figura 1). Encontra-se instalado em um terreno de $76.800 \mathrm{~m}^{2}$, com $5.890 \mathrm{~m}^{2}$ de área construída e $2.440 \mathrm{~m}^{2}$ de área de atividade ao ar livre. Nesta unidade industrial da empresa são realizadas as atividades de recuperação de chumbo e polipropileno a partir de baterias automotivas usadas, obtidas nas oficinas auto-elétricas. Trata-se de um empreendimento classificado pelo Instituto Brasileiro de Geografia e Estatística - IBGE, pelo Instituto Brasileiro de Meio Ambiente - IBAMA e pela CETESB como "potencialmente poluidor", o que torna imprescindivel o devido licenciamento ambiental (Lei $n^{\circ}$ 997/76 e Decreto ${ }^{\circ}$ 
8.468/76). Pelo fato de sua instalação ter sido anterior ao ato legislativo a empresa funciona sem licença.

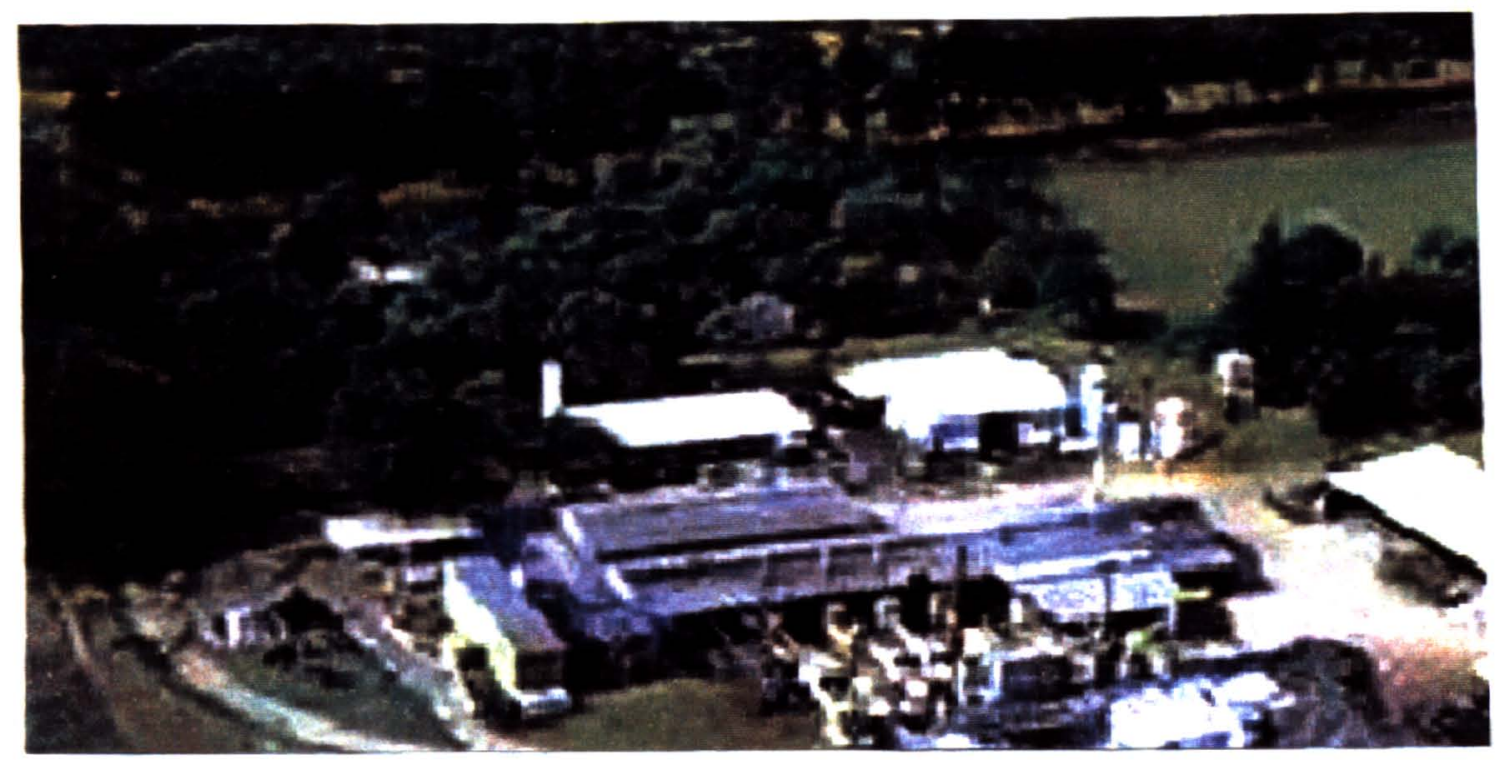

Figura 1. Indústria em estudo no município de Bauru, 2002.

A produção mensal da indústria era de cerca de mil toneladas de lingotes de chumbo e cento e vinte toneladas de polipropileno, provenientes do processamento de aproximadamente mil e setecentas toneladas de baterias automotivas usadas, sendo que na produção de lingotes de chumbo eram acrescidas, aproximadamente, trinta toneladas de pó retidas nos filtros dos equipamentos de controle, trinta toneladas de lodo gerado na estação de tratamento de afluentes líquidos e seis toneladas de escórias geradas nos fornos. Utilizavam-se também os seguintes 
implementos e combustíveis: aproximadamente 3,5 toneladas/mês de cavacos de ferro, 0,3 tonelada/mês de enxofre, trinta e duas toneladas/mês de carvão vegetal, quarenta e oito toneladas/mês de óleo e 8,4 toneladas/mês de gás liqüefeito de petróleo - GLP.

Desde 1984 a indústria vinha sendo autuada pela CETESB, por várias irregularidades, tais como:

emissão de poluentes na atmosfera; realização de queima ao ar livre de residuos sólidos;

> emissão de substâncias odoriferas na atmosfera além dos limites permitidos;

$>$ disposição inadequada de resíduos sólidos industriais no solo;

$>$ lançamento de efluentes líquidos industriais em desacordo com a legislação;

$>$ ampliação e manutenção de fonte de poluição sem a devida licença de funcionamento da CETESB;

> emissão de material particulado na atmosfera, proveniente da operação de fusão e refino do chumbo.

No período de 1984 a 2001 foram aplicadas vinte e sete penalidades, sendo dezessete advertências e dez multas (CETESB, 2002).

Dentre as ações de controle que estavam sendo desenvolvidas pela Agência Ambiental da CETESB de Bauru, foram realizadas, em meados do ano de 2001, amostragens que diagnosticavam episódios graves de poluição do ar, provenientes das atividades de produção da indústria, caracterizando risco iminente à saúde pública, destacando-se: 
no início de abril de 2001 , foram realizadas amostragens de chaminé, cujos resultados indicaram que, considerando o maior limite de emissão aprovado, referente aos fornos rotativos/revérberos, as concentrações obtidas nessa campanha estavam acima dos limites de emissão para material particulado e chumbo;

nas amostragens de poeira sedimentável foram encontradas concentrações de $2300 \mathrm{~kg} / \mathrm{km}^{2} / 30$ dias a duzentos metros da indústria e no seu pátio taxas de até $6000 \mathrm{~kg} / \mathrm{km}^{2} / 30$ dias. Não existem padrões para chumbo em poeira sedimentável, embora na área urbana dos Estados Unidos tenham sido registradas taxas de 3 a $12 \mathrm{~kg} / \mathrm{km}^{2} / 30$ dias (CETESB, 2002).

tendo em vista os resultados das amostragens de chaminés e de chumbo na poeira sedimentável, a CETESB instalou, de junho a agosto de 2001, equipamento para avaliação das partículas finas de chumbo na atmosfera (particulas re-suspensas), emitidas pelas atividades da empresa. Todas as amostras foram realizadas a oitocentos metros da fonte. Os resultados destas amostragens, embora com intervalo de duração inferior a três meses, que é o preconizado pela Agência de Proteção Ambiental Americana - EPA, mostraram que as concentrações de chumbo na atmosfera foram extremamente elevadas, com média de $9,7 \mu \mathrm{g} / \mathrm{m}^{3}$, chegando a alcançar valores de ate $37,7 \mu \mathrm{g} / \mathrm{m}^{3}$ durante 24 horas. Portanto, se estes niveis fossem mantidos, o padrão de $1,5 \mu \mathrm{g} / \mathrm{m}^{3}$ (média trimestral) seria largamente ultrapassado; 
em inspeções na indústria, foram constatadas a destinação final inadequada dos resíduos sólidos e a má condição de operação da sua estação de tratamento de efluentes líquidos;

Com base nos resultados da concentração das partículas totais de chumbo em suspensão na atmosfera e, ainda, devido à existência de residências próximas ao local, a CETESB propôs à Secretaria Estadual do Meio Ambiente - SMA a interdição temporária da empresa, até que esta tomasse as medidas necessárias de proteção ambiental e pudesse funcionar sem riscos à população do entorno.

A área do entorno da empresa, em raio de $1 \mathrm{~km}$, caracteriza-se por vários tipos de ocupação, desde região não habitada até urbanizada e rural (Figura 2):

loteamento residencial popular medianamente ocupado, com ruas sem pavimentação, no chamado Jardim Tangarás, ao norte e do lado oposto à indústria em relação à rodovia;

$>$ loteamento praticamente desocupado, a nordeste e no mesmo lado da indústria em relação à rodovia;

>área de cerrado pertencente ao Jardim Botânico, com inserção de alguns sitiantes posseiros, ao sul e do mesmo lado da indústria em relação à rodovia;

algumas chácaras de alto padrão atrás da indústria;

área desocupada, em frente à indústria, do outro lado da rodovia;

> loteamento residencial densamente habitado, com ruas asfaltadas, no chamado Jardim Regino, a oeste da indústria e após a área desocupada. 


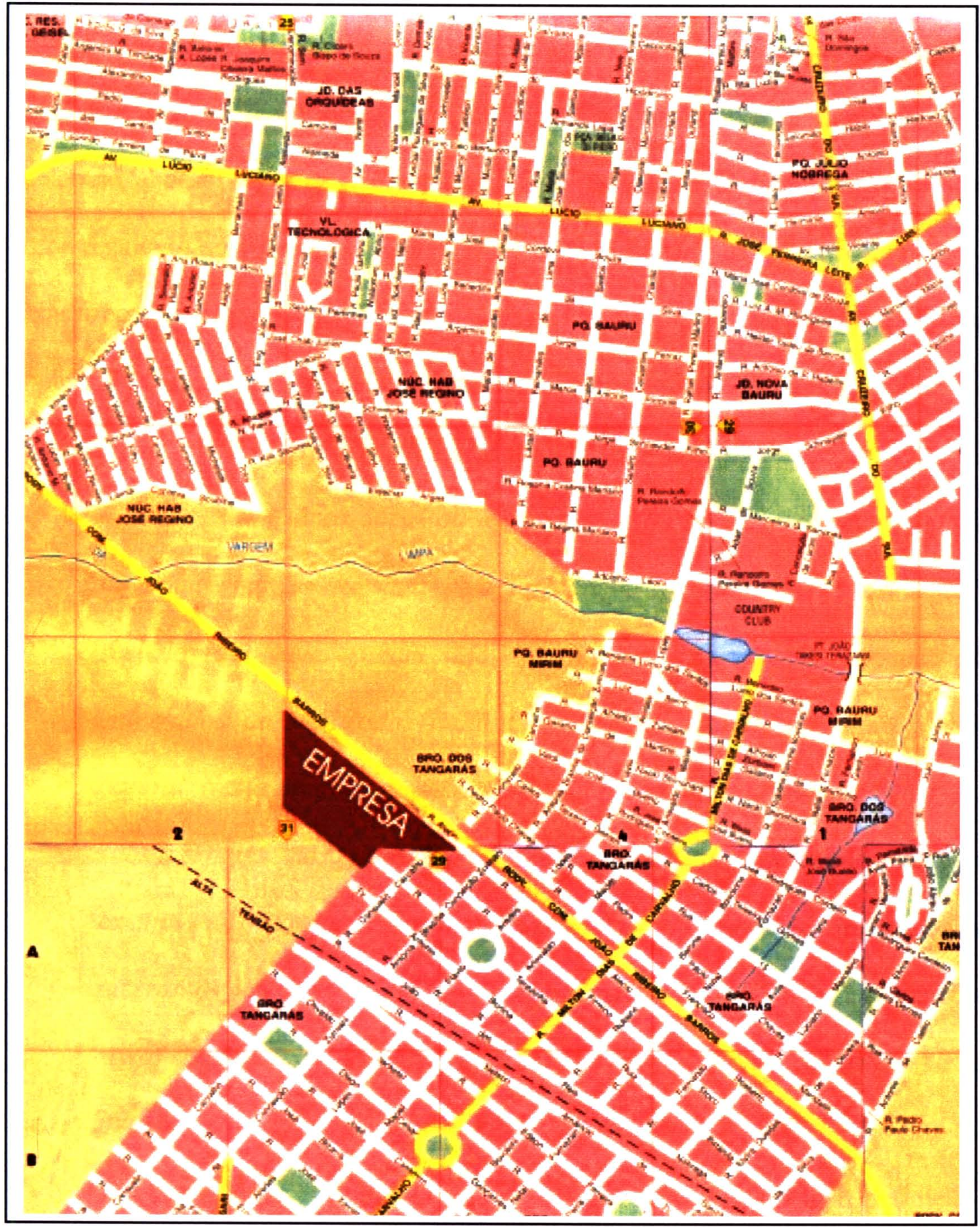

Figura 2. Área do entorno da empresa em estudo. Bauru, 2002. 


\section{1 - Áreas contaminadas}

Segundo Sánchez (1998), todo empreendimento industrial tem vida útil finita, embora este tempo seja indeterminado na maioria dos casos. $\mathrm{O}$ autor argumenta que nos últimos anos, devido a mudanças estruturais na economia mundial, têm se acelerado a desativação e a relocalização de indústrias manufatureiras, deixando como resultado passivos ambientais - áreas contaminadas - particularmente de solos. Estas áreas têm como principais problemas os riscos à segurança pública, à saúde da população, restrições ao desenvolvimento humano e redução do valor imobiliário dos terrenos. Para a CETESB, uma área contaminada pode ser definida como:

“... uma área, local ou terreno onde há comprovadamente poluição ou contaminação causada pela introdução de quaisquer substâncias ou residuos que nela tenham sido depositados, acumulados, armazenados, enterrados ou infiltrados de forma planejada, acidental ou até mesmo natural. Nesta área, os poluentes ou contaminantes podem concentrar-se em subsuperficies nos diferentes compartimentos do ambiente, como por exemplo no solo, nos sedimentos, nas rochas, nos materiais utilizados para aterrar os terrenos, nas águas subterrâneas ou, de uma forma geral, nas zonas não saturada ou saturada, além de poderem concentrar-se nas paredes, nos pisos e nas estruturas de construções" (CETESB, 2003).

O conceito de áreas contaminadas no Brasil está vinculado à definição de bens a proteger, localizados na própria área ou seus arredores, que são identificados pela Lei ${ }^{\circ} 6.938 / 81$ como: 
$\checkmark$ a saúde e o bem-estar da população;

$\checkmark$ a fauna e a flora;

$\checkmark$ a qualidade do solo, das águas e do ar;

$\checkmark$ os interesses de proteção à natureza/paisagem;

$\checkmark$ a ordenação territorial e planejamento regional e urbano;

$\checkmark$ a segurança e ordem pública.

A contaminação do solo por resíduos organoclorados nos municípios de Cubatão e São Vicente, na Baixada Santista foi um dos primeiros episódios de área contaminada de repercussão nacional ainda nos anos oitenta. Os resíduos de pesticidas foram provenientes de fabricação pela empresa Clorogil que, em 1976, foi comprada pela Rhodia. Esta empresa, ao assumir o passivo ambiental da Clorogil, foi ré em ação civil pública ambiental em 1986. A esta se seguiu a identificação de outros sitios como as instalações industriais da Matarazzo, em São Caetano do Sul, onde o solo foi contaminado por mercúrio e pesticida clorado, e a Profundir, indústria de fundição na Praia Grande, litoral de São Paulo (Sánchez, 1998). Dados publicados em 1996, como resultado de inventário de áreas contaminadas na Região Metropolitana de São Paulo, indicaram a existência de 2300 sítios potenciais. A partir de 2002, a CETESB vem divulgando inventário de áreas com contaminação no Estado de São Paulo. Na primeira lista, publicada em 2002 foram citadas 255 áreas. Este montante sobe para 727 em 2003 (CETESB, 2003). A Tabela 1 apresenta a distribuição destas áreas segundo atividade e localização. Nela, em primeiro lugar encontram-se os postos de combustiveis (63\%), e em segundo a indústria com $22 \%$. 
Quanto à localização, o município de São Paulo figura com 43\% das ocorrências; os demais municipios da Região Metropolitana com $23 \%$ e o interior contabiliza $21 \%$. O Estado ainda carece de método de abordagem integrador para o enfrentamento deste problema

Tabela 1. Áreas contaminadas do Estado de São Paulo (outubro de 2003)

\begin{tabular}{lllllll}
\hline Região/ Atividade & Comercial & Industrial & $\begin{array}{l}\text { Disposição de } \\
\text { residuos }\end{array}$ & $\begin{array}{l}\text { Postos de } \\
\text { combustivel }\end{array}$ & Outros & Total \\
\hline São Paulo - capital & 19 & 28 & 14 & 250 & 1 & 312 \\
RMSP - outros & 7 & 45 & 10 & 103 & 2 & 167 \\
Interior & 20 & 56 & 15 & 63 & 5 & 150 \\
Litoral & 1 & 19 & 11 & 44 & 4 & 79 \\
Vale do Paraiba & 1 & 14 & 0 & 4 & 0 & 19 \\
\hline Total & 48 & 162 & 40 & 464 & 13 & 727 \\
\hline
\end{tabular}

Fonte: CETESB

'inclui contaminações por acidentes ferroviários. rodoviários, em dutos ou atividades de serviços.

\section{2 - A industrialização em São Paulo}

No último quartel do século XIX, a acumulação de capital provinda da expansão da lavoura mercantil, a substituição do trabalho escravo por mão-de-obra assalariada, a ocupação de terras da agricultura de subsistência e a expansão das ferrovias desencadearam a formação de uma economia de mercado interno em São Paulo (Simão, 1981).

Na década de 1870 , o novo modelo de produção, baseado no trabalho assalariado, propiciou um grande surto de urbanização em São Paulo, com aumento das atividades artesanais e o aparecimento da indústria têxtil. Embora esta tenha 
liderado o crescimento industrial do Estado até finais da década de 1920, outros setores começam a despontar. Em 1928, o ramo têxtil ocupava 47\% dos operários paulistas. Esta proporção decresce para $36 \%$ na década de 1930 , enquanto o setor metalúrgico/mecânico aumenta sua participação, entre os anos de 1920 a 1927, passando de 6\% para 18\% (Simão, 1981).

Marcado pelas grandes crises da economia mundial, o crescimento do parque industrial de São Paulo foi de grande monta. De 1907 a 1920, o número de empresas registradas passou de 326 para mais de quatro mil. No período de 1928 a 1937, o contingente de empresas subiu de 6923 para 9051 , tendo dobrado o total de assalariados. Os registros dos censos nacionais de 1940 e 1950 dão conta de 14225 e 25016 estabelecimentos industriais no Estado. A maior parte destes estabelecimentos concentrava-se na capital, tendo havido um crescimento para os municípios vizinhos a oeste. Como fatores que contribuíram para este tipo de localização podem ser citados a expansão cafeeira, a imigração, a instalação de ferrovias e o melhoramento do porto maritimo (Simão, 1981). Em 1959, a Grande São Paulo - GSP - detinha $74 \%$ do Valor de Transformação Industrial - VTI ${ }^{1}$ - do Estado e $41 \%$ do País.

A preocupação com o "caos urbano" decorrente desta concentração industrial colocou em pauta o tema "descentralização industrial", que deveria dirigir-se a partir da região metropolitana para o interior e desta para o resto do Brasil (Negri, 1996). Argumentava-se que a elevada concentração industrial na Grande São Paulo levava à

\footnotetext{
' VTI - Valor de Transformação Industrial - é um conceito definido pelo IBGE. que mede a diferença entre o Valor Bruto da Produção Industrial (VBPI) menos os Custos de Operações Industriais (COI), onde
} 
deterioração das condições de vida da população residente, particularmente nas periferias da capital paulistana e municípios do entorno. A ausência de políticas sociais e urbanas nestas áreas tinha como conseqüência sérios problemas ambientais.

As discussões acerca da interiorização da indústria foram colocadas em pauta, já em 1961, pela Federação das Indústrias do Estado de São Paulo - FIESP, envolvendo a comunidade científica e, posteriormente, o governo estadual incorporou-se ao debate criando instrumentos de descentralização. Ao lado da construção de rodovias, foram sendo criados instrumentos legais coercitivos, particularmente relacionados ao controle ambiental. Em 1975, é editado o Decretolei $\mathrm{n}^{\circ} 1413$ que dispõe sobre o controle da poluição do meio ambiente provocado pelas atividades industriais. Por este decreto se adota o conceito de áreas críticas, nas quais será estabelecido o esquema de zoneamento urbano. No mesmo ano, no Estado de São Paulo, publica-se a Lei $n^{\circ} 898$ que disciplina o uso do solo para proteção dos mananciais, cursos e reservatórios de água e demais recursos hídricos da Região Metropolitana da Grande São Paulo. Na mesma linha, em 1976, ficam proibidos o lançamento ou a liberação de poluentes nas águas, ar e solo (Lei ${ }^{\circ}{ }^{997)}$.

Ao lado das medidas restritivas de implantação de novas indústrias na GSP, os municipios criaram uma série de estímulos à industrialização como: isenção parcial ou total de tributos por determinado periodo de tempo, a doação e concessão 
de terrenos, a execução gratuita de infra-estrutura básica e a implantação de distritos industriais.

O interior do Estado de São Paulo começa a se afirmar como uma das regiões mais dinâmicas do processo de industrialização brasileiro no periodo do "milagre econômico" - 1967 a 1973. Neste periodo, as taxas de crescimento do interior paulista foram superiores às taxas nacionais (SMA, 1989). Portanto o surto de desenvolvimento industrial interiorano se deu antes da regulamentação de proteção ambiental. Nobre (2004), analisando as causas da interiorização da indústria em São Paulo, indica que entre elas estão a falta de competitividade da Região Metropolitana, resultado de uma organização sindical forte, a expansão da infraestrutura no interior, além de os valores de terrenos e impostos serem um grande atrativo. Em 1985 o VTI da Grande São Paulo diminuíra para 57\% do total do Estado. Segundo Negri (1996), as prefeituras, com apoio das respectivas câmaras de vereadores, adotaram medidas muitas vezes irresponsáveis para atrair indústrias, sem análise do custo/beneficio dos empreendimentos e com repercussão sobre a urbanização, as finanças municipais e o meio ambiente. Ainda segundo Negri (1996), a interiorização da indústria ocorreu mais por expansão da malha viária e das restrições legais estabelecidas na GSP nos meados da década de 1970, do que devido aos incentivos municipais. As argumentações levantadas pelos diversos autores acerca da interiorização da indústria em São Paulo não são excludentes. Provavelmente todas contribuiram para isto. A industrialização do interior levou para os municipios os mesmos problemas já enfrentados pela Região Metropolitana da 
Grande São Paulo - RMGSP tais como: deficiência de transporte coletivo, saneamento, habitação, falta de escolas e leitos hospitalares, segurança, além de introduzir a poluição ambiental.

\section{3 - O município de Bauru}

O nome Bauru é de origem indígena e, de acordo com a etimologia da palavra, pode estar se referindo às águas turvas do rio Bauru, ou à lagoa escura que se formara na região, ou ainda como é comumente aceito, simplesmente a um cesto de frutas. Fundado em 1896, o município se desenvolveu primordialmente ligado à cultura de café. Marcado por conflitos entre índios e colonizadores, teve seu crescimento atrelado à construção das estradas de ferro Sorocabana (1905), Noroeste do Brasil (1906-39) e Companhia Paulista de Estradas de Ferro (1910), que ligaram a cidade aos pólos em desenvolvimento do país, facilitando o escoamento de seus produtos. A grande concentração urbana e sua comunicação com os pólos em desenvolvimento, tanto pelas estradas de ferro quanto, posteriormente, pelas rodovias, propiciou o crescimento do comércio e serviços, sendo estes atualmente as principais fontes de renda da cidade. As rodovias duplicadas lhe dão acesso às principais cidades do Estado de São Paulo e dos Estados vizinhos (Prefeitura de Bauru, 2003; "Vivendo Bauru", 2003).

Situado na região noroeste, praticamente no centro do Estado de São Paulo (Figura 3), Bauru tem área de $674 \mathrm{~km}^{2}$, tendo o perímetro urbano $120 \mathrm{~km}^{2}(17 \%$ do total). De sua população de 543.462 habitantes, $512.475(94 \%)$ vivem em 
concentrações urbanas (SEADE, 2003). Segundo dados do Censo Agropecuário do IBGE (1995-96), na área rural de Bauru 69\% das terras são ocupadas com pastagens, $17 \%$ com lavouras e $14 \%$ com matas ("VIDÁGUA", 2003). Dentre os 64.993 trabalhadores do mercado formal, 16.716 são empregados nos 884 estabelecimentos industriais. Os demais encontram-se nos setores de comércio (2939 estabelecimentos), serviços (2312 estabelecimentos) e outros (242 estabelecimentos com 948 trabalhadores) (SEADE, 2003). Apesar de situado em região de intensa produção agrícola e pecuária, o município exerce a função de pólo centralizador das atividades comerciais e de serviços, com processo recente de expansão industrial. 


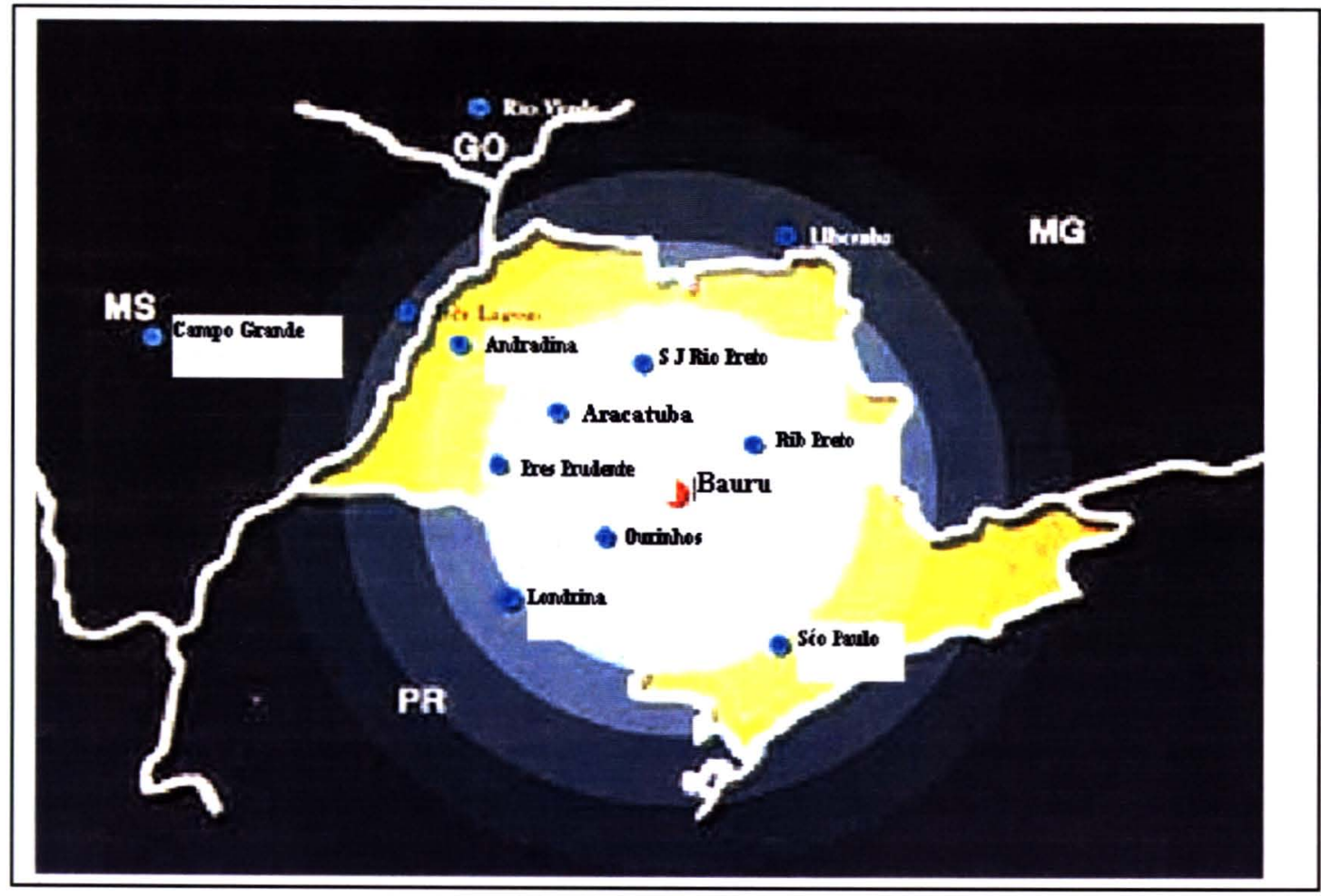

Figura 3. Localização do município de Bauru no Estado de São Paulo.

A topografia do município é plana (tipo planalto), com suaves ondulações. A altitude mínima é de 400 metros e a máxima de 615 metros. Seu clima é tropical temperado, com temperatura média de $26,3^{\circ} \mathrm{C}$, variando de $12,9^{\circ} \mathrm{C}$ no inverno a $32,2{ }^{\circ} \mathrm{C}$ no verão. A média de umidade relativa do ar é de $60 \%$ no inverno e $75 \%$ no verão. A precipitação pluviométrica anual é de $100 \mathrm{~mm}$. O solo é de afloramento précambriano e a vegetação primitiva de floresta tropical, sendo a atual de cerrado. Os recursos hidrográficos estão concentrados no rio Tietê. O principal afluente é o rio Batalha, que é fonte coletora de água do município. 
O saneamento básico atende $98 \%$ da população urbana com água tratada e 95\% com serviço de esgotamento sanitário.

A estrutura de serviços de saúde ambulatorial e hospitalar é bastante desenvolvida, sendo Bauru pólo de atendimento e referência para diversas cidades da região. Destaca-se tanto nacional quanto internacionalmente o Instituto Lauro de Souza Lima em dermatologia sanitária, em especial nas pesquisas, tratamento e treinamentos em hanseniase e o Hospital de Reabilitação de Anomalias Craniofaciais da Universidade de São Paulo, o "Centrinho", na área de má formação de extremidades, craniofaciais, deficiência auditiva, visual e mental (DIR X, 2004)

\subsection{1 - Indústria em Bauru}

A cidade de Bauru possui três distritos industriais em funcionamento e um desativado (Figura 4), nos quais são fabricados produtos dos mais variados: cadernos escolares, baterias automotivas, plásticos, formulários continuos, embalagens, alimentos (balas, chicletes, etc.), derivados de carne e outros. Os setores que mais exportam são o gráfico, o de acumuladores de energia, o de massas alimentícias e o de carne bovina. 


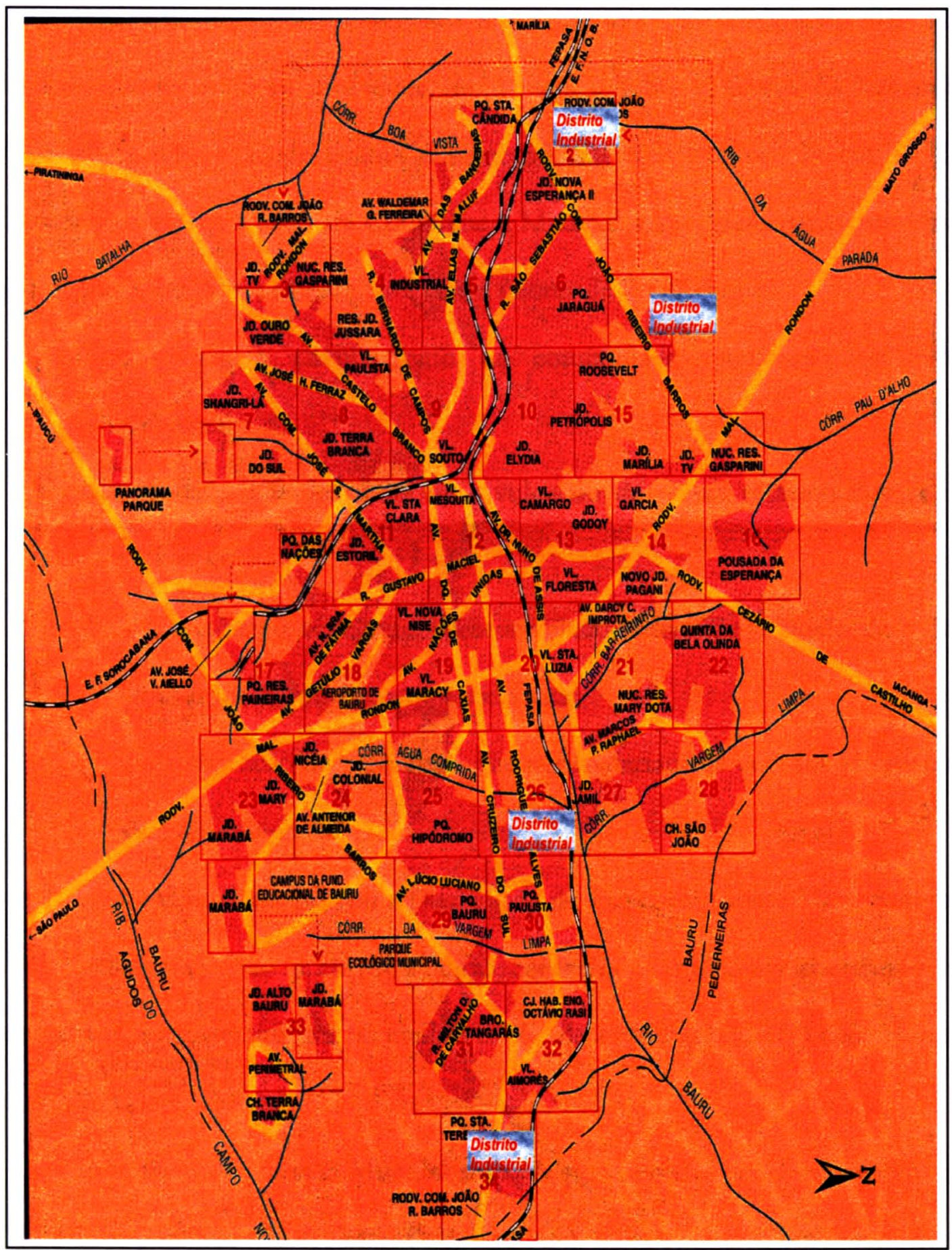

Figura 4. Mapa da cidade de Bauru com os principais bairros e distritos industriais. 


\section{4-Arcabouço legal do setor saúde}

A década de 1970 foi marcada mundialmente por um grande processo de conscientização sobre os problemas ambientais e sobre o futuro da humanidade, tanto em relação à saúde quanto à proteção dos ecossistemas. Já em 1972, em Estocolmo, ocorreu a primeira Conferência Mundial sobre Meio Ambiente Humano que, segundo Le Preste (2000), teve como fatores desencadeantes:

$\checkmark$ o crescente envolvimento da comunidade cientifica nas questões ambientais;

$\checkmark$ a participação da mídia na divulgação de temas relacionados ao meio ambiente;

$\checkmark$ o crescimento econômico descontrolado, alterando o modo de vida das pessoas, com influência no êxodo rural;

$\checkmark$ a identificação de problemas que necessitariam de acordos internacionais para sua mitigação.

Esta conferência aprovou a Declaração de Estocolmo sobre Meio Ambiente e Vida, tendo-se seguido a ela três outras conferências mundiais abordando temas especificos: estabelecimentos humanos (1976); desertificação (1977) e água, também em 1977 (Bonini, 2002).

Em 1987, a Comissão Mundial sobre Meio Ambiente e o Desenvolvimento CMMAD publicou o relatório Brundtland, incorporando o conceito de desenvolvimento sustentável à teoria das questões econômicas relacionadas ao meio ambiente, como forma de proteção às gerações futuras entendendo que: 
“... O desenvolvimento sustentável não é um permanente estado de harmonia, mas um processo de mudanças no qual a exploração dos recursos, a orientação dos investimentos, os rumos do desenvolvimento tecnológico e a mudança institucional estão de acordo com as necessidades atuais e futuras" (CMMAD, 1991).

Em 1992, a Conferência das Nações Unidas sobre Meio Ambiente e Desenvolvimento - CNUMAD ou ECO/92 -, ocorrida no Rio de Janeiro/Brasil, teve no Relatório Brundtland a inspiração para definição de seus objetivos. Buscou-se na Declaração do Rio sobre o Meio Ambiente e Desenvolvimento um consenso entre os paises, estruturado em 27 artigos, que visavam guiar a postura dos governos, suas intenções e a mobilização da sociedade. A Agenda 21, cerne da ECO/92, não corresponde a um instrumento jurídico, mas direciona para questões ambientais que exigem definição política, tendo em vista o desenvolvimento sustentável (Bonini, 2002). O capitulo 6 da Agenda 21 dedica-se à "Proteção e Promoção da Saúde Humana", onde:

“... saúde e desenvolvimento apresentam-se como intimamente ligados, onde tanto o desenvolvimento insuficiente que conduz à pobreza, quanto o desenvolvimento inadequado que resulte em consumo excessivo associados a uma população mundial em expansão, podem resultar em sérios problemas para a saúde relacionados ao meio ambiente tanto nos paises em desenvolvimento quanto nos desenvolvidos" (CNUMAD, 1992). 
No Brasil, já em 1988, a Constituição Federal colocava como atribuição do setor saúde (art. 200, Inc. VII) a colaboração na "proteção do meio ambiente, nele compreendido o do trabalho", apontando para ações interinstitucionais.

A Lei Orgânica da Saúde (Lei n ${ }^{\circ} 8080$ de 20/09/90), em seu artigo $2^{\circ}, \S 1^{\circ}$, dispõe que é "dever do Estado garantir a saúde através da formulação e execução de políticas econômicas e sociais que visem à redução de riscos de doenças e outros agravos". No artigo $3^{\circ}$ coloca que "a saúde tem como fatores condicionantes e determinantes, entre outros, a moradia, o saneamento básico e o meio ambiente. Os artigos $5^{\circ}$ e $6^{\circ}$, que tratam dos objetivos e do campo de atuação do Sistema Único de Saúde - SUS, referem que a identificação e divulgação dos fatores condicionantes e determinantes da saúde estão entre suas funções. Estas devem ser executadas, entre outros, através da Vigilância Sanitária e Vigilância Epidemiológica sendo:

$\checkmark$ Vigilância Sanitária: "um conjunto de ações capaz de eliminar, diminuir ou prevenir riscos à saúde e de intervir nos problemas sanitários decorrentes do meio ambiente, da produção e circulação de bens e da prestação de serviços de interesse da saúde".

$\checkmark$ Vigilância Epidemiológica: "um conjunto de ações que proporcionem o conhecimento, a deteç̧ão ou prevenção de qualquer mudança nos fatores determinantes e condicionantes de saúde individual ou coletiva, com a finalidade de recomendar e adotar medidas de prevenção e controle das doenças ou agravos". 
Na esteira da Agenda 21, em 1995 ocorre a divulgação pelo Ministério da Saúde, do "Plano Nacional de Saúde e Ambiente no Desenvolvimento Sustentável: Diretrizes para Implantação". Este plano foi construído a partir do resultado de ampla discussão, envolvendo o poder executivo e a sociedade civil, tendo como objetivo a construção da proposta brasileira para a Conferência Pan-americana sobre Saúde e Ambiente no Desenvolvimento Humano Sustentável - COPASAD. Por ocasião desta Conferência foi divulgada a Carta Pan-americana sobre Saúde e Ambiente no Desenvolvimento Humano Sustentável. A carta, quando trata das responsabilidades, pontua que: “As organizações de saúde e ambiente são responsáveis pela identificação e avaliação dos riscos ambientais para a saúde, pela vigilância epidemiológica e por assessorar os formuladores de decisões políticas" (OPAS, 1995).

Em dezembro de 1999, o Ministério da Saúde publica a Portaria n ${ }^{\circ} 1399$, que regulamenta a NOB SUS 01/96 no que se refere às competências da União, Estados e municipios na área de epidemiologia e controle de doenças. Nesta mesma época, o Ministério da Saúde formula o Projeto VIGISUS, financiado pelo Banco Mundial, e que se propõe a estruturar as atividades de Vigilância em Saúde. O projeto é constituído de quatro áreas programáticas, sendo uma delas de Estruturação Sistêmica da Vigilância Ambiental. Para atender a esta área, foi criada junto à Fundação Nacional de Saúde - FUNASA mais especificamente no Centro Nacional de Epidemiologia - CENEPI a Coordenação Geral de Vigilância Ambiental em Saúde - CGVAM com o propósito de organizar, orientar, normalizar e coordenar o 
Sistema Nacional de Vigilância Ambiental em Saúde - SINVAS. As atribuições e funções do SINVAS, nas três esferas de governo, foram instituidas a partir da Instrução Normativa $n^{\circ} 1$, da FUNASA, de 25 de setembro de 2001, que regulamenta a Portaria n ${ }^{\circ}$ 1399. Com a reestruturação do Ministério da Saúde em 2003, o CENEPI e todos os órgãos a ele subordinados passam a fazer parte da Secretaria de Vigilância em Saúde (Decreto $n^{\circ} 4726$ de 09/06/2003).

No Estado de São Paulo, as discussões mundiais, tendo como foco a questão ecológica da década de 1970, tiveram como resultado o desmembramento do setor de saneamento da área de saúde e da Superintendência de Saneamento Ambiental SUSAM, com a criação de duas estruturas que passaram a responder pelo controle ambiental (Companhia de Tecnologia e Saneamento Ambiental - CETESB, que incorporou outras atividades de meio ambiente em estruturas diversas ${ }^{2}$ ) e pela água para consumo humano (Companhia de Saneamento Básico do Estado de São Paulo SABESP).

Na década de 1980, a Secretaria de Estado da Saúde de São Paulo - SES foi reestruturada, ocasião em que foram criados o Centro de Vigilância Epidemiológica CVE - e o Centro de Vigilância Sanitária - CVS. O vazio de competência relativa à avaliação do impacto na saúde decorrente de condições ambientais adversas, detectado à época, bem como a necessidade de organizar as atribuições remanescentes ao setor, com relação ao controle ambiental fez com que em ambos os centros se criassem estruturas cujas atribuições buscavam dar conta destas lacunas. 
O Centro de Vigilância Epidemiológica foi criado em 1985 para gerenciar o Sistema de Vigilância Epidemiológica que se conceitua como "o conjunto de atividades que proporcionam a informação indispensável para conhecer, detectar ou prevenir qualquer mudança que possa ocorrer nos fatores condicionantes do processo saúde-doença, com a finalidade de recomendar, oportunamente, as medidas indicadas que levem à prevenção e ao controle das doenças" (CVE, 2002).

O Centro de Vigilância Sanitária foi criado em 1986 com o objetivo de planejar, coordenar, supervisionar, yealizar estudos e propor normas e programas, abrangendo quatro subsistemas fundamentais (CVS, 2002):

$\checkmark$ o controle de bens de consumo que direta ou indiretamente se relacionem à saúde;

$\checkmark$ o controle dirigido à prestação de serviços que se relacionem direta ou indiretamente com a saúde;

$\checkmark$ o controle dirigido às ações de saneamento do meio;

$\checkmark$ o controle específico sobre o ambiente e processo de trabalho.

A questão das áreas contaminadas no Brasil vem se tornando um problema político e institucional com a crescente tomada de consciência da população acerca dos possiveis riscos para a saúde e dos danos materiais. Tem ela demandado do setor público o diagnóstico e a tomada de medidas de controle para remediar o problema. As requisições, ainda sem um fluxo organizado e veiculadas pela mídia, tornam-se explosivas.

\footnotetext{
${ }^{2}$ Para melhor compreensão da criação da CETESB ver Bonini, 2002.
} 
A grande pulverização de competências na área ambiental dificulta o diagnóstico de saúde e a tomada de medidas de controle. A área contaminada por chumbo, no municipio de Bauru, interior do Estado, foi incluída na lista da CETESB em 2002 e é objeto de ação civil pública impetrada por uma organização não governamental de meio ambiente do local - VIDÁGUA. No presente estudo busca-se descrever o modelo de atuação interinstitucional e multidisciplinar aplicado com vistas a contribuir em modelo de atuação que dê conta dos aspectos de saúde e ambiente neste tema.

\section{5 - $O$ chumbo no ambiente}

O chumbo é um metal cinza-azulado, altamente resistente à corrosão, com ponto de fusão a $327,5^{\circ} \mathrm{C}$. Possui quatro isótopos de ocorrência natural, com as seguintes concentrações: ${ }^{204} \mathrm{~Pb}(1,4 \%),{ }^{206} \mathrm{~Pb}(24,1 \%),{ }^{207} \mathrm{~Pb}(22,1 \%)$ e ${ }^{208} \mathrm{~Pb}(52,4 \%)$ (Paoliello e Chasin, 2001). Em sua forma inorgânica o chumbo tem usualmente valência $2^{+}$, embora possa apresentar concomitantemente estados de valência $2^{+}$e $4^{+}$. Apesar de ser muito resistente à corrosão, o chumbo é solúvel em ácido nítrico e sulfúrico (WHO, 1995). Sua solubilidade em água varia de acordo com seus compostos, sendo pouco solúveis os sulfetos e óxidos de chumbo e razoavelmente solúveis os sais: nitrato, cloreto e clorato. $\mathrm{O}$ chumbo também forma sais com ácidos orgânicos como o ácido lático e acético e compostos estáveis como o chumbo tetraetila e chumbo tetrametila (WHO, 1995). Estes são exemplos importantes de compostos ligados ao carbono sintetizados industrialmente e usados como aditivos em combustiveis, sendo 
portanto, fontes de contaminação ambiental (Paoliello e Chasin, 2001). As principais propriedades físico-químicas do chumbo e de alguns de seus sais encontram-se na Tabela 2. 
TABELA 2 - Identificadores e propriedades fisico-químicas do chumbo e alguns sais

\begin{tabular}{|c|c|c|c|c|c|c|c|c|}
\hline $\begin{array}{l}\text { Identificador e } \\
\text { propriededes } \\
\text { fisico-quimicas }\end{array}$ & Chumbo & Acetato de chumbo & $\begin{array}{l}\text { Carbouato de } \\
\text { chumbo }\end{array}$ & $\begin{array}{l}\text { Sulfato de } \\
\text { chumbe }\end{array}$ & $\begin{array}{l}\text { Sulfeto de } \\
\text { chumbo }\end{array}$ & $\begin{array}{l}\text { Monóxido de } \\
\text { chumbo }\end{array}$ & $\begin{array}{l}\text { Dióxido de } \\
\text { chumbo }\end{array}$ & Chumbo tetraetila \\
\hline $\begin{array}{l}\text { CAS } \\
\text { Sinónimos }\end{array}$ & $\begin{array}{l}7439-92-1 \\
\text { Mctal de chumbo } \\
\text { Lasca de chumbo } \\
\mathrm{Cl}^{*} 77575\end{array}$ & $\begin{array}{l}301-04-2 \\
\text { diacetato de chumbo. } \\
\text { acetalo plumbeso. } \\
\text { sal de satumo. } \\
\text { açucar de chumbo, } \\
\text { acetato de chumbo } \\
\text { neutro, } \\
\text { acctato dibásico de } \\
\text { chumbo }\end{array}$ & $\begin{array}{l}598-63-0 \\
\text { cerusita. } \\
\text { Ácido cartionico. } \\
\text { carbonato de } \\
\text { chumbo (II) }\end{array}$ & $\begin{array}{l}7446-14-2 \\
\text { anglesita. } \\
\text { chumbo branco. } \\
\text { sulfato de } \\
\text { chumbo (II). } \\
\text { leitc branco. } \\
\text { C177630 }\end{array}$ & $\begin{array}{l}1314-87-0 \\
\text { galena. } \\
\text { monossulfeto de } \\
\text { chumbo. sulfito } \\
\text { plumboso. sulfieto } \\
\text { de chumbu) (II) }\end{array}$ & $\begin{array}{l}1317-36-8 \\
\text { litargirio. } \\
\text { monoxido de } \\
\text { chumbo, oxido de } \\
\text { chumbo ll. oxide } \\
\text { plumboso. } \\
\text { C177577 }\end{array}$ & $\begin{array}{l}\text { 1309-60-0) } \\
\text { Plammeritc. (d } \\
775 \times 0 \text {. acido } \\
\text { plumbico. chumbo } \\
\text { mantom. ixide d: } \\
\text { chumbo marrom. } \\
\text { peroxido de } \\
\text { chumbo (DOT). } \\
\text { supcrixide de } \\
\text { clumbo }\end{array}$ & 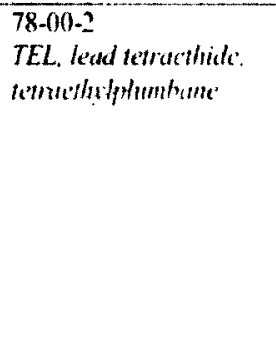 \\
\hline NIOSH RTECS & $(0+7525(x) 0$ & A15250KNo & & $0(i+375000)$ & (xits50000) & (xil750)11) & (xio7)onken & $1 P+5500000)$ \\
\hline $\begin{array}{l}\text { DOT } \\
\text { Fórmula molecular } \\
\text { Peso molecular } \\
\text { Ponto de ebulição } \\
\text { ("C) }\end{array}$ & $\begin{array}{l}\text { NA } 1794 \text { ORM-C } \\
\mathrm{Pb} \\
207.19 \\
1.740\end{array}$ & $\begin{array}{l}\text { UN } 16,6 \\
\mathrm{PbC}_{5} \mathrm{H}_{4} \mathrm{O}_{4} \\
325.28\end{array}$ & $\begin{array}{l}\mathrm{PbCO}_{3} \\
267.20\end{array}$ & $\begin{array}{l}\text { UN } 1794 \\
\text { PbSO, }_{4} \\
303.25\end{array}$ & $\begin{array}{l}\mathrm{N} A 2291 \\
\mathrm{PbS} \\
234.25 \\
1.281 \\
\text { (suhlimi-se) }\end{array}$ & $\begin{array}{l}\text { UN } 1479 \\
\mathrm{PbO} \\
223.19 \\
1.470\end{array}$ & $\begin{array}{l}\mathrm{UN} 1872 \\
\mathrm{PbO} \\
234.19\end{array}$ & $\begin{array}{l}\text { NA } 1649: 1 M O) 6.1 \\
\text { C.11 Pb } \\
323.45 \\
2010: 227.7 \text { (decommpis- } \\
\text { si) }\end{array}$ \\
\hline $\begin{array}{l}\text { Ponto de fusão }\left({ }^{\circ} \mathrm{C}\right) \\
\text { Pressäo de vapor }\end{array}$ & $\begin{array}{l}327.502 \\
1.77 \mathrm{mmllg} \text { a } 1.000^{\circ \mathrm{C}} \text { : } \\
10 \mathrm{mmllg} \text { a } 1.162^{\circ} \mathrm{C} \text { : } \\
1(0) \text { mml lg a } 1.421^{\circ} \mathrm{C} \\
4(1) \mathrm{mmllg} \text { a } 1.630^{\circ} \mathrm{C}\end{array}$ & 280 & 315 (decompois-sc) & 1.170 & $\begin{array}{l}1.114 \\
10 \mathrm{~mm} t \lg \text { a } \\
975 "(\text { ciollide) }\end{array}$ & $\begin{array}{l}88 \mathrm{x} \\
10 \mathrm{mmlly} \\
1.0 \times 54 \mathrm{C}\end{array}$ & $290($ dicompici-se) & $\begin{array}{l}-130^{\circ} \mathrm{C} \\
0.2 \mathrm{mmllg} \text { a } 2 \mathrm{nl}^{\circ} \mathrm{C}\end{array}$ \\
\hline Reatlvidade & 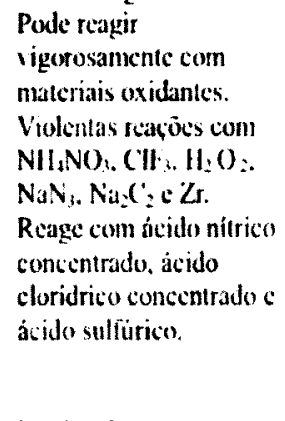 & 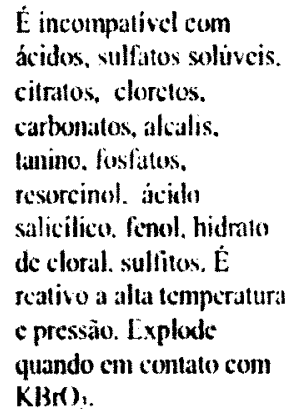 & & & & & 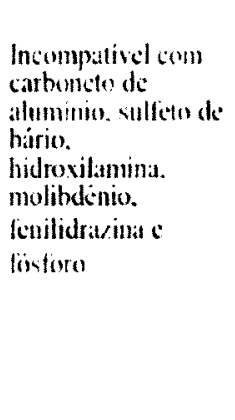 & \\
\hline $\begin{array}{l}\text { Solubilidade cm } \\
\text { Agua fria (e/L) }\end{array}$ & Insolurel & 43 & 0.0011 & $\begin{array}{l}\text { Levemente } \\
\text { solúicl }\end{array}$ & Inselivel & Insolivel & Insolisuel & $020 \mathrm{mg} L$ a 250 \\
\hline
\end{tabular}


O chumbo é um dos mais antigos metais usados pela humanidade, sendo conhecido há cerca de seis mil anos. Egípcios e hebreus usavam chumbo e os fenícios o extraíam há dois mil anos antes de Cristo (Hernberg, 2000). Para os povos antigos o metal muitas vezes era subproduto da extração da prata, sendo desprezado ou usado para outras finalidades (Gilfillan, 1965). Teve seu apogeu no Império Romano, estimando-se que entre oitenta e cem mil toneladas de chumbo por ano tenham sido requeridas para manter o alto estilo de vida da aristocracia. Encontravase presente na construção de aquedutos, na manufatura de taças e de vários utensilios de cozinha. Era adicionado ao vinho, como forma de corrigir a acidez, costume que se manteve durante séculos, atravessando a Idade Média e sendo causa de diversas epidemias de intoxicação (Paoliello e Capitani, 2003; Hernberg, 2000). Os castelos e catedrais da Europa contêm consideráveis quantidades de chumbo nas decorações, telhados, canos e janelas. No início do século XX o uso predominante do metal era em munição, na confeç̧ão de objetos de latão, cerâmica, vidros e cristais. $\mathrm{O}$ desenvolvimento tecnológico após a Primeira Guerra Mundial trouxe outros usos para o chumbo como nos cabos elétricos, solda, baterias de automóveis, além de outros na indústria. Contribuiram para o aumento da demanda suas propriedades de absorver radiações, tendo uso em equipamentos médicos. Também foi muito utilizado como antidetonante na gasolina. Na década de 1980, ao mesmo tempo em que ocorreu um declínio na demanda do chumbo como corante para tintas e antidetonante da gasolina devido aos riscos para a saúde, houve uma expansão de suas aplicações em outros materiais e compostos. 
O chumbo é considerado o sexto metal de maior utilidade industrial (Silva, 2001). No século atual, $88 \%$ do chumbo americano é usado em baterias para automóveis (USGS, 2003). No Brasil, 80\% do metal produzido ou importado são destinados para montagem de baterias de automóveis, o que representa o consumo de cerca de 88 mil toneladas por ano para este item. Outros usos incluem o processamento de óxidos com 12\% de participação e o setor eletroeletrônico (ligas, soldas e diversos), no qual se consomem $8 \%$, com nove mil toneladas por ano do metal (Silva, 2001).

O chumbo é relativamente abundante na crosta terrestre, tendo uma concentração média entre 10 e $20 \mathrm{mg} / \mathrm{kg}$. Pode ter origem em processos naturais ou antropogênicos. Entre os processos naturais encontram-se as emissões vulcânicas e o desgaste natural das rochas, estimados em dezenove mil ton/ano (WHO, 1995). As fontes antropogênicas têm uma estimativa de emissão para o ar em torno de 126 mil ton/ano a partir do consumo de mais de três milhões de ton/ano do metal proveniente de mineração, fundição, processamento, consumo, reciclagem ou rejeito. As concentrações de chumbo nas águas subterrâneas, segundo Allard (1995, apud Paoliello e Chasin, 2001), variam de menos que 0,02 a $120 \mu \mathrm{g} / \mathrm{L}$. Nas águas superficiais estas variações, considerando rios não contaminados, são em torno de 1 a $1000 \mathrm{ng} / \mathrm{L}$ e nos oceanos destaca-se que o Atlântico norte apresenta níveis mais elevados (100 a 150pM) que o Pacífico norte (14 a 50pM) (Paoliello e Chasin, 2001).

Nos diversos compartimentos ambientais, as medidas dos níveis originais de chumbo são dificultadas pela contaminação generalizada dos diferentes biomas 
terrestres através de séculos de uso do metal. A partir de fontes móveis ou fixas, o transporte e distribuição do chumbo se dão por via aérea. A maior parte das emissões é depositada próximo à fonte, no entanto, partículas menores que $2 \mu \mathrm{m}$ podem ser transportadas por longas distâncias e são responsáveis por contaminações nas regiões polares. Em regiões remotas, as concentrações de chumbo no ar giram em torno de $50 \mathrm{pg} / \mathrm{m}^{3}$ (WHO, 1995).

As reservas mundiais do minério de chumbo em 2001 eram estimadas em 132 milhões de toneladas. China, Austrália, Estados Unidos e Canadá detêm cerca de $64 \%$ destas reservas conforme Tabela 3; o Brasil participa com apenas $0,7 \%$ (Silva, 2002).

Tabela 3. Reservas e produção mundial do chumbo.

\begin{tabular}{|c|c|c|c|c|c|}
\hline Discriminação & Reserva & & \multicolumn{3}{|c|}{ Produção ${ }^{(2)}\left(10^{3} t\right)$} \\
\hline$\overline{\text { Paises }}$ & $2001^{(p)}$ & $\%$ & $2000^{(r)}$ & $2001^{(\mathrm{D})}$ & $\%$ \\
\hline$\overline{C h i n a}$ & 30.000 & 22,5 & 570 & 560 & 18,8 \\
\hline Austrália & 28.000 & 21,0 & 699 & 700 & 23,5 \\
\hline Estados Unidos & 20.000 & 15,0 & 468 & 420 & 14,1 \\
\hline Canadá & 9.000 & 6,8 & 143 & 150 & 5,0 \\
\hline África do Sul & 3.000 & 2,3 & 75 & 60 & 2,7 \\
\hline Peru & 3.000 & 2,3 & 271 & 270 & 9,0 \\
\hline Kasaquistão & 2.000 & 1,5 & 40 & 30 & 1,0 \\
\hline México & 2.000 & 1,5 & 156 & 160 & 5,4 \\
\hline Marrocos & 1.000 & 0,8 & 80 & 82 & 2,8 \\
\hline Suécia & 1.000 & 0,8 & 108 & 100 & 3,3 \\
\hline Brasil & 998 & 0,7 & 9 & 10 & 0,3 \\
\hline Outros paises & 33.000 & 24,8 & 490 & 420 & 14,1 \\
\hline Total & 132.998 & 100,0 & 3.109 & 2.982 & 100,0 \\
\hline
\end{tabular}

Fontes: DNPN/DIRIN. Mineral Commodity Summaries, 2002.

Notas (1) Inclui reserva medida e indicada

(p) preliminares

(r) revisado

(2) Chumbo contido no concentrado 
A maior parte do chumbo produzido no Brasil é subproduto da extração do zinco da Mina Morro Agudo em Paracatu, no Estado de Minas Gerais. Devido à escassez da produção do chumbo primário, a importação e o reaproveitamento de baterias de automóveis constituem-se nas principais fontes de consumo. A reciclagem de baterias de automóveis é responsável por $90 \%$ da oferta de chumbo no pais (Silva, 2001), sendo as empresas que reaproveitam o chumbo fontes potenciais de contaminação ambiental em nosso meio. Nos Estados Unidos esta atividade supre $60 \%$ da demanda (USGS, 2003).

A mineração, o processamento e o refino do chumbo, seja a partir de fonte primária ou secundária, podem contaminar o ambiente próximo. A intensidade da contaminação depende de vários fatores como: quantidade produzida, efetividade das medidas de controle, clima, topografia, etc. Usualmente podem ser encontradas altas concentrações de chumbo num raio de três quilômetros da fonte (USEPA, 1989), entretanto, alguns estudos mostram concentrações de chumbo elevadas no ar e no solo até dez quilômetros de fundidoras.

Uma vez contaminado, o solo persiste assim por longos períodos. Estudo efetuado por Davies e colaboradores (1985, apud WHO, 1995) encontrou niveis elevados de chumbo em área do Reino Unido, na qual uma usina deste metal entrou em funcionamento em torno de 2 mil anos antes, tendo encerrado suas atividades no fim da Idade Média. Em Port Pirie, na Austrália, uma comunidade vivendo nas vizinhanças de uma das maiores e mais antigas minas de chumbo do mundo 
apresentou níveis mais elevados deste metal no sangue, em comparação com outras comunidades australianas (Wilson et al., 1986).

Como visto anteriormente, o chumbo é um elemento presente na natureza tanto por ocorrência natural quanto por fontes antropogênicas. Estima-se que o incremento do uso do metal, particularmente após a rápida industrialização nos séculos XVIII e XIX, resultou no aumento em duas vezes de suas concentrações na água, ar e solo, considerando o periodo anterior. Em escala global, o uso do chumbo como aditivo na gasolina foi o fator predominante de sua disseminação em todos os compartimentos ambientais. Esta hipótese é baseada em estudos efetuados na década de 1970 por Nriagu e Pacyna, 1988 (apud WHO, 1995) e confirmada pelas variações nos níveis de chumbo após sua retirada da gasolina nos anos 1980 em diversos países.

\section{6 - Fontes de exposição humana}

O chumbo pode entrar em contato com o homem a partir de sua concentração no ar e dai sua deposição na água e solo. O consumo direto pelo ser humano pode ocorrer através da água, ar e solo e o indireto pela ingestão de animais ou plantas e seus derivados (Figura 5). Vários usos industriais do chumbo podem colocá-lo em contato com as pessoas por meio de tintas, soldas e canos para transporte de água potável. A exposição ao chumbo pode se dar também a partir da ocupação, comportamento, hábitos e outros fatores. Durante a gravidez o feto pode estar exposto ao chumbo por transferência placentária. Estima-se que os niveis de chumbo no feto sejam em torno de $60 \%$ dos níveis maternos. Além disto o chumbo é 
excretado pelo leite materno e pode expor o bebê. Crianças com pica (hábito de ingerir produtos estranhos) e residentes em casas pintadas com tinta à base de chumbo ou em áreas com solo contaminado apresentam niveis mais elevados de chumbo no sangue. $\mathrm{O}$ uso de alguns medicamentos folclóricos, o hábito de fumar e ingestão de bebidas alcoólicas também podem ser fontes de exposição (WHO, 1995). 


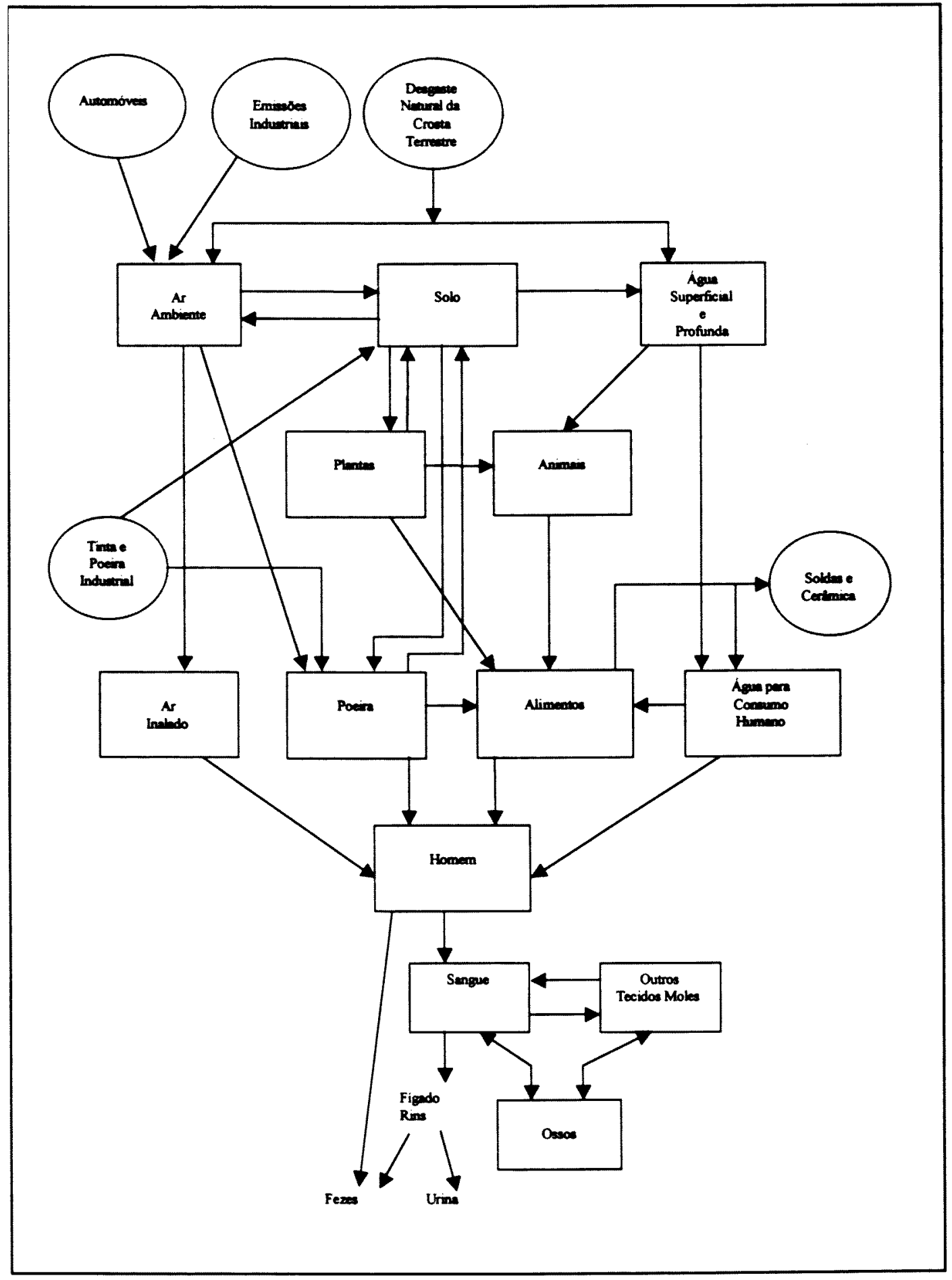

Figura 5. Fontes da contaminação humana por chumbo, principais órgãos de absorção, retenção e vias de excreção. USEPA, 1998. 
Crianças são diferentes de adultos no que se refere à exposição ao chumbo. Proporcionalmente consomem maior quantidade de alimentos, bebem mais água e respiram mais ar. Seu comportamento e estilo de vida influenciam a exposição. Consomem mais certos tipos de alimentos, como leite ou conservas, estão em maior contato com o solo e não têm o julgamento de perigo dos adultos. Crianças absorvem e retêm mais chumbo em proporção à sua massa corpórea total e são mais sensíveis aos efeitos tóxicos do metal (ATSDR, 1999; CDC, 1992).

Por sua importância serão corısideradas aqui as rotas de exposição através do ar e da ingestão, enfocando as possiveis fontes de absorção pelas crianças.

\subsection{1 - O ar como fonte de exposição}

$\mathrm{O}$ ar é a rota mais importante de distribuição do chumbo no ambiente. Quase todo o chumbo do ar é composto de partículas finas (menores que $1 \mu \mathrm{m}$ ) e suas concentrações podem variar de $7,6 \times 10^{-5} \mu \mathrm{g} / \mathrm{m}^{3}$, em áreas remotas como a Antártida, até maiores que $40 \mu \mathrm{g} / \mathrm{m}^{3}$, próximo a fábricas de baterias ou incineradores (WHO, 1995). A fonte predominante de chumbo na atmosfera é proveniente da combustão de gasolina, tetraetila e tetrametila. Países que ainda usam chumbo como aditivo no combustivel apresentam concentrações atmosféricas elevadas. Na França encontraram-se níveis variando de 0,5 a $3 \mu \mathrm{g} / \mathrm{m}^{3}$. No México estes valores chegaram a $5,7 \mu \mathrm{g} / \mathrm{m}^{3}$ em 1982 (GEMS, 1985). A diminuição dos niveis de chumbo na gasolina em diversos países tem sido responsável pela redução dramática da plumbemia em crianças (USEPA, 1998). Entre 1979 e 1983 as concentrações de chumbo em 


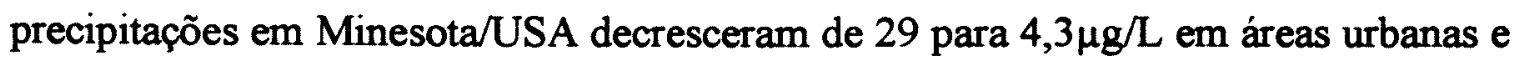
de 5,7 para 1,5 $\mathrm{g} / \mathrm{L}$ em áreas rurais. Entre 1976 e 1995, as concentrações atmosféricas do metal nos Estados Unidos cairam em torno de 97\%. Em 1982-83 o aporte diário de chumbo por inalação para áreas não urbanas foi estimado em $0,5 \mu \mathrm{g} /$ dia para crianças de dois anos, $1 \mu \mathrm{g} /$ dia para adultos trabalhando em ambientes fechados e $2 \mu \mathrm{g} / \mathrm{dia}$ para adultos trabalhando em ambientes externos. Foram consideradas no cálculo a concentração atmosférica de $0,1 \mu \mathrm{g} / \mathrm{m}^{3}$ e relação chumbo

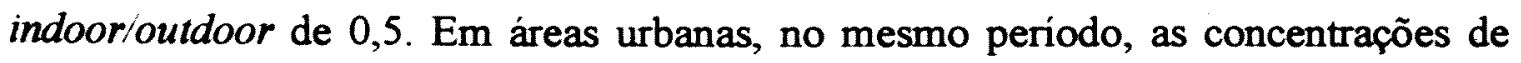
chumbo outoor/indoor foram de $0,75 \mu \mathrm{g} / \mathrm{m}^{3}$ e $0,6 \mu \mathrm{g} / \mathrm{m}^{3}$ respectivamente e nas áreas de alta concentração de trânsito de $5 \mu \mathrm{g} / \mathrm{m}^{3}$. Em 1991, após a substituição do chumbo como antidetonante da gasolina, os níveis do metal nas áreas de tráfego intenso foram de $0,1 \mu \mathrm{g} / \mathrm{m}^{3}$, comparando-se às concentrações nas áreas não urbanas (ATSDR, 1999). Atualmente, nos Estados Unidos, a concentração de chumbo na gasolina tem sido considerada de importância menor na determinação dos niveis de plumbemia em crianças (USEPA, 1998). Na Índia, um dos países onde ainda se usa chumbo como aditivo do combustivel, foi encontrada correlação de 0,88 entre os niveis do metal no ar e no sangue das crianças. Para cada incremento de $1 \mu \mathrm{g} / \mathrm{m}^{3}$ de chumbo no ar ocorre incremento de $3,56 \mu \mathrm{g} / \mathrm{dL}$ no sangue (Raghunath et al., 1999).

As fontes estacionárias podem se constituir em pontos de origem de contaminação do ar por chumbo, embora os niveis do metal decresçam conforme a distância. Wang et al. (1995) apud WHO (1995) observaram que concentrações de chumbo no ar próximo a fundidoras variavam de $10 \mu \mathrm{g} / \mathrm{m}^{3}$ nas vizinhanças das 
empresas, até $1,5 \mu \mathrm{g} / \mathrm{m}^{3}$ numa distância de um quilômetro. Estudo realizado na Bélgica por Roels et al. (1980), próximo a uma fundição primária de chumbo, encontrou concentrações do metal no ar que variavam de 2,68 a $4,06 \mu \mathrm{g} / \mathrm{m}^{3}$ em distâncias menores que um quilômetro da fonte e de 0,49 a $1 \mu \mathrm{g} / \mathrm{m}^{3}$ a $2,5 \mathrm{~km}$.

Em relação a ambientes fechados é importante ressaltar o de trabalho o das residências. Os níveis de chumbo no ambiente de trabalho variam de acordo com as medidas de higiene e segurança adotadas. Na ausência de fontes fixas de emissão, o ar interno das residências construidas antes da década de 1980 (quando o chumbo era usado como corante) pode ser impactado pela poeira presente no solo proveniente do uso de tintas à base de chumbo. Esta poeira pode ser ressuspendida durante a demolição ou remodelamento destes estabelecimentos (USEPA, 1998). Para as concentrações domiciliares encontram-se níveis diferenciais quando se utiliza tinta à base de chumbo nas paredes. Amostrando ar de interiores de residências onde não se utilizavam tintas à base de chumbo, Davies et al. (1987 apud WHO, 1995) encontraram alta correlação entre o ar externo e interno. $\mathrm{O}$ ar interno apresentava concentrações médias de chumbo em torno de $60 \%$ da do ar externo. Estas concentrações podem ser afetadas pela presença de fumadores na residência. Os níveis de chumbo no cigarro são em torno de $2,4 \mu \mathrm{g} / \mathrm{g}$ e $5 \%$ destes pode ser inalado (Mussalo-Rauhamaa et al., 1986 apud WHO, 1995).

O chumbo é um dos poluentes do ar regulamentados no Estados Unidos. Seu valor-padrão é estabelecido em $1,5 \mu \mathrm{g} / \mathrm{m}^{3}$, média trimestral (USEPA, 2003). Os valores-guia europeus definem um limite anual na atmosfera de $2 \mu \mathrm{g} / \mathrm{m}^{3}$ (Leroyer et 
al., 2000). No Brasil não existem parâmetros para as concentrações atmosféricas de chumbo; apesar disso, algumas medidas que resultaram na redução dos níveis do metal no ar, particularmente das áreas urbanas, foram tomadas. A Petrobras não vem mais adicionando chumbo como antidetonante na gasolina desde 1989, sendo o Brasil o segundo país no mundo a tomar esta medida (Anonymus, 1997). A iniciativa não teve efeito uniforme em todo o país. A gasolina fornecida pela Petrobras abastece $98 \%$ do mercado no Brasil. No Rio de Janeiro a Refinaria Manguinhos, responsável por $1 \%$ do fornecimento nacional e a Refinaria Ipiranga, no Rio Grande do $\mathrm{Sul}^{3}$, responsável pelos outros $1 \%$, continuaram a usar o chumbo até 1992 . Neste caso a prática foi anterior à medida regulamentar, de 1993, através da Lei $n^{\circ} 7823$ e da Lei $\mathrm{n}^{\circ} 10.203 / 2001$, fixa o limite de adição de álcool à gasolina em todo o território nacional, substituindo o chumbo como antidetonante. Em seguida a estas leis, a Portaria n 309 da Agência Nacional do Petróleo - ANP, também em 2001, em conjunto com o Regulamento ANP $n^{\circ} 5$, fixa o limite máximo de chumbo permitido na gasolina, enquanto contaminante em $0,005 \mathrm{~g} / \mathrm{L}$. Tal regulamento deixa claro que é proibida a adição. Embora a Petrobras tenha retirado o chumbo da gasolina em todo o país a partir de 1989, a quantidade do metal adicionada vinha de algum tempo diminuindo gradativamente. A Tabela 4 mostra a evolução das quantidades do chumbo tetraetila no combustivel e suas concentrações.

\footnotetext{
${ }^{3}$ Informaçð̃es fornecidas por José Luiz Ferreira Jardim, superintendente adjunto de Qualidade do Produto - Agència Nacional do Petróleo.
} 
Tabela 4. Evolução da quantidade e concentrações do chumbo tetraetila na gasolina no periodo de 1977 a 1988 no Brasil.

\begin{tabular}{lccc}
\hline Ano & $\begin{array}{c}\text { Chumbo tetraetila } \\
(\mathrm{t})\end{array}$ & $\begin{array}{c}\text { Concentração do chumbo } \\
\text { tetraetila na gasolina } \\
(\mathrm{mL} / \mathrm{L})\end{array}$ & $\begin{array}{c}\text { Conteúdo médio de etanol na } \\
\text { gasolina } \\
(\%)\end{array}$ \\
\hline 1977 & 8211 & 0,236 & 4,5 \\
1978 & - & - & 8,5 \\
1979 & 5160 & 0,145 & 15 \\
1980 & - & - & 20 \\
1981 & 3144 & 0,144 & 20 \\
1982 & - & - & 20 \\
1983 & 1809 & 0,087 & 20 \\
1984 & - & - & 20 \\
1985 & 2000 & 0,120 & 22 \\
1986 & - & - & 22 \\
1987 & 1044 & 0,060 & 22 \\
1988 & 858 & 0,063 & 22 \\
\hline
\end{tabular}

Fonte: Romano et al., 1992, modificado.

No Estado de São Paulo, servido pela Petrobras, a substituição do chumbo pelo álcool na gasolina se iniciou em 1979 (Alonso et al., 1985). Estes autores compararam as concentrações de chumbo no ar e na poeira em 1978, antes do início da substituição, com o ano de 1983, em duas localidades da Região Metropolitana da Grande São Paulo - RMGSP (Pinheiros, distrito administrativo do municipio de São Paulo, e município de São Caetano do Sul). Observaram que houve uma redução do chumbo no ar e na poeira em mais de $70 \%$ nas duas localidades. Após avaliar as possíveis causas desta redução, os autores consideram que a hipótese mais plausível é a da redução do contaminante no combustivel. A evolução dos níveis de chumbo no ar atmosférico foi avaliada por Romano et al. (1992) para o periodo de 1978 a 1987 em diversos pontos de monitoramento da RMGSP. Como pode ser observado no Gráfico 1, os niveis se encontram abaixo dos limites estabelecidos pela USEPA. 


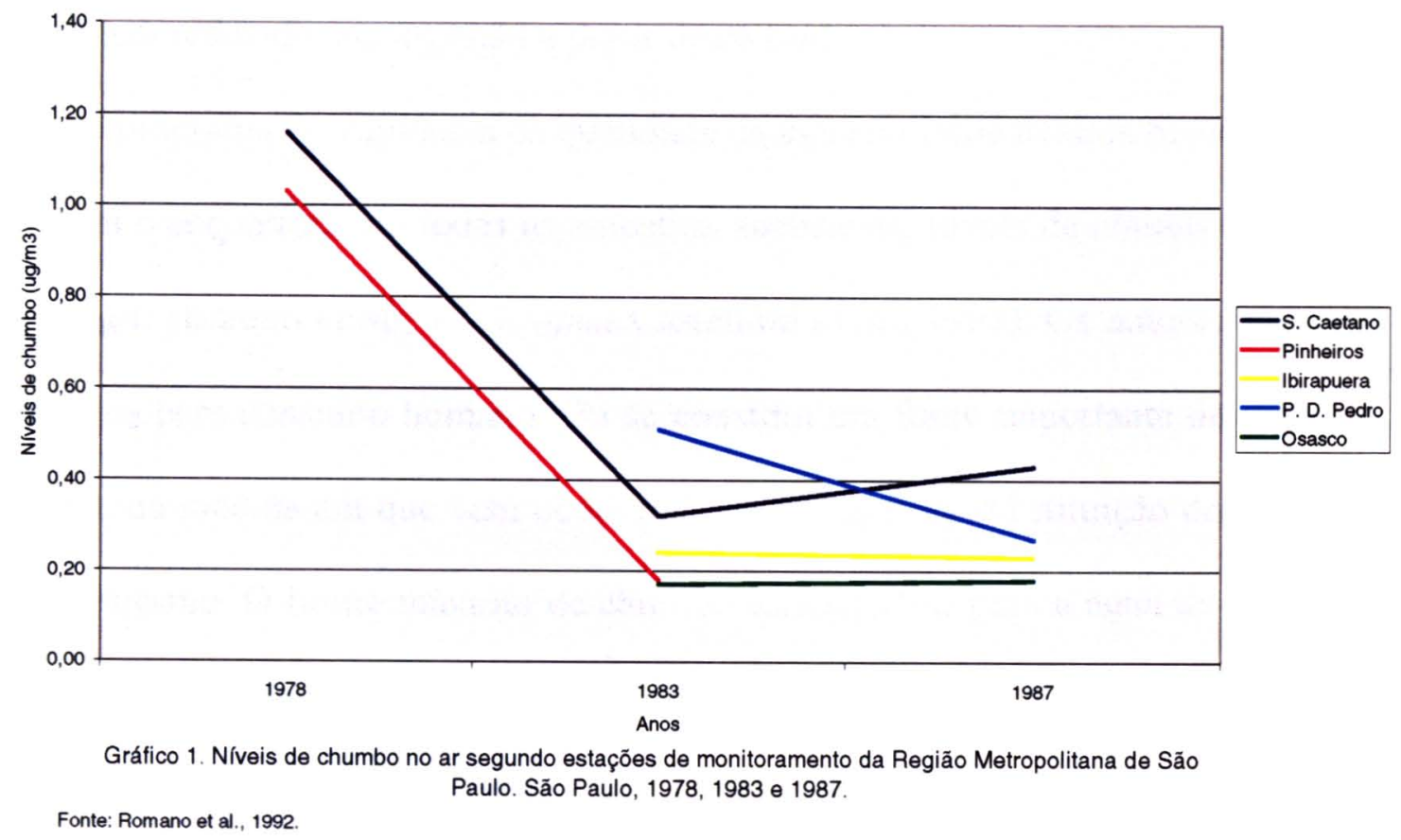

\subsection{2 - Exposição por ingestão}

\subsubsection{1 - Água}

Os níveis basais de chumbo em águas superficiais e profundas, isentas de fonte de contaminação, são em geral baixos. Nos Estados Unidos, estima-se que menos de $1 \%$ dos sistemas de distribuição de água apresentem níveis de chumbo superiores a $5 \mu \mathrm{g} / \mathrm{L}$. Estes servem menos de 3\% da população (ATSDR, 1999). Segundo a Organização Mundial de Saúde - OMS, a exposição humana decorrente da ingestão de água é em geral subestimada (WHO, 1995). Consideram-se os níveis de chumbo presentes no sistema de distribuição, sem levar em conta que em alguns 
casos esta é transportada por canos à base do metal ou soldados com ele. Deve-se lembrar, no entanto, que a substituição de canos e solda à base de chumbo por plástico tem reduzido sua ingestão a partir desta fonte.

O programa de vigilância da qualidade da água na Itália avaliou diversas áreas em Roma e encontrou, em todas as amostras analisadas, niveis de chumbo menores

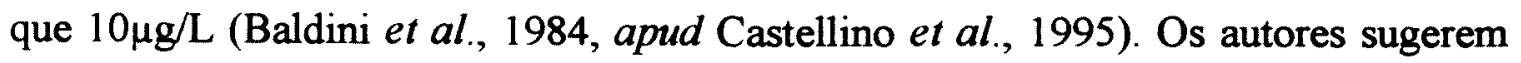
que a água para consumo humano não se constitui em fonte importante de ingestão do metal, na medida em que vem ocorrendo uma gradativa substituição dos canos à base do mesmo. O limite máximo de chumbo estabelecido para a água de consumo nos Estados Unidos é de 0,015mg/L (USEPA, 1999). A OMS recomenda como máximo 0,01mg/L (WHO, 1996). No Brasil, o Conselho Nacional de Meio Ambiente - CONAMA define para o chumbo concentrações máximas de $0,03 \mathrm{mg} / \mathrm{L}$ para águas classificadas como doces e de $0,01 \mathrm{mg} / \mathrm{L}$ para águas classificadas como salinas e salobras. O valor máximo para efluentes de qualquer fonte poluidora é de 0,5mg/L (Resolução $n^{\circ}$ 20/86 CONAMA). Para água de consumo humano, o Ministério da Saúde, através da Portaria ${ }^{\circ} 1469 / 2000$, modificada pela Portaria ${ }^{\circ}$ $518 / 2004$, estabelece o valor máximo de $0,01 \mathrm{mg} / \mathrm{L}$.

Devido às altas taxas de absorção do chumbo quando presente na água, as concentrações do metal neste meio/veículo constituem-se em preocupação constante (USEPA, 1998).

No Estado de São Paulo, os canos à base de chumbo da rede de distribuição pública (adutoras e ramais) foram substituídos gradativamente por canos de ferro 
fundido com revestimento de concreto e PVC (Policloreto de Vinila) sempre que requeriam manutenção (Teixeira, 2001). No entanto, em algumas áreas, persistem canos de cerâmica com junção feita com ligas à base de chumbo. Apesar disto, o Programa de Vigilância da qualidade da água para consumo humano em nosso meio não tem encontrado niveis de chumbo detectáveis nas amostras avaliadas ${ }^{4}$. A responsabilidade do fornecimento de água dentro dos padrões de potabilidade é da concessionária. Em vários municípios de São Paulo, inclusive no município de Bauru, esta concessionária é a Companhia de Saneamento Básico de São Paulo SABESP, que executa a captação, tratamento e distribuição até o cavalete de entrada no prédio, residência ou outro estabelecimento. A partir deste momento a incumbência de manter a água potável é do proprietário do imóvel, incluindo a troca, nos imóveis antigos, dos canos de chumbo por outros materiais não nocivos à saúde. Teixeira (2001), avaliando a água de torneiras em cem escolas públicas no município de São Paulo, construidas a partir de 1931, encontrou onze com níveis de chumbo acima do limite proposto pela legislação brasileira $(0,01 \mathrm{mg} / \mathrm{L})$ no primeiro jato.

\subsubsection{2 - Alimentos}

A carga total de chumbo proveniente da ingestão de alimentos depende de suas concentrações na água, no ar e no solo ou da contaminação agregada pelo processamento industrial (Castellino et al., 1995).

\footnotetext{
${ }^{4}$ Informaçðes obtidas no Instituto Adolfo Lutz e na CETESB.
} 
Quando se avalia a deposição aérea, as folhas de vegetação próximas a rodovias de tráfego intenso ou outras fontes estacionárias de contaminação apresentam altos níveis de chumbo por deposição direta. As partículas aderidas às folhas ou frutos podem ser transportadas depois de colhidas, processadas e ingeridas em áreas distantes do plantio. Para as folhas, esta deposição é considerada a principal via de contaminação. Também podem apresentar altas concentrações as verduras coletadas próximo a áreas urbanas ou fontes de contaminação do chumbo (WHO, 1995; ATSDR, 1999).

A maior parte de chumbo nos vegetais é proveniente de deposição aérea. Apenas uma pequena proporção é absorvida pelas raizes. Os niveis de chumbo originário do solo nas plantas dependem da biodisponibilidade do metal, de sua distribuição nas diferentes profundidades e das características das diversas espécies vegetais; guardam relação com os níveis no solo e apresentam concentrações mais elevadas nas áreas mais contaminadas. A partir dos níveis no solo, raizes em geral contêm mais chumbo que as hastes e folhas, enquanto sementes e frutas têm as mais baixas concentrações. Embora o transporte do chumbo das folhas, frutos e caule em sentido inverso, ou seja, até as raizes, seja de pequena monta, é dificil diferenciar sua origem nas plantas que crescem em sítios com concentrações elevadas do metal. Considera-se que para cada 1000 ppm de $\mathrm{Pb}$ no solo há uma média de 13 ppm nas raizes, embora esta resposta não seja linear, provavelmente porque plantas crescendo em solos contaminados sofrem um processo de adaptação e absorvem menor quantidade do metal (Castellino et al., 1995). 
Os produtos animais representam menos de $1 \%$ da ingestão humana de chumbo, pois este se deposita preferencialmente em órgãos pouco ou quase não comestiveis. Para herbívoros, a principal fonte de contaminação é a ração. Pastos próximos a indústrias de fundição ou minas podem conter altas concentrações de $\mathrm{Pb}$, que depois de ingerido chegam a levar os animais à intoxicação. Neles, os órgãos preferenciais de deposição do chumbo são os ossos, figado e rins. Quando intoxicados, os níveis de chumbo nos músculos de bovinos variam de 0,23 a 0,5mg/kg (ATSDR, 1999).

Distante de áreas contaminadas, os niveis de $\mathrm{Pb}$ em carnes estão geralmente abaixo dos limites de deteç̧ão dos métodos analíticos usualmente empregados. Quando detectados, giram em torno de 0,005mg/kg, embora variem amplamente em diferentes áreas geográficas. Encontram-se valores mais elevados no sul da Europa que no norte e em geral são mais altos nas vísceras dos animais (Castellino et al., 1995).

Os niveis de chumbo nos animais ou nos vegetais de vida aquática dependem da concentração dele na água e nos sedimentos. Análises efetuadas nos Estados Unidos mostraram diminuição das concentrações do metal nos peixes no periodo de 1976 a 1984, provavelmente associada à sua redução na gasolina e ao controle das emissões industriais, baixando as concentrações do contaminante no ambiente aquático (ATSDR, 1999).

O chumbo pode ser excretado por diversas vias, inclusive contaminando produtos de consumo humano como o leite e os ovos. Brams e Anthony (1989), apud 
Castellino et al. (1995) realizaram estudo de impacto ambiental do chumbo após sua adição na cadeia alimentar. Avaliaram a quantidade do metal em tecidos e ovos. Os resultados obtidos mostraram que após uma ingestão média de $13,4 \mu \mathrm{gPb} / \mathrm{kg}$ houve acúmulo médio de $3,38 \mu \mathrm{g} / \mathrm{g}$ na gema do ovo e $4,71 \mu \mathrm{g} / \mathrm{g}$ na clara. Estudo efetuado por Oskarsson et al. (1992), apud ATSDR (1999), avaliando oito vacas expostas a chumbo por duas semanas, encontraram níveis médios de chumbo no leite de $0,08 \mathrm{mg} / \mathrm{kg}$. Após dezoito semanas os níveis chegaram a $0,22 \mathrm{mg} / \mathrm{kg}$ e caíram para $<0,03 \mathrm{mg} / \mathrm{kg}$ seis semanas depois de cessada a exposição. Com relação ao leite materno, os niveis de chumbo encontrados em mulheres que trabalhavam em indústrias de baterias variaram de 4 a $63 \mu \mathrm{g} / \mathrm{L}$ em amostras colhidas após o nascimento dos bebês (Wolf, 1983, apud ATSDR, 1999).

Alimentos enlatados em recipientes confeccionados ou soldados com ligas à base de chumbo podem ser fontes de contaminação. Os níveis do metal no alimento armazenado dependem de suas características fisico-químicas e do tempo de estocagem. A liberação do chumbo pode ser acelerada em alguns produtos após a abertura (Castellino et al., 1995). Nos Estados Unidos, a regulamentação acerca do uso de enlatados à base de chumbo e solda foi responsável pela redução média de 0,31 ppm em 1980 para 0,04 ppm em 1988 (ATSDR, 1999).

Da mesma forma, a retirada do chumbo da gasolina, a substituição dos canos e soldas à base de chumbo do sistema de abastecimento de água e a modificação em diversos processos industriais foram responsáveis pela redução da ingestão do metal. O United States Food and Drug Administration - FDA avalia que a ingestão de 
chumbo na dieta de crianças de dois anos declinou de uma média de $30 \mu \mathrm{g} / \mathrm{dia}$ em 1982 para $13 \mu \mathrm{g} /$ dia em 1985 e em torno de $5 \mu \mathrm{g} /$ dia no periodo de 1986 a 1988 (CDC 1991). Dados de 1990-91, a partir da dieta total para todos os grupos etários, indicam que a ingestão de chumbo varia de 1,8 a $4,2 \mu \mathrm{g} /$ dia (ATSDR, 1999). Estima-se que uma redução similar venha ocorrendo nos locais onde se tomem medidas similares (WHO, 1995).

\subsubsection{3 - Poeiras e solo}

Poeiras e solos são importantes vias de contaminação em crianças. O chumbo pode se originar de fontes estacionárias, como indústrias de fundição ou processamento, tintas na parede da residência, gasolina e outras. Uma vez depositado, o chumbo não se degrada, permanecendo enquanto fonte de exposição por longos periodos. Sendo pouco mobilizado pelos componentes orgânicos do solo, concentra-se em geral nas camadas superficiais (2 a $5 \mathrm{~cm}$ ). Nos Estados Unidos, apesar da eliminação do metal da gasolina, estima-se que permanecem no solo e na poeira em torno de 4 a 5 milhões de toneladas. Próximo a rodovias de grande tráfego e casas com tinta à base de chumbo, pode alcançar niveis de $10 \mathrm{mil} \mathrm{ppm}$. Nas vizinhanças de indústrias de fundição ou mineração de chumbo as concentrações chegam a $20 \mathrm{mil}$ ppm. Estas concentrações decrescem exponencialmente com a distância (CDC, 1991; CDC, 1992b; WHO, 1995).

Independente da pica (mais comum em crianças) o contato manual e hábitos de levar objetos à boca constituem-se nas principais formas de exploração do mundo 
pelas crianças pequenas. Estes comportamentos são as formas principais de ingresso do chumbo no organismo para este grupo etário. Roels et al. (1980), avaliando a contribuição das concentrações de chumbo no ar e nas mãos de crianças, concluem que esta última constitui-se no principal fator de explicação para os niveis de plumbemia em área próxima a uma fundidora. Estima-se que uma criança ingira diariamente, pelas atividades mão-boca, em torno de 20 a $50 \mathrm{mg}$ de solo. Crianças com pica podem ingerir $5 \mathrm{mil} \mathrm{mg} \mathrm{ou} \mathrm{mais} \mathrm{por} \mathrm{dia.} \mathrm{Se} \mathrm{o} \mathrm{solo} \mathrm{contém} \mathrm{chumbo} \mathrm{em}$ doses elevadas, uma criança normal pode ingerir em torno de $5 \mu \mathrm{g} /$ dia do metal apenas desta fonte (ATSDR, 1999). A ingestão de solo ou poeira constitui-se em fonte de exposição mais importante que a inalação em crianças. No interior das casas, as concentrações podem alcançar niveis superiores ao ambiente externo (Galvin et al., 1993). Os estudos de correlação apontam que para cada incremento de mil ppm de chumbo no solo há um incremento de 3 a $7 \mu \mathrm{g} / \mathrm{dL}$ de chumbo no sangue, embora esta relação não seja linear (CDC, 1991; CDC, 1992b). O FDA estimou em 1990 que a ingestão em crianças, calculada em $5 \mu \mathrm{g} /$ dia poderia ser assim dividida: $1 \%$ proveniente do solo, $7 \%$ proveniente da água, $75 \%$ proveniente da poeira e o restante outras fontes.

A Tabela 5 apresenta os niveis de chumbo para solos residenciais em alguns paises 
Tabela 5. Padrões de chumbo para solo de áreas residenciais.

\begin{tabular}{lc}
\hline \multicolumn{1}{c}{ Local } & $\begin{array}{c}\text { Padrão adotado } \\
(\mu \mathrm{g} / \mathrm{g})\end{array}$ \\
\hline Estados Unidos (federal) & 500 \\
Minesota & $500^{\mathrm{a}}$ \\
& $375^{\mathrm{b}}$ \\
OME, Canadá & $500^{\mathrm{c}}$ \\
Holanda & $50^{\mathrm{d}}$ \\
& $150^{\circ}$ \\
Inglaterra & $600^{\mathrm{f}}$ \\
Londres, Reino Unido & $500^{\mathrm{g}}$ \\
\hline
\end{tabular}

${ }^{2}$ regra emergencial proposta

bsolo arenoso

'solo não arenoso

¿valor de fundo

investigacão adicional

valor de limpeza

8 re-desenvolvimento de terras industriais

hpadrão adotado para poeiras

Fonte: Sharma e Reutergardh, 2000, modificado (extraido de Paoliello, 2002).

\subsubsection{4-Outras fontes de exposição}

Várias outras fontes de exposição ao chumbo podem ser descritas. São dependentes dos costumes locais ou do processo industrial de cada pais. Destacamse, para as crianças, o uso de alguns medicamentos caseiros, os brinquedos com tinta ou solda à base de chumbo e a estocagem de alimentos em cerâmica vitrificada cozida a baixas temperaturas. 
Claro está que a exposição a chumbo por ingestão depende de suas concentrações nos diversos veículos e que são diferentes entre os países. A extrapolação dos valores encontrados em uma realidade para outra não é uma conduta recomendável. Faz-se necessário que cada localidade busque a identificação de fontes de contaminação a partir das características do processo industrial, dos costumes ou de manipulação ilegal do metal.

No Brasil, como foi colocado anteriormente, a Petrobras não adiciona chumbo à gasolina desde 1989. Por outro lado, algumas outras medidas, tomadas em geral por iniciativa dos fabricantes, devem ter reduzido a exposição a chumbo em nosso país. Dentre os setores não regulamentados, encontramos uma tendência da indústria de maior porte a seguir os parâmetros estabelecidos nos paises industrializados. Desde 1990, os fabricantes de tinta vêm substituindo o chumbo no processo de produção. Embora estes processos não sejam uniformes, segundo as informações obtidas da associação de fabricantes de tintas, o chumbo ainda está presente no zarcão, usado como anticorrosivo de metais, e em alguns esmaltes (Freitas, 1999).

Os produtores de alimentos enlatados também têm substituído o chumbo como liga na soldagem de embalagens, embora a norma regulamentar desta matéria só tenha sido editada em 1999, através da Lei n 9832.

O legislador brasileiro tem optado por regulamentar os niveis de chumbo permitidos nos produtos finais de consumo em detrimento da regulamentação do processo. Exemplo disto é a regulamentação das concentrações de $\mathrm{Pb}$ na água. $\mathrm{A}$ Portaria n 36 de 1990, do Ministério da Saúde, estabelecia o limite máximo de 
chumbo na água para consumo humano em $0,05 \mathrm{mg} / \mathrm{L}$. No ano de 2000 o Ministério reduziu este limite para $0,01 \mathrm{mg} / \mathrm{L}$ através da Portaria $\mathrm{n}^{\circ} 1469$ e mantido na Portaria $n^{\circ} 518 / 04$. Os niveis de chumbo em alguns alimentos também são regulamentados pela Portaria n 685 de 1998 e encontram-se na Tabela 6.

Tabela 6. Niveis máximos de chumbo permitidos para alimentos na legislação brasileira.

\begin{tabular}{lc}
\hline Produto & $\begin{array}{c}\text { Limite } \\
(\mathrm{mg} / \mathrm{kg})\end{array}$ \\
\hline Óleos, gorduras e emulsões refinadas & 0,1 \\
Caramelos e balas & 2,0 \\
Cacau (exceto manteiga de cacau e chocolate adoçado) & 2,0 \\
Chocolate adoçado & 1,0 \\
Dextrose (glicose) & 2,0 \\
Sucos de frutas cítricas & 0,3 \\
Leite fluido, próprio para consumo & 0,05 \\
Peixes e produtos de pesca & 2,0 \\
Alimentos para fins especiais. preparados especialmente para lactentes e & \\
crianças até três anos & 0,2 \\
Partes comestíveis cefalópodes & 2,0 \\
\hline
\end{tabular}

Fonte: Portaria $\mathrm{n}^{\circ} 685$ do Ministério da Saúde de 27/08/1998.

No Estado de São Paulo foram sugeridos valores orientadores para metais em solos e águas subterrâneas pela Companhia de Tecnologia e Saneamento Ambiental - CETESB, com base em amostras ambientais. Os valores de referência para proteção do solo e das águas subterrâneas sugeridos para o chumbo foram de $17 \mathrm{mg} / \mathrm{kg}$ para solo e abaixo de $\mathrm{lmg} / \mathrm{L}$ para água. Foram estabelecidos também valores de alerta e intervenção. Os valores de alerta representam um limite para 
deteç̧ão de contaminantes no solo, proveniente de tratamento ou disposição de resíduos, sendo que para o chumbo o valor é de $100 \mathrm{mg} / \mathrm{kg}$ de solo.

Os valores de intervenção foram baseados na avaliação de risco, tendo um caráter corretivo, indicando a existência de contaminação do solo ou água. Foram sugeridos de acordo com o uso do solo, tendo para o chumbo os seguintes valores: solo de uso agrícola $200 \mathrm{mg} / \mathrm{kg}$; solo de uso residencial $350 \mathrm{mg} / \mathrm{kg}$ e solo de uso industrial $1200 \mathrm{mg} / \mathrm{kg}$. Para águas subterrâneas o valor de emergência proposto é de $10 \mu \mathrm{g} / \mathrm{L}$ (CETESB, 2001).

São raros os estudos no Brasil acerca de contaminação por chumbo em alimentos ou produtos que possam ser ingeridos por crianças. Em 1990, Garrido et al., realizaram a avaliação dos níveis do metal em artigos escolares. Foram analisados borrachas, lápis preto, canetas hidrográficas e tintas. Foi encontrado chumbo nestes artigos. Os autores levantam a necessidade de regulamentação destes produtos.

Alimentos in natura, particularmente hortaliças comercializadas em diversas regiões do Estado de São Paulo, foram estudadas por Sakuma et al. (1989), quanto a seus teores de chumbo, cádmio e zinco. Estes alimentos foram considerados próprios para consumo humano, segundo os autores. Avaliando os níveis de chumbo em leite pasteurizado e in natura em área contaminada na região do Vale do Paraíba/São Paulo, Okada et al. (1997) encontraram $20 \%$ das amostras com concentrações de $\mathrm{Pb}$ acima do limite estabelecido pela legislação brasileira $(0,05 \mathrm{mg} / \mathrm{kg})$. 


\section{7 - O chumbo no organismo}

\subsection{1 - Absorção}

A absorção do chumbo pelo organismo não depende apenas da quantidade do metal no ambiente. Vários fatores como seu estado físico e químico e características do hospedeiro, entre elas idade, estado fisiológico, estado nutricional e possivelmente fatores genéticos, podem também influenciar no processo (Paoliello, 2002). A atividade física, por aumentar a quantidade de ar que entra nos pulmões, aumenta a absorção. Em relação à massa corpórea, crianças se alimentam mais que o adulto e consomem mais chumbo (ATSDR, 1999).

O chumbo inorgânico é absorvido principalmente por ingestão e inalação. Nas crianças a via digestiva constitui-se na principal fonte e, nos adultos, a inalatória. A absorção por via dérmica só se constitui em via importante quando há exposição ao chumbo orgânico (CDC, 1992).

\subsubsection{1 - Absorção pela via respiratória}

A absorção do chumbo a partir do ar envolve dois processos: deposição das partículas no trato respiratório e passagem para a corrente sanguinea. A deposição do chumbo no trato respiratório é em média de 30 a $50 \%$ do total inalado. Partículas grandes podem ter altas taxas de deposição, mas não permanecem na árvore respiratória. São deslocadas para o estômago. Partículas pequenas (em torno de $0,5 \mu \mathrm{m})$ são absorvidas no trato respiratório baixo (WHO, 1995). A respiratória é a 
principal via de absorção do chumbo na exposição ocupacional. Cerca de 20 a $40 \%$ do metal, que entra pela respiração, permanecem no organismo, seja por deslocamento para o trato gastrointestinal através dos movimentos ciliares e deglutição, seja por absorção nos alvéolos (Paoliello e Capitani, 2003).

\subsubsection{2 - Absorção pela via oral}

A quantidade de chumbo absorvida a partir do trato gastrointestinal é de $10 \mathrm{a}$ $15 \%$ do total nos adultos. Em gestantes e crianças esta quantidade pode chegar a $50 \%$ (EPA, 1998). O estado nutricional também afeta a absorção, particularmente a deficiência de ferro e cálcio, que a aumentam. Alguns estudos também encontram relação positiva entre ingestão de gordura e absorção do chumbo (Lucas et al., 1996; Gallicchio et al., 2002). Em jejum, o chumbo é mais absorvido que na presença de alimentos (WHO, 1995).

Em torno de 5\% do chumbo absorvido são retidos nos adultos. Em crianças, esta retenção chega a 30\% (Poisindex, 2002).

\subsubsection{3 - Absorção pela pele}

A absorção do chumbo inorgânico pela pele integra é mínima, não se constituindo esta em via tão importante quanto a gastrointestinal e a respiratória. Os compostos tetralquilados do chumbo foram extensiva e rapidamente absorvidos pela pele de coelhos e ratos em estudos de experimentação. A absorção pela pele humana 
após escarificação é diferencial dependendo do composto orgânico (ATSDR, 1999; Paoliello, 2002).

\subsection{2 - Distribuição}

Uma vez absorvido, a distribuição do chumbo no organismo ocorre de maneira similar, independente da via (Paoliello, 2002). O chumbo é distribuído nos tecidos moles (sangue, figado, rins, etc.) e duros (ossos e dentes). Em geral, a distribuição parece similar em crianças e adultos, embora nestes $94 \%$ da carga corpórea total se encontrem nos ossos e nas crianças, apenas 73\% (ATSDR, 1999; WHO, 1995).

No sangue, $99 \%$ do chumbo encontram-se nas células vermelhas, tendo a hemoglobina fetal maior afinidade que a hemoglobina adulta. Gerhardson et al. (1995, apud ATSDR, 1999), analisando 32 cadáveres de trabalhadores com história de exposição ocupacional ao chumbo, encontraram concentrações do metal em ordem decrescente no figado, rins, pulmões e cérebro. Em pessoas não expostas ocupacionalmente encontram-se maiores quantidades teciduais do contaminante em homens que em mulheres. Este achado não foi observado em crianças (ATSDR, 1999).

Os ossos aparentemente não são afetados pelo chumbo, servem principalmente como seus maiores reservatórios no organismo. A meia-vida do chumbo nos ossos é em torno de 27 anos. Devido às trocas constantes entre os compartimentos, os ossos podem ser uma fonte endógena do metal muito depois de 
cessada a exposição, podendo chegar a contribuir com 40 a $70 \%$ dos níveis sangüíneos. Durante a gravidez, o catabolismo ósseo da mãe libera o contaminante que pode ser transferido para o bebê. As concentrações do chumbo no cordão umbilical são de 85 a 90\% das concentrações sanguíneas maternas (WHO, 1995; ATSDR, 1999).

A meia-vida do chumbo nos tecidos moles é menor. No sangue é em torno de 36 dias e nos demais em torno de 40 dias. Estudo em humanos expostos ao metal por 18 semanas mostrou que os níveis deste no sangue declinaram depois de cessada a exposição, alcançando as concentrações prévias após 5 meses (ATSDR, 1999).

\subsection{3 - Eliminação}

Tanto em humanos quanto em animais, o chumbo ingerido, quer seja na dieta, quer por inalação e transporte para o trato gastrointestinal, quando não absorvido é excretado pelas fezes. Da fração absorvida, a parcela não retida é excretada na urina pelos rins, ou da bile para o intestino, através do figado. Em torno de $60 \%$ do chumbo absorvido são retidos e 40\% excretados (WHO, 1995; ATSDR, 1999).

Sob condições estáveis e exposição a baixas concentrações, a excreção urinária é de aproximadamente $70 \%$ do chumbo no organismo. Uma pequena proporção é eliminada através do suor e cabelos e, como forma especial de eliminação do metal endógeno, tem-se o leite materno. Existe correlação positiva entre os niveis de chumbo no sangue e no leite. As concentrações no leite variam 
entre 10 a $30 \%$ das concentrações sanguíneas da mãe (WHO, 1995; Poisindex, 2002).

\section{8 - Efeitos na saúde}

Os primeiros registros que dão conta da toxicidade do chumbo encontram-se nos papiros egípcios. Segundo estas informações o chumbo era usado freqüentemente com propósitos homicidas. Hipócrates (370 a. C.), foi talvez o primeiro a descrever a cólica saturnizica e Nicander (200 a. C.) a paralisia nervosa, embora ambos não tenham descoberto sua etiologia (Hernberg, 2000). No primeiro século depois de Cristo, Dioscorides estabeleceu a relação entre exposição a chumbo e manifestações tóxicas e Plínio, na mesma época, descreveu os efeitos tóxicos do metal, comuns em construtores de barcos (Hemberg, 2000; Paoliello e Capitani, 2003).

Devido à ampla difusão do uso do chumbo nos produtos da uva e em conservas de frutas, bem como de utensílios de cozinha à base do metal em Roma, Gilfillan (1965), baseado em estudos arqueológicos e dados demográficos e antropológicos, levanta a hipótese de que a queda do Império Romano teve como uma das causas os efeitos deletérios do contaminante na vitalidade e na reprodução, particularmente das classes mais altas da população.

Diversos efeitos na saúde podem ser atribuidos ao chumbo, afetando os sistemas digestivo, cardiovascular, hematológico, nervoso, endócrino, imunológico e reprodutivo. Os primeiros estudos mostram relação com concentrações sanguineas 
relativamente elevadas. Outros posteriores, com doses corpóreas do metal cada vez menores, continuam a encontrar efeitos antes não detectados devido a pouca acurácia dos marcadores fisiopatológicos. O grande desafio atual é o estabelecimento de limites seguros de exposição. Segundo Landrigan et al. (2000), a toxicidade do chumbo se expressa em várias doses com aparente seqüência. Os efeitos clínicos agudos têm sua contraparte nos efeitos subclínicos. Manifestações óbvias de intoxicação por chumbo, como convulsões, paralisias, anemia e falência renal com altas doses de exposição, possuem seus correlatos, em baixas doses, na redução da inteligência, redução da velocidade de condução nervosa, dano na biossintese da heme e alteração na excreção do ácido úrico. Estas alterações subclínicas representam eventos perigosos para a saúde e não apenas um ajustamento fisiológico ou homeostático à presença do metal.

$\mathrm{Na}$ medida em que o objeto deste estudo são crianças expostas a chumbo, restringimo-nos à descrição dos efeitos à saúde neste grupo etário, citando estudos em adultos apenas em casos específicos.

\subsection{1 - Morte}

A morte pode ser o desfecho final de encefalopatia por chumbo. Os niveis do metal associados à morte em crianças estão entre 125 e $750 \mu \mathrm{g} / \mathrm{dL}$ (média de $327 \mu \mathrm{g} / \mathrm{dL}$ ). Altos níveis de chumbo têm sido relacionados à morte súbita em recém-nascidos, embora os estudos sejam escassos e não se disponha até o momento de conhecimento 
fisiopatológico que embase o achado. As possibilidades incluem efeitos do metal no desenvolvimento neurológico pré ou pós-natal (ATSDR, 1999).

Alguns estudos em adultos encontram relação entre exposição a chumbo e excesso de mortalidade, mas, como lembram Paoliello e Capitani (2003), a maior parte carece de controle dos fatores de confusão. Base de dados promissora para avaliar exposição na infầncia e morte nos parece ser a do National Health and Nutrition Examination Survey - NHANES, no qual as informações constantes permitem o controle de variáveis confundidoras. A partir dos registros do NHANES II (1976-80), Lustberg e Silberg (2002) seguiram grupo populacional de 30 a 74 anos, comparando as taxas de mortalidade por diversas causas e plumbemias até 1992. Seus achados revelaram que os indivíduos com níveis basais de chumbo no sangue entre 20 e $29 \mu \mathrm{g} / \mathrm{dL}$ apresentavam aumento de $46 \%$ (IC:14-86\%) na mortalidade por todas as causas.

\subsection{2 - Câncer}

Chumbo é um carcinógeno reconhecido em experimentos animais. Em humanos sua classificação na International Agency for Research on Cancer - IARC é 2B, ou seja, há dados suficientes de carcinogenicidade em animais e dados inadequados para o homem. Steenlland e Boffetta (2000) colocam que a última avaliação sobre a relação entre o metal e câncer pela IARC remonta a 1987 e precisa ser revista. Os autores argumentam que muitos estudos foram produzidos no decorrer dos anos recentes. Em metanálise de oito publicações de mortalidade por câncer e 
chumbo, estes estudiosos concluem que há uma fraca evidência de associação, sendo os cânceres de pulmão, estômago e os gliomas os principais candidatos a sítios da doença. Também a International Conference on Lead Exposure, Reproductive Toxicity and Carcinogenicity em 1999, avaliando os estudos produzidos até então, concluiu que estes apontam no sentido de haver alguma evidência sugestiva de associação entre chumbo e câncer do pulmão e do estômago (Landrigan et al., 2000).

\subsection{3 - Efeitos cardiovasculares}

A maioria dos estudos acerca dos efeitos do chumbo no sistema cardiovascular é relacionada à exposição em adultos e com resultados controversos (Paoloello e Capitani, 2003). As análises efetuadas a partir do NHANES apontam para uma associação positiva, pequena, mas significativa entre niveis de chumbo e pressão sanguinea (Harlan et al., 1985; Lustberg e Silbergeld, 2002; Vupputuri et al., 2003). Metanálise efetuada por Schwartz (1995) aponta que variação de $10 \mu \mathrm{g} / \mathrm{dL}$ para $5 \mu \mathrm{g} / \mathrm{dL}$ de plumbemia é associada com o decréscimo de $1,25 \mathrm{mmHg}$ (IC: 0,871,63) da pressão sistólica. Estimou-se uma redução de 17,5\% de homens hipertensos entre 40 e 59 anos, como resultado da queda dos níveis de chumbo no sangue da população branca dos Estados Unidos de 1976 a 1980 (Pirkle et al., 1985). Entre as crianças, Factor-Litvac et al. (1996), em estudo transversal, encontraram aumento de $0,5 \mathrm{mmHg}$ na pressão sistólica e $0,4 \mathrm{mmHg}$ na pressão diastólica para cada incremento de $10 \mu \mathrm{g} / \mathrm{dL}$ de chumbo no sangue. Os autores discutem que estes 
pequenos incrementos são compativeis com ausência de efeitos; no entanto, são similares aos observados em estudos com adultos. Avaliando os efeitos tardios da exposição ao chumbo, Hu $\left(1991^{A}\right)$, em coorte retrospectiva de pessoas com história de intoxicação aguda na infância, estuda o risco de hipertensão na vida adulta, pareando estes individuos por local de residência, sexo, raça e idade. Encontra risco sete vezes maior entre os expostos. Gerr et al. (2002), avaliando coorte de adultos jovens com histórias diferentes de exposição na infância, compararam seus niveis pressóricos com os niveis de chumbo ósseo. Entre aqueles com concentrações superiores a $10 \mu \mathrm{g} / \mathrm{Pb} / \mathrm{g}$ a pressão sistólica foi $4,3 \mathrm{mmHg}$ mais elevada que naqueles com $1 \mu \mathrm{g} / \mathrm{Pb} / \mathrm{g}$, sugerindo que exposições elevadas a chumbo na infância podem aumentar os niveis de pressão arterial na juventude. Na mesma direção, McDonald e Potter (1996) encontraram excesso de mortes por doenças cardiovasculares e história de intoxicação aguda na infância. Em necrópsia de crianças cuja causa de morte foi intoxicação por chumbo foram vistas alterações degenerativas do músculo cardíaco tendo-se imputado como uma causas do óbito (ATSDR, 1999).

\subsection{4 - Efeitos gastrointestinais}

A cólica é um sintoma precoce e consistente de intoxicação por chumbo em trabalhadores. Esta é caracterizada por vários sintomas como: dor abdominal, constipaçåo, câimbra, náusea, vômito, anorexia e perda de peso. É também um sintoma de envenenamento em crianças, nas quais o LOAEL (lowest-observed- 
adverse-effect levels) é estabelecido entre 60 e 100 $\mu \mathrm{g} / \mathrm{dL}$ (ATSDR, 1999). Não tem sido encontrada evidência histopatológica de dano gastrointestinal produzido pelo chumbo (ATSDR, 1999; Paoliello e Capitani, 2003).

\subsection{5 - Efeitos hematológicos}

Sumariamente, os efeitos do chumbo na biossíntese da heme ocorrem por inibição de certas enzimas, particularmente o ácido $\delta$-aminolevulinico desidratase $(\mathrm{ALAD})$ e a ferroquetalase. Como conseqüência dessas alterações há um decréscimo na biossintese da heme. Na sequêencia, aumenta a atividade da enzima $\delta$ aminolevulínico sintetase (ALAS) que, retroativamente, é inibida pela heme. Os resultados finais das alterações enzimáticas são: aumento urinário de porfirinas, coproporfirinas e ácido $\delta$-aminolevulínico (ALA); aumento do ALA plasmático e urinário; aumento da protoporfirina eritrocitária livre ligada ao zinco (ZPP). Tem-se atribuido ao aumento do ALA parte dos efeitos neurológicos da exposição ao chumbo (ATSDR, 1999; Paoliello e Capitani, 2003).

A anemia produzida pelo chumbo é conhecida há muito tempo (Hernberg, 2000). Resulta de dois mecanismos principais: prejuízo da biossintese da heme e aumento da taxa de destruição das células vermelhas. Mecanismo adicional, também sugerido como responsável pela anemia saturnínica, relaciona-se à diminuição nas concentrações de eritropoietina sérica por efeito tóxico do contaminante no túbulo renal (Paoliello e Capitani, 2003). Quando induzida pelo metal, a anemia é 
acompanhada de pontilhado basófilo nos eritrócitos, devido à inibição da enzima eritrocitária 5'-nucleotidase (WHO, 1995).

O nivel sanguineo de chumbo proposto como seguro para evitar seus efeitos na redução da hemoglobina é de $50 \mu \mathrm{g} / \mathrm{dL}$ para trabalhadores e é estimado em

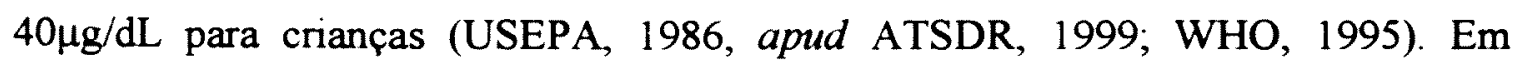
avaliação da relação dose-resposta entre plumbemia e valores do hematócrito em crianças, Schwartz et al. (1990) avaliaram 579 menores de 1 a 5 anos, residentes próximo a uma indústria fundidora de chumbo em 1974. Utilizou como ponto de corte o hematócrito de $35 \%$. Segundo seus achados, o risco de hematócrito abaixo de $35 \%$ foi $2 \%$ maior entre as crianças com plumbemias de 20 a $39 \mu \mathrm{g} / \mathrm{dL} ; 18 \%$ maior entre aquelas com 40 a $59 \mu \mathrm{g} / \mathrm{dL}$ e $40 \%$ maior para as com niveis de chumbo mais elevados. Os autores questionam o limite sanguineo considerado seguro até 1991 pelo CDC $(25 \mu \mathrm{g} / \mathrm{dL})$. Com baixas doses corpóreas, média de $3,3 \mu \mathrm{g} / \mathrm{dL}$ e desvio padrão de 0,7 a $23,9 \mu \mathrm{g} / \mathrm{dL}$, Jacob et al. (2000) associam o incremento de $1 \mu \mathrm{g} / \mathrm{dL}$ do metal no sangue com aumento do número de células vermelhas e, nas meninas ( 5 a 14 anos), com redução do volume corpuscular médio - VCM - e hemoglobina corpuscular média - HCM A argumentação dos estudiosos é que baixos niveis de chumbo no sangue podem levar à produção de células vermelhas com reduzido volume e função, sendo os menores VCM e HCM indicativos de distúrbios qualitativos na sintese da heme. 
A deficiência de ferro, que não é incomum em crianças jovens, afeta os parâmetros hematológicos e pode ser um fator de confusão para o estabelecimento da relação entre anemia e chumbo. Nos paises em desenvolvimento, as condições sociais precárias de boa parcela da população e suas conseqüências no estado nutricional podem mascarar ainda mais os achados. Carvalho et al. (1984), investigando fatores de risco associados com anemia em 463 crianças de 1 a 9 anos, em área contaminada de Santo Amaro da Purificação (Bahia), encontraram relação entre niveis de hemoglobina e malnutrição em interação com deficiência de ferro. Não foi vista associação com plumbemia na população de estudo.

\subsection{6 - Efeitos renais}

Os efeitos do chumbo na função renal podem ser agudos, decorrentes de altas exposições, e tardios, por exposição crônica.

Os efeitos agudos se manifestam clinicamente como insuficiência renal aguda, com aminoacidúria, glicosúria e hiperfosfatúria, semelhante à síndrome de Fanconi. Ocorre principalmente em crianças nas quais a fonte primária de exposição é a via oral. Os niveis sanguíneos de chumbo encontrados são superiores a $80 \mu \mathrm{g} / \mathrm{dL}$. É reversivel ao tratamento com afastamento da exposição e não deixa seqüelas.

A forma crônica é encontrada em especial em adultos trabalhadores, cuja exposição principal é por via inalatória. Os niveis de plumbemia relatados nestas

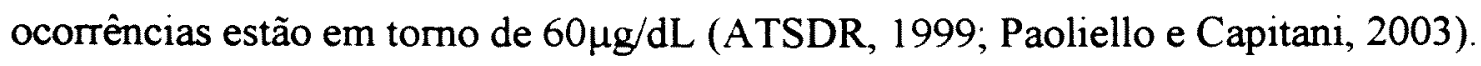


Dos estudos de efeitos renais tardios em crianças expostas a chumbo, citados pela ATSDR (1999), um analisa adolescentes com história de intoxicação na infância, tratados com quelação. Não encontra alterações renais. O outro avalia crianças de 3 a 6 anos residentes nas vizinhanças de empresa fundidora de chumbo, com niveis médios de plumbemia de $34,2 \mu \mathrm{g} / \mathrm{dL}$. De todos os parâmetros de função renal estudados, o único achado é o aumento na atividade da $\mathrm{N}$-acetil- $\beta$-Dglicosaminidase. Hu $\left(1991^{A}\right)$, em coorte retrospectiva de individuos após 50 anos da exposição aguda a chumbo e não expostos na infância, observa aumento no clearance de creatinina entre aqueles com história de intoxicação.

\subsection{7 - Efeitos endócrinos e no desenvolvimento físico}

Os efeitos do chumbo na função tireoideana é estudado em trabalhadores ocupacionalmente expostos e crianças. Os estudos em adultos mostram apenas uma fraca correlação negativa entre duração da exposição e niveis de tiroxina (T4) total e livre. Nas crianças esta relação não é encontrada, mesmo naquelas com plumbemias

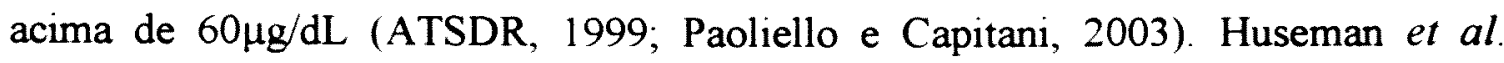
(1992), partindo do achado de correlação negativa entre $\mathrm{PbS}$ (chumbo no sangue) e estatura em crianças nos primeiros 5 anos de vida, do NHANES III, avaliam os níveis de hormônio do crescimento - GH em 12 crianças, após estimulo com L-dopa e insulina. Encontram concentrações de $\mathrm{GH}$ diminuida nas crianças com $\mathrm{PbS}$ $>40 \mu \mathrm{g} / \mathrm{dL}$, apesar deste valor se achar dentro dos limites da normalidade. 
O chumbo interfere na conversão da vitamina $\mathrm{D}$ em sua forma hormonal ativa (1,25-hidroxivitamina D) em altas doses de exposição. Este bloqueio leva ao desequilibrio na homeostase do cálcio, provocando diminuição na velocidade de crescimento celular (Paoliello e Capitani, 2003). Os estudos epidemiológicos acerca da relação do chumbo com o crescimento infantil, ora encontram associação negativa com os niveis de plumbemia, ora não encontram associação (ATSDR, 1999). Vários fatores podem influenciar no crescimento e desenvolvimento físico, sendo difícil o controle das variáveis intervenientes.

A partir dos dados do NHANES III, Bellew et al. (1999) avaliaram a estatura e circunferência craniana em 4391 crianças entre 1 e 7 anos. Encontraram relação negativa entre $\mathrm{PbS}$ e as duas variáveis. Para cada incremento de $10 \mu \mathrm{g} / \mathrm{dL}$ de chumbo no sangue, a estatura foi $1,57 \mathrm{~cm}$ menor. Resultados similares foram obtidos por Factor-Litvac et al. (1999) e Hernandez-Avila et al. (2002).

Também com dados do NHANES III, Wu et al. (2003) avaliaram a maturação sexual de 1706 meninas de 8 a 16 anos, usando como referências a menarca, o crescimento de pelos pubianos, e dos seios e os niveis de plumbemia. Meninas com niveis mais elevados do metal apresentaram maiores taxas de retardo no surgimento da menarca e de pelos pubianos.

Em estudo de coorte de 13 anos de seguimento, crianças foram avaliadas segundo peso, estatura e Índice de Massa Corpórea por Kim et al. (1995). Estes autores encontraram relação dos niveis de chumbo na dentina apenas com o Índice de Massa Corpórea, sugerindo que exposições crônicas podem resultar em obesidade 
na adolescência. Em levantamento bibliográfico realizado pela ATSDR (1999) sugere-se que o possivel retardo no crescimento de crianças é transitório.

\subsection{8 - Efeitos imunológicos}

Os dados de efeitos imunológicos em trabalhadores expostos a chumbo são inconsistentes e limitados. Há alguma indicação de que o metal pode afetar o componente celular do sistema imune e não o humoral. Nas crianças os estudos são inconclusivos (ATSDR, 1999).

\subsection{9 - Efeitos reprodutivos}

Os efeitos de altas exposições ao chumbo sobre a reprodução foram estabelecidos para homens e mulheres desde o século XIX. O metal era usado como droga abortiva entre os egipcios. Nas mulheres expostas durante a gravidez, encontra-se relação com abortamento, nascidos mortos e parto pré-termo (Fewtrell et al., 2003). Estudos em homens indicam que pode ocorrer a diminuição na contagem de espermatozóides, para níveis em torno de 40 $\mu \mathrm{g} / \mathrm{dL}$ (ATSDR, 1999).

Não existem trabalhos conclusivos sobre a relação entre exposição a chumbo e malformações congênitas (Paoliello e Capitani, 2003). Estudo realizado por Hu $\left(1991^{\mathrm{B}}\right)$ em coorte retrospectiva de 35 sobreviventes de intoxicação por chumbo na infância mostrou haver associação entre distúrbios da aprendizagem em filhos cujas 
mães tiveram quadro de intoxicação clínica quando crianças, apontando para provável existência de dano genético levando a distúrbios neurológicos na progênie.

\subsubsection{0 - Efeitos neurológicos}

Altos niveis de exposição a chumbo produzem encefalopatia em adultos e crianças. Nestas, a encefalopatia se manifesta com hiper-reatividade, hiperexcitação, ataxia, convulsões, estupor e coma, podendo levar à morte em pouco tempo. Os niveis de chumbo relatados com alterações neurológicas fatais podem variar desde 90 até $800 \mu \mathrm{g} / \mathrm{dL}$ (ATSDR, 1999; Paoliello e Capitani, 2003). Estudos têm mostrado que crianças com história de intoxicação grave por chumbo apresentam elevada incidência de danos neurológicos e cognitivos permanentes, mesmo sem

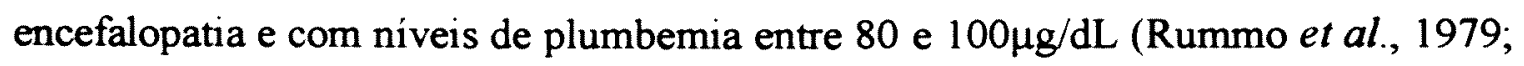
ATSDR, 1999). Quando instituido tratamento quelante, a performance nos testes de inteligência é melhor que nas crianças não tratadas, embora apresente diferenças com relação àquelas sem história de intoxicação (Rosen, 1995).

Os achados de danos cognitivos em crianças com altos niveis de exposição a chumbo remontam à década de 1940. Estes levaram a que vários estudos fossem realizados avaliando os efeitos do metal no desenvolvimento neuropsicomotor. Temse concluido que o chumbo afeta as habilidades intelectuais e o comportamento, mesmo em baixos niveis. As conseqüências são: menores Quocientes de Inteligência 
- QI, aumento de atividade delinqüente e maiores taxas de abandono escolar (Fawtrell et al., 2003)

Os efeitos do chumbo no QI têm sido amplamente estudados. Embora usando diferentes medidas do quociente e também diferentes marcadores biológicos de exposição (chumbo no sangue, dentes, tíbia, etc.), a maioria tem apresentado resultados coerentes entre si. Pocock et al. (1994), avaliando 26 estudos epidemiológicos com diferentes formas de medida da carga corpórea do metal e da inteligência, encontram que, para cada incremento de 10 a $20 \mu \mathrm{g} / \mathrm{dL}$ de chumbo no sangue e 5 a $10 \mu \mathrm{g} / \mathrm{g}$ nos dentes, há um decréscimo de 1 a 2 pontos no QI. Os autores questionam que, apesar do efeito ser pequeno, não se tem idéia dos niveis de exposição em que seria negligenciável. No mesmo ano, Schwartz, também em metanálise de 8 estudos, escolhidos por controlarem os fatores de confusão para redução do QI em crianças, chega a resultados mais preocupantes. Para cada incremento de 10 a $20 \mu \mathrm{g} / \mathrm{dL}$ de $\mathrm{PbS}$, há decréscimo de 2,6 pontos no QI. O autor coloca que o estabelecimento de limite seguro em $10 \mu \mathrm{g} / \mathrm{dL}$ de chumbo no sangue de crianças não é plausivel, na medida em que seus estudos apontam para a inexistência deste. Com efeito, Lanphear et al. (2000), a partir das informações do NHANES III, avaliam 4853 crianças, com níveis médios de $\mathrm{PbS}$ de $1,9 \mu \mathrm{g} / \mathrm{dL}$, quanto a suas funções cognitivas, através de testes aritméticos, de leitura, de raciocínio não verbal e memória. Segundo suas avaliações, para cada incremento de $1 \mu \mathrm{g} / \mathrm{dL}$ de chumbo no sangue há perda de 0,7 pontos nas médias aritméticas dos escores dos testes. 
Avaliando crianças com niveis de plumbemia inferiores a $5 \mu \mathrm{g} / \mathrm{dL}$, encontram relação negativa com os testes de aritmética e leitura.

Foi vista relação estatisticamente significativa entre comportamento antisocial de meninos de 7 a 11 anos, estudantes de escola pública e concentrações de chumbo ósseo. O comportamento de 850 meninos foi avaliado por testes especificos, relato dos investigados, relato dos pais e professores, sem conhecimento quanto aos marcadores de carga corpórea do metal (Needleman et al., 1996). Acerca do mesmo tema, Nevin (2000) realiza extenso levantamento bibliográfico sobre os aumentos do QI no decorrer do tempo e sua relação com a diminuição dos crimes violentos e da maternidade na adolescência. Levanta hipótese, a partir de recuperação histórica do uso indiscriminado do chumbo, da relação entre exposição ao metal e QI, tendo como conseqüência os desvios comportamentais. Para testar sua hipótese compara os dados representativos da população do NHANES II (1984) com os do NHANES III (1992), segundo os quais houve queda significativa dos niveis de chumbo no sangue. Seus resultados sugerem que o aumento no QI e a diminuição nos niveis de chumbo no sangue estão relacionados com a diminuição dos crimes violentos e gravidez na adolescência.

Alguns estudos têm buscado elucidar se os efeitos do chumbo no QI são permanentes ou reversíveis. Para isto, um grupo de estudiosos têm seguido crianças expostas ao metal a partir de uma indústria de fundição na Austrália: o estudo de coorte de Port Pirie. Este seguimento, avaliando níveis de chumbo em gestantes, no cordão umbilical e nas crianças, acompanhando seu desenvolvimento, tem 
demonstrado que exposições a baixas doses são associadas com retardo no desenvolvimento neurofisiológico, particularmente com altas taxas de abandono escolar, problemas de leitura, menor rendimento escolar e vocabulário. Os estudos sugerem que o déficit cognitivo, associado com exposição a chumbo na infância precoce, parece reverter apenas parcialmente com o declinio subseqüente dos níveis sanguineos (Needleman et al., 1990; Baghurst et al., 1992; Tong et al., 1998; Burns et al., 1999). Estudo de coorte retrospectivo entre 281 adultos jovens, expostos ambientalmente a chumbo durante a infância e controles pareados por sexo e idade, encontrou associação entre exposição e alterações nas funções dos nervos periféricos, neurocomportamentais e neuropsiquiátricas (Stokes et al., 1998).

Uma vez estabelecidos os efeitos do chumbo no desenvolvimento neuropsicomotor, alguns autores vêm avaliando os ganhos econômicos obtidos com a redução dos niveis do metal, particularmente na população americana. Em 1995, Salkever estima que do total de 5.060 bilhões de dólares de economia, metade é decorrente de ganhos por melhor performance do QI. Landrigan et al. (2002) avaliam que $2,8 \%$ dos gastos de saúde são decorrentes de danos causados por poluentes ambientais, tendo como conseqüência o câncer na infância, a asma, os distúrbios do desenvolvimento e intoxicações por chumbo, esta com maior participação. Estima-se que a partir da redução média de $15,1 \mu \mathrm{g} / \mathrm{dL}$ de chumbo no sangue em crianças de 1 a 5 anos, de 1976 a 1990, houve ganho de 2,2 a 4,7 pontos no QI, o que se refletiu em ganho na produtividade de 110 a 319 bilhões de dólares (Grosse et al., 2002). 


\section{9 - Biomarcadores de exposição a chumbo}

Marcadores biológicos ou biomarcadores são definidos, genericamente, como indicadores que sinalizam interação entre um sistema biológico e um agente que pode ser químico, físico ou biológico. São usados principalmente como medida no diagnóstico ou na avaliação de risco em saúde ambiental (ATSDR, 1999; Paoliello e Capitani, 2003). Podem ser classificados como marcadores de exposição, marcadores de efeito e marcadores de suscetibilidade. A dose interna produzida por agentes químicos que penetram no organismo é conseqüência de seu metabolismo e dos processos toxicocinéticos (Paoliello e Capitani, 2003).

Marcador de exposição pode ser a medida do próprio xenobiótico, de seus metabólitos ou do produto de uma interação entre o agente e algumas moléculas ou células-alvo, mensurado em um ou mais compartimentos do corpo humano. Este marcador se refere preferencialmente a medidas da própria substância ou de um metabólito especifico, obtido de fluidos corpóreos ou excretas. Dependendo das propriedades da substância (meia-vida) e das condições ambientais (duração da exposição), esta ou seus metabólitos podem não estar mais presentes no organismo quando as amostras biológicas forem coletadas.

Biomarcadores de efeito são definidos como qualquer medida bioquímica, fisiológica ou de alteração orgânica, decorrente da exposição a um xenobiótico, que pode ser reconhecido como relacionado a um dano de saúde potencial ou estabelecido. Esta definição engloba disfunções bioquimicas ou celulares, bem como seus sinais fisiopatológicos. 
Sob as mesmas condições de exposição, alguns indivíduos apresentam doses diferentes do agente em seus órgãos-alvo e, portanto, respostas em diferentes níveis. Estas diferenças podem ser explicadas pela diversidade genética, pelo metabolismo diferencial ou pelas diferenças nos componentes macromoleculares entre as pessoas. Os marcadores de suscetibilidade buscam identificar estas características individuais (ATSDR, 1999; Paoliello e Capitani, 2003).

Devido à especificidade deste estudo, estaremos enfocando os biomarcadores de exposição a chumbo.

\subsection{1 - Chumbo no sangue}

A medida de chumbo no sangue é o biomarcador mais amplamente utilizado, devido à facilidade de amostragem e à homogeneidade nos estudos de exposição. A meia-vida do chumbo no sangue é de 28 a 36 dias, portanto refletiria apenas exposições recentes. Devem-se considerar, no entanto, as trocas entre os níveis de chumbo no sangue e nos ossos. Neste caso, uma única determinação do metal não distingue entre uma exposição crônica ou intermediária a baixos níveis e outra aguda a altos niveis. Para estas diversas exposições, as concentrações de $\mathrm{PbS}$ podem ser as mesmas, devido à homeostase com os niveis ósseos. A plumbemia não é um indicador exato da carga corpórea do chumbo, devido aos processos de transferência, à mobilização e ao estoque entre os diversos compartimentos corpóreos. Apesar destas limitações, a mensuração de chumbo no sangue ainda é considerada a mais recomendada para medidas populacionais de exposição (CDC, 2001). Níveis de 
chumbo no sangue maiores ou iguais a $10 \mu \mathrm{g} / \mathrm{dL}$ indicam que há excessiva exposição (WHO, 1995; ATSDR, 1999)

\subsection{2 - Chumbo no plasma}

As baixas concentrações de chumbo no plasma, em relação aos eritrócitos, têm sido um fator limitante do uso deste indicador em baixas doses de exposição (menores que $20 \mu \mathrm{g} / \mathrm{dL}$ ). Recentemente, técnicas analiticas ainda não consolidadas para crianças vêm sendo desenvolvidas, indicando que há maior correlação entre os níveis de chumbo no plasma e nos ossos do que entre estes e o sangue (ATSDR, 1999).

\subsection{3 - Chumbo na urina}

O uso da mensuração do chumbo na urina como biomarcador de exposição é questionável, devido a seus baixos niveis e a suas flutuações. No entanto este marcador tem sido usado no controle do tratamento da intoxicação pelo metal (WHO, 1995; Paoliello e Capitani, 2003).

\subsection{4 - Chumbo nos cabelos}

As medidas de chumbo nos cabelos têm a vantagem de se constituirem em técnica não invasiva. Referem-se a exposições intermediárias (em torno de dois meses). Várias limitações são levantadas ao uso deste indicador de exposição. As 
concentrações do metal são diferentes dependendo da parte do corpo de onde é retirado o cabelo, a cor do cabelo, sua textura e a fase de crescimento do indivíduo. Outro problema levantado é quanto às técnicas de limpeza da amostra. A purificação da contaminação superficial muitas vezes danifica o fio e altera as concentrações de chumbo em seu interior (WHO, 1995; ATSDR, 1999).

\subsection{5 - Chumbo nos dentes}

As concentrações de chumbo nos dentes são consideradas como potenciais biomarcadores de exposição ao metal. Os dentes são compostos de várias camadas, distintas anatomicamente, que se formam ao longo dos anos e podem dar pistas da história da exposição. Em contraposição ao sangue, os dentes servem como indicadores de deposição do chumbo desde o nascimento até as fases tardias da vida. Como problemas para o uso deste indicador levanta-se que as concentrações do contaminante podem variar em função da localização do dente na boca, da idade ou da avaliação do chumbo total ou chumbo na dentina. Devido à complexa estrutura dos dentes, as concentrações de chumbo dependem do método de amostragem e análise, tipo do dente e sua idade. As diferenças de técnicas de amostragem levam a resultados diversos entre os estudos (WHO, 1995; ATSDR, 1999).

\subsection{6 - Chumbo nos ossos}

O esqueleto humano começa a acumular chumbo desde o desenvolvimento fetal até em torno dos 60 anos. O desenvolvimento de técnicas não invasivas de 
raios-X por fluorescência para mensuração das concentrações de chumbo nos ossos tornou esta um bom biomarcador de exposições crônicas. O chumbo não é distribuído uniformemente nos ossos. Durante a infância acumula-se nas trabéculas e na vida adulta na região cortical e trabecular. A relação entre chumbo ósseo e efeitos na saúde tem sugerido que este é um preditor mais adequado para determinados eventos em adultos como: declínio do hematócrito e hemoglobina, hipertensão e baixo peso ao nascer (ATSDR, 1999).

\subsection{0 - Níveis de plumbemia em crianças no mundo}

Estudo efetuado por Flegal e Smith (1992), com base em análises de chumbo em ossos humanos de épocas pré-industriais e de animais de laboratório, estimou que as concentrações naturais do metal no organismo são em torno de $0,016 \mu \mathrm{g} / \mathrm{dL}$. A evolução da indústria de mineração, o processamento e os usos do chumbo no decorrer dos séculos expuseram o homem ao contaminante, até que o conhecimento de seus efeitos na saúde levou a medidas cada vez mais restritivas de uso, com o estabelecimento de limites considerados seguros.

Em 1975, o CDC recomendava como concentração máxima permitida de PbS em crianças o nivel de $30 \mu \mathrm{g} / \mathrm{dL}$. Este limite, considerado seguro à época, foi diminuindo à medida em que as evidências cientificas mostravam relação entre adoecimento e plumbenias cada vez menores. Em 1985 foi considerado seguro o nivel de $25 \mu \mathrm{g} / \mathrm{dL}$ e, em 1991, o nivel de 10 $\mu \mathrm{g} / \mathrm{dL}$ (CDC, 1991; Paoliello, 2002). Este 
mesmo valor-guia ou de ação foi adotado oficialmente pela Organização Mundial da Saúde e pelo Centro Europeu para Ambiente e Saúde (Jacob et al., 2000). Em vista das evidências de inexistência de limite seguro para o chumbo, a OMS, quando propõe o método de avaliação de Carga de Doença decorrente de exposição ao metal, considera que há queda de 0,65 pontos no QI quando os níveis sanguíneos de chumbo se encontram entre 5 a $10 \mu \mathrm{g} / \mathrm{dL}$, com ponto médio de $7,5 \mu \mathrm{g} / \mathrm{dL}$ (Fewtrall et al., 2003).

O limite seguro de chumbo no sangue proposto pelo $\mathrm{CDC}$, e adotado com algumas modificações pela Academia Americana de Pediatria, pressupõe uma série de medidas de reavaliação, controle ambiental e tratamento de crianças, segundo concentrações sanguineas crescentes do metal. Assim, niveis menores que $10 \mu \mathrm{g} / \mathrm{dL}$ são considerados de baixo risco de exposição, e nenhuma ação é requerida. Entre 10 e $14 \mu \mathrm{g} / \mathrm{dL}$, o exame deve ser repetido e, caso estes valores sejam encontrados em várias crianças da mesma comunidade, deve-se proceder à avaliação ambiental. Níveis entre 15 e $19 \mu \mathrm{g} / \mathrm{dL}$ requerem repetição das análises de $\mathrm{PbS}$ e avaliação ambiental e, entre 20 e $44 \mu \mathrm{g} / \mathrm{dL}$, acrescenta-se o exame médico. Além das condutas anteriormente recomendadas, deve-se considerar a necessidade de quelação em crianças com plumbemias entre 45 e $69 \mu \mathrm{g} / \mathrm{dL}$. A norma estabelece como emergência médica niveis de PbS maiores que 70 $\mathrm{g} / \mathrm{dL}$ (CDC, 1991; AAP, 1998). 
A OMS avalia que nos últimos 15 a 20 anos, os níveis de chumbo no sangue nas populações dos países engajados em programas de prevenção e controle da exposição têm apresentado tendência decrescente (WHO, 1995).

Nos Estados Unidos, as análises de plumbemia em crianças, efetuadas pelo National Health and Nutrition Examination Survey, têm reafirmado as projeções da OMS. Comparando o NHANES II (1976-80), com o NHANES III (1988-91), Pirkle et al. (1994) mostram que houve redução dos niveis de $\mathrm{PbS}$ em $77 \%$ (de 13,7 para $3,2 \mu \mathrm{g} / \mathrm{dL}$ ) em crianças brancas de 1 a 5 anos. A prevalência dos níveis de $\mathrm{PbS}$ maiores ou iguais a $10 \mu \mathrm{g} / \mathrm{dL}$, na mesma faixa etária, caiu de $85 \%$ para $5,5 \%$. Nos resultados recentes do NHANES, de 1999-2000, encontra-se prevalência de plumbemias maiores que $10 \mu \mathrm{g} / \mathrm{dL}$ em apenas $2,2 \%$ das crianças (CDC, 2003).

$\mathrm{Na}$ França, comparando-se os níveis de $\mathrm{PbS}$ em crianças de 1 a 6 anos em 1979 com os níveis em 1982, estimou-se redução de 50\% em Paris e 35\% em Lyon. Em 1995, apenas 5,5\% dos menores de 7 anos apresentaram plumbemias superiores a 10 $\mu \mathrm{g} / \mathrm{dL}$ (MES/SES, 1998; INSERM, 2002). Estudo transversal, realizado na Itália, mostra redução de $25 \%$ nos niveis de chumbo na população em 1985 em relação a 1979 (Morisi et al., 1989).

Seguindo uma coorte de 91 crianças de 6 meses a 5 anos, Rothenberg et al., (1998 e 2000), encontraram tendência de queda dos niveis de plumbemia na cidade do México. A média de PbS em 1990 foi $14,2 \mu \mathrm{g} / \mathrm{dL}$ e, em 1995, de 6,3 $\mu \mathrm{g} / \mathrm{dL}$. Os 
autores creditam esta diferença às medidas de controle ambiental tomadas, inclusive com a redução da venda de gasolina com chumbo.

No Brasil, encontramos dois estudos acerca de populações não expostas ocupacionalmente e que apenas consideram adultos. O primeiro, de Fernícola e Azevedo (1981), compara três grupos de pessoas: residentes em área rural (niveis médios de $\mathrm{PbS}$ de $11,2 \mu \mathrm{g} / \mathrm{dL}$ ), residentes em área urbana (niveis médios de $\mathrm{PbS}$ de $12,4 \mu \mathrm{g} / \mathrm{dL}$ ) e residentes próximo a indústria de recuperação de chumbo ( $\mathrm{PbS}$ médio de $20,5 \mu \mathrm{g} / \mathrm{dL}$ ). O segundo estudo (Paoliello et al., 1997) busca estabelecer valores de referência para plumbemia em população urbana. A mediana de $\mathrm{PbS}$ encontrada foi de $7,9 \mu \mathrm{g} / \mathrm{dL}$, com intervalo entre 2,4 e $16,6 \mu \mathrm{g} / \mathrm{dL}$. Em nosso país não foram encontrados estudos de valores de referência para chumbo no sangue em crianças. Do ponto de vista legal, o único regulamento aqui existente refere-se à exposição ocupacional e considera plumbemia até $40 \mu \mathrm{g} / \mathrm{dL}$ como valor de referência de normalidade (Portaria $n^{\circ} 3.214 / 78$, do Ministério do Trabalho)

Os estudos transversais que buscam estabelecer valores de referência para crianças não expostas a fontes fixas de emissão de chumbo apresentam resultados diversos segundo as localidades. A Tabela 7 apresenta os resultados de alguns destes estudos. Em geral, quando se declara o uso de chumbo na gasolina, os níveis de plumbemia são mais elevados. 
Tabela 7. Plumbemias ( $\mu \mathrm{g} / \mathrm{dL})$ em crianças não expostas a fontes fixas de emissão de chumbo. Estudos em várias localidades do mundo.

\begin{tabular}{|c|c|c|c|c|}
\hline Local & $\mathrm{N}^{\circ}$ & Idade (anos) & $\begin{array}{l}\text { Niveis médios de } \mathrm{PbS} \\
\mu \mathrm{g} / \mathrm{dL}\end{array}$ & Referência \\
\hline Himalaia & 47 & $3-12$ & 3,5 & Piomelli et al., 1980 \\
\hline Itália & 1968 & $0-14$ & $\begin{array}{l}\text { Masc- } 9,4 \\
\text { Fem }-8,6\end{array}$ & Morisi et al., 1989 \\
\hline Arábia Saudita & 1047 & $0,2-16$ & $10,37^{*}$ & Al-Saleh et al., 1994 \\
\hline Alemanha Ocidental & 2311 & 6 & $3,93-6,81$ & Bergerow et al., 1994 \\
\hline Lucca, Itália & 172 & $0-14$ & 5,72 & $\begin{array}{l}\text { Montesanti et al., } \\
1995\end{array}$ \\
\hline Austrália & 1575 & 14 & $5,8^{*}$ & DEH, 1995 \\
\hline $\begin{array}{l}\text { Provincia de Capi, } \\
\text { África do Sul }\end{array}$ & Várias localidades & crianças & $13-16^{*}$ & $\begin{array}{l}\text { Von Schimding et al., } \\
\text { 1995, apud Nriagu et } \\
\text { al., } 1996\end{array}$ \\
\hline Pequim, China & 119 & $5-7$ & $7,8^{*}$ & Shen et al., 1996 \\
\hline Hungria & 1401 & $0-4$ & 5,7 & Bittó et al., 1997 \\
\hline Nigéria, África & 87 & $1-6$ & $10,6^{*}$ & Nriagu et al., 1997 \\
\hline Cidade do México & 91 & $3-5$ & 8,6 & $\begin{array}{l}\text { Rotehenberg et al., } \\
2000\end{array}$ \\
\hline França & Amostra populacional & $1-6$ & 3,6 & INSERM/RNSP, 2002 \\
\hline Taiwan & 1885 & $7-12$ & $5,0^{*}$ & Yang et al., 2002 \\
\hline Rússia & 2882 & $2-6$ & $6,4-6,8$ & Rubin et al., 2002 \\
\hline Jakara, Indonésia & 397 & $6-12$ & $8,6^{*}$ & Albalak et al., 2003 \\
\hline Estados Unidos & 723 & $1-5$ & 2,23 & $\begin{array}{l}\text { CDC, } 2003 \text { do } \\
\text { NHANES (1999- } \\
2000)\end{array}$ \\
\hline Estados Unidos & 905 & $6-11$ & 1,51 & $\begin{array}{l}\text { CDC, } 2003 \text { do } \\
\text { NHANES } \\
2000)\end{array}$ \\
\hline
\end{tabular}

* Autores declararam que o pais usa chumbo na gasolina. Adaptado de Paoliello. 2002. 


\subsection{1 - Os estudos de populações expostas a fontes fixas de emissão de chumbo}

Os estudos realizados em várias áreas contaminadas no mundo têm priorizado a avaliação dos niveis de plumbemia em crianças. A quase totalidade são de corte transversal, em populações expostas a uma ou várias fontes na mesma localidade. Podem ser classificados em dois grupos: aqueles que utilizam grupo-controle não exposto e aqueles que avaliam apenas os expostos. Neste caso, trabalham com faixas de distância da fonte e/ou o valor de ação proposto pelo $\mathrm{CDC}$, que variou em niveis decrescentes no decorrer dos anos. Em grande parte das análises o grupo de crianças é dividido segundo niveis de plumbemia, iguais ou maiores e menores que um valor de referência, para avaliação de fatores de risco associados em análise de regressão. Outros autores comparam as médias de $\mathrm{PbS}$ segundo as diversas variáveis possivelmente relacionadas com diferenciais de exposição. Em artigos publicados mais recentemente, ao lado do estudo epidemiológico, são realizadas avaliações ambientais e os dados, em conjunto, são analisados em regressão linear múltipla. Classicamente são avaliadas as variáveis ligadas à pessoa, sendo aquelas relacionadas ao local definidas a partir da caracterização da área.

Dentre os estudos transversais que utilizam grupo-controle para avaliação dos diferenciais das médias de plumbemia e realizam a investigação de fatores de risco podem-se citar publicações da Bélgica, Alemanha, Filipinas, França, Suécia, Brasil e México, que serão abordados a seguir. 
Na Bélgica, próximo a uma mineradora de chumbo, Roels et al., (1980) avaliaram cinco estudos transversais, comparando as médias de plumbemia das crianças de onze anos, residentes no raio de 1 a $2,5 \mathrm{~km}$ da fonte de contaminação, com as médias em crianças das áreas rural e urbana. As análises dos níveis de $\mathrm{PbS}$ foram realizadas a cada ano, desde 1974 até 1978 , para avaliar o impacto do controle da fonte de emissão. As médias de plumbemia foram diferentes entre os grupos de expostos e não expostos, tendendo a estabilizar na distância de $2,5 \mathrm{~km}$. Ao comparar os diferentes anos de investigação, detectaram queda significativa dos niveis de chumbo no sangue apenas entre o primeiro e o segundo ano. Levando em conta os níveis de chumbo no solo, na poeira e nas mãos das crianças, os autores concluem que a contribuição do metal no ar foi de pequena monta para explicar os níveis de plumbemia e que as medidas de remediação deveriam levar em conta a contaminação de outros compartimentos ambientais.

Na Alemanha, Trepka et al. (1997) avaliaram diversas localidades sob influência de três mineradoras, tendo como controle uma comunidade distante, residente em apartamentos. $\mathrm{Na}$ análise das áreas em conjunto, observaram que quanto mais as residências se distanciavam da fonte, menores eram os niveis de plumbemia. Em regressão multipla concluiram que os preditores dos níveis de $\mathrm{PbS}$ foram: localização da residência (norte ou sul), sexo (masculino), educação dos pais, construção da casa anterior à II Grande Guerra, presença de chumbo na água de torneira e na poeira da casa, consumo de vegetais de horta local e aparência da criança após brincar no parque (suja ou limpa). 
Estudo transversal realizado nas Filipinas, comparando niveis de plumbemia em crianças residentes nas proximidades de indústria de reciclagem de baterias e de indústrias de radiadores com crianças não expostas, encontrou diferença entre as médias de $\mathrm{PbS}$ apenas quando se comparou o primeiro grupo com o de não expostos (Suplido e Ong, 2000).

No norte da França, Leroyer et al. (2000), avaliando duzentas crianças de oito a onze anos residentes nas vizinhanças de duas fontes de emissão de chumbo com duzentas crianças não expostas, encontraram diferenças significativas nas médias de plumbemia. Na análise do conjunto de dados foi detectada associação entre níveis elevados de $\mathrm{PbS}(\geq 6,5 \mu \mathrm{g} / \mathrm{dL})$ e as seguintes variáveis: residir próximo à empresa, beber água de torneira com canos à base de chumbo, sexo (masculino), estação do ano, residir em área de tráfego intenso e genitor trabalhar em uma das duas empresas.

Crianças residentes próximo a uma indústria de fundição de chumbo na Suécia não apresentaram niveis mais elevados de plumbemia que seus controles na área urbana. Maiores níveis de PbS foram relacionados à existência de fumantes na casa (Berglund et al., 2000).

No Vale do Ribeira, no Estado de São Paulo, menores entre sete e quatorze anos, residentes nas proximidades de uma refinaria de chumbo, apresentaram níveis médios de $\mathrm{PbS}$ de $11,25 \mu \mathrm{g} / \mathrm{dL}$ e seus controles, níveis de $4,4 \mu \mathrm{g} / \mathrm{dL}$. No conjunto das informações de expostos e não expostos, foram identificados com fatores de risco de 
plumbemias elevadas $(\geq 10 \mu \mathrm{g} / \mathrm{dL})$ a proximidade da refinaria, genitor trabalhar na empresa e sexo masculino (Paoliello et al., 2002).

Em estudo realizado em Torreón, México, comparou-se a proporção de crianças com plumbemia maiores ou iguais a $10 \mu \mathrm{g} / \mathrm{dL}$, residentes em área próxima à fonte de emissão de chumbo, com a proporção em crianças residentes distante da fonte. A proporção foi maior nas primeiras. A partir do conjunto de dados foram associados a niveis elevados de plumbemia: idade, distância de fonte, renda familiar e educação dos pais (Albalak et al., 2003).

As abordagens de áreas contaminadas que não utilizaram grupo-controle para comparação das médias de plumbemia analisam os gradientes de concentração sanguinea do metal segundo distância da fonte. Comparam os resultados com regulamentações internas ou externas ao pais, particularmente os limites propostos pelo $\mathrm{CDC}$, investigam fatores de risco e avaliam impacto de medidas de controle.

$\mathrm{Na}$ área mexicana de influência de uma empresa de fundição em El Paso, Texas, foram avaliados os níveis de plumbemia em crianças de um a nove anos. Estes niveis foram tanto mais elevados quanto mais as residências das crianças se aproximavam da fonte de contaminação. Outro fator de risco identificado foi a poeira intradomiciliar contaminada por chumbo (Ordonez et al., 1976).

Em Santo Amaro da Purificação, Bahia, foram realizados estudos transversais de exposição a chumbo proveniente de uma fundidora nos anos de 1985, 1989 e 1992. Foi considerado o raio de $900 \mathrm{~m}$ da fonte, tendo-se investigado as diferenças entre as médias de plumbemia segundo possiveis preditores. Após a 
primeira avaliação, foram adotadas medidas de controle de emissão e por fim a fábrica foi fechada em 1993. No primeiro estudo, as médias de plumbemia diminuem à medida que as residências se afastam da empresa. Outros fatores associados foram: raça (negra), residir há mais de um ano no local e genitor trabalhar na fonte de contaminação. $\mathrm{Na}$ avaliação efetuada em 1989 , foram detectados como fatores de risco os niveis de chumbo no solo e hábito de comer terra. No terceiro estudo, além dos fatores anteriores, as crianças do sexo feminino apresentaram médias de plumbemia superiores aos meninos (Carvalho et al., 1985; Silvany-Neto et al., 1989; Silvany-Neto et al., 1996). Em 1989, Tavares et al., avaliando os niveis de chumbo em cabelo de crianças na mesma área, encontraram fatores de risco semelhantes.

Estudo efetuado no sul da Austrália, na cidade de Port Pirie, onde ocorreu contaminação por chumbo a partir de uma mineradora, avaliou 1239 crianças, o que correspondeu a $50 \%$ dos alunos do ensino fundamental. Neste estudo observou-se diferença significativa dos níveis de plumbemia segundo área de residência. Da amostra analisada, $7 \%$ das crianças apresentavam níveis de $\mathrm{PbS}$ superiores a $30 \mu \mathrm{g} / \mathrm{dL}$, limite proposto pelo CDC como seguro à época (Wilson et al., 1986).

Em 49 crianças residentes nas vizinhanças de uma mina de cobre na Suécia, onde havia cerca de dez mil toneladas de chumbo, foram encontradas diferenças significativas entre as médias de plumbemia no inverno e no verão, sendo maiores na última estação. Os autores argumentam que no verão as crianças têm mais contato com o solo (Bjerre et al., 1993). 
Investigando fontes e formas de exposição a chumbo em crianças de 6 a 71 meses, residentes nas vizinhanças de mineração e processamento do metal no Colorado, Cook et al. (1993) encontraram 40,7\% com plumbemias superiores a $10 \mu \mathrm{g} / \mathrm{dL}$. Como fatores de risco de niveis elevados de PbS foram identificados: a ocupação dos pais (trabalhar em uma das empresas), niveis de chumbo no solo, a pica e fazer refeições no parque.

Santos Filho et al., 1993, concluíram que a influência do consumo de organismos aquáticos nos niveis de plumbemia em crianças, residentes no estuário de Santos, no litoral paulista, não era significativa, embora a média de $\mathrm{PbS}$ neste grupo fosse elevada $(17,8 \mu \mathrm{g} / \mathrm{dL})$. Outros fatores deveriam ser investigados.

A partir da identificação da contaminação ambiental proveniente da mineração de chumbo em Port Pirie, foi criada uma coorte para avaliar a evolução dos níveis de plumbemia com a idade, investigar fatores de risco, avaliar medidas de controle e impacto na saúde das crianças. Um dos estudos desta coorte avaliou crianças desde o nascimento até os treze anos de idade. Nesta publicação, os fatores de risco relacionados aos niveis de plumbemia foram: ocupação dos pais, tempo de residência da mãe na área contaminada antes da gravidez, distância da empresa e precariedade da residência (Baghust et al., 1999).

$\mathrm{Na}$ Tabela 8 estão listados os resultados de estudos realizados em vários paises onde foram avaliadas crianças. 
Tabela 8. Niveis médios de plumbemia $(\mu \mathrm{g} / \mathrm{dL})$ em crianças residentes no entorno de fontes de emissão de chumbo.

\begin{tabular}{|c|c|c|c|c|c|c|c|c|}
\hline \multirow[t]{2}{*}{ Local } & \multirow[t]{2}{*}{ Fonte } & \multirow{2}{*}{$\begin{array}{l}\text { Distância } \\
\text { da fonte }\end{array}$} & \multirow{2}{*}{$\begin{array}{l}\text { Idade } \\
\text { (anos) }\end{array}$} & \multicolumn{2}{|c|}{ Expostos } & \multicolumn{2}{|c|}{ Controles } & \multirow[t]{2}{*}{ Referència } \\
\hline & & & & $\mathrm{N}$ & $\mathrm{PbS}$ & $\mathrm{N}$ & $\mathrm{PbS}$ & \\
\hline $\begin{array}{l}\text { Cidade Juarezd } \\
\text { México }\end{array}$ & Fundição & 8 milhas & 1 a 9 & 752 & 29,27 & & & $\begin{array}{l}\text { Ordonez et al., } \\
1976\end{array}$ \\
\hline Bélgica & Fundição & $<1 \mathrm{~km}$ & 11 & 43 & 27.8 & 29 & 12,7 & Roels et al., 1980 \\
\hline $\begin{array}{l}\text { Santo Amaro da } \\
\text { Purificação, } \\
\text { Bahia/ Brasil }\end{array}$ & Fundição & $900 \mathrm{~m}$ & 1 a 9 & 555 & 58,7 & & & $\begin{array}{l}\text { Carvalho et al., } \\
1985\end{array}$ \\
\hline $\begin{array}{l}\text { Port Pirie. } \\
\text { Austrália }\end{array}$ & Indústria & $\begin{array}{l}\text { Toda a } \\
\text { cidade }\end{array}$ & 1 a 14 & 1239 & 18,2 & & & Wilson et al., 1986 \\
\hline Suécia & Mineração & & 0.7 a 7 & 49 & 3.1 & & & Bjerre et al., 1993 \\
\hline $\begin{array}{l}\text { Colorado. } \\
\text { EEUU }\end{array}$ & Mineração & & 0.7 a 6 & 239 & 10.1 & & & Cook et al., 1993 \\
\hline Polônia & Indústria & & 7 & +31 & 7.94 & & & Zejda et al., 1995 \\
\hline Alemanha & Mineração & & 5 a 14 & 14 & 7.8 & 157 & 3.00 & Trepka et al., 1997 \\
\hline Munbai. Índia & Indústria & & 6 a 10 & 21 & 14.4 & & & $\begin{array}{l}\text { Raghunat et al., } \\
1999\end{array}$ \\
\hline Norte da França & Fundição & & 8 a 12 & 200 & 3.97 & 200 & 3.06 & $\begin{array}{l}\text { Leroyer et al., } \\
2000\end{array}$ \\
\hline $\begin{array}{l}\text { Antofogasta/ } \\
\text { Chile }\end{array}$ & $\begin{array}{l}\text { Armazena- } \\
\text { mento }\end{array}$ & $400 \mathrm{~m}$ & Até 2 & 486 & 8.7 & 75 & 4.22 & $\begin{array}{l}\text { Sepúlveda et al., } \\
2000\end{array}$ \\
\hline $\begin{array}{l}\text { Manilla/ } \\
\text { Filipinas }\end{array}$ & $\begin{array}{l}\text { Reciclagem } \\
\text { de baterias }\end{array}$ & & Até 12 & 10 & 49,8 & 5 & 9,92 & $\begin{array}{l}\text { Suplido e Ong. } \\
2000\end{array}$ \\
\hline Suécia & Mineração & & 1 a 4 & 48 & 2.2 & 89 & 3.00 & $\begin{array}{l}\text { Berglund et al. } \\
2000\end{array}$ \\
\hline $\begin{array}{l}\text { Vale do Ribeira/ } \\
\text { Brasil }\end{array}$ & $\begin{array}{l}\text { Mineracão e } \\
\text { Refinaria }\end{array}$ & & 7 a 14 & 94 & 11.25 & 201 & 4.40 & $\begin{array}{l}\text { Paoliello et al., } \\
2002\end{array}$ \\
\hline $\begin{array}{l}\text { Torrén/ } \\
\text { México }\end{array}$ & Indistria & & 1 a 6 & 72 & 7.50 & 222 & 5.50 & $\begin{array}{l}\text { Albalak et al.. } \\
2003\end{array}$ \\
\hline
\end{tabular}

Conforme literatura cientifica, o chumbo é um metal de elevada toxicidade à saúde humana. Embora em doses baixas seus efeitos sejam ainda discutidos, não há dúvidas de que as crianças são as maiores vitimas. As crianças, em fase de desenvolvimento, absorvem mais o metal e ainda não desenvolveram mecanismos de defesa, particularmente do sistema nervoso, para fazerem frente a uma exposição 
excessiva. Devido a estes fatores os menores de 12 anos foram prioridade neste estudo.

A investigação da exposição e a identificação de fatores de risco relacionados a plumbemias elevadas são passos imprescindiveis para a adoção de medidas de controle e prevenção dos danos à saúde relacionados ao chumbo. Buscou-se, ao lado das avaliações ambientais, caracterizar a exposição e identificar as variáveis da pessoa, do lugar e do tempo que pudessem estar associadas com altas concentrações do metal no sangue

O chumbo, ao contrário dos micronutrientes, não faz parte do metabolismo natural do ser humano, é sempre uma substância estranha ao organismo. As dificuldades de se estabelecerem limites seguros para este metal têm levado a que se recomendem medidas cada vez mais restritivas quanto à sua exposição.

Como legado do modelo de industrialização, há um grande número de áreas contaminadas por diversas substâncias quimicas, sendo o chumbo um dos protagonistas. O setor saúde ainda carece de método para abordá-las.

A contaminação por chumbo em área residencial e agrícola no municipio de Bauru propiciou à equipe de saúde uma oportunidade para o desenvolvimento de método de abordagem especifico ao tema. O municipio de Bauru é sede da regional estadual de saúde, que conta com equipe técnica atuante, da mesma forma que a Secretaria Municipal de Saúde. Isto permitiu desenvolver um trabalho articulado desde o diagnóstico até a avaliação das medidas de controle, integrando os diversos 
setores da saúde e de ambiente em um plano comum. A experiência desenvolvida em Bauru é o objeto deste trabalho. 


\section{2 - OBJETIVOS}

\section{1 - Objetivo geral:}

Contribuir na discussão para a abordagem do setor saúde em áreas contaminadas no Estado de São Paulo.

\section{2 - Objetivos específicos:}

2.2.1 - Avaliar a exposição ao chumbo em crianças residentes no entorno de uma fonte de emissão no municipio de Bauru.

2.2.2 - Identificar fatores de risco associados a niveis elevados de plumbemia com a finalidade de propor e adotar medidas de controle da exposição

2.2.3 - Avaliar o impacto das medidas de remediação adotadas a partir da comparação de médias de plumbemia antes e após a remediação da área.

2.2.4 - Descrever a dinâmica institucional para enfrentamento do problema da contaminação a partir do arcabouço legal de interinstitucionalidade, noções de redes e governança. 


\section{3-MÉTODOS}

Muito se discute sobre a necessidade de abordagem interinstitucional e multidisciplinar, particularmente na investigação do impacto na saúde decorrente de condições ambientais adversas. No tocante às áreas contaminadas no Estado de São Paulo, onde existem diversas instituições atinentes ao tema, para avaliação do dano na população fazem-se necessárias informações e ações de, no mínimo, quatro atores: setor ambiental, através da CETESB, que responde pela identificação e controle das fontes de exposição que possam causar impacto na saúde e no meio; o setor saúde através da vigilância sanitária, instância de controle das possiveis rotas que ligam o individuo à fonte de contaminação; do Laboratório de Saúde Pública na orientação, estabelecimento de padrões e realização de exames toxicológicos; e da vigilância epidemiológica, que estuda a exposição e efeitos nos indivíduos e, em conjunto com os demais, recomenda medidas de controle a partir da identificação dos fatores determinantes e condicionantes da saúde humana.

No Estado, não existe um corpo de profissionais formado para a investigação de áreas contaminadas no tocante à seus impactos na saúde das pessoas. $O$ conhecimento encontra-se disperso entre especialidades, sempre centrado nos efeitos no individuo. A abordagem do coletivo, buscando a construção de método integrador, é uma novidade entre nós. O caso Bauru foi utilizado como um exercício de integração interinstitucional e multidisciplinar, onde cada setor foi requisitado a cumprir com sua vocação e suas obrigações legais, de forma coordenada, tendo como objetivo o bem-estar da população. Este exercicio buscava contribuir na construção 
de um modelo, do ponto de vista da saúde, que pudesse vir a ser utilizado em situações similares. A adequação deste modelo foi avaliada através da participação de cada setor, da tomada de decisões frente aos problemas apresentados e do cumprimento das recomendações do grupo, desde o diagnóstico até a medida do impacto das ações propostas, visando minimizar a exposição e seus efeitos.

\section{1 - O problema e as primeiras ações}

O setor saúde tomou conhecimento da contaminação por chumbo proveniente da empresa em estudo por meio de ofício da CETESB de 01/02/2002, enviado para a Direção Regional de Saúde de Bauru - DIR X, comunicando a interdição da empresa em 21/01/2002 e solicitando investigação epidemiológica da população residente na área do entorno. O oficio também foi encaminhado ao Ministério Público com a mesma solicitação. Os niveis de chumbo no ar foram colocados como justificativa para a suspensão das atividades da fábrica.

Ao tomar conhecimento do problema, a DIR $\mathrm{X}$ iniciou o reconhecimento da área e buscou informações mais detalhadas do caso junto a CETESB. O fato foi também comunicado pela DIR X à Divisão de Doenças Ocasionadas pelo Meio Ambiente - DOMA, do Centro de Vigilância Epidemiológica - CVE, que procedeu a levantamento bibliográfico sobre o tema e consultou especialistas em toxicologia. Disto resultou a constatação de que as crianças são mais sensíveis aos efeitos do chumbo e, por caracteristicas de seu metabolismo, absorvem mais o contaminante. Foi então definido que o grupo prioritário de investigação seria o de crianças. Outra 
questão levantada foi a inexistência de níveis de referência para chumbo no Brasil, para este grupo etário. Para contornar este problema foi proposto um estudo-piloto como recomendado por Kjellström (1992). O autor recomenda, para fundamentar a necessidade de estudos epidemiológicos mais aprofundados de exposição a chumbo, avaliar no mínimo 25 crianças de 1 a 2 anos e suas mães na área-problema (expostos), em conjunto com 25 crianças não expostas como grupo de referência. Em Bauru, nas duas áreas, foram avaliados apenas os menores de 7 anos tendo-se acrescentado os critérios de a criança ter nascido ou residir no local há 4 anos ou mais e da população de referência ter condições socioeconômicas similares à áreaproblema. Recomendou-se investigar 30 crianças de cada grupo. A equipe abordava os responsáveis de cada residência, em visita domiciliar, e perguntava se havia crianças que preenchessem os critérios de idade e tempo de residência. Caso houvesse era solicitada assinatura de termo de consentimento, preenchia-se um questionário e procedia-se a coleta de sangue com agulha descartável em tubo vacutainer. Não foi feito sorteio nesta fase. Devido a ocupação recente da regiãoproblema, a equipe de campo teve dificuldade em encontrar crianças dentro das regras estabelecidas. Foram então avaliados os níveis de chumbo no sangue de 29 crianças no entorno da empresa e 31 na área de referência situada há $11 \mathrm{~km}$ da fábrica.

$\mathrm{Na}$ discussão dos resultados do estudo-piloto, entre a DIR X, a DOMA e a Vigilância em Saúde do município, decidiu-se por realizar estudo transversal, segundo o apontado nos trabalhos científicos sobre o tema, para investigar a 
exposição de crianças ao metal e identificar fatores de risco relacionados aos niveis de plumbemia.

Delimitou-se o raio de mil metros a partir da empresa como área inicial de estudo (Roels et al.,. 1980; Landrigan e Baker, 1981; Wang et al.,. 1995). Os trabalhos citados na literatura, avaliando exposição a chumbo a partir de sítios contaminados, analisam grupos etários distintos, excluindo-se em geral os menores de 1 ano. Nesta investigação optou-se pelo estabelecido pela Academia Brasileira de Pediatria que define como crianças as pessoas de zero a doze anos completos.

Julgou-se que, ao lado da investigação epidemiológica dos expostos, seria necessária a avaliação dos diversos compartimentos ambientais - água, ar, solo e alimentos - de forma a contemplar as possiveis rotas de exposição das crianças. $\mathrm{O}$ Ministério da Saúde foi acionado e colaborou na constituição de um grupo de suporte técnico ao trabalho, composto pelas instituições atinentes ao tema e especialistas de reconhecido saber. Este grupo teria caráter deliberativo e prestaria assessoria aos executores da investigação nos seus diversos niveis hierárquicos.

Fizeram parte do grupo de suporte técnico as seguintes instituições e especialidades:

$\checkmark$ Ministério da Saúde, através da Coordenação Geral de Vigilância Ambiental CGVAM;

$\checkmark$ Ministério do Meio Ambiente; 
Secretaria de Estado da Saúde de São Paulo, com representantes da Vigilância Epidemiológica, Vigilância Sanitária, DIR X Bauru e o Laboratório de Saúde Pública: Instituto Adolfo Lutz - IAL;

$\checkmark$ Secretaria de Saúde do município de Bauru, através da Vigilância em Saúde local;

$\checkmark$ Secretaria do Meio Ambiente do Estado, através da Gerência de Áreas Contaminadas, Gerência de Solos e Gerência de Toxicologia da CETESB;

$\checkmark$ Toxicologistas com experiência no tema em questão, pertencentes aos quadros da UNICAMP, da Faculdade de Medicina de Londrina (PR), do Centro de Controle de Intoxicações do Hospital do Jabaquara (São Paulo, capital) e da FUNDACENTRO;

$\checkmark$ Neuropediatra do centro formador mais próximo de Bauru, sendo o representante profissional da Faculdade de Medicina de Botucatu.

As funções institucionais de cada parte envolvida foram definidas a partir de suas vocações e do aparato legal que estabelece as atribuições de cada órgão. Em cada reunião do grupo era estabelecida uma pauta, aberta a sugestões dos participantes, que tinha como objetivo a tomada de decisões com base em argumentos técnicos. Assim coube:

$\checkmark$ ao Ministério da Saúde: apoio técnico e propiciar infra-estrutura para o funcionamento do grupo;

$\checkmark$ ao Ministério do Meio Ambiente: apoio técnico; 
à Vigilância Epidemiológica no nivel central estadual: produção dos relatórios de exposição das crianças para o Ministério Público, definição do desenho e assessoria na execução do estudo transversal, análise dos dados e coordenação do grupo de suporte técnico, através da DOMA/CVE. Estas atividades foram desenvolvidas pela autora deste trabalho;

à Vigilância Sanitária no nivel central estadual: suporte técnico nas avaliações de produtos para o consumo humano na área sob investigação e a avaliação dos trabalhadores da empresa, através da Divisão de Ações sobre o Meio Ambiente;

$\checkmark$ ao Instituto Adolfo Lutz: discussão sobre indicadores e execução das análises de chumbo em amostras humanas e em alimentos consumidos no local;

$\checkmark$ à CETESB: assessoria na discussão de possiveis rotas de exposição e avaliação dos compartimentos ambientais: águas superficiais e profundas, solo, vegetação e ar;

$\checkmark$ aos toxicologistas: assessoria na matéria, discussão dos resultados das avaliações ambientais, dos alimentos de consumo humano e da investigação epidemiológica, contribuindo na orientação de medidas de controle e remediação;

$\checkmark$ ao neuropediatra: assessoria e coordenação das investigações de impacto na saúde das crianças e no tratamento quando necessário;

$\checkmark$ às Vigilâncias Epidemiológica e Sanitária no nível regional estadual: suporte técnico ao município, reconhecimento da área, digitação e controle de qualidade dos dados, centralização e distribuição de todas as informações e coordenação das atividades de campo; 
$\checkmark$ à Direção da DIR X - Bauru: coordenação política dos trabalhos, representando o grupo junto ao Ministério Público, às organizações da sociedade e à imprensa;

à Secretaria Municipal de Saúde de Bauru: participação nas discussões, execução dos trabalhos de campo, retroalimentação das informações ao grupo de suporte técnico e discussões com a população local.

Devido a problemas enfrentados pelo município de Bauru no período da investigação, este solicitou à DIR X que coordenasse o processo.

As reuniões do grupo de suporte técnico ocorreram sempre que surgiram questionamentos ou fatos novos nas avaliações ambientais ou na investigação epidemiológica, fatos estes que pudessem reorientar o trabalho. No intervalo das reuniões mantinha-se a discussão por correio eletrônico.

Para avaliar a dinâmica institucional local gerada como decorrência desta demanda foi realizada entrevista com o gestor de saúde da Diretoria Regional de Bauru - DIR X, coordenador político do processo. A entrevista foi aberta, tendo o investigador feito anotações e descrição do conteúdo em momento posterior (Anexo 1). Esta descrição foi encaminhada ao gestor de saúde para possíveis correções de entendimento ou interpretações errôneas, bem como para sua autorização quanto a inclusão do material no corpo deste trabalho.

Foram feitas três questões ao gestor de saúde, tendo como base um roteiro no qual se priorizava conhecer as formas de relação institucionais: 
Questão 1: A DIR X coordenou as atividades relativas à investigação da exposição da população a chumbo proveniente de empresa de acumuladores de baterias no município de Bauru. Gostaria que contasse a experiência de gestão das diversas instituições, as articulações políticas para viabilizar o trabalho, os embates e encaminhamentos, bem como a visão da DIR sobre o processo.

Questão 2: Como avaliou o papel do nível central?

Questão 3: Avaliando o processo das demais áreas contaminadas, chegamos a pensar que Bauru foi um caso único, cuja liderança, por caracteristicas próprias, possibilitou o encaminhamento a contento de todas as fases do trabalho. $\mathrm{O}$ que o gestor acha disto?

$\mathrm{Na}$ análise da dinâmica institucional buscou-se contextualizar a experiência de Bauru a partir do arcabouço legal da interinstitucionalidade e das noções de redes e governança.

\section{2 - As avaliações ambientais}

O documento da CETESB que serviu como argumento técnico para a interdição da empresa ( Informação Técnica n 164/01/CPN-B) dava conta de níveis elevados de chumbo em estação de monitoramento da qualidade do ar, instalada a $800 \mathrm{~m}$ da fonte e na poeira ressuspensa do solo na indústria. As concentrações de chumbo na atmosfera, medida entre os meses de junho a agosto de 2001, variavam de $0,7 \mu \mathrm{g} / \mathrm{m}^{3}$ a $37,3 \mu \mathrm{g} / \mathrm{m}^{3}$. A média foi de $9,7 \mu \mathrm{g} / \mathrm{m}^{3}$ no período. O regulamento da agência de proteção ambiental americana - EPA - estabelece como aceitável a 
concentração média avaliada durante 3 meses de $1,5 \mu \mathrm{g} / \mathrm{m}^{3}$. No documento, a poeira ressuspensa do solo, medidas em dois pontos do entorno da empresa, apresentaram concentrações de chumbo de $0,32 \%$ e $0,27 \%$. Percentuais bem maiores que na áreacontrole, onde foi encontrado chumbo na proporção de $0,02 \%$. As atividades da empresa foram suspensas em 21/01/2002 sendo recomendadas diversas medidas de controle.

De posse destes resultados a DIR X, em conjunto com a DOMA, solicitou à CETESB que avaliasse os níveis de chumbo no solo e nas águas dos rios da área de influência da empresa. Em sua primeira campanha foi colhido solo superficial de 0 a $20 \mathrm{~cm}$ (35 pontos) e solo sub-superficial de 80 a $100 \mathrm{~cm}$ ( 7 pontos). Para a escolha destes locais foram estabelecidos dois critérios: o primeiro foi a probabilidade de haver residuos da indústria ou áreas de maior interesse em investigar a lixiviação de contaminantes para camadas mais profundas. O segundo critério foi a escolha de pontos onde a principal suspeita era de contaminação por deposição atmosférica de partículas contendo chumbo, sendo alguns deles orientados pelos dados preliminares da investigação epidemiológica. Por solicitação do municipio de Bauru foram colhidas algumas amostras do zoológico local, distante $2 \mathrm{~km}$ da fonte.

Nesta campanha foram investigados a água e os sedimentos da microbacia composta pelo córrego Vargem Limpa, que deságua no rio Bauru. Os pontos de amostragem foram distribuidos ao longo desses dois corpos de água, com maior concentração de pontos no córrego Vargem Limpa. 
Coletou-se também o ar com amostradores de grandes volumes, por $24 \mathrm{~h}$ em sete dias; águas subterrâneas em 7 pontos, sendo um na área da indústria, um no zoológico e os demais em áreas residenciais. A vegetação foi colhida em 8 pontos.

Numa segunda campanha e uma vez que as crianças entram em contato com o solo superficial, foram solicitadas análises levando em conta estas características de exposição. Colheu-se solo com profundidade de $0 \mathrm{a} 2 \mathrm{~cm}$, água de cacimba e de fonte na área da empresa. Os locais escolhidos para amostras de solo desta segunda campanha foram aqueles onde as crianças apresentaram níveis mais elevados de plumbemia.

O método para análise de água baseou-se na $20^{\mathrm{a}}$ edição do "Standard Methods for the Examination of Water and Wastewater" APHA AWWA WEF, 1998, método 3113 por espectrometria de absorção atômica com forno de grafite. A avaliação dos niveis de chumbo no solo foram fundamentados na norma "Test Methods for Evaluating Solid Wastes" EPA/SW 846 Method 3051, 1994.

Como limites aceitáveis de chumbo no solo foram tomados os valores orientadores estabelecidos pela CETESB, em seus níveis de alerta e intervenção para área de uso residencial. Os limites para águas subterrâneas obedeceram ao preconizado na Portaria $n^{\circ}$ 1469/2000 do Ministério da Saúde e para águas superficiais ao estabelecido na Resolução $n^{\circ}$ 20, CONAMA. Os exames foram realizados no laboratório da CETESB.

Após a segunda campanha da CETESB, o grupo de suporte técnico solicitou avaliações ambientais em solo mais superficial, particularmente da poeira dos 
quintais e das casas. Estas amostras foram colhidas pela UNICAMP e analisadas no Instituto Adolfo Lutz. Foram colhidas amostras de poeira, utilizando-se lenços umedecidos (Sayre et al., 1974), na área em estudo e em área-controle situada há $11 \mathrm{~km}$ da fonte.

A avaliação de alimentos de consumo humano produzidos no local foi coordenada pelo Centro de Vigilância Sanitária e executada pela Vigilância Sanitária da DIR X em conjunto com o município de Bauru. Foram colhidas amostras de leite, ovos, hortaliças e verduras bem como de água dos poços utilizados pelos moradores. O método de análise laboratorial destes produtos seguiu norma da "Association of Official Analitical Chemist" (AOAD, 1995) e as análises foram realizadas pelo Instituto Adolfo Lutz. Os niveis aceitáveis de contaminação obedeceram ao ditado pelas Portarias n 685/1998 e n 1469/2000, ambas do Ministério da Saúde.

\section{3 - A avaliação da exposição humana}

Neste estudo, não se dispunha do tempo de exposição da população. Optou-se por seguir a recomendação do CDC (1991), que aponta para o uso dos níveis de chumbo no sangue como indicador mais consolidado para aferição da exposição em crianças.

Estabeleceram-se, como nivel de ação, plumbemias iguais ou superiores a $10 \mu \mathrm{g} / \mathrm{dL}$, como proposto para crianças pelo CDC e pela Comunidade Européia (Jacobi et al.,. 2000), adotado com pequenas modificações pela Associação 
Americana de Pediatria (AAP, 1998). Os limites e ações requeridas são apresentados na Tabela 9.

O grupo de suporte técnico recomendou considerar como critério de exposição os resultados das análises obtidos no grupo controle que fez parte do estudo-piloto. 
Tabela 9. Níveis e ações relativos a concentrações de chumbo no sangue em crianças, propostos pelo Centro de Controle de Doenças e Academia Americana de Pediatria - AAP.

\begin{tabular}{|c|c|c|}
\hline $\mathrm{Pb}-\mathrm{S}(\mu \mathrm{g} / \mathrm{dL})$ & CDC (1991) & AAP (1998) \\
\hline$<10$ & $\begin{array}{l}\text { Se alto risco de exposição avaliar a cada } 6 \\
\text { meses }\end{array}$ & Nenhuma ação é requerida \\
\hline 10 a 14 & $\begin{array}{l}\text { Reexaminar a cada } 3 \text { ou } 4 \text { meses } \\
\text { Se várias crianças no grupo apresentam } \\
\mathrm{PbS}>10 \mu \mathrm{g} / \mathrm{dL} \text {, proceder atividades de } \\
\text { prevenção primária }\end{array}$ & $\begin{array}{l}\text { Confirmar em } 1 \text { mês. Se persiste: } \\
\text { Proceder atividades educativas } \\
\text { Repetir exame em } 3 \text { meses }\end{array}$ \\
\hline 15 a 19 & $\begin{array}{l}\text { Reexaminar a cada } 3 \text { ou } 4 \text { meses } \\
\text { Educação ambiental e alimentar dos } \\
\text { familiares } \\
\text { Levantamento de riscos ambientais } \\
\text { Se persiste níveis de POS. medidas de } \\
\text { mitigação ambiental }\end{array}$ & $\begin{array}{l}\text { Confirmar em } 1 \text { mês. Se persiste: } \\
\text { Educação ambiental e alimentar dos familiares } \\
\text { para prevenir a exposição e diminuir a } \\
\text { absorção } \\
\text { Levantamento de riscos ambientais } \\
\text { Repetir teste em } 2 \text { meses }\end{array}$ \\
\hline 20 a 44 & $\begin{array}{l}\text { Repetir o teste. Se persiste: } \\
\text { Avaliação e acompanhamento médico } \\
\text { especializado } \\
\text { Educação ambiental e alimentar dos } \\
\text { familiares } \\
\text { Levantamento e mitigação de riscos } \\
\text { ambientais } \\
\text { Reavaliar PbS a cada } 3 \text { ou } 4 \text { meses }\end{array}$ & $\begin{array}{l}\text { Confirmar em } 1 \text { semana. Se persiste: } \\
\text { Avaliação e acompanhamento médico } \\
\text { especializado } \\
\text { Educação ambiental e alimentar dos familiares } \\
\text { Levantamento e mitigação de riscos ambientais } \\
\mathrm{Se} \mathrm{PbS}>25 \mu \mathrm{g} / \mathrm{dL} \text { avaliar necessidade de } \\
\text { quelacão }\end{array}$ \\
\hline 45 a 69 & $\begin{array}{l}\text { Confirmar } \\
\text { Iniciar medidas de tratamento clínico e } \\
\text { remediação ambiental em } 48 \mathrm{~h} \\
\text { Medidas ambientais como descrito nos } \\
\text { itens anteriores }\end{array}$ & $\begin{array}{l}\text { Confirmar em } 2 \text { dias } \\
\text { Iniciar tratamento em serviço especializado } \\
\text { Medidas ambientais como descrito nos itens } \\
\text { anteriores }\end{array}$ \\
\hline 70 e mais & $\begin{array}{l}\text { Confirmar } \\
\text { É uma emergência médica. requer } \\
\text { tratamento especializado imediato } \\
\text { Medidas ambientais como descrito nos } \\
\text { itens anteriores }\end{array}$ & $\begin{array}{l}\text { Confirmar imediatamente } \\
\text { Hospitalize o paciente e inicie o tratamento } \\
\text { imediatamente } \\
\text { Medidas ambientais como descrito nos itens } \\
\text { anteriores }\end{array}$ \\
\hline
\end{tabular}

Fonte: CDC. 1991; AAP, 1998. Adaptado.

$\mathrm{PbS}$ - Chumbo no sangue.

AAP - American Academy of Pediatrics.

CDC - Centers for Disease Control.

Buscou-se investigar todos os menores de 13 anos residentes no raio de $1 \mathrm{~km}$ da empresa. Para isto, foram visitadas as residências deste raio. $\mathrm{O}$ morador era inquirido sobre a existência de crianças no domicilio. Quando existentes, explicava- 
se o motivo da investigação e solicitava-se do genitor ou responsável pela criança permissão por escrito (Anexo 2), caso este se decidisse em participar do estudo. Era então aplicado questionário onde se buscavam dados pessoais e de possíveis rotas de exposição a chumbo para cada criança da casa (Anexo 3). As informações constantes no questionário buscavam refletir as características do local e as variáveis citadas na literatura e relacionadas à exposição ao metal. Após a aplicação do questionário se procedia a coleta de sangue por profissional treinado do municipio, com agulha descartável em tubo vacutainer. Se a casa estivesse fechada ou a criança não fosse encontrada, realizava-se nova visita. Por fim, constituiu-se um local permanente onde os genitores ou crianças não encontrados nas duas visitas poderiam comparecer. A população estava mobilizada e preocupada com os possíveis danos à saúde provocados pela contaminação e concordavam em participar.

Para garantir a retaguarda quanto aos aspectos de saúde e desenvolvimento neuropsicomotor, a DIR $\mathrm{X}$ articulou os serviços públicos de especialidades $\mathrm{e}$ as universidades próximas propondo a criação de um grupo-tarefa para diagnóstico e acompanhamento das crianças. A equipe instituida pela DIR $X$, coordenada por um neuropediatra da Universidade Estadual Paulista (UNESP) da Faculdade de Medicina de Botucatu, formou um grupo de estudos permanente para diagnóstico, tratamento e acompanhamento dos menores, em conjunto com um neurologista contratado pelo município de Bauru. Todos os moradores com idade inferior a 13 anos que apresentaram plumbemias superiores a $10 \mu \mathrm{g} / \mathrm{dL}$ foram examinados quanto a possiveis alterações clínicas, neurológicas e quanto ao desenvolvimento 
neuropsicomotor na medida em que estudos mais recentes apontam para efeitos na saúde com níveis de $\mathrm{PbS}$ inferiores aos estabelecidos pelo $\mathrm{CDC}$ e AAP.

$\mathrm{Na}$ medida em que o chumbo atravessa a barreira placentária e também é excretado pelo leite materno (WHO, 1995), foi estabelecido que para controlar estas fontes de exposição seriam realizadas análises no sangue das gestantes e no leite das nutrizes. Tinha-se em vista verificar a necessidade de interromper a amamentação ou afastar a grávida da área. Foi definido que os níveis aceitáveis de chumbo no leite materno obedeceriam ao disposto para o produto in natura na Portaria $n^{\circ} 685 / 98$ do Ministério da Saúde $(0,05 \mu \mathrm{g} / \mathrm{kg})$; para gestantes adotaram-se, como nível de ação, concentrações sanguíneas do metal superiores a $10 \mu \mathrm{g} / \mathrm{dL}$

$\mathrm{Na}$ averiguação dos niveis de chumbo no sangue foram utilizados tubos a vácuo próprios para análise de traços, com heparina. As determinações do metal foram efetuadas por espectrometria de absorção atômica com forno de grafite, com corretor Zeeman (modelo SIMAA 6000 Perkin Elmer). O limite de quantificação das primeiras análises foi de $5 \mu \mathrm{g} / \mathrm{dL}$, sendo posteriormente diminuido para $2 \mu \mathrm{g} / \mathrm{dL}$ e o limite de detecção $1,08 \mu \mathrm{g} / \mathrm{dL}$.

As análises do leite foram feitas por espectrometria de absorção atômica com chama, como preconiza a Association of Official Analitical Chemist - AOAC (1995). Neste caso o limite de quantificação foi de $0,01 \mathrm{mg} / \mathrm{kg}$ e o de detecção $0,003 \mathrm{mg} / \mathrm{kg}$.

O Instituto Adolfo Lutz, através do setor de bromatologia, realizou todas as análises de chumbo no sangue e leite materno requeridas neste estudo. 


\section{4 - Análise dos fatores de risco de exposição}

As amostras de sangue das crianças para primeira análise foram colhidas de fevereiro a novembro de 2002. Para permitir o cálculo de médias, os resultados de plumbemia inferiores ao limite de quantificação do método foram substituídos pela metade do limite de deteç̧ão, ou seja, $0,54 \mu \mathrm{g} / \mathrm{dL}$. Na medida em que estes dados não apresentaram uma distribuição normal, pelo teste de Kolmogorov-Smirnov, utilizaram-se testes não paramétricos.

Foram estabelecidos como critérios de inclusão no estudo morar no raio de um km da empresa e ter até doze anos completos. Como critério de exclusão, a existência de fonte de contaminação por chumbo na residência, particularmente o desmonte ou processamento de baterias de automóvel, comuns no Estado de São Paulo segundo a Vigilância Sanitária.

As análises foram efetuadas buscando os fatores de risco relacionados a níveis elevados de chumbo no sangue, segundo as variáveis da pessoa (sexo, idade, raça, número de crianças no domicilio, queixas de saúde, hábitos alimentares e de lazer, ocupação dos pais), do lugar (características da residência, presença ou não de asfalto na rua distância da fonte) e do tempo (de residência no local e de permanência na casa)

Foi testada a correlação entre distância da fonte e idade com os niveis de plumbemia pelo teste de Spearman. As variáveis distância da fonte e idade foram categorizadas segundo faixas crescentes e niveis de chumbo no sangue $\geq 10 \mu \mathrm{g} / \mathrm{dL}$ e 
menores que $10 \mu \mathrm{g} / \mathrm{dL}$ e efetuado o teste de Chi-quadrado para tendência linear em proporções.

Analisaram-se os diferenciais de médias de plumbemia para cada um dos fatores considerados de risco, pelo teste de Mann-Whitney ou Kruskal-Wallis. Para tanto, algumas variáveis foram agrupadas. Com relação ao consumo de água, os dados foram agrupados em uso de água do sistema público e de fontes alternativas de qualquer origem. Brincar em lago, rio ou riacho foi categorizado em conjunto sendo criada variável dicotômica ( $\operatorname{sim}$ ou não). Estabeleceu-se o mesmo critério para a ingestão de frutas ou verduras produzidas no local e para o trabalho do genitor em qualquer empresa que possa usar chumbo no processo de produção. Os dados de distância da empresa e número de crianças no domicílio foram tratados segundo faixas crescentes e dicotômicas: distância menor e maior que $500 \mathrm{~m}$; existência de até duas crianças ou mais. Tempo de moradia no local e tempo de permanência em casa foram classificados em duas faixas: tempo de moradia menor ou igual a um ano e maior; permanência na casa menor ou igual a 18 horas e maior. A idade foi trabalhada segundo faixas para a comparação de médias de $\mathrm{Pb}$ e como variável contínua na regressão logística. A população de estudo foi dividida entre aqueles que residem em área asfaltada e sem asfalto.

$\mathrm{Na}$ regressão logística univariada, os níveis de chumbo no sangue foram classificados em menores que $10 \mu \mathrm{g} / \mathrm{dL}$ e iguais ou maiores que $10 \mu \mathrm{g} / \mathrm{dL}$. Esta foi a variável dependente dos modelos. Testou-se então cada uma das variáveis independentes e consideradas como fatores de risco para níveis elevados de 
plumbemia. Na regressão logística múltipla foram introduzidas, uma a uma, aquelas com nível de significância obtido no modelo univariado menor que 0,20 . A ordem de entrada das variáveis obedeceu aos valores de significância estatística na análise univariada, em ordem crescente. A permanência ou não de cada variável no modelo foi estabelecida a partir da razão de máxima verossimilhança. Aquelas que foram significativas ou modificaram as anteriores em $10 \%$ ou mais continuaram. Sempre que uma variável modificou as anteriores em $10 \%$ ou mais foi testada interação. As respostas ignorado não foram consideradas na análise.

Em todo o estudo estabeleceu-se o nível de significância $\alpha=5 \%$. Os dados foram analisados nos pacotes estatísticos EPI-INFO versão 6.4 e SPSS versão 10.0 .

Os resultados do estudo epidemiológico de exposição e investigação de fatores de risco foram apresentados ao grupo de suporte técnico em várias etapas, com número crescente de crianças participantes. A cada análise dos dados parciais discutiam-se as medidas de controle, a necessidade de avaliações ambientais mais aprofundadas e os rumos do processo. Assim, a partir do estudo de exposição, foram definidos os pontos de amostragem de solo, a reavaliação dos níveis de chumbo no ar e a análise de alimentos produzidos no local.

\section{5 - Avaliação do impacto das medidas de controle}

A partir dos dados provenientes de cada instituição participante do trabalho, o grupo de suporte técnico, considerando o conjunto das informações, orientava as medidas de controle. A quantificação do impacto destas medidas foi feita nas 
diversas etapas do processo, particularmente a partir das análises de plumbemia das crianças. Em uma primeira avaliação, comparou-se as médias de chumbo no sangue entre a primeira amostra e uma segunda com intervalo médio de 75 dias, daquelas crianças que apresentaram $\mathrm{PbS} \geq 10 \mu \mathrm{g} / \mathrm{dL}$. Buscava-se seguir o protocolo da Associação Americana de Pediatria sobre exposição a chumbo, estimar o impacto da interdição da empresa e das orientações dadas aos genitores acerca do comportamento das crianças. Neste caso, o tipo de distribuição pelo teste de Kolmogorov-Smirnov foi normal. As médias foram então comparadas por testes paramétricos para amostras repetidas.

A vida média de chumbo no sangue é de 28 a 36 dias (CDC, 1991), podendo ser mobilizado dos ossos em estados fisiológicos como a gravidez ou algumas patologias. Após a avaliação de todas as crianças e identificação das rotas de exposição, foram orientadas diversas medidas de controle relacionadas ao ambiente. No segundo momento, seis meses após a adoção destas medidas recomendou-se nova avaliação dos menores de treze anos que apresentaram no primeiro exame plumbemias maiores ou iguais a $10 \mu \mathrm{g} / \mathrm{dL}$. Considerou-se o primeiro e o último exame no conjunto das crianças que foram avaliadas nos dois momentos. Foram comparadas também as médias de plumbemia segundo cada um dos fatores de risco identificados na regressão logística, tentando identificar diferenciais de impacto.

Uma vez que nem todas as crianças foram reavaliadas, buscou-se identificar a existência de possível viés de adesão a partir de duas abordagens: comparação das médias de $\mathrm{PbS}$ no primeiro exame entre os faltosos e não faltosos considerando-se o 
total de crianças e segundo faixas crescentes dos níveis de chumbo no sangue. A segunda abordagem se constituiu em comparar as proporções das crianças segundo comparecimento ou não às duas campanhas, utilizando o teste do Chi-quadrado, de acordo com as variáveis sexo e grupos de idade.

Devido à precariedade das residências e discordância dos moradores, em algumas não foram adotadas as medidas de controle sanitário. Em ruas de cinco quadras não foi realizada remoção do solo superficial. Em quatro delas havia grama e a última foi excluida por apresentar erosão do terreno. A adesão à aspiração das moradias não foi homogênea, sendo quase total entre as crianças com plumbemias superiores a $25 \mu \mathrm{g} / \mathrm{dL}$ e menos constante entre as demais com niveis de $\mathrm{PbS}$ inferiores, segundo informações do município. Não dispomos da discriminação destas residências para comparação entre os grupos.

O grupo de suporte técnico, com base nas avaliações de plumbemia das gestantes e da literatura acerca de casos semelhantes, considerou que não se fazia necessário estender o estudo para os adultos não trabalhadores da empresa. Para testar esta hipótese e fundamentar a resposta para o Ministério Público, o grupo decidiu avaliar mulheres não gestantes cujos filhos apresentaram níveis de $\mathrm{PbS}$ acima de $25 \mu \mathrm{g} / \mathrm{dL}$. Buscava-se identificar aquelas sob maior risco. Foram colhidas amostras de sangue de 25 mulheres e se estabeleceu como aceitáveis níveis de chumbo no sangue menores que $25 \mu \mathrm{g} / \mathrm{dL}$, abaixo dos $30 \mu \mathrm{g} / \mathrm{dL}$ propostos pela ACGIH para adultos, levando em conta ausência de possíveis efeitos na saúde a partir de exposição ocupacional. 


\section{4-RESULTADOS}

O presente trabalho é resultado de uma ação de Saúde Pública, requisitada pelo órgão ambiental do Estado e acompanhada pelo Ministério Público. As avaliações foram feitas na medida em que se analisavam os resultados de cada etapa do trabalho. Tentou-se dar conta desta dinâmica. Serão apresentadas em primeiro lugar as investigações realizadas em cada compartimento ambiental e nas crianças, incluindo-se posteriormente uma descrição da dinâmica do trabalho a partir das discussões do grupo de suporte técnico e da entrevista com o gestor regional. Por fim serão apresentados os resultados das reavaliações das crianças.

\section{1 - O estudo-piloto}

Foram avaliados os níveis de plumbemia de 29 crianças residentes nas proximidades da indústria constituindo o grupo exposto e 31 crianças residentes a uma distância maior que $11 \mathrm{~km}$, o grupo-controle. Todas as crianças com niveis de chumbo no sangue iguais ou superiores a $10 \mu \mathrm{g} / \mathrm{dL}$ foram reavaliadas em busca de possiveis outras fontes de exposição. No grupo-controle foi encontrada uma criança com história de exposição ao metal. O genitor fazia desmonte clandestino de baterias de automóvel na residência. Esta criança foi retirada da análise. No grupo exposto os niveis médios de plumbemia foram de $7,72 \mu \mathrm{g} / \mathrm{dL}$ e no grupo-controle, abaixo do limite de quantificação do método $(5,00 \mu \mathrm{g} / \mathrm{dL})$. A comparação das médias, pelo teste de Mann-Whitney, mostrou diferença significativa entre estes grupos. 
Analisando apenas o grupo exposto, encontrou-se forte relação entre distância da fonte e níveis de $\mathrm{PbS}(\mathrm{R}=0,73)$, mostrando que na medida em que as residências se afastavam os níveis de plumbemia eram menores (Gráfico 2). Diante destes resultados a DOMA, a DIR X e o município de Bauru optaram por realizar o estudo transversal para avaliação das crianças residentes no raio de mil metros da empresa. A escolha da distância, além do indicado em estudos obtidos no levantamento bibliográfico, se deveu aos achados do estudo-piloto. As crianças com plumbemias maiores que $10 \mu \mathrm{g} / \mathrm{dL}$ se encontravam a uma distância menor que $1000 \mathrm{~m}$ da fonte.

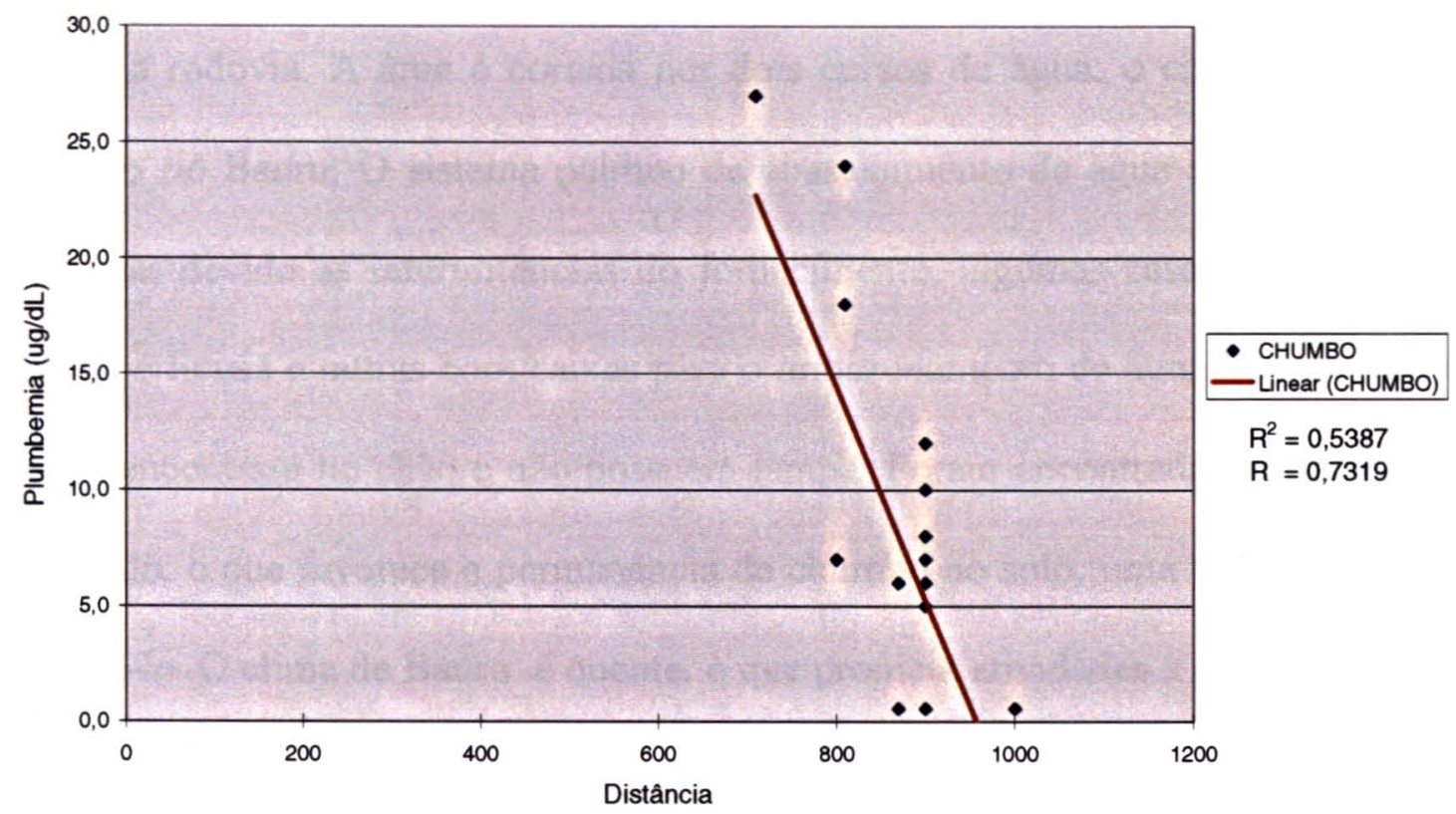

Gráfico 2. Correlação entre plumbemia em crianças residentes no entorno da empresa e distância da fonte de exposição no estudo-piloto. Município de Bauru 2002 


\section{2 - O reconhecimento preliminar da área}

Foi realizado pela DIR X o reconhecimento preliminar da área, com o objetivo de identificar fatores de risco de exposição a chumbo e caracterizar o local (Figura 6)

Trata-se de área de urbanização recente, contando ainda com propriedades rurais, onde se desenvolvem atividades agropecuárias. $\mathrm{Na}$ região ocupada por residências encontram-se dois bairros densamente povoados. Um deles é uma vila popular asfaltada e o outro possui construções mais precárias e ruas ainda sem pavimentação. Ao lado da indústria há um loteamento praticamente desocupado e à frente uma rodovia. A área é cortada por dois cursos de água: o córrego Vargem Limpa e o rio Bauru. O sistema público de abastecimento de água abrange toda a região, mas devido às intermitências do fornecimento, algumas casas contam com poços superficiais e outras com caixas para o armazenamento de água. Estas muitas vezes se encontram no chão e não possuem tampa. Foram encontradas moradias de chão batido, o que favorece a permanência de chumbo no solo, uma vez que não se pode lavá-lo. O clima de Bauru é quente, o que propicia atividades a céu aberto e as crianças brincam nas ruas.

Foram arroladas 503 residências no raio de mil metros, onde se encontraram 857 crianças. A média destas por moradia foi de 1,69 (desvio padrão de 0,96 ), sendo o minimo de uma e o máximo de oito. O responsável por uma família que contava com quatro crianças preencheu o inquérito domiciliar mas não compareceu ao posto de coleta de sangue para avaliação das plumbemias; estas crianças foram excluidas 
da análise. Também foi excluída uma família (três crianças) que contava com fonte de chumbo na residência.

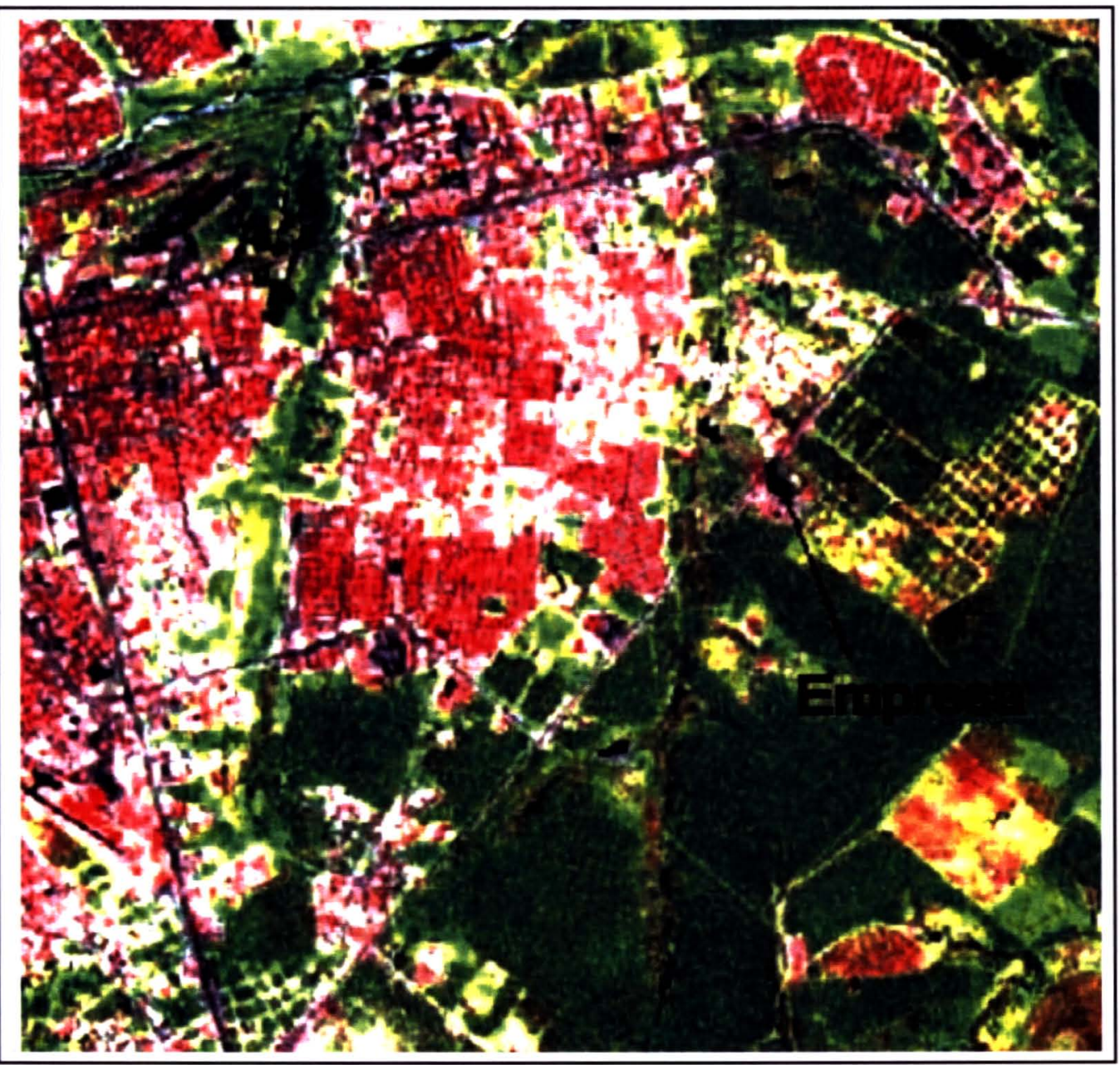

Fonte: CETESB

Figura 6. Área do entorno da empresa em estudo - Bauru, 2002. 


\section{3 - As avaliações ambientais}

Foram realizadas análises ambientais do solo, água, ar e produtos da horta e dos animais do local. Cada compartimento foi visto dentro das competências legais das instituições. Assim, participaram a CETESB identificando os níveis de chumbo na água, ar, solo e vegetação e o Centro de Vigilância Sanitária - CVS nos produtos da horta, dos animais e da água utilizada para consumo humano. A investigação da poeira foi feita pela UNICAMP, que detinha o método especifico para tal.

\subsection{1 - As avaliações da CETESB}

Após a interdição da empresa, a CETESB realizou duas campanhas de avaliação ambiental. Na primeira campanha foram analisados o ar (área com e sem asfalto), o solo ( 0 a $20 \mathrm{~cm}$ e 80 a $100 \mathrm{~cm})$, as águas superficiais e subterrâneas, o sedimento dos rios e a vegetação. Os pontos de amostragem se encontram na Figura 7. Foram realizadas investigações em 36 pontos de solo superficial $(0$ a $20 \mathrm{~cm})$; seis de solo subsuperficial ( 80 a $100 \mathrm{~cm}$ ); seis de águas superficiais e sedimentos; $10 \mathrm{de}$ águas subterrâneas; 15 amostras de vegetação e 10 de ar, sendo estas em duas localizações: um ponto na área não asfaltada e outro na área asfaltada. Dentre as análises efetuadas na primeira campanha vale salientar os seguintes achados:

$\checkmark$ na avaliação do ar apenas três amostras da área não asfaltada superaram o limite de deteç̧ão do método $\left(0,08 \mu \mathrm{g} / \mathrm{m}^{3}\right)$, sendo a maior delas de $0,12 \mu \mathrm{g} / \mathrm{m}^{3}$, indicando que esta via de exposição deixou de ser importante após o fechamento da empresa: 
as análises de solo fora da área da indústria detectaram chumbo na área residencial a $400 \mathrm{~m}$ da fonte (ponto 2 com $79 \mu \mathrm{g} / \mathrm{g}$ ); em nascente de água em frente ao estabelecimento, ponto $15 \mathrm{~A}(169 \mu \mathrm{g} / \mathrm{g})$; em chácara atrás da mesma (ponto 22 com $60 \mu \mathrm{g} / \mathrm{g}$ ) e junto à rodovia (ponto $36 \mathrm{com} 200 \mu \mathrm{g} / \mathrm{g}$ ). O limite de detecção do método era de $50 \mu \mathrm{g} / \mathrm{g}$ e todos os valores se encontraram abaixo do estabelecido pela CETESB como valor de intervenção para uso residencial de solo $(350 \mu \mathrm{g} / \mathrm{g})$. Apenas duas amostras superaram o limite de alerta $(100 \mu \mathrm{g} / \mathrm{g})$. No pátio da empresa pontos 34,35 e 47 , os niveis foram muito elevados, ultrapassando o limite para solo de uso industrial $(1200 \mu \mathrm{g} / \mathrm{g})$;

$\checkmark$ das análises de água subterrânea apenas a nascente em frente da empresa, ponto 15 , apresentou niveis superiores $(0,07 \mathrm{mg} / \mathrm{L})$ ao limite estabelecido pela Portaria $n^{\circ} 1469$ do Ministério da Saúde $(0,01 \mathrm{mg} / \mathrm{L})$. As águas superficiais tiveram valores acima da Portaria ${ }^{\circ} 20$ CONAMA na estação de tratamento de efluentes (ponto 34) e o sedimento do rio no ponto 36. Este é o ponto onde o córrego passa mais próximo da empresa e, segundo a CETESB, a contaminação decorre de extravasamento do sistema de lagoas para tratar as águas residuárias;

dentre as quinze amostras de vegetação avaliadas, apenas duas ultrapassaram os valores de referência: o figo $(147 \mu \mathrm{g} / \mathrm{g})$ no ponto 35 , dentro da área da empresa e a hortelã - ponto $24(12,98 \mu \mathrm{g} / \mathrm{g})$, situado há $950 \mathrm{~m}$ da fonte.

A segunda campanha de amostragem da CETESB foi realizada por solicitação do grupo de suporte técnico, buscando avaliar solo mais superficial que aquele 
amostrado na primeira campanha. Foi colhido solo de 0 a $2 \mathrm{~cm}$ de profundidade e os pontos de coleta foram orientados pelos dados da investigação epidemiológica: locais onde existisse grupo de crianças com níveis de chumbo sanguíneo maiores que $15 \mu \mathrm{g} / \mathrm{dL}$. A CETESB colheu solo em treze pontos, além de amostras de água de cacimba de outros três pontos e da nascente em frente à empresa. Como controle foi amostrado o solo da CETESB. Os resultados destas análises se encontram na Tabela 10.

Tabela 10. Amostragem de chumbo em solo superficial $(0$ a $2 \mathrm{~cm})$ e água de cacimba e mina, Bauru 2002.

\begin{tabular}{|c|c|c|}
\hline Meio & Distância da fonte (m) & $\begin{array}{l}\text { Concentração de chumbo } \\
\text { solo:mg/kg e água:mg/L }\end{array}$ \\
\hline Solo & Controle & 15,8 \\
\hline Solo & 1000 & 18,5 \\
\hline Solo & 1000 & 23,8 \\
\hline Solo & 300 & 30,3 \\
\hline Solo & 450 & 44,4 \\
\hline Solo & 650 & 74,5 \\
\hline Solo & 780 & 76,0 \\
\hline Solo & 450 & 110,0 \\
\hline Solo & 650 & 117,0 \\
\hline Solo & 560 & 121,0 \\
\hline Solo & 180 & 272,0 \\
\hline Solo & $660^{*}$ & 854,0 \\
\hline Solo & $50 \ddagger$ & 2660,0 \\
\hline Cacimba & 180 & $<0,002$ \\
\hline Cacimba & 660 & $<0,002$ \\
\hline Mina & $150+$ & 0,06 \\
\hline
\end{tabular}




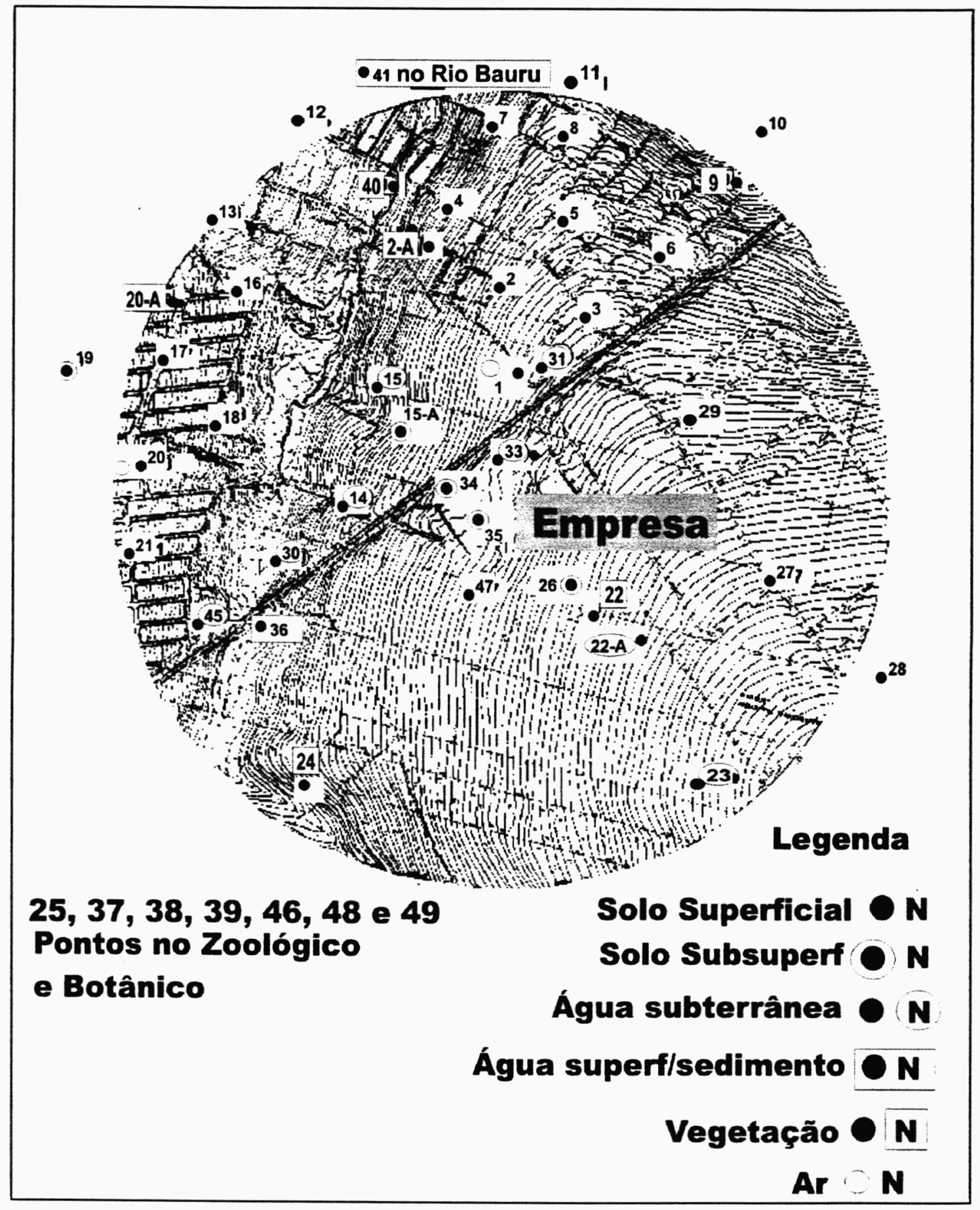

Fonte: CETESB

Figura 7. Entorno da empresa em estudo e pontos de amostragem de solo, água e sedimentos. Bauru, 2002. 
Como pode ser visto na Tabela 10 na análise de solo com profundidade de 0 a $2 \mathrm{~cm}$ foram encontrados cinco pontos que ultrapassaram o limite de alerta e dois o limite de intervenção. Vale ressaltar no entanto que, dentre os pontos que ultrapassaram o limite de intervenção, em um havia uma fonte residencial de exposição. $\mathrm{O}$ antigo morador da residência que apresentou niveis de chumbo no solo de $854 \mathrm{mg} / \mathrm{kg}$ fazia desmonte clandestino de baterias de automóvel no domicílio. Por outro lado, o ponto de amostragem distante $50 \mathrm{~m}$ da empresa se encontra na rodovia em frente da mesma. Levando em conta essas ressalvas, foram encontradas quatro amostras acima do limite de alerta para solo na área residencial, estando todas abaixo do limite de intervenção. Com base nestes achados, a CETESB recomendou a retirada do solo superficial no raio de $200 \mathrm{~m}$ da empresa. Tendo estes resultados na segunda reunião, o grupo de suporte técnico resolveu que se fazia necessária a avaliação dos niveis de chumbo na poeira dos quintais, nas casas e nas mãos das crianças, para que se decidisse acerca do raio de retirada do solo.

\subsection{2 - Avaliação da poeira}

Foram avaliados seis domicilios da área de influência da empresa, nos quais foram encontradas crianças com niveis de chumbo no sangue superiores a $30 \mu \mathrm{g} / \mathrm{dL}$. Como controle buscou-se investigar domicilios distantes $11 \mathrm{~km}$ da fonte, com as mesmas condições sócio-econômicas (cinco casas). Os resultados destas análises encontram-se na Tabela 11 
Tabela 11. Níveis de chumbo em poeira domiciliar e mãos das crianças em casas dos bairros do entorno de empresa de acumuladores de baterias e área controle. Bauru, 2002.

\begin{tabular}{|c|c|c|c|c|c|}
\hline Residència & Distância (m) & $\mathrm{PbS}(\mu \mathrm{g} / \mathrm{dL})$ & Local da coleta & $\mathrm{Pb}$ (ppm) & $\begin{array}{l}\text { Controle (ppm) } \\
\text { Média do grupo }\end{array}$ \\
\hline Residência l & 780 & 31,9 & $\begin{array}{l}\text { Poeira sobre a } \\
\text { cabeceira da } \\
\text { cama } \\
\text { Batente superior } \\
\text { porta do } \\
\text { dormitório } \\
\text { Batente superior } \\
\text { porta da sala } \\
\text { Mãos }\end{array}$ & $\begin{array}{l}5.083 \\
97\end{array}$ & $\begin{array}{l}135 \\
\text { ND a } 125\end{array}$ \\
\hline Residência 2 & 780 & 30,2 & $\begin{array}{l}\text { Trava sobre a } \\
\text { cama e berço } \\
\text { Parte superior } \\
\text { do armário do } \\
\text { dormitório } \\
\text { Mãos }\end{array}$ & $\begin{array}{l}255 \\
168\end{array}$ & $\begin{array}{l}135 \\
\text { ND a } 125\end{array}$ \\
\hline Residência 3 & 900 & 39,1 & $\begin{array}{l}\text { Trava superior } \\
\text { do dormitónio } \\
\text { Batente superior } \\
\text { de janela da sala } \\
\text { Beiral superior } \\
\text { do guarda-roupa }\end{array}$ & $\begin{array}{l}6.499 \\
1.581 \\
251\end{array}$ & $\begin{array}{l}135 \\
25 \\
42 \text { a } 59\end{array}$ \\
\hline Residência 4 & 900 & 33,3 & $\begin{array}{l}\text { Batente inferior } \\
\text { do quarto de } \\
\text { dormir } \\
\text { Beiral superior } \\
\text { do guarda-roupa }\end{array}$ & 4.432 & $\begin{array}{l}135 \\
42 \text { a } 59\end{array}$ \\
\hline Residència 5 & 500 & & $\begin{array}{l}\text { Trava superior } \\
\text { da cabeceira da } \\
\text { cama } \\
\text { Trava lateral da } \\
\text { cama } \\
\text { Mãos }\end{array}$ & $\begin{array}{l}856 \\
283\end{array}$ & $\mathrm{ND}$ a 125 \\
\hline Residència $6^{*}$ & 660 & 90.0 & $\begin{array}{l}\text { Beiral superior } \\
\text { do guarda-roupa } \\
\text { Batente superior } \\
\text { do quarto } \\
\text { Beiral da janela } \\
\text { do dormitório } \\
\text { Poeira } \\
\text { superficial do } \\
\text { quintal }\end{array}$ & $\begin{array}{l}795 \\
377 \\
935 \\
1.170\end{array}$ & $\begin{array}{l}135 \\
10\end{array}$ \\
\hline
\end{tabular}

Fonte: UNICAMP (modificado).

* Criança com fonte de exposição no domicilio. ND: Não detectado. 
Exceto nas mãos das crianças, os níveis de chumbo na poeira das casas do entorno da empresa são sempre superiores que na área-controle. Estes resultados levaram à orientação de retirada do solo superficial da área não asfaltada no raio de mil metros da fonte e aspiração das residências.

\subsection{3 - Avaliação dos produtos de hortas e animais}

A Vigilância Sanitária realizou a avaliação das verduras, frutas, hortaliças e produtos animais (ovos e leite) de origem local no raio de mil metros da empresa. Algumas residências, como colocado anteriormente, utilizam poços superficiais para abastecimento, buscando suprir a intermitência da água servida pelo sistema público. A água destes poços também foi analisada. Dentre os produtos investigados pela Vigilância Sanitária, em várias campanhas amostrais, apresentaram-se impróprios para consumo os seguintes: leite in natura, hortelã, ovos, almeirão e mandioca. A água dos diversos pontos apresentou-se própria para consumo humano. Como medida de precaução, além da interdição dos impróprios para consumo, recomendouse à população não consumir os produtos da área. Os resultados de todas as análises se encontram no Anexo 4.

\section{4 - Avaliação epidemiológica da exposição a chumbo}

Foram entrevistados os responsáveis por 857 crianças. Quatro destas não estavam presentes no domicilio quando do preenchimento do questionário e na visita subseqüente, não tendo procurado o posto de coleta permanente, portanto não se 
conta com seus níveis de plumbemia. Das 853 restantes, três moravam na casa onde se fazia desmonte clandestino de baterias de automóveis e foram excluídas do estudo. Uma destas crianças apresentou plumbemia de $90 \mu \mathrm{g} / \mathrm{dL}$ e foi internada para tratamento. Restaram para análise 850 crianças.

O nível médio de chumbo no sangue do grupo estudado foi de $8,77 \mu \mathrm{g} / \mathrm{dL}$ (desvio padrão de $7,47 \mu \mathrm{g} / \mathrm{dL}$ ) e mediana de $7,30 \mu \mathrm{g} / \mathrm{dL}$. O nível mínimo foi abaixo do limite de detecção do método e o máximo foi de $45,40 \mu \mathrm{g} / \mathrm{dL}$.

Das 850 crianças, $311(36,6 \%)$ apresentaram plumbemias iguais ou superiores a $10 \mu \mathrm{g} / \mathrm{dL}$, sendo que do total, $161(18,9 \%)$ estiveram entre 10 e $14 \mu \mathrm{g} / \mathrm{dL} ; 80(9,4 \%)$ entre 15 e $19 \mu \mathrm{g} / \mathrm{dL} ; 67(7,8 \%)$ entre 20 e $39 \mu \mathrm{g} / \mathrm{dL}$ e $3(0,4 \%)$ níveis superiores a $39 \mu \mathrm{g} / \mathrm{dL}$ (Gráfico 3).

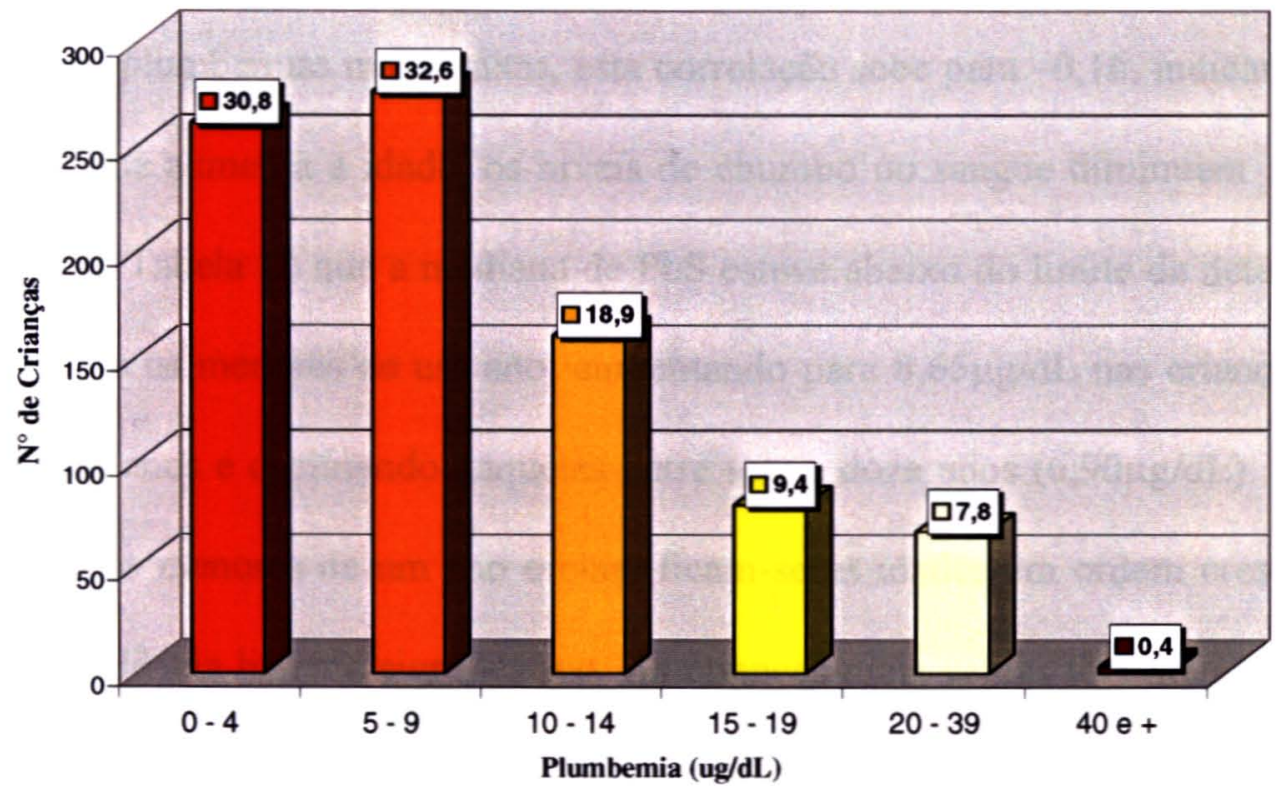

Gráfico 3. Número e percentual das crianças segundo níveis de plumbemia. Bauru, 2002. 


\subsection{1 - Variáveis ligadas à pessoa}

As variáveis ligadas à pessoa foram classificadas em: gerais, aquelas provenientes dos hábitos das crianças e as demais, relacionadas à ocupação dos pais.

\subsubsection{1 - Gerais}

$\mathrm{Na}$ distribuição do grupo predomina o sexo masculino com $52,8 \%$ das ocorrências. Não se detectaram diferenças significativas nas médias de plumbemia desta variável (Tabela 12), no entanto, quando se consideram apenas crianças de 7 a 12 anos, os meninos apresentam niveis de chumbo no sangue superiores às meninas (medianas de $7,40 \mu \mathrm{g} / \mathrm{dL}$ e $5,70 \mu \mathrm{g} / \mathrm{dL}$, respectivamente).

A correlação entre idade e $\mathrm{PbS}$ pelo teste de Spearman foi negativa e, embora baixa $(R=-0,07)$, significativa. Quando se retiram os menores de um ano, que apresentam plumbemias mais baixas, esta correlação sobe para $-0,16$, indicando que, à medida que aumenta a idade, os niveis de chumbo no sangue diminuem. Pode-se observar na Tabela 12 que a mediana de PbS esteve abaixo do limite de deteç̧ão do método para os menores de um ano, aumentando para $8,65 \mu \mathrm{g} / \mathrm{dL}$ nas crianças entre um e cinco anos e declinando naquelas entre seis e doze anos $(6,90 \mu \mathrm{g} / \mathrm{dL})$. Quando se retiram os menores de um ano e classificam-se as idades em ordem crescente, $o$ teste de tendência linear é significativo. As crianças mais velhas têm menor risco de apresentar plumbemias superiores a $10 \mu \mathrm{g} / \mathrm{dL}$. Vale salientar no entanto que entre os menores de um ano foram encontradas treze crianças $(23,6 \%$ do grupo) com plumbemias superiores a $10 \mu \mathrm{g} / \mathrm{dL}$. 
Foi constatada diferença estatisticamente significativa entre as raças. A raça branca apresentou níveis de $\mathrm{PbS}$ inferiores à não branca. Durante a coleta desta informação, os responsáveis pelos menores responderam a cor da criança (branca, preta ou parda). Quando se comparou os pardos e pretos não se encontrou diferença entre as médias, no entanto a variável raça não foi respondida por $253(29,8 \%)$ dos entrevistados, o que prejudicou a avaliação do dado.

O número de crianças no domicílio se relaciona com os níveis de chumbo no sangue. Em geral residências com baixo número de menores de doze anos apresentam médias inferiores. Quando se agrupam as moradias com até duas crianças e se faz a comparação com aquelas de três ou mais as diferenças são marcantes (medianas de $6,30 \mu \mathrm{g} / \mathrm{dL}$ e $10,30 \mu \mathrm{g} / \mathrm{dL}$, respectivamente).

O questionamento acerca de problemas de saúde foi aberto para qualquer queixa referida. Não houve diferença entre as médias de $\mathrm{PbS}$ nos dois grupos. Quando se avalia o tipo de queixa, há 21 relatos que podem ser relacionados ao desenvolvimento ou ao sistema nervoso, sendo: duas queixas de convulsões, onze de agitação e oito de dificuldade de aprendizado. 


\begin{tabular}{|c|c|c|c|c|c|c|c|}
\hline Variável & Tipo & Número & Percentagem & Mediana & Percentil 25\% & Percentil $75 \%$ & Valor de $p$ \\
\hline \multirow[t]{2}{*}{ Sexo } & M & 449 & 52,80 & 7,60 & 3,90 & 13,10 & \\
\hline & $\mathrm{F}$ & 401 & 47,20 & 7,00 & 2,10 & 12,00 & 0,08 \\
\hline \multirow[t]{3}{*}{ Idade } & $<1$ ano & 55 & 6,50 & 0,54 & 0,54 & 9,90 & \\
\hline & 1 a 5 anos & 364 & 42,80 & 8,65 & 5,00 & 14,30 & \\
\hline & 6 a 12 anos & 431 & 50,70 & 6,90 & 2,70 & 11,20 & 0,00 \\
\hline \multirow[t]{2}{*}{ Raça } & Branca & 511 & 85,60 & 6,80 & 0,54 & 11,30 & \\
\hline & Năo branca & 86 & 14,40 & 10,20 & 6,20 & 15,40 & 0,00 \\
\hline Crianças no & 1 & 267 & 53,10 & 5,80 & 0,54 & 9,50 & \\
\hline \multirow[t]{4}{*}{ domicilio } & 2 & 164 & 32,60 & 6,85 & 2,50 & 11,80 & \\
\hline & 3 & 49 & 9,70 & 10,55 & 6,10 & 16,20 & \\
\hline & 4 & 15 & 3,00 & 9,65 & 3,20 & 15,05 & \\
\hline & $>=5$ & 8 & 1,60 & 10,10 & 7,65 & 14,30 & 0,00 \\
\hline Queixas de & Sim & 245 & 29,00 & 7,00 & 3,30 & 13,50 & \\
\hline saúde & Não & 601 & 71,00 & 7,50 & 2,80 & 12,30 & 0,88 \\
\hline
\end{tabular}

Foran realizados tedes de Man-Whitney o KrustortWals.

\subsubsection{2 - Hábitos das crianças}

Buscou-se identificar os hábitos das crianças a partir da observação local. A região é pobre, ainda com uma área rural considerável e amplo espaço para as atividades ao ar livre, o que é estimulado pelo clima em Bauru. A maior parte dos menores brinca na terra $(70,2 \%)$ e vários $(13,9 \%)$ desenvolveram o hábito de comer objetos estranhos. Os cursos de água locais são utilizados para atividades de lazer por $8 \%$ deles e os alimentos produzidos no local são consumidos pelos moradores ( $12,5 \%$ referem consumir leite e $39,3 \%$ os produtos da horta ou pomar). As médias de plumbemia segundo estes diversos fatores de risco (Tabela 13) foi significativamente maior entre os expostos, exceto para o consumo de frutas e 
verduras. Estas variáveis apontam para contaminação dos diversos compartimentos ambientais e destes para as crianças por contato direto ou, indiretamente, pela contaminação dos animais. Na medida em que a absorção do chumbo pela pele, que poderia ser propiciada no contato com a água, e pelo transporte do metal das raizes das plantas para os frutos é pequena, as diferenças das médias de chumbo no sangue estariam mais relacionadas às suas concentrações no ar e no solo, disponiveis para respiração e ingestão.

Uma das grandes preocupações da equipe de trabalho era com o uso de brinquedos vendidos por camelôs, provenientes de países nos quais não existe regulamentação quanto à tinta pigmentada à base de chumbo. Durante a realização das entrevistas observou-se que boa parte das crianças não tinha brinquedos. Aquelas que possuiam os brinquedos importados apresentaram plumbemias mais baixas.

Tabela 13. Distribuição das crianças segundo mediana e percentis de PbS com os respectivos valores de p. Variáveis da pessoa: hábitos. Área de estudo-Bauru, 2002,

\begin{tabular}{|c|c|c|c|c|c|c|c|}
\hline Variável & Tipo & Número & Percentagem & Mediana & Percentil 25\% & Percentil $75 \%$ & Valor de p \\
\hline Brinca na terra & $\begin{array}{l}\text { Sim } \\
\text { Não }\end{array}$ & $\begin{array}{l}596 \\
253 \\
\end{array}$ & $\begin{array}{l}70,20 \\
29,80 \\
\end{array}$ & $\begin{array}{l}8,80 \\
4,60\end{array}$ & $\begin{array}{l}5,40 \\
0,54\end{array}$ & $\begin{array}{r}14,40 \\
7,80 \\
\end{array}$ & 0,00 \\
\hline Come terra & $\begin{array}{l}\text { Sim } \\
\text { Não }\end{array}$ & $\begin{array}{l}117 \\
722 \\
\end{array}$ & $\begin{array}{r}13,90 \\
86,10 \\
\end{array}$ & $\begin{array}{r}12,30 \\
6,85 \\
\end{array}$ & $\begin{array}{l}7,00 \\
2,40 \\
\end{array}$ & $\begin{array}{l}19,70 \\
11,30 \\
\end{array}$ & 0,00 \\
\hline $\begin{array}{l}\text { Tem brinquedo } \\
\text { importado }\end{array}$ & $\begin{array}{l}\text { Sim } \\
\text { Nảo }\end{array}$ & $\begin{array}{l}479 \\
371 \\
\end{array}$ & $\begin{array}{l}56,40 \\
43,60 \\
\end{array}$ & $\begin{array}{l}6,80 \\
8,10 \\
\end{array}$ & $\begin{array}{l}2,70 \\
3,20 \\
\end{array}$ & $\begin{array}{l}11,40 \\
14,00 \\
\end{array}$ & 0,00 \\
\hline $\begin{array}{l}\text { Toma banho no } \\
\text { no ou lago local }\end{array}$ & $\begin{array}{l}\text { Sim } \\
\text { Não }\end{array}$ & $\begin{array}{r}68 \\
782 \\
\end{array}$ & $\begin{array}{r}8,00 \\
92,00 \\
\end{array}$ & $\begin{array}{r}10,00 \\
7,00 \\
\end{array}$ & $\begin{array}{l}7,25 \\
2,50\end{array}$ & $\begin{array}{l}17,15 \\
12,20 \\
\end{array}$ & 0,00 \\
\hline Toma leite local & $\begin{array}{l}\text { Sim } \\
\text { Năo }\end{array}$ & $\begin{array}{l}106 \\
744 \\
\end{array}$ & $\begin{array}{l}12,50 \\
87,50 \\
\end{array}$ & $\begin{array}{r}10,90 \\
7,00 \\
\end{array}$ & $\begin{array}{l}6,40 \\
2,45 \\
\end{array}$ & $\begin{array}{l}18,00 \\
11,85 \\
\end{array}$ & 0,00 \\
\hline $\begin{array}{l}\text { Come frutas ou } \\
\text { verduras locais }\end{array}$ & $\begin{array}{l}\text { Sim } \\
\text { Não }\end{array}$ & $\begin{array}{l}334 \\
516 \\
\end{array}$ & $\begin{array}{l}39,30 \\
60,70\end{array}$ & $\begin{array}{l}7,65 \\
7,10\end{array}$ & $\begin{array}{l}4,20 \\
2,30\end{array}$ & $\begin{array}{l}12,90 \\
12,40\end{array}$ & 0,17 \\
\hline
\end{tabular}




\subsubsection{3 - Ocupação dos pais}

Os responsáveis pelos menores foram inquiridos acerca de sua ocupação ou dos membros da familia. Do total de entrevistados, $74(8,7 \%)$ disseram ter alguém da residência trabalhando na empresa sob investigação. As médias de chumbo no sangue das crianças deste grupo foi significativamente maior (Tabela 14), indicando que estes trabalhadores estão contaminando o ambiente domiciliar, trazendo chumbo do trabalho para casa.

A empresa investigada garante oferecer banho e troca de roupa dos trabalhadores, no entanto, entre os entrevistados com atividades na companhia, 14 $(19,7 \%)$ disseram trazer roupas do trabalho para lavar em casa.

Ter atividades profissionais em outros locais, mesmo que pudessem estar relacionados ao uso do chumbo como fábricas de baterias, pigmentos, tintas e cerâmica não se constituiu em fator de risco para níveis de plumbemias elevados nas crianças.

\begin{tabular}{|c|c|c|c|c|c|c|c|}
\hline Variável & Tipo & Número & Percentagem & Mediana & Percentil 25\% & Percentil $75 \%$ & Valor de $p$ \\
\hline $\begin{array}{l}\text { Familiar trabalha } \\
\text { na empresa }\end{array}$ & $\begin{array}{l}\text { Sim } \\
\text { Nð̃o }\end{array}$ & $\begin{array}{r}74 \\
776 \\
\end{array}$ & $\begin{array}{r}8,70 \\
91,30 \\
\end{array}$ & $\begin{array}{r}13,15 \\
7, \infty 0 \\
\end{array}$ & $\begin{array}{l}8,60 \\
2,45 \\
\end{array}$ & $\begin{array}{l}18,70 \\
11,85 \\
\end{array}$ & $0, \infty$ \\
\hline $\begin{array}{l}\text { Traz roupa para } \\
\text { lavar em casa }\end{array}$ & $\begin{array}{l}\text { Sim } \\
\text { Não }\end{array}$ & $\begin{array}{l}14 \\
57 \\
\end{array}$ & $\begin{array}{l}19,70 \\
80,30 \\
\end{array}$ & $\begin{array}{l}13,85 \\
13,00 \\
\end{array}$ & $\begin{array}{l}6,40 \\
8,40 \\
\end{array}$ & $\begin{array}{l}17,40 \\
21,40 \\
\end{array}$ & 0.92 \\
\hline $\begin{array}{l}\text { Trabalha em outra } \\
\text { empresa que pode } \\
\text { usar chumbo }\end{array}$ & $\underset{\text { Sim }}{\text { Sáo }}$ & $\begin{array}{r}94 \\
756\end{array}$ & $\begin{array}{l}11.10 \\
88,90\end{array}$ & $\begin{array}{l}6,70 \\
7,40\end{array}$ & $\begin{array}{l}2,10 \\
3,20\end{array}$ & $\begin{array}{l}11,80 \\
12,60\end{array}$ & 0,28 \\
\hline
\end{tabular}




\subsection{2 - Variáveis relacionadas ao lugar}

Dentre as variáveis do lugar foram pesquisadas aquelas ligadas à possibilidade de contaminação interna à residência e externas, nas quais se incluem a localização do imóvel em relação à fonte e a presença ou não de asfalto nas ruas.

\subsubsection{1 - Fatores internos às residências}

O uso de utensílios de cerâmica para acondicionar alimentos, particularmente o artesanal, cozido a baixas temperaturas, tem sido relacionado a niveis elevados de plumbemia em crianças. Neste estudo, para apenas $34(4,3 \%)$ dos menores foi referida esta possivel fonte de contaminação.

No Brasil, ainda se usa chumbo como anticorrosivo de metais. O zarcão, com o qual se faz a primeira cobertura dos portões e grades de ferro é à base de chumbo. Quando não coberto pode sofrer descamação e ser ingerido pelas crianças menores

Durante a estruturação da investigação várias denúncias foram trazidas à DIR $\mathrm{X}$ acerca do descarte de carcaças de baterias em terrenos baldios pela empresa, desmonte clandestino e uso indevido dos recipientes para guarda de alimentos. Embora não se tivesse esperança de descobrir os desmontes clandestinos, introduziuse no questionário uma pergunta sobre a presença de baterias de automóveis na residência ou arredores. Os responsáveis por $40(4,7 \%)$ crianças responderam afirmativamente. Durante as investigações de campo foram localizados restos de baterias em área de litígio entre a empresa e um sítio vizinho 
Toda a região é servida pelo sistema público de abastecimento de água. Devido à intermitência no fornecimento de água, algumas residências $(3,8 \%)$ construiram poços e os utilizam.

O teste de Mann-Whitney para as diferenças entre as médias de plumbemia das crianças utilizando as variáveis ligadas a possíveis fontes de contaminação intradomiciliar não foi significativo em nenhum dos casos (Tabela 15).

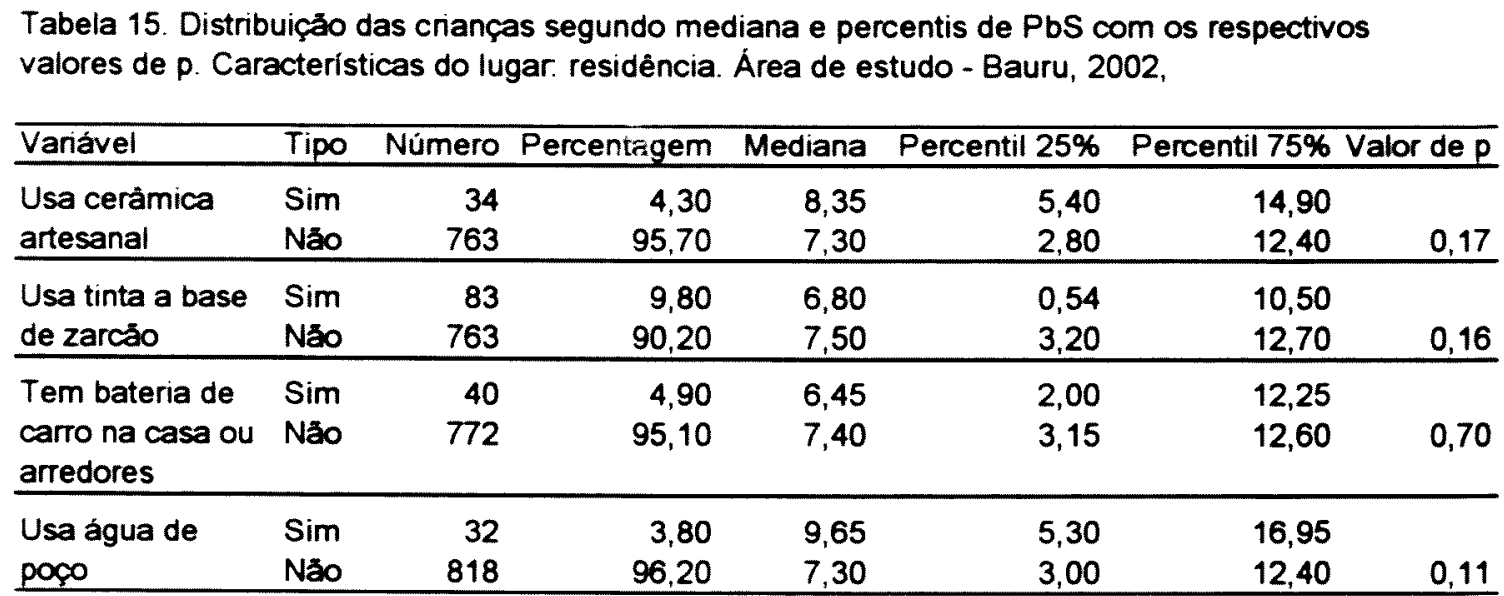

\subsubsection{2 - Fatores externos a residência}

As crianças que moram em casas cujas ruas são asfaltadas têm niveis médios de chumbo no sangue mais baixos. A mediana neste grupo foi de $4,15 \mu \mathrm{g} / \mathrm{dL}$, enquanto os que residem na região não asfaltada tiveram mediana de $11,44 \mu \mathrm{g} / \mathrm{dL}$ (Tabela 16)

Quando se analisa a distância em relação à fonte de emissão, observa-se que há um decréscimo das medianas na medida em que as moradias se afastam. $\mathrm{O}$ teste de correlação de Spearman foi de $0,51 \quad(p<0,05)$. Classificando-se estas crianças segundo as faixas apresentadas na Tabela 17 e niveis de chumbo no sangue menores 
que $10 \mu \mathrm{g} / \mathrm{dL}$ ou maiores e iguais a $10 \mu \mathrm{g} / \mathrm{dL}$, o teste de Chi-quadrado para tendência linear em proporções é significativo. O Gráfico 4 apresenta as OR, também utilizando o teste de Chi-quadrado para tendência linear, obtidas para as classes de distância tomando como referência as residências mais próximas à empresa ( 0 a $200 \mathrm{~m}$ ). Pode-se observar que as crianças residentes a mais de $800 \mathrm{~m}$ da empresa apresentaram risco menor (em torno de 1/5) em relação à distância de referência. 
Tabela 16. Distribuição das crianças segundo mediana e percentis de PbS com os respectivos valores de p. Características do lugar: externos à residência. Área de estudo - Bauru, 2002,

\begin{tabular}{llrrrrrr}
\hline Variável & Tipo & Número & Percentagem & Mediana & Percentil 25\% & Percentil 75\% Valor de p \\
\hline Tem asfalto & Sim & 311 & 36,60 & 4,15 & 0,54 & 6,30 & \\
na rua & Não & 539 & 63,40 & 11,44 & 6,40 & 15,60 & 0,00 \\
\hline Distância da & 0 a 200 & 50 & 5,90 & 13,40 & 9,90 & 17,40 & \\
empresa (m) & 201 a 400 & 74 & 8,70 & 13,15 & 8,70 & 16,80 & \\
& 401 a 600 & 127 & 14,90 & 10,60 & 6,20 & 17,40 & \\
& 601 a 800 & 155 & 18,20 & 9,50 & 6,50 & 14,90 & \\
& 801 e + & 444 & 52,20 & 5,10 & 0,54 & 8,00 & 0,00 \\
\hline
\end{tabular}

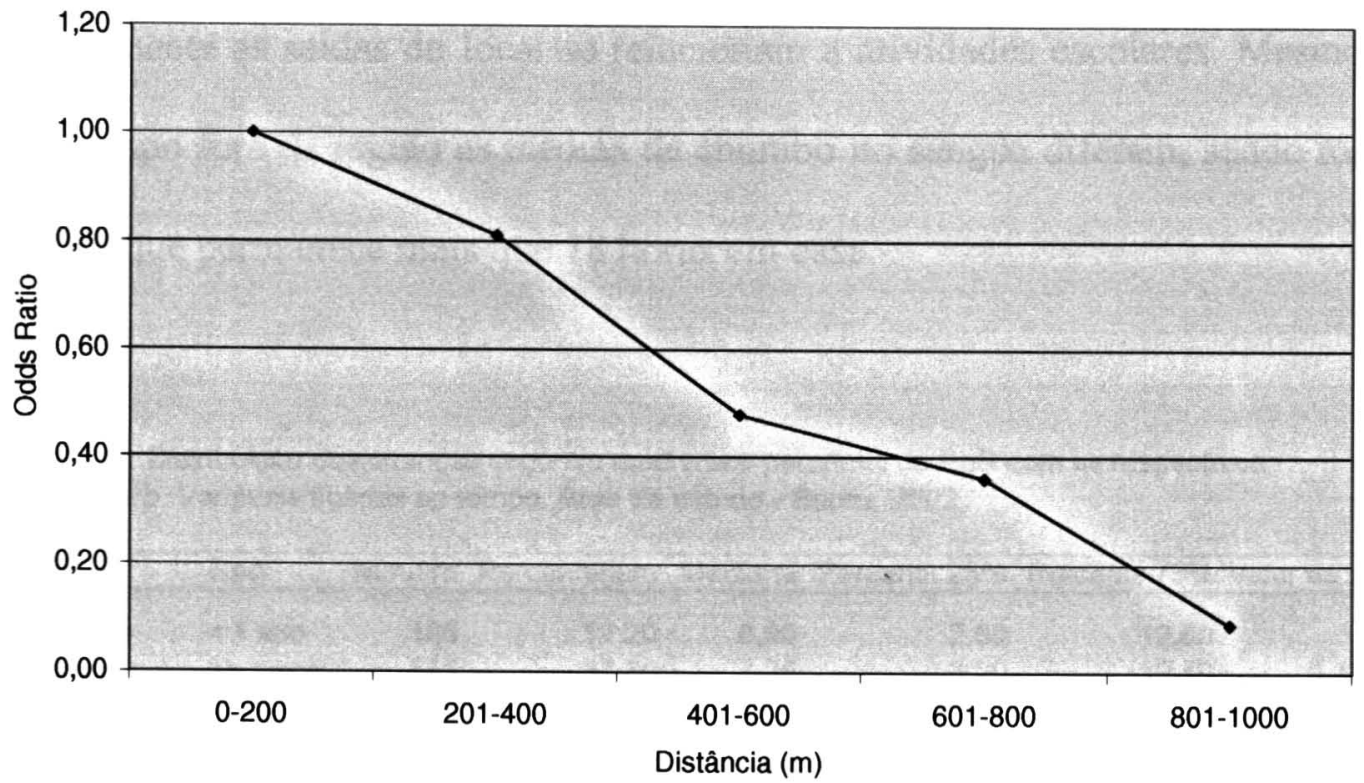

Gráfico 4. Odds Ratio para categorias crescentes de distância da fonte de emissão de chumbo. Teste de tendência linear - Bauru, 2002. 


\subsection{3 - Características ligadas ao tempo}

A ocupação da área é recente, com tempo médio de moradia de 4,3 anos, não se tendo encontrado diferença entre a área asfaltada e não asfaltada (4,8 e 4,0 anos, respectivamente). Para se avaliar exposição a chumbo e tempo no local, a população foi dividida em residentes há menos de um ano e um ano ou mais. As médias de plumbemia das crianças não diferiram entre os dois grupos (Tabela 17).

O tempo médio de permanência dos menores na área é de 18 horas por dia. Provavelmente as saidas do local se relacionam a atividades escolares. Mesmo com pouco tempo fora da região as médias de chumbo no sangue diferem, sendo maiores no grupo que permanece mais que 18 horas em casa.

Tabela 17. Distribuição das crianças segundo mediana e percentis de PbS com os respectivos
valores de p. Variáveis ligadas ao tempo. Área de estudo - Bauru, 2002,
\begin{tabular}{llrrrrrrr}
\hline Variável & Tipo & Número & Percentagem & Mediana & Percentil $25 \%$ & Percentil $75 \%$ Valor de p \\
\hline Tempo de & $<1$ ano & 103 & 12,20 & 6,90 & 2,00 & 12,60 & \\
moradia & $>=1$ ano & 744 & 87,80 & 7,35 & 3,20 & 12,40 & 0,49 \\
\hline Permanência & $>18 \mathrm{hs}$ & 360 & 42,40 & 8,00 & 4,20 & 14,25 & \\
na casa & $<=18 \mathrm{hs}$ & 490 & 57,60 & 6,95 & 2,50 & 11,30 & 0,00 \\
\hline
\end{tabular}




\subsection{4 - Regressão logística}

Exceto a idade, que se trabalhou de forma contínua, todas as demais variáveis com mais de duas opções de resposta foram transformadas em dicotômicas. O número de crianças na residência foi classificado em até dois ou mais e as distâncias da empresa em duas faixas: até $500 \mathrm{~m}$ e maior que $500 \mathrm{~m}$. As crianças foram classificadas segundo os níveis de chumbo no sangue: $>=10 \mu \mathrm{g} / \mathrm{dL}$ e $<10 \mu \mathrm{g} / \mathrm{dL}$, sendo esta a variável dependente nos modelos. Foram calculadas as Odds Ratio (OR) para cada um dos fatores de risco em regressão univariada. Pode-se observar na Tabela 18 que as variáveis que apresentam valores de OR significativos coincidem com aquelas que já apresentavam diferenças entre as médias. 
Tabela 18. Regressão Logistica Univariada: Odds Ratio, Intervalos de Confiança de $95 \%$ e valores de p. Área de estudo - Bauru, 2002,

\begin{tabular}{|c|c|c|c|}
\hline Variáveis & OR & IC de $95 \%$ & Valor de $p$ \\
\hline Morar em área não asfaltada & 11,20 & $7,17-17,62$ & 0,00 \\
\hline Genitor trabalhar na empresa & 5,04 & $2,88-8,88$ & 0,00 \\
\hline Morar a menos de $500 \mathrm{~m}$ da empresa & 4,72 & $3,26-6,86$ & 0,00 \\
\hline Brincar na terra & 3,92 & $2,67-5,76$ & 0,00 \\
\hline Comer terra & 3,19 & $2,09-4,87$ & 0,00 \\
\hline Ter mais de duas crianças no domicilio & 2,71 & $1,98-3,71$ & 0,00 \\
\hline Tomar leite não industrializado & 2,27 & $1,47-3,50$ & 0,00 \\
\hline Brincar no rio ou lago local & 2,07 & $1,22-3,53$ & 0,00 \\
\hline Permanecer em casa mais de $18 \mathrm{~h}$ & 1,52 & $1,13-2,03$ & 0,00 \\
\hline Raça branca & 0,37 & $0,23-0,61$ & 0,00 \\
\hline Brincar com brinquedos importados & 0,58 & $0,43-0,79$ & 0,00 \\
\hline Idade (como continua) & 0,94 & $0,90-0,98$ & 0,00 \\
\hline Usar água de poço & 1,80 & $0,83-3,87$ & 0,07 \\
\hline Genitor trabalhar em empresa que pode usar chumbo & 0,70 & $0,43-1,15$ & 0,08 \\
\hline Usar zarcão como anticorrosivo & 0,70 & $0,41-1,18$ & 0,09 \\
\hline Usar cerâmica artesanal & 1,56 & $0,74-3,30$ & 0,14 \\
\hline Sexo & 1,15 & $0,86-1,54$ & 0,18 \\
\hline Criança com problemas de saúde & 0,86 & $0,62-1,19$ & 0,19 \\
\hline Contato com baterias em casa ou nos arredores* & 0,81 & $0,39-1,67$ & 0,33 \\
\hline Comer alimentos de horta ou pomar locais & 1,03 & $0,76-1,39$ & 0,45 \\
\hline Morar no local há mais de 1 ano & 0,97 & $0,62-1,53$ & 0,49 \\
\hline Lavar roupa do trabalho em casa & 0,83 & $0,21-3,41$ & 0,49 \\
\hline
\end{tabular}


O modelo final de regressão logística é apresentado na Tabela 19. Pode-se observar que morar em área não asfaltada é o principal preditor de níveis elevados de plumbemia, com OR = 5,0 (IC95\%: 3,1-8,12). As crianças residentes nestas áreas têm cinco vezes mais chances de apresentar níveis de chumbo no sangue maiores que $10 \mu \mathrm{g} / \mathrm{dL}$. A seguir e também com relação forte encontra-se o trabalho de familiares na empresa em estudo: OR = 3,8 (IC95\%: 2,1-6,9), indicando que os genitores estão trazendo chumbo para casa e contaminando a residência. Além da presença de asfalto nas ruas, as variáveis distância da empresa, brincar na terra, comer terra e consumo de leite local estão relacionadas à contaminação do solo em sua camada superficial, provavelmente por deposição aérea. O asfalto, por ser impermeável, facilita a limpeza do local durante as chuvas. O carreamento da poeira é menor quando há permeabilidade do solo. A deposição de chumbo nas folhas de vegetais, que é consumido pelo gado, deve ser o fator responsável pela contaminação do leite local, encontrada nas análises efetuadas pela Vigilância Sanitária e pelo achado da regressão logistica quanto ao seu consumo e os níveis de $\mathrm{PbS}$ nas crianças.

A idade foi fator de proteção para níveis elevados de plumbemia. Apesar de pequena, a relação permaneceu significativa no modelo final.

Não se investigaram os diferenciais de renda da população. Como se tratava de um núcleo residencial carente, a equipe de trabalho julgou que este fator não era importante. No entanto, algumas variáveis que poderiam estar relacionadas com a situação socio-econômica da população foram signifícativas. $\mathrm{Na}$ regressão 
univariada, a raça, o número de crianças na residência e, no caso em particular, a existência de brinquedos importados, ainda que comprados em camelôs, foram significativos. Como já colocado, uma das preocupações dos pesquisadores era com o uso de brinquedos importados provenientes de países sem regulamentação quanto ao chumbo na tinta. No estudo-piloto as crianças cujos responsáveis referiram sua existência foram visitadas. As condições da residência deste grupo eram melhores. A introdução da variável raça super-ajusta o modelo, embora seja significativa, provavelmente por contar com grande número de crianças sem informação. Há relação significativa entre raça e número de crianças no domicílio. Brinquedo importado e número de crianças na casa são significativos individualmente mas, quando introduzidos em conjunto, o primeiro perde a significância estatística. A relação entre estas duas variáveis também é significativa e não há interação entre elas. Optou-se por deixar no modelo o número de crianças na residência como dicotômica (até duas ou mais).

As demais variáveis testadas não permaneceram significativas e também não modificaram as anteriores em mais de $10 \%$. Os termos de interação introduzidos não foram significativos. 
Tabela 19. Odds Ratio, Intervalo de Confiança de $95 \%$ e respectivos valores de $p$ do modelo final da regressão logística múltipla. Área de estudo - Bauru, 2002.

\begin{tabular}{l|rrr}
\hline Variáveis & OR & IC de 95\% & Valor de p \\
\hline Morar em área não asfaltada & 5,06 & $3,15-8,12$ & 0,00 \\
Genitor trabalhar na empresa & 3,81 & $2,09-6,92$ & 0,00 \\
Morar a menos de 500m da empresa & 2,54 & $1,69-3,82$ & 0,00 \\
Brincar na terra & 2.09 & $1,30-3.35$ & 0,00 \\
Comer terra & 1,81 & $1,08-3,00$ & 0,02 \\
Tomar leite nåo industrializado & 1,73 & $1,07-2,81$ & 0,02 \\
Ter mais de duas crianças no domicilio & 1,68 & $1,18-2,39$ & 0,00 \\
Idade (como contínua) & 0.94 & $0.89-0.99$ & 0,03 \\
\hline OR-Odds Ratio & & &
\end{tabular}

OR - Odds Ratio

IC: Intervalo de Confiança 


\subsection{5 - Avaliações dos adultos}

Os niveis de plumbemia das gestantes residentes no raio de mil metros da empresa foram avaliados no sentido de julgar a necessidade de afastamento destas mulheres da área, uma vez que o chumbo ultrapassa a barreira placentária. Das 26 gestantes, foram medidos os niveis de chumbo no sangue de 25 . Uma delas não compareceu ao posto de coleta. A média encontrada foi de $2,5 \mu \mathrm{g} / \mathrm{dL}$ (mediana de $2,0 \mu \mathrm{g} / \mathrm{dL}$ ) sendo o valor máximo de $12,40 \mu \mathrm{g} / \mathrm{dL}$. Apenas uma gestante apresentou plumbemia acima de $10 \mu \mathrm{g} / \mathrm{dL}$. Esta já se encontrava no $9^{\circ}$ mês de gestação e pariu o concepto antes do sistema receber o resultado do exame. O bebê, examinado logo após o nascimento, apresentou niveis de $\mathrm{PbS}$ de $8,0 \mu \mathrm{g} / \mathrm{dL}$.

Não se detectou chumbo no leite de nove nutrizes investigadas. Dentre elas, apenas uma teve plumbemia maior que $10 \mu \mathrm{g} / \mathrm{dL}$. Recomendou-se continuar a amamentação.

Com base nos resultados das análises das gestantes e nutrizes, o grupo de suporte técnico julgou que não se fazia necessário investigar os adultos. Para responder à demanda do Ministério Público, foram examinadas vinte e cinco mulheres cujos filhos apresentaram plumbemias superiores a $25 \mu \mathrm{g} / \mathrm{dL}$. A média de chumbo no sangue destas mulheres foi de $7,25 \mu \mathrm{g} / \mathrm{dL}$ (mediana de $7,7 \mu \mathrm{g} / \mathrm{dL}$ ) e valor máximo de $12,7 \mu \mathrm{g} / \mathrm{dL}$, bem abaixo do valor estabelecido como aceitável para adultos $(25 \mu \mathrm{g} / \mathrm{dL})$. Resolveu-se por não ampliar a investigação deste grupo. 


\section{5 - O grupo de suporte técnico}

Durante o levantamento bibliográfico, efetuado pela DOMA e encaminhado para a DIR X e municipio, constatou-se a pouca regulamentação acerca da exposição humana não ocupacional a chumbo no Brasil. Várias questões foram levantadas e o grupo de suporte técnico foi criado para estabelecer as diretrizes da investigação, propor normas e avaliar os resultados, criando novas demandas. Foram efetuadas apenas duas reuniões com todos os participantes convidados. Buscou-se só realizálas quando fosse imprescindível discutir pontos polêmicos ou tomar decisões a partir de fatos novos. No intervalo destas reuniões, sempre que surgiam demandas, a coordenação técnica em conjunto com a DIR X buscava resolvê-las através de correio eletrônico. Procurou-se em todo o processo obter diretrizes consensuais. Embora estivessem previstas votações em caso de inexistência de consenso, não foi necessário recorrer a este recurso. Toda a assessoria prestada foi gratuita, tendo o Ministério da Saúde financiado passagens e diárias aos participantes.

A primeira reunião do grupo de suporte técnico ocorreu em 21/05/2002. Visava à discussão de condutas e parâmetros, a partir dos dados ambientais e de saúde obtidos até aquele momento. Teve como pauta:

$\checkmark$ discutir a conduta frente à população, particularmente sobre o risco de permanência ou não na área;

$\checkmark$ discutir valores de referência de plumbemia para crianças;

$\checkmark$ discutir valores de referência de plumbemia para adultos em geral e para mulheres em idade fértil, gestantes e nutrizes em particular. 
Nesta reunião foram apresentados os dados iniciais do inquérito epidemiológico e as avaliações da CETESB efetuadas em solo, com profundidades de 0 a $20 \mathrm{~cm}$ (superficial) e 80 a $100 \mathrm{~cm}$ (solo sub-superficial); em águas superficiais, subterrâneas; em sedimentos; no ar (após fechamento da indústria) e na vegetação.

Os dados da CETESB mostraram que o limite de intervenção para chumbo em solos de uso residencial $(350 \mu \mathrm{g} / \mathrm{g})$ foi ultrapassado apenas na área da empresa, que estava acima do limite para uso industrial $(1200 \mu \mathrm{g} / \mathrm{g})$. As aferições das águas superficiais superaram o estabelecido pelo CONAMA no pátio interno da fábrica e na estação de tratamento; as das águas profundas, em ponto situado em frente, do lado oposto à rodovia. Não há padrões brasileiros para concentrações de chumbo em sedimentos. Foram utilizados pela CETESB os recomendados no Canadá, onde se estabelecem dois parâmetros: o TEL (Threshold Effect Level de $35 \mu \mathrm{g} / \mathrm{g}$ ) e o PEL

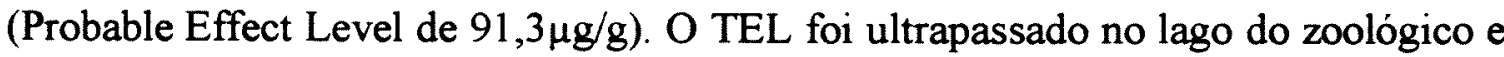
o PEL no córrego Vargem Limpa, junto à rodovia. Após a interdição da empresa, os niveis de chumbo no ar foram bastante inferiores ao estabelecido pela EPA $\left(1,5 \mu \mathrm{g} / \mathrm{m}^{3}\right)$, alcançando o máximo de $0,12 \mu \mathrm{g} / \mathrm{m}^{3}$ a $800 \mathrm{~m}$ da fonte (área sem asfalto), não tendo sido detectado na área asfaltada. Da vegetação colhida, apenas hortelã e o figo apresentaram-se impróprios para consumo.

No estudo epidemiológico de exposição, na ocasião da primeira reunião do grupo de suporte técnico, contava-se com avaliação de 323 crianças. A média de plumbemia em todo o grupo era de $10,14 \mu \mathrm{g} / \mathrm{dL}$, mediana de $9,00 \mu \mathrm{g} / \mathrm{dL}$. Os níveis do metal no sangue decaiam com o distanciamento da fonte, tendo mediana nos 
primeiros $200 \mathrm{~m}$ de $14,00 \mu \mathrm{g} / \mathrm{dL}$ e nos últimos 800 a $1000 \mathrm{~m}$ de $6,00 \mu \mathrm{g} / \mathrm{dL}$. Havia uma criança residente há $600 \mathrm{~m}$ da indústria que apresentava plumbemia de $90 \mu \mathrm{g} / \mathrm{dL}$, destoante do restante da amostra nesta distância. Foi recomendada a investigação da residência para detectar outras possiveis fontes de exposição.

As crianças com plumbemias superiores a $15,00 \mu \mathrm{g} / \mathrm{dL}$ tinham sido submetidas à segunda avaliação após um mês do primeiro exame. Apesar do teste de Wilcoxon para amostras relacionadas apresentar queda significativa entre as médias, dos 41 menores reavaliados, onze apresentavam concentrações de chumbo no sangue superiores no segundo exame, sugerindo que, apesar da interdição da fábrica, ainda havia fonte de exposição no local.

Levando em conta estes resultados, o grupo de suporte técnico, nesta primeira reunião, decidiu pela não retirada das crianças da área. Os profissionais do setor saúde levantaram que o solo provavelmente era a fonte de contaminação remanescente, em particular o solo mais superficial que o colhido pela CETESB. Recomendou-se repetir as análises com amostras o mais superficial possível e realizar medidas de saneamento do meio como asfaltar as ruas, colocar pisos nas calçadas e nas casas, evitando assim a exposição.

Dentre os outros pontos discutidos nesta primeira reunião acordou-se por adotar o limite de intervenção proposto pelo $\mathrm{CDC}$, de $10 \mu \mathrm{g} / \mathrm{dL}$. As crianças com plumbemias iguais ou superiores a este limite seriam submetidas a avaliação neurocomportamental e tratamento se fosse o caso, tendo suas residências investigadas quanto a possiveis outras fontes de exposição. Quanto à definição de 
exposição ou não, seriam utilizados os niveis médios encontrados na população controle do estudo-piloto, uma vez que não se dispõe de valores de referência para crianças. Decidiu-se aprofundar o conhecimento quanto aos valores de referência em adultos, mulheres em idade fértil e nutrizes, tendo como consenso que nestas últimas os niveis deveriam ser menores e que se analisassem as concentrações de chumbo no leite materno (relatório no Anexo 5). Uma segunda reunião seria agendada pela DOMA e DIR X logo que se dispusesse das novas análises da CETESB.

O relatório foi encaminhado a todos os participantes, à DIR X e aos níveis superiores das Secretarias de Saúde e do Meio Ambiente.

Para eleger os novos pontos de análise do solo ocorreu reunião entre a CETESB, DOMA e o CVS. Buscou-se estabelecer os locais de amostragem a partir da identificação de áreas críticas, definidas como as ruas onde as residências contassem com crianças com níveis de plumbemia superiores a $15 \mu \mathrm{g} / \mathrm{dL}$. Os resultados foram colocados em mapa e selecionadas as áreas nas quais o solo de 0 a 2 $\mathrm{cm}$ de profundidade seria colhido.

A segunda reunião do grupo de suporte técnico se deu em 23/07/2002. Já se dispunha dos dados de solo superficial $(0 \mathrm{a} 2 \mathrm{~cm})$ e da indicação da CETESB de que seria necessário sua retirada no raio de $200 \mathrm{~m}$ da empresa. Os dados da avaliação epidemiológica contavam naquele momento com 825 crianças, apontando que as variáveis relacionadas com o solo (como área sem asfalto, comer terra e brincar na terra) eram os principais preditores de níveis elevados de plumbemia. Foi investigada pelo município a residência da criança que apresentava níveis de $\mathrm{PbS}$ de $90 \mu \mathrm{g} / \mathrm{dL}$, 
tendo-se constatado que o proprietário anterior lavava ilegalmente no local baterias de automóveis para revenda.

Após novas discussões entre o setor ambiental e de saúde, a equipe concluiu que a poeira era aquilo que mais estava em contato com as mãos das crianças e disponivel para a absorção pelas vias digestiva e respiratória. Decidiu-se que seriam avaliadas pela UNICAMP as poeiras do peridomicílio, domicilio e das mãos dos menores. Julgou-se que já existiam dados suficientes para encaminhar relatório ao Ministério Público no sentido de aue se exigisse da empresa as medidas de remediação da área (relatório no Anexo 6). Foram relacionadas as seguintes medidas a serem tomadas:

$\checkmark$ retirada da camada superficial de solo;

$\checkmark$ colocar piso nas casas de chão batido;

$\checkmark$ asfaltar as ruas;

$\checkmark$ colocar calçadas ao redor das casas;

$\checkmark$ plantar grama nos quintais;

$\checkmark$ aspirar as casas;

$\checkmark$ não reabrir a empresa enquanto as medidas de controle de emissão não fossem tomadas.

Uma vez que foi encontrada forte associação entre o genitor trabalhar na empresa e niveis de chumbo no sangue das crianças, recomendaram-se medidas de higienização dos funcionários na fábrica, evitando o carreamento do contaminante para as residências. 
Como medidas de acompanhamento, decidiu-se pela reavaliação dos menores após a remediação e avaliação clínica e psicológica com seguimento dos que apresentaram plumbemias maiores ou iguais a $10 \mu \mathrm{g} / \mathrm{dL}$.

Acordou-se que todas as decisões seriam levadas pelos participantes institucionais, com o mesmo conteúdo, para os diversos níveis dos sistemas.

Foram encaminhados os relatórios da Divisão de Doenças Ocasionadas pelo Meio Ambiente e do setor ambiental com as mesmas recomendações. Os resultados de avaliação da poeira foram encaminhados em momento posterior e, em conjunto com aqueles da avaliação epidemiológica dos fatores de risco relacionados com niveis elevados de plumbemia, subsidiaram a DIR $\mathrm{X}$ e a CETESB regional a recomendar a retirada de solo superficial e aspirar as casas em toda a área não asfaltada.

Ainda nesta segunda reunião do grupo de suporte técnico foi discutida uma das demandas do Ministério Público, relativa à avaliação de plumbemias de todos os adultos residentes na área. Resolveu-se proceder a análise preliminar para julgar a necessidade de tal solicitação. Foram apresentadas as concentrações de chumbo no sangue das gestantes e nutrizes investigadas no processo. Ficou estabelecido que o nivel de referência de chumbo no sangue para adultos seria de $25 \mu \mathrm{g} / \mathrm{dL}$ e que se faria uma investigação preliminar no grupo de maior risco, definido como: mulheres residentes em domicilios onde houvesse crianças com plumbemias superiores a $25 \mu \mathrm{g} / \mathrm{dL}$. 


\section{6 - A gestão regional}

Ao lado das discussões e orientações técnicas do grupo de suporte, o município de Bauru, logo após a divulgação da contaminação da área, fervilhava com o problema do impacto nas crianças e requeria do poder público a tomada de medidas de controle imediatas. Antes de a notícia ser divulgada na imprensa, o gestor regional já havia tomado algumas decisões, tais como solicitar informações mais detalhadas à CETESB, comunicar o problema aos níveis superiores do sistema e constituir grupo técnico interno à DIR X para discussão dos passos a serem tomados frente a cada fato novo ou requisição de informações de outras instituições.

O grupo interno da DIR X compunha-se das Vigilâncias - Epidemiológica e Sanitária - e da assistência técnica. De acordo com o relato do gestor regional foram estabelecidos contatos e realizadas reuniões periódicas com a CETESB, com o gestor municipal e com o Ministério Público, tendo, em momento posterior, sido estabelecidos encontros regulares com a empresa. Todas as decisões foram discutidas com os diversos atores. As diferenças existentes entre as coordenações de Vigilância do Estado e do município eram resolvidas pelos gestores e encaminhadas como decisões aos niveis hierárquicos. Toda esta estrutura não impediu que o gestor regional chegasse a pensar que a situação estava fora de controle após a divulgação do caso pela imprensa. As diversas instituições da sociedade bauruense se voltaram para a DIR X requerendo informações, condutas e soluções. A condução política do problema, esclarecendo os passos da investigação, permitiu que estes setores entendessem a demora do processo e, apesar de cobrarem soluções, aguardassem o 
momento e a conduta adequada. A construção do processo no caso Bauru não foi sem atritos. Ocorreram embates com a empresa em primeiro lugar, chegando a levar o gestor a levantar o arcabouço legal do setor saúde para manter a empresa fechada. A Câmara de Vereadores instituiu uma comissão de saúde para avaliar os encaminhamentos efetuados e convidou a população, empresas e especialistas na área para discutir o tema. Coincidentemente estes especialistas eram em parte os que compunham o grupo de suporte técnico; a relação com o "Centrinho", apesar de amistosa no primeiro momento, se deteriorou devido à ameaça de continuidade da assistência às crianças; o sindicato de trabalhadores tentou mobilizar a população com passeata, questionando as atividades de investigação e levantando a possibilidade da transferência da empresa para outro local, tendo como conseqüência o desemprego na cidade.

A partir do relato da entrevista com o diretor da DIR X (Anexo 1) foram destacados alguns passos decisivos, para os quais a decisão política foi fundamental:

$\checkmark$ articulação com o órgão ambiental regional antes que o problema chegasse à imprensa, permitindo discurso uniforme;

$\checkmark$ decisão de ser transparente com os meios de comunicação de massa, buscando evitar furos de reportagem que pudessem pôr em descrédito o trabalho;

$\checkmark$ manter a discussão com todos os setores da sociedade, explicitando a necessidade de cada medida e o tempo requerido para isto;

$\checkmark$ articulação com as universidades locais para garantir a continuidade da assistência especializada às crianças; 
apesar de delegada a direção do processo, buscar discutir cada passo com os parceiros regionais e municipais;

$\checkmark$ adiantar-se na articulação junto ao Ministério Público tornando-o parceiro no trabalho;

$\checkmark$ entender a importância do serviço e da pesquisa sabendo priorizá-los nos momentos adequados $\mathrm{e}$

negociar as medidas de remediação no momento em que se dispunha das informações adequadas para subsidiar a argumentação.

\section{7 - As medidas de remediação}

Durante todo o processo de investigação a empresa esteve fechada e, de acordo com os dados do levantamento feito pela CETESB sobre chumbo no ar, este não se constituia mais em fonte de exposição. Restava a ressuspensão da poeira do solo e do interior das residências que poderia ser ingerida pelas crianças.

Com base nos resultados da avaliação epidemiológica e do ambiente, foram tomadas diversas medidas de remediação da área recomendadas pelo grupo de suporte técnico ou decididas pelos atores regionais e locais. Estas ações foram executadas pela empresa e município e coordenadas pelo último, com suporte técnico da CETESB.

A DIR X capitaneou o processo de discussão com o Ministério Público, em conjunto com a CETESB e o município, para viabilizar o cumprimento das recomendações. A empresa declarou não ter recursos para asfaltar as ruas. Tendo em 
vista que o asfaltamento era inviável naquele momento, tanto por parte da empresa quanto do municipio, foram decididas e encaminhadas as seguintes medidas:

$\checkmark$ impermeabilização de pisos no interior das residências;

$\checkmark$ limpeza e aspiração da poeira sedimentada em mobiliários, pisos e estrutura das casas;

$\checkmark$ limpeza e vedação de caixas d'água;

$\checkmark$ remoção de $5 \mathrm{~cm}$ de solo em áreas não edificadas dos lotes, ruas e calçadas sem pavimentação;

$\checkmark$ saneamento do meio e re-qualificação urbana.

A Secretaria Municipal de Saúde realizou reunião com moradores dos bairros para orientar e discutir sobre as medidas a serem tomadas quanto ao saneamento das habitações.

As diversas instituições locais foram envolvidas no trabalho, tendo-se priorizado iniciá-lo a partir das residências que apresentavam crianças com níveis mais elevados de plumbemia ou devido à proximidade da fábrica. As atividades de descontaminação se iniciaram em meados de outubro de 2002 e foram encerradas em janeiro de 2003, sendo as seguintes:

$\checkmark$ levantamento das condições físicas da região pela Secretaria Municipal de Administrações Regionais de Bauru, incluindo o número de interiores de residências sem piso, quantidade de quintais e calçadas de terra e tipo de construção; 
$\checkmark$ limpeza, desinfecção e vedação das caixas d'água, realizadas pelo Departamento de Água e Esgoto de Bauru, totalizando 177 visitas com 82 limpezas e coberturas;

$\checkmark$ revestimento com piso de cimento do interior de três residências pela Secretaria Municipal de Obras;

$\checkmark$ raspagem de $5 \mathrm{~cm}$ de solo superficial das ruas de terra, realizada pela empresa com acompanhamento de técnicos da Secretaria Municipal de Saúde, Meio Ambiente e CETESB. Foram feitas 80 raspagens de rua e a terra depositada em área cimentada e coberta do pátio da fábrica até se decidir seu destino final;

$\checkmark$ raspagem de $5 \mathrm{~cm}$ do solo superficial dos quintais e calçadas das moradias que não eram impermeabilizadas, por funcionários da empresa poluidora com acompanhamento das Secretarias Municipal de Saúde, Meio Ambiente e CETESB. Esta atividade envolveu 270 residências;

$\checkmark$ aspiração do interior de residências. Nesta operação foram priorizadas as moradias sem forro ou próximas à empresa contaminante, tendo sido realizada por funcionários da fábrica e da Secretaria de Meio Ambiente. Foi computado um total de 164 interiores de residência aspirados.

O saldo do trabalho contabilizou a retirada de 203 caminhões de terra, correspondendo a $1392 \mathrm{~m}^{3}$. De todas as áreas selecionadas para remediação ocorreram 25 recusas de moradores quanto a aspirar suas residências e em cinco quadras o solo não foi retirado. 


\section{8 - As reavaliações de plumbemia das crianças}

As reavaliações dos niveis de chumbo no sangue das crianças foram feitas durante todo o processo de investigação. Buscava-se cumprir o protocolo da Academia Americana de Pediatria, que recomenda confirmar em um mês os valores entre 10 e $19 \mu \mathrm{g} / \mathrm{dL}$, e observar se havia tendência de queda dos níveis de PbS com o fechamento da indústria. Após os resultados das primeiras análises, foram feitas recomendações aos responsáveis acerca de cuidados frente a situações de risco de exposição e interditados produtos ag̣ropecuários do local. A repetição dos exames das crianças com niveis de chumbo no sangue $\geq$ a $15 \mu \mathrm{g} / \mathrm{dL}$ teve prioridade na ordem de coleta. Por fim, seis meses depois de tomadas as medidas de remediação de solo, foi iniciada uma nova avaliação de todas as crianças que no primeiro exame apresentaram plumbemias maiores ou iguais a $10 \mu \mathrm{g} / \mathrm{dL}$

\subsection{1 - Avaliação antes da remediação do solo}

Foram reavaliadas, antes das medidas de remediação do solo, 276 crianças cujos niveis de chumbo no sangue no primeiro exame foram iguais ou superiores a $10 \mu \mathrm{g} / \mathrm{dL}$. A distribuição das crianças segundo faixas de plumbemia foi: $139(50,4 \%)$ de 10 a $14 \mu \mathrm{g} / \mathrm{dL} ; 69(25,0 \%)$ de 15 a $19 \mu \mathrm{g} / \mathrm{dL} ; 64(23,9 \%)$ de 20 a $39 \mu \mathrm{g} / \mathrm{dL} ;$ e 2 $(0,7 \%)$ de $40 \mu \mathrm{g} / \mathrm{dL}$ ou mais. O intervalo entre a primeira e a segunda análise foi em média de 75 dias. A média de níveis de chumbo neste grupo, na primeira avaliação foi $16,76 \mu \mathrm{g} / \mathrm{dL}$ (mediana de $14,90 \mu \mathrm{g} / \mathrm{dL}$ ) e na segunda $14,73 \mu \mathrm{g} / \mathrm{dL}$ (mediana = $13,45 \mu \mathrm{g} / \mathrm{dL}$ ). O teste paramétrico para amostras relacionadas foi significativo, 
mostrando que a média da segunda amostra foi menor que da primeira. Considerando os valores individualmente, em 55 crianças $(20 \%)$ houve aumento das plumbemias e a diferença entre as médias foi significativa. Das crianças que tiveram aumento, 51 não tinham asfalto na rua. Os resultados desta primeira reavaliação, com pequena diferença entre os niveis médios de chumbo no sangue entre a primeira e a segunda amostra, além de uma grande parcela com resultados superiores, fez suspeitar que, mesmo com a empresa fechada, havia fontes de contaminação na área, o que veio a se confirmar com as análises de poeira no domicilio. Observamos que houve diferença entre as médias de $\mathrm{PbS}$ no primeiro exame entre as que compareceram e as que não compareceram para esta reavaliação (Tabela 21). Os grupos não foram homogêneos

\subsection{2 - Reavaliação após as medidas de controle}

Até o dia 16/07/2004, o sistema de Vigilância Epidemiológica contava com $241(77,5 \%)$ resultados de plumbemia de crianças reavaliadas após as medidas de controle, do total de 311 que apresentaram $\mathrm{PbS}$ iguais ou superiores a $10 \mu \mathrm{g} / \mathrm{dL}$ no primeiro exame. O tempo médio decorrido entre estas análises foi de um ano e meio, seis meses após a remediação do solo. Os dados foram analisados comparando-se as médias entre o primeiro exame e aquele realizado após as medidas de remediação propostas. Consideraram-se num primeiro momento apenas as crianças que contavam com as duas avaliações. No segundo momento, comparou-se o grupo de 
menores com informações completas com os demais setenta restantes para avaliar se eram homogêneos.

Do total de 241 exames realizados $167(69,3 \%)$ encontraram-se abaixo de $10 \mu \mathrm{g} / \mathrm{dL} ; 50(20,7 \%)$ entre 10 e $14 \mu \mathrm{g} / \mathrm{dL} ; 14(5,8 \%)$ entre 15 e $19 \mu \mathrm{g} / \mathrm{dL}$; e $10(4,1 \%)$ entre 20 e $39 \mu \mathrm{g} / \mathrm{dL}$. Foram utilizados testes paramétricos para verificação das diferenças entre estas medidas relacionadas. Podem ser vistos na Tabela 20 os resultados de $\mathrm{PbS}$ no primeiro exame e na avaliação de controle. Ressaltamos que entre eles houve uma queda de $46,2 \%$, ou seja, de $16,83 \mu \mathrm{g} / \mathrm{dL}$ para $9,05 \mu \mathrm{g} / \mathrm{dL}$. As proporções de queda giram em torno de $45 \%$ considerando cada um dos fatores de risco identificados na regressão logística. Destaca-se a menor redução para as crianças cujo familiar trabalha na empresa. Analisou-se a idade como variável contínua. Para observação das diferenças entre as médias, estas foram categorizadas segundo faixas. De acordo com os dados da Tabela 21 a menor queda se observa entre os menores de um ano. Avaliando os resultados individualmente, foram encontradas três crianças em que ocorreu elevação dos niveis de chumbo, tendo apenas uma delas diferença significativa (de $15,00 \mu \mathrm{g} / \mathrm{dL}$ para $18,60 \mu \mathrm{g} / \mathrm{dL}$; de $10,10 \mu \mathrm{g} / \mathrm{dL}$ para $10,50 \mu \mathrm{g} / \mathrm{dL}$; de $36,00 \mu \mathrm{g} / \mathrm{dL}$ para $36,10 \mu \mathrm{g} / \mathrm{dL}$ ), e uma que teve resultado similar ao primeiro $(\mathrm{PbS}$ de $16,20 \mu \mathrm{g} / \mathrm{dL})$. De acordo com o conjunto de dados apresentados pode-se supor que houve redução da exposição após as medidas de controle neste conjunto analisado. A Tabela 22 mostra um resumo das análises de reavaliação. $\mathrm{O}$ valor de $p$ para as diferenças entre as médias 6 meses após as medidas de remediação foi de 0,10 indicando que os grupos são homogêneos. 
Tabela 20. Distribuição e comparação das médias de plumbemia das crianças entre o primeiro exame e após as medidas de controle ambiental efetuadas na área segundo fatores de risco. Média,

desvio padrão, mediana, percentual de diferença e valores de p. Bauru, 2004.

\begin{tabular}{|c|c|c|c|c|c|c|c|c|c|}
\hline \multirow[b]{2}{*}{ Variáveis } & \multirow[b]{2}{*}{ Número } & \multicolumn{3}{|c|}{$1^{\circ}$ Resultado } & \multicolumn{3}{|c|}{ Após medidas de controle } & \multirow[b]{2}{*}{$\%$ de dif* } & \multirow[b]{2}{*}{ Valor de $p$} \\
\hline & & Média & DP & Mediana & Média & $\mathrm{DP}$ & Mediana & & \\
\hline Todos os resultados & 241 & 16,83 & 6,52 & 15,00 & 9,05 & 4,82 & 8,00 & 46,23 & 0,00 \\
\hline Morar em área não asfaltada & 227 & 17,12 & 6,58 & 15,40 & 9,21 & 4,86 & 8,10 & 46,20 & 0,00 \\
\hline Morar em área asfaltada & 14 & 12,21 & 2,79 & 11,40 & 6,52 & 3,06 & 6,00 & 46,60 & 0,00 \\
\hline Genitor trabalhar na empresa & 35 & 17,19 & 6,02 & 15,40 & 10,29 & 4,41 & 9,30 & 40,14 & 0,00 \\
\hline Genitor năo trabalhar na empresa & 206 & 16,79 & 6,62 & 15,00 & 8,86 & 4,86 & 7,80 & 47,23 & 0,00 \\
\hline Morar a menos de $500 \mathrm{~m}$ da empresa & 96 & 17,30 & 6,12 & 15,95 & 9,62 & 4,80 & 8,85 & 44,39 & 0,00 \\
\hline Morar a mais de $500 \mathrm{~m}$ da empresa & 145 & 16,52 & 6,77 & 14,60 & 8,67 & 4,80 & 7,50 & 47,52 & 0,00 \\
\hline Criança brinca na terra & 214 & 17,04 & 6,66 & 15,50 & 9,13 & 4,90 & 8,00 & 46,42 & 0,00 \\
\hline Criança não brinca na terra & 27 & 15,21 & 5,01 & 14,10 & 8,39 & 4,08 & 7,80 & 44,84 & 0,00 \\
\hline Criança come terra & 58 & 19,93 & 8,74 & 16,45 & 10,75 & 6,69 & 8,55 & 46,06 & 0,00 \\
\hline Criança não come terra & 177 & 15,93 & 5,35 & 14,80 & 8,55 & 3,96 & 7,90 & 46,33 & 0,00 \\
\hline Toma leite não industrializado & 48 & 18,52 & 7,32 & 17,05 & 9,94 & 4,97 & 8,25 & 46,33 & 0,00 \\
\hline Toma leite industrializado & 193 & 16,41 & 6,25 & 14,70 & 8,83 & 4,76 & 7,90 & 46,19 & 0,00 \\
\hline Tem mais de duas crianças no domicilio & 119 & 17,36 & 7,32 & 15,30 & 9,55 & 5,57 & 7,90 & 44,99 & 0,00 \\
\hline Tem até duas crianças no domicilio & 122 & 16,31 & 5,61 & 14,80 & 8,57 & 3,90 & 8,15 & 47,46 & 0,00 \\
\hline
\end{tabular}

- Percentagem da diferença 
Tabela 21. Distribuição e comparação das médias de plumbemia das crianças entre o primeiro exame e após as medidas de controle ambiental efetuadas na área por grupos de idade.

Média, mediana, percentual de diferença e valores de p. Bauru, 2004.

\begin{tabular}{|c|c|c|c|c|c|c|c|c|c|}
\hline \multirow[b]{2}{*}{ Faixas de Idade } & \multirow[b]{2}{*}{ Número } & \multicolumn{3}{|c|}{ Primeiro resultado } & \multicolumn{3}{|c|}{ Após medidas de controle } & \multirow{2}{*}{\multicolumn{2}{|c|}{$\%$ diferença Valor de $p$}} \\
\hline & & Média & DP & Mediana & Média & DP & Mediana & & \\
\hline Menor de 1 ano & 10 & 15,18 & 3,91 & 14,90 & 10,24 & 4,91 & 10,55 & 32,54 & 0,00 \\
\hline Criança de 1 a 5 anos & 128 & 17,47 & 7,20 & 15,05 & 9,09 & 5,33 & 7,70 & 52,10 & 0,00 \\
\hline Criança de 6 a 12 anos & 103 & 16,20 & 5,73 & 15,00 & 8,88 & 4,10 & 8,20 & 45,20 & 0,00 \\
\hline Total & 241 & 16,83 & 6,52 & 15,00 & 9,05 & 4,82 & 8,00 & 46,23 & 0,00 \\
\hline
\end{tabular}


A raspagem de solo superficial não foi realizada em cinco quadras de ruas não asfaltadas. Dentre estas, quatro contavam com grama e na última a medida não foi executada por que apresentava erosão do terreno. Não há criança residindo nesta quadra. A média de $\mathrm{PbS}$ no exame de controle do grupo de crianças em que não se

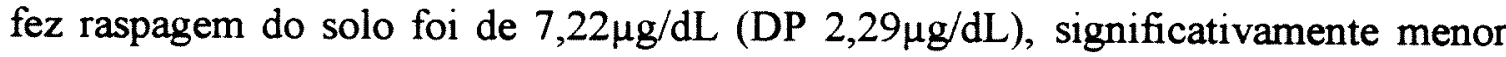
que no primeiro exame. O Sistema de Vigilância Epidemiológica ainda não conta com a discriminação das residências que não foram aspiradas.

As médias dos níveis de chumbo no sangue da primeira avaliação entre as crianças que realizaram os dois exames foi de $16,83 \mu \mathrm{g} / \mathrm{dL}$ (DP de $6,52 \mu \mathrm{g} / \mathrm{dL}$ ) e entre as que realizaram apenas a primeira medida de $\mathrm{PbS}$ foi de $15,43 \mu \mathrm{g} / \mathrm{dL}$ (DP de $5,67 \mu \mathrm{g} / \mathrm{dL}$ ). De acordo com o teste ANOVA estas distribuições são semelhantes ( $\mathrm{p}=$ $0,10)$. As diferenças de médias entre as que compareceram e não compareceram ao exame de controle segundo os níveis de plumbemia também são semelhantes (Anexo 7). Foram avaliadas ainda as diferenças de proporção pelo teste do Chi-quadrado, entre estas crianças para as variáveis sexo e grupos de idade, tendo-se constatado que há homogeneidade entre as distribuições. De acordo com estas análises pode-se concluir que os grupos são homogêneos e que não houve viés de comparecimento para o exame de controle dos niveis de chumbo no sangue. 
Tabela 22. Sumário das reavaliações das 311 crianças com plumbemiasiguais ou superiores

a 10ug/dL segundo medidas de controle, antes e após a remediaçãoda área: múmero, média, mediana e valores de p. Bauru, 2004.

\begin{tabular}{|c|c|c|c|c|c|c|c|c|}
\hline \multirow[b]{2}{*}{ Variável } & \multicolumn{4}{|c|}{$1^{\circ}$ Exame } & \multicolumn{4}{|c|}{$2^{\circ}$ Exame após controle ambiental } \\
\hline & Número & Média & Mediana & Valor de $p^{1}$ & Média & Mediana & \% Diferença & Valor de $p^{2}$ \\
\hline Total $\geq 10 u g / d L$ & 311 & 16,56 & 14,75 & & - & & & \\
\hline \multicolumn{5}{|c|}{ Examinadas após 75 dias do $1^{\circ}$ exame (empresa } & \multicolumn{4}{|c|}{ Resultados após 75 dias do $1^{\circ}$ exame (empresa } \\
\hline Avaliadas & 276 & 16,76 & 14,90 & & 14,73 & 13,45 & 12,11 & 0,00 \\
\hline S/ Avaliação & 35 & 14,56 & 13,10 & 0,03 & & & & \\
\hline \multicolumn{5}{|c|}{ Examinadas 6 meses após controle } & \multicolumn{4}{|c|}{ Resultados 6 meses após controle } \\
\hline Avaliadas & 241 & 16,83 & 15,00 & & 9,05 & 8,00 & 46,23 & 0,00 \\
\hline S/ Avaliação & 70 & 15,43 & 14,00 & 0,10 & & & & \\
\hline
\end{tabular}

1- Toste de diferença entre as médias (ANOVA).

2 - Toste de diferença entre as medias para amostras repetidas. 


\section{5 - DISCUSSÃO}

No momento em que a Divisão de Doenças Ocasionadas pelo Meio Ambiente recebeu a demanda da DIR X acerca da contaminação por chumbo em área residencial de Bauru, a DOMA já contava com algumas experiências com maior ou menor êxito. Dentre estas experiências podem ser citados o estudo de exposição ao chumbo em São Lourenço da Serra (SP) e o da contaminação do Condominio Residencial Barão de Mauá, em Mauá (SP), por benzeno, que tinham trazido aporte básico para construção de diretrizes mínimas no enfrentamento de problemas similares. Atendendo os princípios e diretrizes emanados do Sistema Único de Saúde - SUS (Lei ${ }^{\circ}$ 8080/90), ou seja, de universalidade, de descentralização político-administrativa, de regionalização e hierarquização, de igualdade da assistência, de participação da comunidade e do uso da epidemiologia para o estabelecimento de prioridades, a DOMA elaborou uma lista de atividades e consensos de políticas para investigação do problema. Abaixo estão relacionadas (DOMA, 2003):

$\checkmark$ definição do município como gerente do processo;

$\checkmark$ participação da comunidade;

$\checkmark$ levantamento dos dados ambientais e/ou outras informações;

$\checkmark$ levantamento bibliográfico;

$\checkmark$ constituição de grupo de assessores técnicos (toxicologistas e especialidades envolvidas, em conjunto com os órgãos ambientais e de saúde (CVE, CVS, IAL, DIR e municipio(s) atingido(s); 


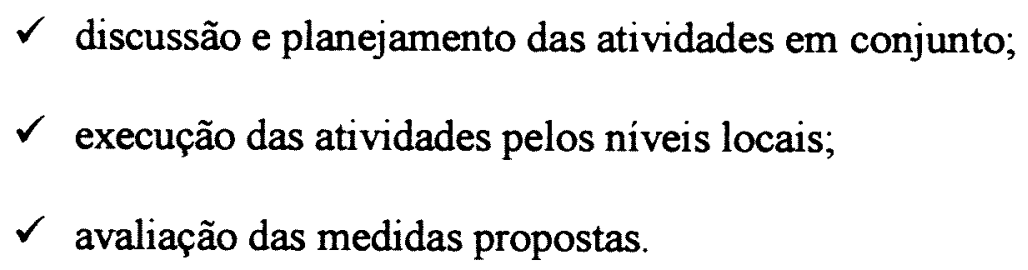

$\mathrm{Na}$ área contaminada de Bauru buscou-se seguir estas diretrizes. O grupo não dispunha de um arcabouço teórico mais aprofundado e procurou orientar o trabalho a partir da experiência prática e da urgência requerida nessas ocorrências. Tendo em conta a riqueza do processo, julgamos interessante explorar e tentar caracterizar a iniciativa, dentro da área de políticas públicas, restringindo-nos ao olhar do serviço e utilizando as formulações mais em foco na atualidade que são: a intersetorialidade, as redes e a governança. Entendemos que estas formulações são inter-relacionadas e podem se constituir em estratégias para viabilizar o trabalho conjunto, indispensável particularmente nas questões ligadas ao ambiente, onde diversos atores fazem parte do processo.

\section{1 - Intersetorialidade: fundamentos jurídico-legais}

As competências legais do setor saúde na área ambiental em São Paulo remontam ao final do século XIX com a edição do primeiro Código Sanitário, através do Decreto ${ }^{\circ} 233$, de 1894 . Este decreto centralizava no âmbito estadual o controle da gestão dos serviços de saneamento - água, esgoto, lixo - além de definir regras para a ocupação do solo urbano e pantanoso das ruas, para as praças e para a arborização da cidade. Foram proibidas as instalações de cocheiras e estábulos dentro do perímetro urbano; disciplinada a localização de edifícios 
coletivos, com regras relativas a volume e altura; a largura das ruas; localização de cemitérios. Enfim, foram estabelecidos regulamentos para o espaço público e privado, inclusive das fábricas (Costa, 2003). Embora todo este corpo de regras tivesse como finalidade o controle de epidemias decorrentes de doenças infectocontagiosas, permitia o desenvolvimento de atividades voltadas à salubridade ambiental.

Entende-se que a fragmentação de competências no campo da regulamentação e controle do binômio saúde/ambiente, fruto das discussões mundiais na área, além de todas as argumentações a respeito (Farah, 2001), deveu-se à crescente complexidade das ações e ao requerimento de estruturas especializadas para fazer frente ao aporte de conhecimentos em cada setor: saúde e ambiente. Não se consegue visualizar o setor saúde, mantendo as competências e atribuições dos dois órgãos (saúde e ambiente).

Analisando as políticas públicas do Estado brasileiro até o inicio dos anos 1980, Farah (2001) coloca como caracteristico o componente setorial destas, particularmente a partir dos anos 1960. Ressalta também a criação progressiva de estruturas especializadas em cada área de atuação governamental decorrente do crescimento da problemática social do pais. A setorialização resultou em autonomia e independência de cada área, sem articulação entre elas. Segundo Tambellini e Câmara (1998), a desarticulação é que se constitui problema.

Foram se estabelecendo instituições que ocuparam o espaço regulamentar e gerenciador das águas de mananciais, esgoto, lixo, parcelamento urbano, ar, 
solo, etc., mantendo algumas vezes competências concorrentes com o remanescente arcabouço legal do setor saúde.

Ao lado da perda de identidade do setor saúde na área ambiental, crescia a demanda pela assistência individual aos enfermos, mantendo-se a abordagem do coletivo apenas para os fatores relacionados às doenças infecto-contagiosas ou que pudessem causar surtos.

As reformulações institucionais no Estado de São Paulo, a nosso ver, levaram a que as funções primordiais no campo da saúde ambiental se restringissem ao estabelecimento das articulações necessárias para o estudo da relação entre condições adversas do meio ambiente e a exposição ou dano à saúde da comunidade. Mesmo com as reformas instituidas até o momento, talvez este seja o espaço prioritário de atuação da vigilância em saúde ambiental frente a situações como a contaminação por substâncias quimicas. O caminho para alcançar estes objetivos é árduo e o conhecimento mundial ainda pouco desenvolvido, sendo essencial o investimento no desenvolvimento institucional e na formação de recursos humanos.

Retomando a questão no Estado de São Paulo, onde ocorreu a maior dicotomização das ações entre saúde e ambiente (Freitas et al., 2002), buscou-se retomar as funções do setor a partir da proposta de reestruturação da Secretaria da Saúde, iniciada em 1986, para responder às formulações da Reforma Sanitária, de integração entre as ações preventivas e curativas. No bojo desta reestruturação foi delegada ao Instituto de Saúde (órgão da Secretaria de Saúde) a formulação de novas politicas. Dentre as discussões das novas práticas no Instituto de Saúde, 
registra-se a proposta de criação de um Instituto de Saúde Ambiental no âmbito da SES, bem como de um Instituto de Saúde do Trabalhador. Estes novos institutos buscavam sistematizar as competências dos setores, incorporando-os à rede de serviços, preencher lacunas de atuação e propor a integração com os demais órgãos. Mesmo ainda no restrito círculo de discussão entre técnicos, o embate gerado no campo interinstitucional levou à restrição das propostas e resultou na tímida criação da Divisão de Ações sobre o Meio Ambiente - SAMA no CVS e da Divisão de Doenças Ocasionadas pelo Meio Ambiente - DOMA no CVE (Freitas et al., 2002). No campo ambiental as ações destas duas instâncias foram pontuais e incipientes até a questão ser encampada nacionalmente pelo Projeto VIGISUS de estruturação do Sistema Nacional de Vigilância em Saúde, financiado pelo Banco Mundial, que tem como uma de suas áreas temáticas a estruturação sistêmica da vigilância ambiental. Segundo o documento que especifica as diretrizes do VIGISUS, o modelo de atuação da vigilância ambiental deve fundamentar-se nas relações com outras instituições, viabilizando as ações (VIGISUS, 1998).

O Projeto VIGISUS é estruturado sob as diretrizes da Agenda 21 internacional e do Plano Nacional de Saúde e Ambiente no Desenvolvimento Sustentável, elaborado na Conferência Pan-americana sobre Saúde e Ambiente no Desenvolvimento Sustentável - COPASAD, tendo a primeira colocado a questão da intersetorialidade como uma das soluções para a salubridade urbana e a segunda (COPASAD) que a intersetorialidade constitui-se em proposta de governo no Brasil. Ambas enfatizam a necessidade da descentralização e 
intersetorialidade, fortalecendo os níveis locais a partir de estratégias capacitantes "fazer junto com"; a necessidade de criar mecanismos de cooperação entre Estados, setores da sociedade, da população e a busca de consensos (CNUMAD, 1992; COPASAD, 1995).

Em particular, no campo da contaminação ambiental, a ECO-92 recomenda a incorporação de análises adequadas dos riscos para a saúde em todos os programas nacionais de controle e gestão ecológica, com especial atenção a substâncias tóxicas como o chumbo (CNUMAD, 1992).

Os avanços obtidos no fórum internacional não tiveram a mesma repercussão nacionalmente. $\mathrm{Na}$ Agenda 21 brasileira as propostas do setor saúde são tímidas, com focalização interna ao setor, que deve buscar a adequação do SUS com vistas a reduzir os riscos, atender a população e realizar programas preventivos. Quando se refere à intersetorialidade, o faz no sentido de estabelecer políticas de melhoria das condições de vida da população. Dentre as questões ambientais recomenda a aplicação do princípio da precaução, tanto para reduzir as doenças ligadas à pobreza, quanto aquelas que surgem em decorrência do progresso científico e tecnológico. Dentre estas, destaca as ações de defesa do consumidor, controle de alimentos e remédios (CPDS, 2002).

Na construção das propostas do Estado de São Paulo para a Agenda 21 brasileira, não houve participação do setor saúde. Outras instituições chegaram a propor alguns itens relacionados ao tema e em seus anais encontram-se algumas cobranças quanto à ausência da área (SMA, 2001). 
Apesar do descompasso entre as propostas, o Projeto VIGISUS e seu componente de estruturação sistêmica da Vigilância Ambiental foi assumido enquanto projeto de governo. Na área ambiental, o objetivo geral é o de “prevenir, reduzir, eliminar ou controlar as doenças e agravos decorrentes dos fatores adversos do ambiente". Dentre os objetivos especificos, destacamos o primeiro que é o de "estruturar nos niveis municipal, estadual e federal um sistema nacional de Vigilância Ambiental... para descrever, interpretar, avaliar e analisar os fatores ambientais que produzem riscos à saúde e impacto sobre a morbimortalidade das doenças e agravos" (VIGISUS, 1998). As áreas de atuação descritas são:

controle dos fatores biológicos condicionantes do risco e transmissão (vetores, hospedeiros, reservatórios e animais peçonhentos);

$\checkmark$ água para consumo humano;

$\checkmark$ contaminantes ambientais hidricos;

$\checkmark$ contaminantes ambientais atmosféricos;

$\checkmark$ contaminantes ambientais do solo;

$\checkmark$ desastres naturais e acidentes com produtos perigosos;

$\checkmark$ ações integradas de vigilância ambiental.

A Coordenação Geral de Vigilância Ambiental em Saúde, criada para gerenciar a área, vem trabalhando de forma integrada com os diversos setores atinentes ao tema, tendo a intersetorialidade e a articulação com especialistas 
como diretrizes de atuação. Estas diretrizes têm sido repassadas para os diversos niveis do sistema. No momento existem estruturados ou em fase de estruturação nos niveis estaduais no Brasil 24 núcleos de Vigilância Ambiental. Alguns independentes todavia operando junto com a VE e VS, outros na Vigilância Sanitária e alguns na Vigilância Epidemiológica ou envolvendo as duas instâncias, sem uma formulação própria. Embora a maioria deles tenha como focos centrais de atividades os vetores e a água para consumo humano, outras rotinas vêm sendo incorporadas, particularmente aquelas relacionadas às áreas contaminadas por substâncias quimicas, desastres e poluição atmosférica (CGVAM, 2004).

A flexibilização, descentralização e o estabelecimento de parcerias entre as instituições têm se mostrado alternativa cada vez mais adequada ao modelo centralizado que não se adapta mais à “idade da informação" (Pimenta, 1995).

O modelo brasileiro até o início dos anos 1980 tinha suas políticas públicas caracterizadas pela centralização decisória e financeira na esfera federal; fragmentação institucional com crescimento do aparato estatal desordenado e por sobreposição de agências; discriminação progressiva de estruturas especializadas em cada área de atuação governamental e, principalmente, exclusão da sociedade civil do processo decisório. O debate iniciado na década de $1970 \mathrm{em}$ torno da democratização enfatizava a descentralização e a participação da população na formulação e implementação de políticas. Estes debates culminam com a Constituição de 1988. Apesar de incorporar alguns componentes da proposta neoliberal vigentes à época, a Constituição cria garantias de democratização, 
descentralização e participação social. O Estado reduz seu papel centralizador e passa ao papel de fiscalizador e coordenador de serviços, que podem ser prestados pelos diversos atores, tanto públicos quanto privados (Farah, 2001).

A descentralização promovida pela Constituição, delegando aos niveis locais não só o poder político, mas ainda um maior aporte financeiro, permitiu aos municípios ampliar significativamente sua ação, particularmente no campo das politicas sociais e desenvolvimento local. Em muitas localidades estas políticas caracterizam-se por ações integradoras das diversas instituições promovendo o bem comum, muitas vezes incentivadas pelos governos estaduais e federal (Farah, 2001).

Do ponto de vista da saúde, as ações intersetoriais tornam-se imprescindiveis na medida em que seu direito, de acordo com o artigo 196 da Constituição Federal pressupõe: a) o acesso universal e igualitário às ações e serviços de saúde para a sua promoção, proteção e recuperação; e $b$ ) a adoção de políticas sociais e econômicas que objetivem a redução do risco da doença e outros agravos.

A Lei Orgânica da Saúde (Lei n 8080/90) é mais explícita em seus artigos 12 e 13, pelos quais dispõe sobre a criação de comissões intersetoriais de âmbito nacional para integrar políticas e programas de interesse da saúde, entre elas as de meio ambiente. Segundo Santos (2002), a saúde e o meio ambiente são áreas intrinsecamente interligadas. Não é possivel prevenir e proteger a saúde individual e coletiva sem cuidar do ambiente. 
É nesse espírito que foi editado o Decreto $n^{\circ} 3450 / 00$ que institui o Sistema Nacional de Vigilância Ambiental em Saúde e a Instrução Normativa ${ }^{\circ}$ 01/01 da Fundação Nacional de Saúde - FUNASA que trata das atribuições das diversas esferas de governo.

Como exemplos de instâncias estruturadas intersetorialmente, envolvendo a saúde, o ambiente e a sociedade civil entre outros setores, temos os Comitês de Bacias Hidrográficas - CBHs. Cada CBH possui representantes dos órgãos afins e dos segmentos organizados da sociedade. Estes respondem aos Conselhos Estaduais e Nacional de Recursos Hídricos, cujas funções são normativas e deliberativas. Todo este aparato constitui o Sistema Integrado de Recursos Hidricos.

No Estado de São Paulo existem 22 unidades de gerenciamento de recursos hídricos, tendo todas elas representação do setor saúde. Nas Regionais de Saúde e/ou nos municipios são realizadas avaliações da qualidade da água para consumo humano em todo o Estado rotineiramente. Desafortunadamente, de acordo com a avaliação dos próprios representantes do setor, a participação da saúde nos comitês não é satisfatória. A quase totalidade (90\%) questiona sua capacidade técnica e politica para atuar (Bonini, 2002). Esta autora indaga se a multidisciplinaridade e intersetorialidade foram absorvidas pela saúde quando participa dos CBHs.

Claro está que as participações são diferenciadas. No I Congresso Interamericano de Saúde Ambiental (2004), foram apresentadas as atividades desenvolvidas pelos $\mathrm{CBHs}$ dos rios Piracicaba, Capivari e Jundiai, envolvendo 
ações com a participação de técnicos e da população na preservação e cuidado com a água, desde o manancial até o consumo (Agujaro et al., 2004). Outras experiências neste sentido podem existir.

Uma outra atividade intersetorial no Estado de São Paulo vem ocorrendo a partir da Resolução Conjunta $n^{\circ} 01$ SMS/SS/97. Propõe-se a integração e intercâmbio de informações para o estudo dos efeitos na saúde decorrentes da poluição veicular e do impacto das medidas de controle. O objetivo é orientar políticas voltadas ao controle da poluição do ar. O programa iniciou-se no município de São Paulo em 1997 (Freitas, 2000). A partir de 2003 e, coordenada pelo CVE, a iniciativa estendeu-se para os demais municipios da RMSP que contam com estações de monitoramento da qualidade do ar. A proposta de São Paulo coincidiu com a política do Ministério da Saúde/CGVAM que vem trabalhando intersetorialmente em alguns Estados e municípios.

Dentre as diversas publicações acerca da contaminação da região amazônica por mercúrio (Pinheiro et al., 2000; Silbergeld et al., 2002; Santos et al., 2003), em 1998, Câmara e colaboradores propõem a construção de um programa de vigilância ambiental dos riscos e efeitos da exposição ao contaminante em áreas de produção de ouro. Segundo os formuladores este programa deve envolver a população interessada a partir da criação de um sistema de informação sobre o agente, as caracteristicas do ambiente, os individuos expostos e os efeitos. Todo este sistema deve levar à proposição e à execução de medidas de controle. Além da intersetorialidade os autores ressaltam a necessidade de multidisciplinaridade. 
A experiência de Bauru foi consoante com os principios instituídos no Sistema Nacional de Vigilância Ambiental em Saúde - SINVAS: construir uma proposta intra e intersetorial com caráter multidisciplinar buscando, como coloca Walgenbach et al. (2000), romper a simples reunião de conhecimentos particulares e propondo a permeabilidade entre os pares, reconhecendo, como analisam Teixeira e Paim (2000), que a busca da intersetorialidade no campo da saúde tem suas raizes na inadequação do modelo do setor às mudanças demográficas, epidemiológicas, políticas e cultirais das sociedades contemporâneas. A meta, como recomendam os estudiosos, foi a conjugação de esforços e recursos dos diversos atores, visando alcançar resultados mais sustentáveis do que poderia alcançar o setor saúde individualmente.

A intrasetorialidade foi garantida com a participação dos diversos niveis do SUS, desde o município até a Federação, e a intersetorialidade com o concurso do setor de meio ambiente e das universidades. A participação da população no processo veio a partir da cobrança de medidas de controle e busca de esclarecimento quanto aos efeitos e cuidados que o sistema estaria oferecendo para garantir seu bem-estar.

A multidisciplinaridade nos processos de investigação de áreas contaminadas pode ser resolvida através da intersetorialidade, como em Bauru, onde cada ator tem formação diferenciada e contribui de maneira complementar, construindo um conhecimento, embora nem sempre novo, mas integrador com relação a propostas de diagnóstico e resolução do problema. $O$ grupo constituido em Bauru teve este espirito. 
A prática da intersetorialidade exige arranjos entre os grupos uma vez que cada instituição dispõe de arcabouço legal diferenciado, sendo independentes quanto à tomada de decisões. A estrutura organizacional e hierarquia também são distintas, tendo algumas poder de mando entre os niveis e outras apenas função orientadora. Destaca-se a perplexidade diante dos arranjos necessários à reorganização do poder e à reorganização dos processos de trabalho (Teixeira e Paim, 2000). Segundo Augusto (2003), a multidisciplinaridade e intersetorialidade exigem uma relação de cooperação entre especialistas e setores envolvidos e não subordinação de qualquer das partes. Para superar estas particularidades e garantir uma proposta de ação integrada e coerente, em Bauru, fez-se necessário buscar alternativas organizacionais e de gerenciamento mais horizontais e inspiradas em outros ideários. Nesse sentido, a construção de redes vem sendo colocada como alternativa.

\section{2 - As noções de rede e a experiência de Bauru}

Existe uma grande variedade de conceitos e de aplicações de rede que se constitui em formas de abordagem nos vários campos da ciência. Especificamente estaremos enfocando a incorporação do ideário de redes na formulação e gerenciamento das práticas de políticas públicas. Segundo Börgel (1997), a definição mais simplificada de redes é "uma série de relações relativamente estáveis e não hierárquicas, com atores variados e independentes, mas relacionados a interesses comuns no que se refere a uma politica. Compartilham 
recursos perseguindo interesses e reconhecendo que a cooperação é o melhor caminho para alcançar as metas do grupo".

A partir desta formulação básica, várias vertentes podem ser identificadas: formas alternativas de distribuição do poder em governos democráticos liberais; combinação de modelos de organização estrutural dos sistemas de governo com interesses de grupos; e, entre outras, como uma organização complexa, de estruturas conectadas, mas independentes (como grupos de poder). Podem abarcar relações interpessoais quando relacionadas a redes empresariais (Börzel, 1997).

Segundo Minhoto e Martins (2001), as redes têm suas origens ligadas à globalização; às reações das empresas, enquanto forma de reorganização frente às crises do capital e, no Estado moderno, como estratégia de recuperação da soberania. Por outro lado, particularmente as redes sociais, a partir da lógica de articulação e solidariedade, representam a entrada na arena político-institucional de movimentos ligados a outros conteúdos como: exclusão, qualidade de vida, meio ambiente, direitos humanos entre outros. Estas disseminam seus posicionamentos, denúncias e propostas servindo-se de modernas tecnologias de informação e de estratégias para alcançar seus objetivos (Jacobi, 2000; Minhoto e Martins, 2001)

No campo das politicas públicas, as redes partem da constatação de que nenhuma instituição, considerada individualmente, teria condições de atingir suas metas por si só (Martins, 1996, appud Minhoto e Martins, 2001). Börzel (1977) levanta que a abordagem das redes é ambiciosa e deve superar dois grandes 
desafios para tornar-se mais do que apenas uma ferramenta para o estudo das políticas públicas. O primeiro diz respeito à existência real das redes e sua relevância no processo de decisão e resultados. O segundo é o problema da ambigüidade, que pode tanto realçar quanto reduzir o poder do gestor. Assume-se que a existência das redes influencia, mas não determina a decisão política.

Apesar das questões ainda pendentes, as redes vêm sendo propostas na área da saúde. Dentre os argumentos, são levantadas críticas com relação à insuficiência do setor para dar respostas aos problemas desde sua origem e quanto à persistência da centralização das decisões (Machado e Porto, 2003; Misoczky, 2003).

Embora ainda sem formulação clara enquanto proposta de governo, as práticas de saúde do trabalhador têm apresentado experiências que, de acordo com Machado e Porto (2003), podem ser sistematizadas. Os autores propõem a criação de redes entre os diversos setores envolvidos na área saúde e trabalho, inclusive a população, tendo a saúde papel mais catalisador que executor, uma vez que as ações para resolver os problemas de base estão entre as competências de outras instituições. No centro desta rede se encontrariam o trabalhador e o ambiente, mediados pelos sindicatos patronal e operário. Na primeira esfera, os órgãos responsáveis pela assistência, controle e fiscalização como os Programas de Saúde do Trabalhador do SUS, Delegacias de Trabalho e Ministério Público. $\mathrm{Na}$ segunda esfera as entidades de suporte técnico e da sociedade civil (universidades e ONGs). A terceira esfera seria de estratégia global, com macro- 
negociações, estabelecimento de políticas estratégicas e relacionamentos internacionais.

Partindo da crítica de que as Normas Operacionais Básicas - NOB (1993 e 1996) e a Norma Operacional de Assistência à Saúde - NOAS (2001, reeditada em 2002) mantêm em sua essência o perfil centralizador do sistema político brasileiro através de seu financiamento, regulamentação e fragmentação segundo níveis de complexidade, retirando do gestor municipal a decisão sobre determinadas áreas do setor saúde, Misoczky (2003) também propõe a criação de redes. Estas redes teriam como pressupostos atividades "interorganizacionais" e interdisciplinares no campo das políticas públicas, tendo o território como referência. Coloca também que os grandes desafios das redes estão no estabelecimento de modalidades de gerência que possibilitem alcançar os objetivos propostos e manter a articulação.

A estrutura criada para responder à contaminação por chumbo no município de Bauru poderia ser classificada como rede em sua estrutura mais simplificada, como uma série de relações não hierárquicas, com atores variados e independentes, relacionados a interesses comuns. Os atores, mesmo internos ao setor saúde, tinham no grupo técnico assessor, o mesmo status com relação a propostas e decisões. O grupo técnico assessor era composto pelos representantes dos diversos níveis do sistema de saúde, além de representantes dos órgãos ambientais e universidades, que em si constituía uma rede. Tinha caráter deliberativo, em seu nivel, com relação a propostas de avaliação ambiental, assistência médica aos expostos e medidas de remediação. Mesmo assim o grupo 
não pode ser considerado apenas como um nivel central da hierarquia, pois integrava as instâncias regional e local além de não ter poder de mando. $\mathrm{Na}$ realidade, a proposta assumia características mais complexas, com múltiplos focos de poder (rede no nivel regional e das universidades locais), que embora interdependentes quanto ao problema de interesse (a contaminação por chumbo) e do ponto de vista técnico, mantinham independência quanto às políticas. Tinham fóruns independentes e reelaboravam as propostas acordadas no grupo técnico assessor de acordo com a realidade do lugar buscando a melhor e mais viável solução para o problema. As relações interpessoais foram importantes na constituição das redes, ora contribuindo, ora dificultando, mas em todo o processo o grupo de suporte técnico priorizou discutir recomendações e garantir o intercâmbio de conhecimentos (o "fazer junto"), deixando a gestão política do processo para os atores mais próximos da população. Nem todas as propostas emanadas do grupo de suporte técnico foram encaminhadas, embora outras tenham sido agregadas a partir da observação da área. Isto caracteriza um prérequisito das redes que é o da articulação horizontal, formas de atuação conjunta e cooperação, voltados para o enfrentamento de uma situação-problema, sem prejuizo da autonomia de seus integrantes (Minhoto e Martins, 2001).

Enquanto momento de questionamento do aparato legal, que determina o nivel de referência populacional para chumbo no Brasil em $40 \mu \mathrm{g} / \mathrm{dL}$, a rede constituída pelo grupo de suporte técnico teve papel fundamental. Definiu que, para crianças, o nivel de ação seria o proposto pelo CDC e OMS de $10 \mu \mathrm{g} / \mathrm{dL}$. 
Esta decisão fundamentou documento enviado pela DOMA à Promotoria Pública de Bauru que foi acatado.

Como levanta Misoczky (2003), uma das questões das redes é o seu gerenciamento. Em Bauru havia um gerente das redes que era o Diretor Regional de Saúde, o que diferencia a experiência. Internamente ao setor saúde, as orientações emanadas do grupo técnico assessor eram encaminhadas ao grupo regional através dos técnicos das vigilâncias e readaptadas em conjunto com o gestor regional e secretário municipal de saúde. Neste caso, embora sem poder de mando, apenas orientação técnica, houve uma hierarquia.

A rede constituida pelas universidades locais revia as orientações do grupo técnico assessor, organizava a assistência e definia linhas de investigação que vêm sendo executadas, tendo momentos de atrito com o gestor regional.

As demais instituições como a CETESB regional, Ministério Público e empresa, participavam do processo em fóruns paralelos, não se constituindo em rede, mas apenas em articulações intersetoriais.

Os arranjos consensuados em Bauru envolveram não só redes, mas uma gerência complexa de relações entre setores às vezes com interesses diversos, mesmo que em torno do mesmo tema.

Embora as redes venham sendo construidas e se mostrando em formas alternativas no encaminhamento de propostas, alguns aspectos, como colocados anteriormente, vêm sendo questionados.

Rhodes (1996), discutindo governança, levanta que as redes, muito difundidas na Inglaterra, alocam recursos autoritariamente, exercendo controle e 
coordenação. Cada rede é caracterizada por confiança, ajustamentos mútuos e põe em xeque a governabilidade. Tornam-se autonomas e resistem ao comando central. São um desafio, pois, esvaziando o Estado, colocam a necessidade de novas propostas de gerência.

\section{3 - Aspectos de governança na experiência de Bauru}

As incertezas são inerentes ao conhecimento científico e, mais notadamente, em relação às substâncias químicas e ao meio ambiente. $O$ reconhecimento das incertezas leva, segundo Funtowicz e Ravetz (1997), a um novo empreendimento científico a que os autores chamam de "ciência pósnormal". Outro problema a ser enfrentado é o da complexidade, na qual não se pode reduzir os problemas a componentes isolados, sem tentar entender e integrar suas diversas dimensões (Porto, 2002; Freitas et al., 2002). Leff (2003) levanta que o conhecimento construido até o momento não dá conta da complexidade ambiental. Para apreendê-la faz-se necessária uma desconstrução dos saberes; de se aprender a aprender, como uma reapropriação do mundo; uma hibridação do conhecimento na interdisciplinaridade e transdisciplinaridade, inserindo a subjetividade dos valores e dos interesses na tomada de decisões e abrindo espaço para o encontro entre o racional e o moral.

Defende-se, frente às incertezas, à complexidade e à qualidade, no que se refere às abordagens para o enfrentamento da contaminação ambiental, um novo método que se denomina "comunidade ampliada de pares". Esta comunidade seria composta não só por peritos capazes, mas também pelos interessados: 
empresas, sociedade organizada e população, desde que se dispusessem ao debate sincero e verdadeiro. $\mathrm{Na}$ medida em que os problemas ambientais extrapolam o campo da cientificidade e migram para o campo político, colocam-se como uma questão de governança. Na proposta da comunidade ampliada de pares, os interessados, direta ou indiretamente envolvidos, fazem parte da investigação em pé de igualdade com os experts. Os formuladores desta proposta colocam que se pode chegar a soluções mais inovadoras e adequadas a cada realidade. A proposta de governança na comunidade ampliada de pares requer uma relação de confiança que deve ser construida (Funtowicz e Ravetz, 1997; De Marchi e Ravetz, 1999).

As experiências com áreas contaminadas no Estado de São Paulo vêm colocando a necessidade de novos arranjos políticos entre o público e o privado para viabilizar o processo decisório e as ações com a urgência requerida em boa parte dos casos. Mesmo recorrendo à intersetorialidade entre os órgãos públicos com poder de polícia, este poder é questionado pelo setor privado. As incertezas, como as levantadas por Funtowicz e Ravetz (1997), inerentes ao conhecimento dos efeitos e difusão das substâncias químicas, levam a processos judiciais que perduram por anos a fio e a debates intermináveis entre estudiosos, enquanto a população exposta reclama uma solução definitiva.

O trabalho desenvolvido em Bauru não pode ser classificado como o de uma comunidade ampliada de pares uma vez que a população interessada participou do processo apenas com pressão política esclarecida, não como formuladora de propostas. No entanto, alguns aspectos relativos à governança 
devem ser entendidos para clarear os acontecimentos e ajustamentos que fizeram parte da atuação do gestor político do processo.

Não se trata neste estudo de elaborar uma discussão aprofundada de governança. Apenas de buscar algumas formulações conceituais e de avaliação da proposta, no sentido de contextualizar a experiência.

Segundo alguns autores a palavra governança tem sua origem no século XVI e, para outros, no século XVII como termo francês que fazia parte das aspirações dos iluministas em associar um governo esclarecido às aspirações da sociedade civil (Gaudin, 1998).

Entre os teóricos, as definições de governança são múltiplas. A primeira diferenciação a ser feita é entre esta e governo. Governo refere-se a instituições formais de Estado e ao monopólio do poder coercitivo, para manter a ordem e fortalecer a ação coletiva. Tem estrutura hierarquizada, administrações unificadas e interesses integrados. O uso tradicional de governança dá-se como sinônimo de governo. A mudança diz respeito a um novo processo de governar, uma mudança nas regras, com a criação de condições para organizar normas e ações coletivas. A diferença pode não estar nos resultados, mas no processo, respeitando o poder da sociedade e rejeitando o papel fundamental de comando e controle do governo, em favor de uma abordagem interativa de poder e responsabilidades. Aponta para a criação de uma ordem que não pode ser imposta externamente, mas ser o resultado da conjugação de esforços entre governos e demais atores da sociedade (Stoker, 1998; Gaudin, 1998). Segundo Koiman (1993, apud Merrien, 1998), na governança, a convergência entre problemas e soluções é mais importante que as 
divergências, podendo ser obtida através do rompimento das diferenças entre o público e o privado.

Para as agências de financiamento internacional a governança busca promover uma interação construtiva entre Estado, sociedade civil e setor privado. Para o Banco Mundial em particular, "boa governança é um processo politico previsivel, aberto e esclarecido (transparência); uma burocracia imbuida de ética profissional; um ramo executivo de governo responsável por suas ações e uma sociedade civil forte e participativa dos assuntos públicos, todos eles agindo sob o primado da lei" (World Bank, 1994. UNDP, 1997). Segundo Alcântara (1998), as agências de financiamento questionam a forma como a proposta de livre-mercado foi conduzida nos paises em desenvolvimento, os quais acreditavam que os problemas da economia poderiam ser resolvidos apenas através do processo de negociação política. Esta prática teria, em maior ou menor grau, resultado nas distorções responsáveis pela maioria dos problemas enfrentados atualmente. Ressaltamos que a crítica não se refere à participação do setor privado no governo. Dentre as formulações de governança das agências de financiamento propõe-se a partilha de poder entre o Governo, o setor privado e a sociedade.

Apesar de não constar de seus estatutos o poder de mando nos países, estas agências buscam redirecionar financiamentos do campo econômico para questões sociais e políticas cruciais. As questões estão relacionadas com a reestruturação e desenvolvimento, em particular nos países "pós-coloniais" (Pagden, 1998). Denominando-se boa governança este redirecionamento busca (Alcântara, 1998): 
$\checkmark$ combater a corrupção na administração pública;

$\checkmark$ tratar as questões políticas como questões técnicas;

$\checkmark$ reformar os serviços, tendo como foco a descentralização e a privatização em busca do Estado minimo;

$\checkmark$ introduzir novas formas de gerenciamento através de práticas de auditoria;

$\checkmark$ construção de um aparato legal e judiciário independente mas compatível com a privatização e a garantia dos direitos humanos;

$\checkmark$ dividir o poder com a sociedade: do Governo e do setor público para os grupos privados e organizações da sociedade civil para equipá-la e fortificá-la no estabelecimento do Estado.

Enfim, na boa governança o Estado deve ter legitimidade, autoridade, eficiência, responsabilidade e promover a distribuição de poder dentro dos marcos da democracia liberal (Rhodes, 1996; Stoker, 1998).

Para a Comissão de Governança Global - CGG, governança "é a soma de numerosas formas em que os individuos e instituições, públicas e privadas, administram seus assuntos comuns. Trata-se de um processo contínuo que possibilita a acomodação de interesses conflitantes ou divergentes e a adoção de uma ação cooperativa. Inclui instituições e regimes formais dotados de poder para induzir a observância, bem como processos informais que pessoas e instituições acordam entre si ou percebem ser do seu próprio interesse" (CGG, 2002). A Comissão de Governança Global está mais voltada em garantir relações internacionais igualitárias e para isto estabelece alguns valores fundamentais 
como a liberdade, eqüidade, solidariedade, tolerância, respeito pela natureza e responsabilidades partilhadas (CGG, 1995).

Várias críticas são levantadas ao conceito de governança: o Banco Mundial a reduz a um governo eficiente e responsável. Definições mais amplas a colocam como a interdependência entre o setor público, privado e o voluntariado em paises em desenvolvimento. Pode ainda ser usada como sinônimo de governo, uma vez que este termo não se adequa às negociações em uma sociedade privatizada e orientada para o mercado, ou é uma reinvenção de boas práticas de governo onde está envolvida a necessidade de reduzir custos como conseqüência da crise fiscal mundial. Alguns a definem como uma provável revalorização dos agentes econômicos (Gaudin, 1998; Stoker, 1998).

Mesmo concordando com as críticas dos autores, resolvemos abordar governança segundo propõe Stoker (1998). O autor defende que a contribuição da discussão teórica dessa proposta não é oferecer uma nova teoria, mas a capacidade para entender as mudanças nos processos de Governo. Ao mesmo tempo em que identifica questões, pode encontrar respostas. Dentro desta perspectiva, coloca cinco proposições de governança, analisando os desafios de cada uma delas. Refere que o conceito está em estruturação e pode vir a ser uma forma mais avançada de Governo, caso sejam encontradas as melhores formas de gerenciamento.

Dentre as diversas formas de governança, Rhodes (1996) identifica seis usos do conceito com diferentes conotações: 
governança como Estado mínimo: redefine a extensão e forma de intervenção pública com o recurso à privatização ou quase privatização para os serviços públicos. O controle do Governo passa a ser através da regulamentação;

governança corporativa - sistema em que as organizações são dirigidas e controladas. O Governo não dita regras, mas orientações gerais para as companhias. São identificados três princípios aplicados, tanto ao setor público quanto ao privado: transparência da informação, honestidade e responsabilidade com definição clara das regras;

governança como nova forma de gerenciamento - introduzindo técnicas do setor privado no setor público ou como uma nova economia institucional, com estruturas de incentivo e competição;

governança como boa governança - é a definição das agências de financiamento, citada anteriormente

governança como sistema sócio-cibernético ou coordenação, controle e avaliação com intervenção de esforços interativos para envolver todos os atores - as políticas não são produto do Governo central. As regras são editadas e sofrem influência dos diversos níveis, dos setores não governamentais e privados. As normas editadas são resultado destas interações e das negociações das várias partes afetadas. Reconhece-se que os resultados dependem da interdependência e não de um único ator, seja público ou privado. $\mathrm{O}$ intercâmbio de informações e o conhecimento 
técnico são cruciais neste tipo de governança, onde existem vários núcleos de poder. De acordo com o autor estes arranjos são abundantes; governança como redes auto gerenciadas: envolve grupos complexos de organizações públicas e privadas em redes. Estas são construídas a partir de atores que necessitam permuta de recursos, sejam financeiros, de informação ou de conhecimento. O grande desafio é como gerenciar as redes, pois devem ser auto-organizadas, sem interferência direta do Governo. Gerenciar as redes requer reputação, confiança, reciprocidade e interdependência. Neste caso, governança é gerenciar redes.

Algumas formas de governança, em especial as duas últimas, são referenciadas por Gaudin (1998) e Rhodes (1996) como mais comuns nos governos locais e anteriores à nova discussão do conceito.

É patente que os artigos que tratam da questão da governança discorrem sobre a falência fiscal do Governo e a necessidade de buscar formas alternativas de gerenciamento a partir da inclusão da população organizada ou voluntária e do setor privado. Jessop (1998) critica o consenso criado em torno do conceito e seu risco de falência. Levanta que as condições para a criação das redes hierárquicas podem não ser suficientes para superar as forças do mercado ou o controle centralizado do Estado. Segundo ele, já existem muitos relatos de falência tanto do Estado quanto da iniciativa privada. A governança enquanto ações integradas entre Estado e mercado deve também estar sujeita a observações de seus sucessos 
e fracassos. Poder-se-ia perceber suas falhas nas contínuas mudanças de regras frente às discordâncias entre as partes envolvidas. Os fatores que limitam o sucesso da governança, como a dinâmica do capitalismo, os diferentes modelos de coordenação, de suporte e de recursos entre setor público e privado, bem como a própria natureza de auto-regulação das redes, podem ser minimizados nos niveis locais.

Analisando as propostas de governança em relação ao moderno estado de bem-estar na Europa ${ }^{6}$, Merrien (1998) avalia que há algumas mudanças neoliberais nas políticas públicas, mas que estas não são uniformes nem generalizadas. O Estado continua com papel fundamental e as instituições constituem-se espaço para o exercício da imaginação política e do sucesso empresarial. Na França, mais de $95 \%$ da população julga que o Governo deve garantir os direitos da população. As discussões em torno do pluralismo social e da reorganização do Estado têm admitido que o welfare state é ainda um fato inalienável. As iniciativas envolvendo outros setores da sociedade funcionam sob estrito controle e regulação dentro da lógica das políticas públicas.

De acordo com Jessop (1998), faz-se necessário criar mecanismos para avaliação dos processos de governança ou pode-se cair na euforia de que acordos e compromissos funcionam e se constituem em propostas alternativas.

Dentro do emaranhado de críticas e planos de governança, Gaudin (2001) sugere que a coordenação, como cooperação cognitiva entre agentes, pode ser compreendida como uma composição de conhecimentos; acordos para construção

\footnotetext{
${ }^{6}$ Crescimento relativamente homogêneo da sociedade. entre as quais há divisão de riscos e a grande maioria da população tem trabalho permanente (Merrien. 1998).
} 
de fluxo de informações, simpatias e aprendizagem. Neste caso, os acordos e as negociações políticas podem ser mensurados. $O$ autor se questiona se o caos das negociações pode vir a constituir uma nova ordem política ou se estamos diante de uma fantasia, que na prática se revela como consumidora de tempo e energia e não possui legitimidade.

Enquanto proposta em construção, o debate em torno da governança reflete a divergência de opiniões necessária para a formação de um novo consenso ou uma nova definição. A liberdade não é compatível com uma opinião unanimemente mantida. Quando todos pensam de maneira uniforme, não há criação (Arendt, 1990).

No Brasil, as propostas de descentralização e as dificuldades de efetivação frente aos vários problemas enfrentados pelos municipios e sua relação com o poder central vêm sendo avaliadas a partir do Programa de Gestão Pública e Cidadania da Fundação Getúlio Vargas - FGV, bem como por outras instituições. Spink et al. (1999) analisando as reuniões realizadas anualmente na FGV para apresentação de práticas inovadoras, a partir de três anos de experiência destes fóruns, apontam que os resultados iniciais, embora não representem uma estratégia articulada de descentralização, podem ser considerados como a emergência ou criação de novas práticas e alianças que estariam assumindo configurações de governança. Em 2001, Farah avalia algumas destas práticas e, segundo a autora, estas redes inauguram uma nova governança, sugerindo que no pais as políticas sociais não são mais atribuição exclusiva do Estado. Como levantam Spink et al. (1999) nem todos os municípios estavam preparados técnica 
e administrativamente para enfrentar novos desafios colocados pela legislação. Julgamos que as propostas de descentralização e hierarquização, discutidas tanto pelos setores de esquerda, quanto de direita, a partir de ideologias diversas, que foram respaldadas na Constituição de 1988, podem ter contribuído na incorporação do discurso da intersetorialidade, das redes e, finalmente, da governança. Esta hipótese não inclui uma critica ao processo, mesmo porque neste estudo busca-se discutir a adaptação desses discursos a partir das realidades e dos interesses dos niveis locais.

No municipio de Bauru, quando se tenta classificar a experiência como governança, a partir das proposições de Rhodes (1996), o conceito mais adequado, a nosso ver, é o de coordenação, controle e avaliação, com intervenção de esforços para envolver todos os atores, incluindo a gerência de redes. Teve um gerente do processo que, apesar de possuir capacidade de mando no setor saúde, assumiu a liderança por consenso e adotou a negociação como política de trabalho. Como conclui Alcântara (1998), para os paises da América Latina, há que se mudar a direção das propostas oriundas das agências financiadoras, aproveitando os avanços, mas tornando-as exeqüiveis.

Tanto a população quanto a Câmara dos Vereadores chegaram a se colocar contra os encaminhamentos em pauta em suas manifestações públicas. Por outro lado, o setor saúde, diante dos primeiros resultados das avaliações das crianças aventou a hipótese de retirada da população do local, tendo em conta as incertezas do conhecimento quanto aos danos ao desenvolvimento neuropsicomotor. Estes 
fatos colocaram tanto o gestor regional quanto o grupo de suporte técnico frente ao problema da complexidade e do dilema da decisão ética e política.

Do ponto de vista intersetorial, todas as instituições cumpriram suas funções legais, mas não sem embate técnico. Entre os setores envolvidos as propostas e interesses eram diversos

O grupo de suporte técnico buscava, além da difusão de conhecimentos e informações, a construção de uma proposta "perfeita" que não foi possível atender em sua integra no nível local. Entre os técnicos de nível regional e local, por sua vez, havia disputa de liderança quanto às formas de encaminhamento e às diretrizes, apesar dessas discordâncias do nível local não transparecerem no grupo de suporte técnico. Diante da falta de consenso entre os profissionais houve momentos em que os gestores regional e local tiveram que ditar as regras. Entre a DOMA e o nivel regional o processo foi de troca de experiências e informações constantes. O CVS, apesar de não questionar nem trazer demandas para o grupo de suporte técnico, encaminhava isoladamente ações diretas com o nível local. Para garantir a continuidade da assistência e não da pesquisa como carro-chefe na investigação dos efeitos na saúde das crianças, foi necessária a mudança do local onde o atendimento vinha sendo realizado, tendo-se então constituído um grupo de assistência que incorpora a pesquisa. Ou seja, internamente ao setor saúde os consensos foram sendo reorganizados, tendo como pano de fundo as disputas, próprias de um processo de descentralização ainda incipiente. A presença de um gestor político do processo foi fundamental para negociar as diferenças e 
identificar as melhores saidas, muitas vezes tendo que tomar decisões respaldadas na maioria ou na autoridade conferida.

$\mathrm{Na}$ questão da intersetorialidade, o primeiro obstáculo a ser enfrentado foi a demora da comunicação da CETESB ao setor saúde das análises efetuadas na atmosfera. Estas foram concluídas em agosto de 2001 e só em fevereiro de 2002, quando a empresa foi fechada, o oficio foi encaminhado. Várias hipóteses podem ser levantadas a este respeito, desde os trâmites burocráticos do órgão ambiental; a falta de compreensão da gravidade da situação; o entendimento da importância do setor saúde nestas avaliações até a precariedade dos canais formais de comunicação.

No grupo de suporte técnico, o maior embate se deu entre o setor saúde e o ambiental. As primeiras avaliações do solo apontavam para a ausência de contaminação. A polarização foi a partir de dois pontos de vista: a avaliação ambiental para remediação ou para o diagnóstico de exposição. A saúde tinha como trunfo as análises de plumbemia das crianças que continuavam elevadas mesmo com a empresa fechada. Durante as discussões e reavaliações, ambos os setores adquiriram conhecimento. A saúde quanto a reconhecer seu papel fundamental nestes estudos, apontando a necessidade de mudança de concepção na avaliação ambiental e realizando um diagnóstico mais refinado dos riscos de contaminação. O setor ambiental reconhecendo que, para o estudo da exposição humana, faz-se necessário utilizar métodos diferenciados na avaliação do meio. Na prática, possivelmente a pluma de contaminação do chumbo no ambiente foi construída a partir das análises do metal no sangue das crianças, ao contrário das 
práticas de análise em paises desenvolvidos, onde se preconiza uma avaliação ambiental levando em conta as rotas de exposição em humanos para a partir daí recomendar pesquisas de exposição e saúde (ATSDR, 1999; EPA, 1998). Os novos pareceres da CETESB recomendam levantamento de dados do solo a partir de camadas mais superficiais ( 0 a $2 \mathrm{~cm}$ ou $0.0 \mathrm{~cm}$, o que corresponde a poeira) (CETESB, 2002b; CETESB, 2004). A construção desse novo conhecimento só foi possivel a partir da constatação da incompatibilidade entre eles e do abandono da rigidez disciplinar, como recomendam Walgenbach et al. (2000).

O relacionamento com a empresa foi mais conflituoso. Os contatos com a indústria foram apenas nos níveis regional e local, tendo o grupo de suporte técnico como assessoria dos setores públicos. Apesar da manutenção de reuniões periódicas com a DIR X e garantia da informação, a indústria utilizou várias estratégias para voltar a funcionar e questionar parâmetros que a colocassem como ré no processo do Ministério Público.

Como uma das dificuldades para o exercicio da governança, Jessop (1998) refere as caracteristicas da economia de mercado, que é racional, formal em sua natureza. Prioriza a continuidade poupando custos e perseguindo a maximização do lucro.

Em Bauru, a empresa partiu inicialmente de argumentos técnicos, questionando o valor de chumbo no sangue estabelecido pelo grupo de suporte técnico como de referência para ação em crianças. Colocava que a legislação brasileira estabelece como parâmetro valores bem superiores. No embate colocou-se que os valores brasileiros são estabelecidos para adultos. O grupo de 
suporte técnico argumentou que os níveis adotados partiam de regulamentações internacionais de proteção da saúde, uma vez que não existem estudos no Brasil indicando quais são os nossos padrões em populações não expostas. Estes argumentos tiveram apoio do poder judiciário.

Vencida esta etapa, a empresa partiu para a mobilização da população a partir dos trabalhadores e foi superada com as entrevistas constantes do gestor regional com os setores da sociedade através da imprensa, que segundo Tomita et al. (2004) teve papel importante na comunicação do problema. Também ocorreu a participação da Câmara de Vereadores, mesmo que inicialmente questionando o processo, e do grupo de discussão do município com a comunidade local.

As estratégias da empresa continuaram no sentido de buscar apoio nos políticos locais e entrar com recurso na Secretaria do Meio Ambiente explorando caminhos que permitissem sua volta ao funcionamento, mesmo sem cumprir todas as recomendações de proteção ambiental editadas pela CETESB. Nestes casos foi necessário não só o argumento científico, mas o uso do poder legal do gestor regional contido no Código Sanitário, caracterizando uma ação de Governo.

Com o poder judiciário a relação dos diversos gestores foi estritamente técnica, mantendo fluxos de informações constante, tendo sido fundamental na etapa de remediação da área habitada. O conhecimento construído permitiu a tomada de decisão do Ministério Público em responsabilizar o município pelo gerenciamento da remediação da área às custas da empresa mesmo antes da 
finalização do processo e estabelecimento da "culpa". A empresa, então, não recorreu mais da decisão.

Embora a relação dos setores saúde e ambiente com o Ministério Público tenha sido de pares, com a empresa não o foi. Diante disso, vale ressaltar dois aspectos que fogem às propostas de governança quanto a decisões consensuais. $\mathrm{O}$ primeiro foi a necessidade do uso do poder do Estado para manter a empresa fechada e, o segundo, a necessidade de um poder judiciário forte e independente para apoiar e tomar decisões. A existência de um gestor político foi fundamental para garantir o cumprimento das etapas do processo. Este construiu uma relação de confiança entre os pares, indispensável quando se trata do gerenciamento de situações complexas.

Particularmente no gerenciamento de áreas contaminadas o custo empresarial é alto. Dificilmente a empresa vai aceitá-lo sem recorrer ao aparato legal ainda existente para postergar ou proteger-se dos danos financeiros. Estes abrangem a suspensão das atividades, o diagnóstico da situação, o ressarcimento dos acometidos chegando até à remediação da área. Não é muito provável que a indústria seja uma parceira espontânea nestes casos. Por outro lado, a inexperiência na gestão dos negócios intersetoriais e a insipiência da prática da democracia exige que se disponha de liderança política interna ao setor público, democrática e confiável, que às vezes tenha que tomar decisões quando o consenso não ocorre, dentro dos principios da lei. Estes aspectos diferenciais talvez sejam uma constante nas propostas de governança em sítios contaminados no Estado de São Paulo. 
$\mathrm{Na}$ medida em que a Constituição garante aos níveis locais o poder legal para administrar e resolver problemas relacionados às áreas contaminadas restritos ao seu território, este nível deve ser o gestor político do processo. A articulação e busca de consenso são fundamentais. Não deve, no entanto, abandonar o poder que lhe confere a lei nem o aparato jurídico de que pode dispor. Os técnicos dos níveis centrais e regionais do sistema dariam apenas apoio e sugestão normativa. Isto não exclui o papel das estruturas estaduais e centrais de arquitetar políticas e buscar articulações para o enfrentamento do problema da contaminação química ambiental no Brasil.

Do ponto de vista das politicas públicas nacionais para as substâncias químicas, Freitas et al. (2002), frente ao mandato brasileiro de presidir o Fórum Intergovernamental sobre Segurança Química - FISQ, defendem a necessidade do desenvolvimento de métodos transparentes, participativos, democráticos e integrados como desafio a ser enfrentado. Partindo das recomendações da Comissão sobre Governança Global de que a segurança química é uma questão de governança, cujos pré-requisitos mínimos são a democracia, a segurança e a eqüidade, discute que no Brasil o embate é maior devido à insipiência da resolução destas questões. Nos países em industrialização a vulnerabilidade populacional e institucional é problema fundamental enquanto que do ponto de vista das substâncias químicas, questões como a complexidade e incerteza estão em jogo, requerendo do Governo maior capacidade de articulação com a academia e a população. 
Ainda segundo Freitas et al. (2002) na prática brasileira a gestão da segurança química vem sendo discutida de forma fragmentada e desintegrada, com as instituições de saúde e ambiente esvaziadas de recursos humanos e financeiros. Corremos o risco do preenchimento desse espaço pelas políticas auto-regulatórias, substituindo a carência de políticas governamentais. Os autores propõem ampliar a colaboração entre os governos e setores como: indústrias, sindicatos, consumidores, organizações não governamentais, corporações profissionais e instituições cientificas, transferindo o problema da área da governabilidade para a da governança.

Os niveis gestores, apesar de buscar o consenso, não devem esquecer o que coloca Ranciére (1999) de que este não é mais que a supressão da política. Os sonhos persistem e o litígio não desaparece sem remanescência. $O$ consenso está sempre ameaçado de desaparecer e uma das formas de enfrentar o dissenso é a gestão dos interesses dos grupos sociais gerando uma outra razão, que também não será permanente. Em geral quando uma população constata estar vivendo em uma área contaminada entra em pânico e requer dos governantes soluções imediatas, nem sempre exeqüiveis. Por outro lado, em nosso meio, os residentes da área não aceitam creditar ao contaminador a tarefa de realizar o diagnóstico de exposição e saúde. Cabe ao Estado, enquanto atribuição definida no Sistema Único de Saúde, criar estrutura e assumir os cuidados buscando formas de ressarcimento. 


\section{4 - A avaliação das crianças}

Foi realizado estudo de corte transversal para avaliar a exposição, investigar fatores de risco associados ao aumento de plumbemias e orientar medidas de remediação e controle. Os fatores de risco identificados como associados aos níveis de plumbemia foram: residir em área não asfaltada, genitor trabalhar na empresa, distância da fonte, brincar na terra, comer terra, consumo de leite local, ter mais de duas crianças no domicílio e idade (relação negativa). Do total de crianças avaliadas $36,6 \%$ apresentaram chumbo no sangue igual ou superior a $10 \mu \mathrm{g} / \mathrm{dL}$.

No estudo foram utilizadas duas abordagens básicas. Análise univariada a partir de comparação de médias e regressão logística univariada dos diversos fatores de risco. A segunda abordagem foi regressão logística múltipla. Vale ressaltar que tanto na regressão univariada quanto na múltipla faz-se a estimativa do risco a partir da OR. Esta não é a melhor ferramenta para estudos de prevalência, onde a freqüência do evento em estudo é elevada. As estimativas de risco a partir da OR são indicadas para eventos raros (Hennekens e Buring, 1997), o que não é o caso neste trabalho. Espera-se no entanto que, devido ao tamanho da amostra e à força da associação, as estimativas de risco não teriam variações significativas em qualquer dos métodos.

Os niveis médios de chumbo no sangue encontrados neste estudo (mediana $7,3 \mu \mathrm{g} / \mathrm{dL}$ ) para toda a população exposta foram inferiores a estudos realizados no Brasil em outras áreas contaminadas. Silvany-Neto et al., 1989, em crianças residentes próximo a uma fundição de chumbo no Estado da Bahia, encontraram 
concentrações médias do metal no sangue de $1,77 \pm 1 \mu \mathrm{mol} / \mathrm{L},(36,7 \pm$ $20,7 \mu \mathrm{g} / \mathrm{dL}$ ). Nesta área as concentrações de chumbo no solo chegavam a 10.000ppm. Estudo realizado por Santos-Filho et al. (1993) em área industrializada no município de Cubatão, Estado de São Paulo, constataram níveis médios de plumbemia em crianças de 4 a 10 anos de $17,8 \mu \mathrm{g} / \mathrm{dL}$. Em estudo de Paoliello et al. (2002) na região do Alto Vale do Ribeira, Estado de São Paulo, a mediana de chumbo no sangue da amostra residente próximo a uma fundição foi de $11,2 \mu \mathrm{g} / \mathrm{dL}$. Das 94 crianças estudadas, $56(59,6 \%)$ apresentaram níveis de $\mathrm{PbS}$ superiores a $10 \mu \mathrm{g} / \mathrm{dL}$ e destas $12(12,8 \%$ do total), superiores a $20 \mu \mathrm{g} / \mathrm{dL}$. Não dispomos de dados ambientais dos trabalhos citados, mas julgamos que a contaminação seja menor em Bauru.

No Brasil não contamos com valores de referência para chumbo no sangue em crianças. Supõe-se que em São Paulo, onde desde 1979 não se usa mais chumbo na gasolina, estes niveis sejam similares aos encontrados nos paises com esta condição. Com efeito, a mediana de plumbemia no grupo-controle foi menor que o limite de quantificação do método $(5 \mu \mathrm{g} / \mathrm{dL})$. A mediana de $\mathrm{PbS}$ em crianças de 1 a 5 anos encontradas no NHANES (1999-2000) foi de 2,2 $\mu \mathrm{g} / \mathrm{dL}$ e entre aquelas de 6 a 11 anos, $1,30 \mu \mathrm{g} / \mathrm{dL}$. De acordo com os dados do III NHANES, a proporção de menores americanos de 1 a 5 anos com níveis de chumbo no sangue iguais ou superiores a $10 \mu \mathrm{g} / \mathrm{dL}$ foi de $4,4 \%$. Dentre as crianças de 1 a 2 anos esta proporção foi de 5,9\% (Pediatrics, 1998), bem inferiores ao observado no presente trabalho (respectivamente $45,3 \%$ e $45,1 \%$ ). 
Optou-se, na discussão deste estudo, por analisar algumas das variáveis ligadas à pessoa e posteriormente explorar as possiveis rotas de exposição.

Em Bauru não foi encontrada diferença significativa entre sexo e médias de plumbemia para o total de crianças como visto por Franco (1975) e Albalak et al. (2003). Quando separadas segundo faixa etária, as médias daquelas entre 6 e 12 anos foram maiores para o sexo masculino, o que deve estar relacionado ao comportamento diferenciado neste grupo (Roels et al., 1980; Leroyer et al., 1993; Terpka, 1997; Gutiérrez et al., 1999; Baghust et al., 1999). Nos estudos brasileiros, Silvany-Neto et al. (1996) encontraram maiores niveis de zincoprotoporfirina em meninas (1 a 5 anos) e Paoliello et al. (2002), maiores plumbemias em meninos ( 7 a 14 anos).

Quando se avaliou a idade enquanto variável continua, as plumbemias foram menores nas crianças de maior idade (na verdade há uma relação em forma de $\mathrm{U}$ invertido). A discriminação em grupos mostra que os menores de 1 ano tiveram $\mathrm{PbS}$ mais baixas (mediana abaixo do limite de detecção do método); nas crianças de 1 a 2 anos a mediana foi de $8,4 \mu \mathrm{g} / \mathrm{dL}$; entre 3 e 4 anos $9,3 \mu \mathrm{g} / \mathrm{dL}$, decrescendo a partir dai.

As análises efetuadas em áreas contaminadas em geral excluem os menores de 1 ano. Para ter um parâmetro de comparação, levantamos estudos de coortes que avaliam a evolução da plumbemia com a idade. Rothenberg et al. (1993) acompanharam coorte de crianças desde o nascimento até 30 meses na cidade do México, mostrando que os níveis do metal aumentam a partir do parto até os 24 meses e depois decaem lentamente. Em Port Pirie, Baghust et al. (1999) 
seguiram a população também desde o nascimento até os 13 anos. Segundo seus achados, as plumbemias aumentam a partir dos 6 meses, chegando ao máximo aos dois anos, tendendo então ao declínio. Aos 13 anos os menores apresentam $\mathrm{PbS}$ similares ao nascimento. Estes estudos mostram que os níveis de chumbo no sangue têm um comportamento peculiar e acompanham os hábitos próprios das fases de crescimento. Embora não seja possivel fazer comparações diretas devido ao tipo de desenho utilizado em Bauru, há alguma semelhança entre os achados, embora os niveis mais elevados encontrados neste estudo estejam entre as crianças de 3 a 4 anos, provavelmente devido às características do lugar, com área não asfaltada e clima propício a atividades ao ar livre, com fonte extema de exposição.

As variáveis que poderiam estar relacionadas com renda foram significativas neste estudo, indicando que este fator, apesar de não ter sido pesquisado, pode ter influenciado os resultados. No Brasil há diferenciais de condições sócio-econômicas segundo a cor, tendo a raça negra os piores indicadores de saúde (Batista et al., 2004) em várias regiões; salários mais baixos e maiores taxas de desemprego (DIEESE, 2004). O número de pessoas na residência por si só não indica níveis de renda familiar e sim a relação entre esta e o número de moradores em conjunto com diversos outros parâmetros (PCV, 1994). Estudos mais recentes têm colocado algumas questões fazendo supor que o número de pessoas no domicilio pode se relacionar com renda. No Relatório da Situação de Trabalho no Brasil (DIEESE, 2001), encontra-se que as famílias de menor renda tendem a ter maior número de filhos e maior número de pessoas na 
residência. Outros autores argumentam que as estratégias das familias de incluir no mercado de trabalho as mulheres e filhos para aumentar o poder aquisitivo vêm se esgotando devido aos baixos salários e o desemprego (Carvalho, 2002; Carvalho e Almeida, 2003).

Em todo o grupo avaliado em Bauru, os não brancos tiveram níveis de chumbo no sangue mais elevados. Resultados similares foram encontrados em outros estudos brasileiros (Carvalho et al., 1985; Silvany-Neto et al., 1996). Nos Estados Unidos, observa-se que os afro-americanos são a população de maior risco e também a parcela mais carente (Pediatrics, 1998). Em nosso estudo, apresentaram plumbemias mais elevadas as familias com mais de dois filhos. Em região onde a pobreza predomina supomos que estes indicadores estejam refletindo níveis de renda. Elhelu et al. (1995) encontraram solos mais contaminados em áreas de maior pobreza.

Uma outra variável que também pareceu estar refletindo diferenciais de poder aquisitivo foi a presença de brinquedos importados na residência, mesmo comprados em camelôs. Não era comum as crianças terem brinquedos. Todas estas variáveis estão relacionadas entre si na regressão logística.

Apesar de apenas a contaminação aérea por chumbo ser um importante fator de risco para a população (Roels et al., 1980; Romieu et al., 1995; Raghunath et al., 1999), é mais citada na literatura a contribuição do solo que, uma vez não remediado, persiste como fonte particularmente em crianças (Roels et al., 1980; Cook et al., 1993; Silvany-Neto et al., 1996; Trepka et al., 1997). Sem desprezar a contaminação aérea, a partir da qual os demais compartimentos 
foram afetados, os achados do presente trabalho, relacionando o contato direto com o solo superficial - como brincar na terra e comer terra - tanto nas análises univariadas quanto múltiplas encontram diversos similares na literatura (Wilson et al., 1986; Cook et al., 1993; Gulson et al., 1994; Silvany-Neto et al., 1996; Lanphear et al., 1996).

Outras formas de contato com o solo superficial foram investigadas. Morar em área não asfaltada, onde pode haver maior exposição à poeira apresentou-se como a variável preditora mais importante dos níveis de plumbemia. Cook et al. (1993) avaliam a pavimentação dos quintais como indicador indireto da contaminação em crianças e encontram relação positiva com niveis mais elevados de chumbo no sangue. A distância da fonte, também relacionada como fator preditivo independente nesta análise, é regularmente citada na literatura (Ordónez et al., 1976; Carvalho et al., 1985; Gulson et al., 1994; Trepka et al., 1997; Meyer et al., 1999; Leroyer et al., 2000; Paoliello et al., 2002; Albalak et al., 2003). Apesar do pequeno número de amostras, a poeira interna no domicílio deve ter sido fator importante, e no caso de Bauru foi originária predominantemente de fonte externa. A ocupação da área é recente e provavelmente não há uso de tintas à base de chumbo. Esta hipótese foi reforçada pelos baixos niveis do metal da poeira intradomiciliar na área de controle. Vários autores estudam a relação entre poeira contaminada na residência e niveis de $\mathrm{PbS}$, encontrando relação significativa tanto com concentrações elevadas quanto aquelas abaixo dos limites regulamentares (Ordónez et al., 1976; Lanphear et al., 1996 e 1998, 
estudiosos propõem estar atento a revisão das normas ${ }^{7}$. As variáveis que fizeram parte deste estudo e que podem estar relacionadas com a poeira intradomiciliar foram genitor trabalhar na empresa (significativa nas duas abordagens de análise), tempo de moradia e permanência na área, sendo a segunda significativa apenas na abordagem univariada. Tanto o tempo de moradia quanto o de permanência na casa não foram fatores de risco na análise múltipla.

Há muitos anos vem se encontrando relação entre o trabalho de familiares em fundidoras e niveis de chumbo em crianças. O mais dramático dos relatos foi feito por Knishkowy et al. (1986), em que houve um surto de intoxicação aguda, tendo oito crianças necessitado de quelação. Entre os estudos da literatura encontram-se tanto casos em que os trabalhadores levavam a roupa suja do trabalho para casa, quanto aqueles em que a empresa oferecia troca de uniforme e banho, como no caso de Bauru (Rice et al., 1978; Meyer et al., 1999; Roscoe et al., 1999; Leroyer et al., 2000; Paoliello et al., 2002).

Não se pesquisou o tempo de permanência na residência e, no caso de Bauru, o clima propicia atividades ao ar livre. Os autores que avaliaram este comportamento e os níveis de contaminação em crianças encontraram relação positiva (Ordónez et al., 1976; Cook et al., 1993; e Trepka et al., 1997). O tempo de moradia foi fator de risco para plumbemias elevadas nos estudos de Carvalho et al. (1985) na Bahia e Baghurst et al. (1999) em Port Pirie.

As variáveis pesquisadas que indiretamente estão relacionadas ao contato com o solo foram: uso de água de fonte alternativa; atividades de lazer em rios ou

\footnotetext{
- A EPA estabelece como niveis de risco valores de chumbo na poeira superiores a $40 \mu \mathrm{g} / \mathrm{ft}^{2}$ na poeira do assoalho: $250 \mu \mathrm{g} / \mathrm{ft}^{2}$ no peitoril de janelas e $400 \mathrm{ppm}$ em áreas de recreação (EPA. 2001).
} 
lagos; comer frutas ou verduras locais e tomar leite local. Dentre estas, apenas a última apresentou-se como fator de risco na análise univariada, mantendo-se na regressão múltipla. As avaliações ambientais mostraram que a água estava própria para consumo e recreação, exceto na área da empresa. Dos demais produtos para consumo humano, que apresentaram contaminação, destaca-se o leite de comércio local. Sendo o leite alimentação de base de crianças isso talvez explique a associação de seu consumo com plumbemias mais elevadas. Os autores que analisam o uso do leite animal e $\mathrm{PbS}$ não constatam este produto como fator de risco (Rothenberg et al., 1993; Paoliello et al., 2002). Quanto ao uso de água do sistema público, quatro estudos encontram relação positiva, todos em paises industrializados: Alemanha, França e Estados Unidos (Lanphear et al., 1996 e 1998b; Trepka et al., 1997; Leroyer et al., 2000). Dentre estes, apenas Lanphear et al. (1998b) não referem a existência de residências antigas e encontra relação entre $\mathrm{PbS}$ e água tendo esta os níveis recomendados nos Estados Unidos.

No caso Bauru as avaliações de solo da CETESB, mesmo com amostras de 0 a $2 \mathrm{~cm}$ não encontraram chumbo acima do limite de intervenção na área residencial. As análises dos domicilios fizeram sugerir que a contaminação era em niveis mais superficiais, na poeira, e que esta era a principal fonte de contaminação das crianças. Com efeito, na regressão logística múltipla predominam como fatores de risco aqueles ligados ao solo. Tomando-se como base o estudo-piloto, em que os niveis médios de plumbemia foram inferiores ao limite de quantificação do método, pode-se fazer um exercício de calcular o número de crianças expostas, tendo-se como pressuposto que o valor de 
referência populacional é inferior a $5 \mu \mathrm{g} / \mathrm{dL}$. Teremos então 588 crianças cujos níveis de $\mathrm{PbS}$ foram iguais ou superiores a este limite, o que sobejamente indica a necessidade de intervenção ambiental no sentido da remediação. Este exercício sofre de limitações, pois o grupo-controle não foi estimado com base em parâmetros estatísticos adequados para representar a população. No entanto outros elementos contribuem para a suspeita de que nossos valores de referência sejam baixos. No estudo de Paoliello et al. (2002), o grupo-controle apresentou plumbemia inferior a $5 \mu \mathrm{g} / \mathrm{dL}$ e no estudo-piloto efetuado em Jacarei/SP o grupo de referência teve valores abaixo do limite de quantificação do método de $2 \mu \mathrm{g} / \mathrm{dL}$ (Ushirobira et al., 2004).

Foram introduzidos na análise alguns questionamentos que na literatura se relacionam a níveis elevados de chumbo no sangue como uso de cerâmica vitrificada (Trepka et al., 1997; Gutiérrez et al., 1999; Rothenberg et al., 2000; Romieu et al., 2000); levar utensilios da empresa para casa (Silvany-Neto et al., 1996) e uso de zarcão, que é à base de chumbo. Todas estas variáveis não foram significativas no presente estudo.

\section{5 - As reavaliações das crianças}

$\mathrm{Na}$ primeira reavaliação, efetuada em média 75 dias após as análises de diagnóstico de situação, houve uma queda de niveis médios de chumbo no sangue em torno de $12 \%$. As medidas de controle tomadas se restringiram a orientações aos genitores e fechamento da indústria emissora. 
São raros os estudos de reavaliação de áreas contaminadas após medidas de controle. Silvany-Neto et al. (1996) realizaram o acompanhamento de zincoprotoporfirina - ZPP das crianças de Santo Amaro da Purificação, Estado da Bahia nos anos de 1985 e 1992 tendo como base uma avaliação preliminar em 1980. A partir de 1980 foram tomadas medidas de controle de emissão da indústria. A primeira reavaliação em 1985 constatou a redução dos níveis médios de ZPP e da prevalência dos valores mais elevados. No entanto, novas crianças apresentaram resultados acima dos limites seguros, o que acarretou ausência de redução na proporção de crianças com ZPP acima do limite estabelecido como seguro (92,2\% em 1980 e 98,4\% em 1995). Em 1992 esta última proporção se manteve $(97,0 \%)$. A fábrica foi fechada em 1993 e o passivo ambiental permanece até os dias atuais (Carvalho et al., 2003).

Avaliando os níveis de plumbemia de crianças residentes próximo a uma fundição de chumbo na Bélgica, de 1974 a 1978, onde foram tomadas medidas de controle para diminuir as emissões do metal, Roels et al. (1980) encontram uma redução de $14 \%$ nas médias de $\mathrm{PbS}$ após o primeiro ano. Apesar de ter havido diminuição dos niveis de $\mathrm{Pb}$ na atmosfera de $3,8 \mu \mathrm{g} / \mathrm{m} 3$ em 1974 para $2,3 \mu \mathrm{g} / \mathrm{m} 3$ em 1978 as análises posteriores mostraram não haver queda significativa nos níveis médios de chumbo nos anos seguintes. Todos os autores argumentam que medidas isoladas de redução das emissões, sem outras intervenções ambientais e nos demais fatores relacionados ao aumento de plumbemias, são ineficazes. No raio de $1 \mathrm{~km}$ da empresa, em Santo Amaro da Purificação no ano de 1998, foram encontradas 52 crianças de 1 a 4 anos, todas nascidas no local após o fechamento 
da indústria. Destas, 47 foram examinadas tendo apresentado níveis médios de $\mathrm{PbS}$ de $17,1 \mu \mathrm{g} / \mathrm{dL}$ (Carvalho et al., 2003), indicando que o solo continua sendo fonte de contaminação.

Em Bauru, após as medidas de remediação, houve uma redução de $46 \%$ nos níveis médios de chumbo, comparando o primeiro exame das crianças com plumbemias iguais ou superiores a $10 \mu \mathrm{g} / \mathrm{dL}$ com o último exame, em média 1,5 anos depois. Uma vez que não foi avaliado o total de crianças não dispomos da prevalência daquelas acima de $10 \mu \mathrm{g} / \mathrm{dL}$. Desconhece-se se houve aumento do $\mathrm{PbS}$ nos menores não avaliados que se encontravam com valores abaixo do limite de intervenção proposto pelo CDC e OMS.

A mediana do grupo que fez as duas avaliações (241 crianças), no primeiro exame foi de $15 \mu \mathrm{g} / \mathrm{dL}$. Após a remediação caiu para $8 \mu \mathrm{g} / \mathrm{dL}$, abaixo do limite estabelecido como de intervenção, apesar de ainda serem encontrados menores com níveis elevados de $\mathrm{PbS}$. No primeiro exame, das 311 crianças com niveis de chumbo no sangue superiores a $10 \mu \mathrm{g} / \mathrm{dL}, 51,8 \%$ encontravam-se entre 10 e $14 \mu \mathrm{g} / \mathrm{dL} ; 25,7 \%$ entre 15 e $19 \mu \mathrm{g} / \mathrm{dL} ; 21,5 \%$ entre 20 e $39 \mu \mathrm{g} / \mathrm{dL}$ e $1 \%$ entre $40 \mu \mathrm{g} / \mathrm{dL}$ e mais. Na segunda reavaliação, após controle, houve um deslocamento em todas as faixas: $20 \%$ entre 10 e $14 \mu \mathrm{g} / \mathrm{dL} ; 5,8 \%$ entre 15 e $19 \mu \mathrm{g} / \mathrm{dL}$ e $4,1 \%$ entre 20 e $39 \mu \mathrm{g} / \mathrm{dL}$. Não foram encontradas crianças entre $40 \mu \mathrm{g} / \mathrm{dL}$ e mais. Das 241 reavaliadas, $167(69,3 \%)$ encontravam-se com plumbemias abaixo de $10 \mu \mathrm{g} / \mathrm{dL}$. A queda de $46 \%$ nos níveis médios de plumbemia foi relativamente equivalente, avaliando todos os fatores de risco identificados na regressão logística múltipla. Apenas uma criança apresentou aumento dos níveis de $\mathrm{PbS}$. 
Dentre os fatores que poderiam estar confundindo a conclusão de que houve queda dos niveis de plumbemias, podem ser citadas as estações do ano e o envelhecimento das crianças. Apesar destes fatores não terem sido controlados, a coleta de sangue na primeira avaliação foi feita durante quase todo o ano de 2002 (fevereiro a novembro), incluindo todas as estações. A coleta de controle ocorreu entre os meses de setembro e novembro de 2003 , período de primavera, que em Bauru se caracteriza por clima quente. Quanto à idade, houve queda significativa em todas as faixas avaliadas, mesmo entre os menores de um ano, que estariam entrando na fase de maior exposição e aumentando os níveis sangüineos de chumbo. De qualquer forma, para as faixas de idade mais avançadas o envelhecimento deve ter influído, o que pode se presumir a partir das taxas menores de queda de $\mathrm{PbS}$ entre os menores de um ano.

O CDC, em 2002, realizou levantamento bibliográfico dos estudos que avaliam crianças após medidas de remediação ambiental de contaminação por chumbo e chegou a resultados controversos.

São citados oito autores que realizaram análises de plumbemia depois da limpeza da casa com aspiradores e de medidas de educação ambiental e alimentar aos familiares. Em alguns casos a limpeza foi efetuada por profissionais especializados e em outros, por pessoal treinado para este fim. Em apenas dois estudos houve redução significativa dos niveis de $\mathrm{PbS}$ das crianças (CDC, 2002). Vale salientar que a grande preocupação dos Estados Unidos com a poeira no interior das casas relaciona-se ao uso de tintas entre aquelas construidas em periodo anterior a 1950. Também em 2002, Haynes et al. conduziram metanálise 
de 4 estudos, entre os quais se incluíram residências afetadas por proximidade de fundição de chumbo. Os autores concluem que após a aspiração das residências há uma queda na plumbemia nas crianças com níveis mais elevados. Os argumentos levantados para o pouco sucesso da medida apontam para a necessidade de profissionais especializados para esta tarefa e a insistência junto aos genitores sobre os cuidados com as crianças. Argumenta-se também que as aspirações nos domicílios devem ser contínuas (cada 2 ou 3 semanas), pois os níveis de chumbo retornam aos valores anteriores em torno de três meses.

Deve-se levar em conta, nos estudos de reavaliação de plumbemias após remediação do solo em paises desenvolvidos, que há asfalto nas ruas e as medidas se restringem geralmente aos quintais das casas e parques, incluindo também a limpeza do interior das residências. Estes estudos comparam áreas onde foram tomadas medidas de controle com outras onde não houve intervenção.

Avaliando a intervenção em áreas urbanas envolvendo medidas relativas ao solo, à poeira e tinta das casas, temos as experiências de sítios contaminados em Boston, Midvale e Vale da Prata em Idaho (Weitzman et al., 1993; Lanphear et al., 2003; Lindern et al., 2003).

Em Boston, Weitzman et al. (1993) analisam 152 menores em área urbana industrializada contaminada por diversas fontes. Os niveis médios de chumbo no solo eram de 2075ppm. Foram incluídas no estudo crianças de 6 meses a 5 anos, com plumbemias entre 10 e $20 \mu \mathrm{g} / \mathrm{dL}$, constituindo 3 grupos. No primeiro foram feitas remediação do solo, poeira e tinta das casas; no segundo, poeira e tinta; e no terceiro apenas a tinta das residências. Onze meses após houve queda de 
$2,44 \mu \mathrm{g} / \mathrm{dL}$ na média de plumbemia do primeiro grupo $(\mathrm{p}<0,05) ; 0,91 \mu \mathrm{g} / \mathrm{dL}$ no segundo grupo $(\mathrm{p}<0,05)$ e $0,52 \mu \mathrm{g} / \mathrm{dL}$ no terceiro grupo (não significativo). Os autores concluem que a queda, apesar de significativa, é de pouca monta e argumentam que a remediação do solo apenas em torno das casas não impede a migração do chumbo das vizinhanças. Um ano depois, Aschengrau et al. (1994) reavaliam as crianças e apesar de concluir que o impacto foi maior que o estimado anteriormente, questionam o custo-benefício das medidas. O CDC (2002), após análise dos estudos de remediação do solo coloca que, para a contaminação humana, são medidas suficientes aquelas que impedem o contato direto com o chumbo como cobri-lo com areia ou terra limpa, ou ainda plantar grama. Clark et al. (2004), avaliando a carga de chumbo nos diversos ambientes, como: interior da casa, entrada da casa e ruas, encontram níveis maiores no primeiro e em ordem decrescente nos demais. Sugerem que há intercâmbio do metal de um espaço para outro e concluem que a mitigação das fontes exteriores deve ser considerada.

Em 2003, Lanphear et al. publicam dois estudos de corte transversal em Midvale comparando plumbemias de crianças de 6 a 72 meses antes e após as medidas de controle tomadas em área contaminada por fundidora de chumbo. A empresa encerrou as atividades em 1958 e foram tomadas medidas de remediação entre os anos de 1993 a 1996. O primeiro estudo foi realizado em 1989, quando a média de $\mathrm{PbS}$ entre os expostos era de 5,6 $\mathrm{g} / \mathrm{dL}(11 \% \geq 10 \mu \mathrm{g} / \mathrm{dL})$. No grupocontrole os níveis médios de chumbo no sangue eram de $3,9 \mu \mathrm{g} / \mathrm{dL}(2,6 \% \geq$ $10 \mu \mathrm{g} / \mathrm{dL}$ ). Em 1998 foi realizado o segundo estudo transversal, no qual as médias 
no grupo exposto foram de $3,0 \mu \mathrm{g} / \mathrm{dL}(1 \% \geq 10 \mu \mathrm{g} / \mathrm{dL})$ e no controle $2,6 \mu \mathrm{g} / \mathrm{dL}$ (nenhum com niveis maiores ou iguais a $10 \mu \mathrm{g} / \mathrm{dL}$ ). Controlando os possíveis fatores de confusão os autores concluem que a redução de $1000 \mathrm{ppm}$ no solo corresponde a um declínio de $3,5 \mu \mathrm{g} / \mathrm{dL}$ de chumbo no sangue nas crianças de 6 a 36 meses. Não foram encontradas diferenças quando considerado todo o grupo.

Estudo prospectivo seguiu 372 crianças pelo periodo de 14 anos (1988 a 2001) no Vale da Prata (Lindern et al., 2003). A empresa contaminadora teve suas atividades encerradas em 1981, quando os níveis médios de chumbo nos menores era de $40 \mu \mathrm{g} / \mathrm{dL}$. A partir de 1985 foram iniciadas as medidas de remediação internas à fábrica e implementadas para as vilas próximas em 1989 . Em 1989 os niveis de chumbo nos quintais das casas eram de $2069 \mathrm{mg} / \mathrm{kg}$ e, em 1990 , de $581 \mathrm{mg} / \mathrm{kg}$. Antes desta remediação $56 \%$ das crianças apresentavam plumbemias maiores ou iguais a $10 \mu \mathrm{g} / \mathrm{dL}$. Em 1990 apenas $29 \%$ encontravam-se nesta condição. As medidas de controle foram diversas, com abrangência para toda a área das cinco comunidades, e concluidas em 1998. No ano de 2001, apenas $3 \%$ dos menores apresentaram plumbemias $\geq 10 \mu \mathrm{g} / \mathrm{dL}$, com média de chumbo no sangue no grupo, menor que $4 \mu \mathrm{g} / \mathrm{dL}$.

A partir dos dados da literatura pode-se supor que quando se investe em todas as possiveis fontes de contaminação os resultados são promissores, embora os custos sejam elevados.

Em Bauru ainda há um longo caminho a seguir. Diversas crianças se encontram ainda com plumbemias superiores ou iguais a $10 \mu \mathrm{g} / \mathrm{dL}$ e necessitam reavaliação das fontes de contaminação ambiental. O método adotado para 
investigação do solo, de forma emergencial na área, a partir dos dados de exposição humana, não permite uma visualização adequada da contaminação do meio. Sabedora disto, a CETESB exigiu da empresa um estudo amplo e em todos os compartimentos ambientais. Esta nova análise e as avaliações das crianças serão as bases para a reorientação das medidas de controle.

O diagnóstico de exposição mostrou haver 311 crianças com plumbemias acima do limite de intervenção proposto pelo CDC e um total de 588 com niveis de chumbo no sangue acima da média do grupo-controle, tomado como referência. Os encaminhamentos efetuados até o momento apontam para um trabalho longo, mas promissor, uma vez que todas as instituições estão desenvolvendo as atividades de forma articulada, buscando as soluções mais adaptadas para cada momento e realidade.

A experiência de gerenciamento em Bauru não pode ser classificada como a forma mais avançada de governança que se constitui no "gerenciamento de redes", apesar de ter sido caracterizada pela intersetorialidade, com redes alocadas hierarquicamente sem poder de mando entre os niveis dos sistemas. No município estas redes foram dirigidas pelo gestor regional que, embora buscasse $o$ consenso, quando este não foi possível, usou o poder legal a ele conferido. Neste caso, também foram usados instrumentos de "governo" como define Stoker (1998). Talvez este possa ser o nosso método: ações intersetoriais com um misto do ideário de redes e governança, tendo gestor que seja líder reconhecido com mesmo nível hierárquico de seus pares. Que seja do setor público, portanto 
investido de poder, mas tenha uma postura democrática e agregadora, negociando e respeitando as competências de cada instância envolvida.

Bauru é apenas um caso entre as 727 áreas contaminadas do Estado de São Paulo. Estas carecem de uma politica de abordagem integradora. Claro está que não é uma solução operacional criar grupos de suporte técnico para cada uma destas áreas. Deve-se buscar priorizar e categorizar problemas similares. Do total de 727 áreas contaminadas, $464(63,8 \%)$ são postos de combustíveis, que do ponto de vista da saúde, teriam o mesmo método de investigação. Por outro lado, os dados disponiveis na internet sobre estas áreas não permitem classificá-las de modo adequado. Não há padronização quanto aos nomes das substâncias envolvidas em cada processo. A partir deles buscou-se identificar as demais áreas do Estado de São Paulo onde o chumbo é o contaminante. Foram encontradas 21 citações desta substância. No entanto, em 32 casos a palavra "metal" é citada sem outras especificações.

Em junho de 2002 foi publicada Resolução Conjunta $n^{\circ} 01$ das Secretarias de Saúde e Meio Ambiente definindo procedimentos para ação conjunta no tocante às áreas contaminadas por substâncias perigosas. O CVS foi definido como representante do setor saúde para, em conjunto com a CETESB, definir procedimentos e rotinas, comuns e especificas de cada Secretaria, levando em conta as questões ambientais, sanitárias e epidemiológicas. A partir dai, o CVS recebe os relatórios completos das áreas contaminadas. Até o momento não há qualquer integração entre as instâncias da Secretaria de Saúde para proposição de políticas comuns. O CVE tem em avaliação aproximadamente 32 áreas 
contaminadas e o CVS possui outros sítios em seu acervo. Estes, ora estão em andamento quanto à investigação, ora em completo esquecimento. A maioria das vezes, as áreas são coincidentes entre CVE e CVS, o que se constata quando os niveis locais do sistema de saúde solicitam orientação técnica e propõem discussão conjunta. Em boa parte dos casos as gerências não são definidas e o problema se arrasta por anos a fio. Com a instituição de nova direção no CVS, ocorreu em 28/09/2004 uma primeira reunião conjunta entre CVE e CVS para discussão de integração das atividades. Nesta reunião, foram elencados como prioritários os temas agrotóxicos e áreas contaminadas para discussão em reuniões posteriores. Esperamos que diante destes novos encaminhamentos o “caso" Bauru não seja único. 


\section{6- CONCLUSÕES}

6.1 - A dinâmica das instituições envolvidas não pode ser classificada como um modelo puro de intersetorialidade, redes ou governança na medida em que envolveu estas diversas formas de articulação, inclusive com características de "governo", apontando para a necessidade de inaugurar formas de gerenciamento adaptadas à nossa realidade.

6.2 - As instituições envolvidas cumpriram com seu papel legalmente estabelecido e todas contribuíram para a efetivação do trabalho.

6.3 - As redes estabelecidas no nível central e das universidades locais mantiveram independência quanto ao encaminhamento das propostas, mantendo o eixo comum que se constituía em reduzir a exposição a chumbo no entorno da empresa e avaliar os danos à saúde das crianças.

6.4 - Para o andamento das propostas emanadas dos diversos grupos $\mathrm{e}$ instituições foi indispensável a existência de um gestor político do processo, que embora tenha exercido o gerenciamento enquanto governança na maior parte do trabalho, assumiu em alguns momentos a postura de Governo.

6.5 - As atividades de vigilância desenvolvidas em sítio contaminado em Bauru diagnosticaram uma situação grave, com $36,6 \%$ das crianças com níveis de chumbo no sangue acima do limite de intervenção proposto pelos organismos internacionais e requerendo ações no sentido de remediar a área para minimizar a exposição.

6.6 - As ações integradas dos setores saúde e ambiente no caso tiveram impacto nos niveis de contaminação das crianças, obtendo-se redução de $46 \%$ dos niveis 
médios de chumbo no sangue entre aquelas que apresentavam maior risco de efeitos na saúde.

6.7 - O caso da contaminação em Bauru ainda tem um longo caminho a trilhar uma vez que ainda há um contigente expressivo de crianças com níveis de chumbo acima dos valores de intervenção e a área agrícola não foi remediada tendo impacto nos niveis de plumbemia dos residentes.

6.8 - No setor saúde, para o gerenciamento das áreas contaminadas, faz-se necessária a integração de suas instâncias internas, tendo o nível central do sistema papel fundamental nesta articulação.

6.9 - Para que a experiência de Bauru não se torne "única" no Estado de São Paulo, concluimos com as palavras do gestor regional quando inquirido sobre esta possibilidade: "Não acho que se trata de uma questão pessoal... No caso do chumbo em Bauru houve delegação completa por parte do nível central para todas as articulações possiveis. Não é o que sinto em algumas outras áreas. A própria Secretaria precisa assumir que existem atores nos diversos niveis. Ter clareza das instâncias, de suas responsabilidades e saber delegar. Faz-se necessário investir no conhecimento técnico e gerencial para o enfrentamento de problemas como este. O Estado precisa começar a pensar estrategicamente e investir em pessoas agregadoras que possam assessorar quem está na linha de frente". 


\section{7 - BIBLIOGRAFIA}

[AAP] - AMERICAN ACADEMY OF PEDIATRICS, Committee on Environmental Health. Screening for elevated blood lead levels. Pediatrics 1998; 101(6): 1072-1078. Disponível em: http://www.aap.org/polict/re9815.html. Acesso em 10/04/2003.

AGUJARO, LF; BUENO, RMFM; ABRAHÃO, CEC. Intersetorialidade e saúde ambiental: a experiência dos comitês das bacias hidrográficas dos rios Piracicaba, Capivari e Jundiai (CBH-PCJ e PCJ Federal, Brasil. Anais. I Congresso Interamericano de Saúde Ambiental. Porto Alegre/RS, Brasil. 27 a 29 de abril de 2004.

ALBALAK, R.; McELROY, R.H.; NOONAN, G.; BUCHANAN, S.; JONES, R.L.; FLANDRES, W.D. et al. Blood lead levels and risk factors for lead poisoning among children in mexican smelting community. Arch. Environ Health, 2003; 58(3):172-183.

ALBALAK, R; NOOMAN, G; BUCHANAN, S; FLANDERS, WD; GOTWAYCRAWFORD, C; KIM, D; JONES, RL et al. Blood lead levels and risk factors for lead poisoning among children in Jakarta, Indonésia. Sci Total Environ, 2003; 301: 75-85.

ALCÁNTARA, CH. Uses and abuses of the concept of governance. International Social Science Journal 1998; 50(155): 105-113.

ALONSO, CD; ROMANO, J; BARBOSA FILHO, $\mathrm{H}$. Teores de chumbo nas atmosferas urbanas da região da grande São Paulo. IN $13^{\circ} \mathrm{CONGRESSO}$ BRASILEIRO DE ENGENHARIA SANITÁRIA E AMBIENTAL. Maceió. Anais, agosto, 1985

AL-SALEH, I; DEVOL, E; TAYLOR, A.Distribution of blood lead levels in 1.047 Saudi Arabian children with respect to province, sex, and age. Arch Environ Health, 1994; 49(6): 471-476.

[Anonymus] Gasolina brasileira não tem chumbo (Da equipe de reportagem). Jornal do Brasil, Rio de Janeiro, 1997, fev. 22.

[AOAC] Association of official analitical chemist. Official methods of analysis of the association official analitical chemists. Internation, Gaithersburg, Maryland, $15^{\text {th }} \mathrm{ed}$, chapter 9 , p. 16, 1995

ARENDT, A. Da revolução. Editora Ática/UnB; 1990. A tradição revolucionária e seu tesouro perdido; p. 172-255. 
ASCHENGRAU, A; BEISER, A; BELLINGER, D; COPENHAFER, D; WEITZMAN, $M$. The impact of soil lead abatement on urban children's blood lead levels: phase II results from the Boston Lead-in-soil Demonstration Project. Environ Res 1994; 67: 125-148.

[ATSDR] AGENCY FOR TOXIC SUBSTANCES AND DESEASES REGISTRY. Toxicological profile for lead. Division of Toxicology/Toxicology Information Branch, 1999. Disponivel em: http://www. atsdr.cdc.gov. Acesso em 14/08/2003.

AUGUSTO, LGS. Saúde e vigilância ambiental: um tema em construção. Epidemiologia e Serviços de Saúde, 2003; 12(4): 177-187.

BAGHURST, PA; MCMICHAEL, AJ; WIGG, NR; VIMPANI, VG; ROBERTSON, EF; ROBERTS, RJ; et al. Environmental exposure to lead and children's inteligence at the age of seven years. The Port Pirie coort study. The New England Journal of Medicine, 1992; 327(18):1279-1284,.

BAGHURST, PA; TONG, S; SAWYER, MG; BURNS, J; MCMICHAEL, AJ. Sociodemographic and behavioural determinants of blood lead concentrations in children aged 11-13 years. The Port Pirie cohort study. MJA, 1999; 170: 63-67.

BALLEW, C; KHAN, LK; KAUFMANN, R; MOKDAD, A; MILLER, DT; GUNTER, EW. Blood lead concentration and children's anthropometric dimensions in the Third National Health and Nutrition Examination Survey (NHANES III), 1988-1994. J Pediatr, 1999; 134(5):623-630.

BATISTA, LE; ESCUDER, MM; FERREIRA, RV. Monitorando os indicadores de mortalidade: diferenças de raça/cor. [Abstract]. Revista Brasileira de Epidemiologia 2004, Número especial - CD-ROM. [Apresentado no VI Congresso Brasileiro de Epidemiologia; 2004, 19-23 jun; Recife (PE).

BERGEROW, J; FREIER, I; TURFELD, M; KRÃMER, U; DUNEMANN, L. Internal lead and cadmium exposure in 6-year-old children from western and eastern Germany. Int Arch Occup Environ Health, 1994; 66: 243-248.

BERGLUND, M; LIND, B; SORENSEN, S; VAHTER, M. Impact of and dust lead on children's blood lead in contaminated areas of Sweden. Arch of Environ Health, 2000; 55(2): 93-97.

BITTÓ, A; HORVATH, A; SÁRKÁMY, E. Monitoring of blood lead levels in Hungary. Cent Eur Jornal of Public Health, 1997; 5(2): 75-78.

BJERRE, B.; BERGLUND, M.; HARSBO, K.; HELLMAN, B. Blood lead concetrations of Swedish preschool children in a community with high lead levels from mine waste in soil and dust. Scand J Work Environ Health, 1993; 19:154-161. 
BONINI, EM. O Setor Saúde estadual nos comitês de bacias hidrográfucas do estado de São Paulo. Campinas, 2002. [Dissertação de Mestrado - Faculdade de Ciências Médicas da Universidade Estadual de Campinas].

BÖRZEL, TA. What's so special about policy networks? - In: Exploration of the concept and its usefulness in studying european governance. EioP, 1997; vol 1, $N^{\circ} 16$, $28 \mathrm{p}$.

BRASIL. Constituição da República Federativa do Brasil. São Paulo: IMESP; 1988.

BRASIL. Decretos Lei. Decreto Lei 1413 (14/08/1975). Dispõe sobre o controle da poluição do meio ambiente provocada por atividades industriais. Diário Oficial da União, Brasília, 14 de ago de 1975.

BRASIL. Leis. Lei 6938 (31/08/1981). Dispõe sobre a política nacional do meio ambiente, seus fins e mecanismos de formulação e aplicação, e dá outras providências.

Diário Oficial da União, Brasilia, 02 set. de 1981.

BRASIL. Leis. Lei 8080 (20/09/1990), dispõe para as condições para a promoção, proteção e recuperação da saúde, a organização e o funcionamento dos serviços correspondentes e dá outras providências. Diário Oficial da União, Brasília, 20 set. 1990.

BRASIL. Leis. Lei 9832 (14/09/1999). Proíbe o uso industrial de embalagens metálicas soldadas com liga de chumbo e estanho para o acondicionamento de gêneros alimentícios, exceto para produtos secos e desidratados. Diário Oficial da União, Brasília, 15 set. de 1999

BRASIL. Leis. Lei 10.203 (22/02/2001), dá nova redação aos arts. $9^{\circ}$ e $12^{\circ}$ da Lei 8723 de 28 de outubro de 1993, que dispõe sobre a redução de emissão de poluentes por veículos automotores e dá outras providências. Diário Oficial da União, Brasília, 23 fev. de 2001.

BRASIL. Decretos. Decreto 3450 (09/05/2000). Aprova o estatuto e o quadro demonstrativo dos cargos em comissão e das funções gratificadas da Fundação Nacional de Saúde - FUNASA, e dá outras providências. Diário Oficial da União, Brasilia, 10 de maio de 2000.

BRASIL. Portarias. Portaria 36 (19/01/1990) do Ministério da Saúde. Aprova normas e o padrão de potabilidade da água destinada ao consumo humano. Diário Oficial da União, Brasília, 23 jan. de 1990.

BRASIL. Portarias. Portaria 685 (27/08/1998) do Ministério da Saúde. Estabelece os niveis máximos de contaminantes químicos em alimentos. Diário Oficial da União, Brasília, 24 set. de 1998 
BRASIL. Portarias. Portaria 1.469 (29/12/2000) do Ministério da Saúde. Estabelece os procedimentos e responsabilidades relativos ao controle e vigilância da qualidade da água para consumo humano e seu padrão de potabilidade, e dá outras providências. Diário Oficial da União, Brasília, 29 dez. de 2000.

BRASIL. Portarias. Portaria ANP 309 (27/12/2001). Estabelece as especificações para a comercialização de gasolinas automotivas em todo o território nacional e define obrigações dos agentes econômicos sobre o controle de qualidade do produto. Diário Oficial da União, Brasília, 28 dez. de 2001.

BRASIL. Portarias. Portaria 518 (25/03/2004) do Ministério da Saúde. Estabelece os procedimentos e responsabilidades relativos ao controle e vigilância da qualidade da água para consumo humano e seu padrão de potabilidade, e dá outras providências. Diário Oficial da União, Brasília, 26 mar de 2004.

BRASIL. Resoluções. Resolução CONAMA 20 de 18/06/1986. Estabelece a classificação das águas e os níveis de qualidade exigidos. Diário Oficial da União, Brasilia, 30 jul. de 1986.

BRASIL. Resoluções. Resolução CONAMA, 257 de 30/06/1999. Dispõe sobre o destino de baterias que contenham em sua composição chumbo, cádmio, mercúrio e seus compostos. Diário Oficial da União, Brasília, 22 jul. de 1999.

BRASIL. Regulamentos. Regulamento Técnico ANP 5/2001. Aplica-se às gasolinas automotivas comercializadas em todo o território nacional e estabelece suas especificações. Diário Oficial da União, Brasilia, 28 dez. de 2001.

BRASIL. Instruções Normativas. Instrução Normativa ${ }^{\circ} 1$ do Ministério da Saúde (25/09/2001). Regulamenta a Portaria MS n ${ }^{\circ} 1399$ de 15/12/1999, no que se refere às competências da União, Estados e Distrito Federal na área de Vigilância Ambiental em Saúde.

BURNS, JM; BAGHURST, PA; SAWYER, MG; MCMICHAEL, AJ; TOG S. Lifetime low-level exposure to environmental lead and children's emotional and behavioral development at ages 11-13 years. The Port Pirie cohort study. Am J of Epidemiology, $1999 ; 149(8): 740-749$,

CÂMARA, VM; ALEXANDRE, P; SILVA, CANCIO, JA. Notas para a constituição de um programa de vigilância ambiental dos riscos e efeitos da exposição do mercúrio metálico em áreas de produção de ouro. Informe Epidemiológico do SUS, 1998; 7(2): $35-44$.

CARVALHO, FM; BARRETO, ML; SILVANY-NETO, AM; WALDRON, HÁ; TAVARES, TM. Multiple causes of anaemia amongst childres living near a lead smelter in Brazil. Sci Total Environ, 1984; 35: 71-84. 
CARVAlHO, IMM. Familia e pobreza. In: Pobreza e desigualdades sociais. Série Estudos e Pesquisas (SEI) 2002: 63 - Superintendência de Estudos Econômicos e Sociais da Bahia.

CARVAlHo, IMM e AlMEIDA, PH. Familia e proteção social. São Paulo em Perspectiva 2003; 17(2): 109-122.

CARVALHO, M.C.; SILVANY-NETO, A.M; TAVARES, T.M.; LIMA, M.E.C.; WALDRON, H.A. Lead poisoning among children from Santo Amaro, Brazil. PAHO Bulletin, 1985; 19(2):165-175.

CARVALHO, MC; SILVANY-NETO, AM; TAVARES, TM; COSTA, ACA; CHAVES, CR; NASCIMENTO, LD et al. Chumbo no sangue de crianças e passivo ambiental de uma fundição de chumbo no Brasil. Rev . Pananm Salud Publica 2003; 13(1): 19-23.

CASTELlinO, N; CASTELLINO, P; SANNOLO, N. Inorganic lead exposure, metabolism and intoxication. London, Lewis Publishers, 1995.

[CDC] CENTERS FOR DISEASES CONTROL AND PREVENTION. Preventing lead poisoning in young children: a statment by the Centers for Diseases Control, 1991. Disponivel em: www.cdc.gov/nceh/lead/publications/books/plpyc/contents.htm. Acesso em 15/12/2003.

[CDC] CENTERS FOR DISEASES CONTROL AND PREVENTION. Case studies in environmental medicine: lead toxity, 1992a . Disponivel em:

www phppo.cdc. gov/cdcRecommends/showarticle. asp/a artid=P0000017e TopNum $=50$ eCallPg=Adv. Acesso em 15/12/2003.

[CDC] CENTERS FOR DISEASES CONTROL AND PREVENTION. Impact of leadcontaminated soil on public health, 1992b. Disponivel em:

www.phppo.cdc. gov/cdcRecommends/showarticle. asp/a artid=P0000015eTopNum=50 eCallPg=Adv. Acesso em 15/12/2003.

[CDC] CENTERS FOR DISEASES CONTROL AND PREVENTION. Managing elevates blood lead levels among young children: recommendations from the Advisory Committee on Chilhood Lead Poisoning Prevention, 2002. Disponivel em: www.cdc.gov/nceh/lead/CaseManagement/caseMange main.htm. Acesso em $15 / 12 / 2003$.

[CDC] CENTERS FOR DISEASES CONTROL AND PREVENTION. Results for chemical group. Metal: Lead, 2003. Disponivel em:

www cdc.gov/exposurereport/metals/pdf/lead.pdf. Acesso em 14/12/2003. 
[CERH] CONSELHO ESTADUAL DE RECURSOS HÍDRICOS. Atribuições.

Disponivel em: http://www. recursoshidricos.sp.gov.br. Acesso em 29/06/2004

[CETESB] COMPANHIA DE TECNOLOGIA DE SANEAMENTO AMBIENTAL.

Relatório de estabelecimento de valores orientadores para solos e águas subterrâneas no estado de São Paulo. CETESB. São Paulo, 2001, 232p. Disponivel em: www. cetesb.sp.gov.br/solo/solo geral asp. Acesso em 14/12/2003.

[CETESB] COMPANHIA DE TECNOLOGIA DE SANEAMENTO AMBIENTAL. Avaliação da contaminação do solo na região de influência da indústria Acumuladores Ajax Ltda, em Bauru. Informe técnico 019/ECC/02, 2002 - Relatório.

[CETESB] COMPANHIA DE TECNOLOGIA DE SANEAMENTO AMBIENTAL. Avaliação confirmatória da contaminação ambiental na área de influência da indústria Tonolli do Brasil S/A em Jacaréi (SP). Informação técnica 024/ECC/EQQ/EQS/EQR/02, volume 1, 2002b - Relatório.

[CETESB] COMPANHIA DE TECNOLOGIA DE SANEAMENTO AMBIENTAL. Áreas contaminadas no estado de São Paulo. CETESB, São Paulo, 2003. Disponível em: www.cetesb.sp.gor.br. Acesso em 06/03/2004.

[CETESB] COMPANHIA DE TECNOLOGIA DE SANEAMENTO AMBIENTAL. Diagnóstico ambiental referente à empresa Apliquim Equipamentos e Produtos Quimicos Ltda. Informação técnica 012/04/CPr-PA, 2004 - Relatório.

[CGG] COMMISSION ON GLOBAL GOVERNANCE. Our global neigbhood: the report of the commission on global governance. Oxford University Press, 1995.

[CGG] COMMISSION ON GLOBAL GOVERNANCE. Governance. 2002. Disponivel em hltp://www.cgg.ch. Acesso em 20/02/2002.

[CGVAM] COORDENAÇÃO GERAL DE VIGILÂNCIA AMBIENTAL EM SAÚDE. I inventário nacional de vigilância ambiental em saúde (versão preliminar, mimeo), fev 2004. CGVAM/SVS/MS.

[CMMAD] COMISSÃO MUNDIAL SOBRE MEIO AMBIENTE E DESENVOLVIMENTO. Nosso futuro comum. $2^{\circ}$ edição, Rio de Janeiro, Editora da Fundação Getúlio Vargas, 1991.

CLARK, S; MENRATH, W; CHEN, M; SUCCOP, P; BORNSCHEIN, R; GALKE, W et al. [Abstract] The influence of exterior dust and soil lead on interior dust lead levels in housing that had undergone lead-based paint hazadr control. J Occup Environ Hyg 2004; 1(5): 273-282 
[CNRH] CONSELHO NACIONAL DE RECURSOS HÍDRICOS. Atribuições.

Disponível em: http://www.cnrh-srh.gov.br. Acesso em 29/06/2004.

[CNUMAD] CONFERÊNCIA DAS NAÇÕES UNIDAS SOBRE MEIO AMBIENTE E DESENVOLVIMENTO SUSTENTÁVEL. Agenda 21, 1992.

COOK, M.; CHAPPELL, W.R.; HOFFMAN, R.E.; MANGLONE, E.J. Assessment of blood lead levels in children living in a historic mining and smelting community. Am $\mathbf{J}$ of Epidemiology, 1993; 137(4):446-455.

[COPASAD] CONFERÊNCIA PAN-AMERICANA SOBRE SAÚDE E AMBIENTE NO DESENVOLVIMENTO SUSTENTÁVEL. Plano nacional de saúde e ambiente no desenvolvimento sustentável. Brasília, Ministério da Saúde, 1995.

[CPDS] COMISSÃO DE POLÍTICAS DE DESENVOLVIMENTO SUSTENTÁVEL E DA AGENDA 21 NACIONAL. Agenda 21 brasileira. Disponível em: http://nww. mma.gov.br/port/se/agen21/ag21bra/corpo.html. Acesso em 18/04/2004.

COSTA, LAM. O ideário urbano paulista na virada do século: o engenheiro Theodoro Sampaio e as questões territoriais e urbanas modernas (1886-1903). São Carlos. Ed. Rima, 2003.

CUNHA, FG e FIGUEIREDO, BR. Estudos sobre a dispersão de chumbo em água e sedimentos de corrente no Vale do Ribeira, Sp-Pr: visando a saúde pública. IN:

CONGRESSO DE GEOQUÓMICA DOS PAÍSES DE LÍNGUA PORTUGUESA, 5. 1999; CONGRESSO BRASILEIRO DE GEOQUIMICA, 7., 1999, Porto Seguro.

Anais. Porto Seguro: Sociedade Brasileira de Geoquímica, 1999, p. 80-81.

[CVE] Centro de Vigilância Epidemiológica. Disponível em: www.cve.saude.sp.gov.br. Acesso em 9/12/2002.

[CVS] Centro de Vigilância Sanitária. Disponivel em: www. cıs saude.sp.gov.br. Acesso em 9/12/2002.

DE MARCHI, B e RAVETZ, JR. Risk management and governance: a post-normal science approach. Futures 1999; 31: 743-757.

[DEH] AUSTRALIAN GOVERNMENT DEPARTMENT AND HERITAGE. Lead in australian children: sumary of the national survey of lead in children. Disponível em: http://www deh.gov. au/atmosphere/airqualitv/lcad/leadsurvev. htm. Acesso em 08/08/2004.

[DIEESE] DEPARTAMENTO INTERSINDICAL DE ESTATÍSTICA E ESTUDOS SÓCIO-ECONÔMICOS. A situação do trabalho no Brasil. DEESE, 2001. 
[DIEESE] DEPARTAMENTO INTERSINDICAL DE ESTATISTICA E ESTUDOS SÓCIO-ECONÔMICOS. O mercado de trabalho brasileiro no inicio de 2004. In Global Policy Network, 2004. Disponível em http://www.gpn.org. Acesso em 04/09/4004.

[DIR X] DIRETORIA REGIONAL DE SAÚDE DE BAURU. Relatório preliminar da investigação epidemiológica de exposição a chumbo em crianças. Mimeo, 2004.

[DOMA] DIVISÃO DE DOENÇAS OCASIONADAS PELO MEIO AMBIENTE. Contribuição da epidemiologia enquanto forma de abordagem para as áreas contaminadas em São Paulo. [Apresentado no I Seminário Regional de Áreas Contaminadas e Saúde da Baixada Santista; 2003 jul 12; Santos/SP (BR)].

ELHELU, MA; CALDWELL, DT; HIRPASSA, WD. Lead in inner-city soil and its possible contribution to children's blood lead. Arch Environ Health 1995; 50(2): 165169.

FACTOR-LITVAK, J.; KLINE, JK; POPOVAC, D.; HADZIALJEVIC, S.;LEKIC, V. PRETENI-REXHEP, E. et al. Blood lead and blood pressure in young children. Epidemiology, 1996; 7: 633-637.

FACTOR-LITVAK, P; WASSERMAN, G; KLINE, JK; GRAZIANO, J. The Yugoslavia prospective study of environmental lead exposure. Environ Health Perspect, 1999; 107(1):9-15.

FARAH, MFS. Parcerias, novos arranjos institucionais e politicas públicas no nível local de governo. RAP, 2001; 35(1): 119-144.

FERNÍCOLA, NAGG e AZEVEDO, PA. Níveis de chumbo e atividade do ácido $\delta$ aminolevulínico ( $\delta$ - ALAD) no sangue da população da Grande São Paulo, Brasil. Rev Saúde Publ S Paulo, 1981; 15: 272-282.

FEWTRELL, L; KAUFMANN, R; PRUSS-USTUN, A. [WHO] WORLD HEALTH ORGANIZATION. Lead: assessing the environmental burden of disease at national and local levels. Environmental Burden of Desease Series, $N^{\circ} 2$. Disponivel em: http://www. who.int/peh/burden/9441546107/leadtoc.htm. Acesso em 29/01/2004.

FLEGAL, AR e SMITH, DR. Lead levels in preindustrial humans. The New Engl J of Med. 1992; 326(19): 1293-1294.

FRANCO, LV; ROMO, AH; CAMACHO, CM. Niveles de plomo en la sangre de ninos residentes en la ciudad de Mexico, D. F. Salud Publica de Mexico 1975; 17(3): 337 342 . 
FREITAS, C; BONINI, EM; USHIROBIRA, MFH; SILVA, MAFR; LEITE, AP; COSTA, AP et al. Buscando a estruturação da vigilância ambiental em saúde no estado de São Paulo: avanços, dificuldades e perspectivas. Monografia apresentada para conclusão do curso de especialização em Vigilância Ambiental em Saúde, 2002. Mimeo. NESC/UFRJ.

FREITAS, CM; PORTO, MF; MOREIRA, JC; PIVETTA, F; MACHADO, JMH; FREITAS, NBB et al. Segurança química, saúde e ambiente - perspectivas para a governança no contexto brasileiro. Cad. Saúde Pública 2002; 18(1): 249-256.

FREITAS, CU. Chumbo. 1999. Disponível em: www.cre.saude.sp.gov.br. Acesso em 05/03/2004

FREITAS, CU. Explorando modelos e indicadores para o estabelecimento de vigilância dos efeitos na saúde decorrentes da poluição atmosférica na cidade de São Paulo. São Paulo, 2000. [Dissertação de Mestrado - Faculdade de Saúde Pública - Universidade de São Paulo].

FUNTOWICZ, S e RAVETZ, J. Ciência pós-normal e comunidades de pares face aos desafios ambientais. História, Ciências, Saúde 1997; 4(2): 219-230

GALLICCHIO, L; SCHERER, RW; SEXTON, M. Influence of nutrient intake on blood lead levels of young children at risk for lead poisoning. Environ Health Perspec, 2002; 110(12): A767-A772.

GALVIN, G; STEPHENSON, J; WLODARCZYK, J; LOUGHRAN, R; WALLER, G. Living near a lead smelter: na environmental health risk assessment in Boolaroo and Argenton, New South Wales. Australian J of Public Health, 1993; 17(4): 373-378.

GARRIDO, NS; PREGNOLATTO, NP; MURATA,LTF; SILVA, MR; NUNES, MCD; ENGLER, VM; SAKUMA, AM. Determinação de chumbo e cádmio em artigos escolares. Rev. Inst. Adolfo Lutz, 1990; 50(1/2): 291-296.

GAUDIN, JP. Modern governance, yesterday and today: some clarifications to be gained from french government policies. International Social Science Journal, 1998; 50(155): 47-56.

GAUDIN, JP. A governança moderna, ontem e hoje: alguns esclarecimentos a partir das políticas públicas francesas. In: Curso de Gestão Urbana das Cidades; 2001. Maio, 14 a 26, Belo Horizonte/MG. EG/FJP WBI LILP ESAF IPEA. Disponivel em http://ntww.eg.fjp.gor.br/gestaourbana/arquivos/abertura/abl.htm. Acesso em 31/07/2004.

[GEMS] GLOBAL ENVIRONMENTAL MONITORING SYSTEM. Assessment of human exposure to lead: comparison between Belgium, Malta, Mexico and Sweden. Stockholm, Karolinska Institute, 1985. 
GERR, F.; LETZ, R.; STOKES, L.; CHETTLE, D.; MCNEIL, F.; KAYE, W. Association between bone lead concentration and blood pressure among young adults. Am J Ind Med, 2002; 42(2): 98-106.

GILFILLAN, SC. Lead Poisoning and the fall of Rome. J of Occup Medicine, 1965; 7(2): 53-60.

GROSSE, SD; MATTE, TD; SCHWARTZ, J. JACKSON, RJ. Economic gains resulting from the reduction in children's exposure to lead in the United States. Environ Health Perspect, 2002; 110(6): 563-569.

GULSON, BL; DAVIS, JJ; MIZON, KJ; KORSCH, MJ; LAW, AJ. Lead bioavailability in the environment of children: blood lead levels in children can be elevated in a mining community. Arch Environ Health 1994; 49(5): 326-331.

GUTIÉRREZ, CJ; ROMIEU, I; SÁNCHEZ, ALR; RÉNDON, EP; QUILES, IM. Exposition a plomo en ninos de 6 a 12 anos de edad. Salud Publica de Mexico 1999; 41 Suppl 2: S72-S81.

HARLAN, WR; LANDIS, JR; SCHMOUDER, RL; GOLDSTEIN, NG; HARLAN, LC. Blood lead and blood pressure. JAMA, 1985; 253(4):530-534.

HAYNES, E; LANPHEAR, BP; TOHN, E; FARR, N; RHOADS,GG. The effects of interior lead hazard controls on children's blood lead concentration: a systematic evaluation. Environ Health Perspect 2002; 110(1): 103-107.

HENNEKENS, CH e MAYRENT, SL. Epidemiology in Medicine. Little Brown and Company, 1987, Boston/Toronto.

HERNANDEZ-AVILA, M; PETERSON, KE; GONZALEZ-COSSIO, T; SANIN, LH; ARO, A; SCHNAAS, L; HU, H. The effect of maternal bone lead on lenght and head circunference of newborns and 1-month-old infants. Arch environ Health, 2002; 57(5): 482-488.

HERNBERG, S. Lead poisoning in a historical perspective. Am J of Industrial Medicine, 2000; 38: 244-254.

HU, H. A 50-year follow-up of childhood plumbism. AJDC, 1991a; 145: 681-687.

HU, H. Knowledge of diagnosis and reproductive history among survivors of chidhood plumbism. Am J Public Heath, 1991b ; 81(8): 1070-1072.

HUSEMAN, CA; VARMA, MM; ANGLE, CR. Neuroendocrine effects of toxic and low blood lead levels in children. Pediatrics, 1992; 90(2 Pt 1): 186-189. 
[INSERM] INSTITUT NATIONAL DE LA SANTÉ ET DE LA RECHERCHE MEDICALE, France, 2002. Expertise collective "Plomb dans l'enviroment": quels risques pour la santé?. Disponivel em www.inserm.fr. Acesso em 18/12/2003.

JACOB, B.; RITZ, B.; HEINRICH, J.; HOELSCHER, B.; WICHMANN, HE. The effect of low-level blood on hematologic parameters in children. Environ Res, Section 2000; A 82: 150-159.

JACOBI, P. Meio ambiente e redes sociais: dimensões intersetoriais e complexidade na articulação das práticas coletivas. RAP, 2000; 34(6): 131-158.

JESSOP, B. The rise of governance and the risks of failure: the case of economic development. International Social Science Journal 1998; 50(155): 29-45.

KIM, R; HU, H; ROTNITZKY, A; BELLINGER, D; NEEDLEMAN, H. A longitudinal study of chronic lead exposure and physical growth in Boston children. Environ Health Perspect, 1995; 103(10): 952-957.

KJELLSTRÖM, T e MAGE, D. Appropriate field application of human exposure assessment and environmental epidemiology. In: [WHO] WORLD HEALTH ORGANIZATION. Human exposure to lead. Hu man Exposure Assessment Series. Geneva, 1987: 15-19.

KNISHKOWY, B e BAKER, EL. Transmission of occupational disease to family contacts. Am J Ind Med 1986; 9: 543-550.

LANDRIGAN, P. e BAKER E. Exposure of children to heavy metals from smelters: epidemiology and toxic consequences. Environ Res, 1981; 25: 204-224.

LANDRIGAN, PJ; BOFFETTA, P.; APOSTOLI, P. The reproductive toxicity and carcinogenicity of lead: a critical review. Am J of Ind Medicine, 2000; 38: 231-243.

LANDRIGAN, PJ; SCHECHTER, CB; LIPTON, JM; FAHS, MC; SCHWARTZ, J Environmental pollutants and disease in american children: estimates of morbidity, mortality, and costs for lead poisoning, asthma, cancer, and developmental disabilities. Environ Health Perspect, 2002; 110(7): 721-728.

LANPHEAR, BP; WEIZTZMAN, M; WINTER, NL; EBERLY, S; YAKIR, B; TANNER, M et al. Lead contaminated house dust and urban children's blood lead levels. American Journal of Public Health 1996; 86(10): 1416-1421.

LANPHEAR, BP; MATTE, TD; ROGERS, J; CLICKNER, RP; DIETZ, B; BORNSCHEIN, RL et al. The contribution of lead-contaminated house dust and residential soil to children's blood lead levels. Environ Res 1998 ${ }^{\mathrm{a}}$, Section A; 79: 5168. 
LANPHEAR, BP; BURGOON, DA; RUST, SW; EBERLY, S; GALKE, W. Environmental exposure to lead and urban children's blood lead levels. Environ Res 1998 ; Section A 76: 120-130.

LANPHEAR, BP; DIETRICH, K; AUINGER, P; COX, C. Cognitive deficits associated with blood lead concentrations $<10 \mu \mathrm{g} / \mathrm{dL}$ in US children and adolescents. Public Heath Reports, 2000; 115(6): 521-529.

LANPHEAR, BP; SUCCOP, P; RODA, S; HENNINGSEN, G. The effect of soil abatement on blood lead levels in children living near a former smelting and milling operation. Public Health Reports 2003; 118: 83-91.

LEFF, E. Pensar a complexidade ambiental. In : Leff, E. (Coordenador). A complexidade ambiental. Editora Cortez, 2003.

LE PRESTE, P. Ecopolítica Internacional. São Paulo, Editora SENAC, 2000.

LEROYER, A.; NISSE, C.; HEMON, D.; GRUCHOCIAK, A.; SALOMEZ, J.L.; HAGUENOER, J.M. Environmental lead exposure in a population of children in Northern France: factors affecting lead burden. Am J of Indust Med, 2000; 38: 281289.

LINDERN, IV; SPALINGER, S; PETROYSAN, V; BRAUN, M. Assessing remedial effectiveness through the blood lead; soil/dust lead relatioship at the Bunker Hill Superfund Site in the Silver Valley of Idaho. Sci Total Environ 2003; 302(1-2): 139170 .

LUCAS, SR; SEXTON, M; LANGENBERG, P. Relationship between blood lead and nutritional factors in preschool children: a cross-sectional study. Pediatrics, 1996; 97(1): 74-78.

LUSTBERG, M. e SILBERGELD, E. Blood lead levels and mortality. Arch Intern Med 2002; 162(21): 2443-2449.

MACHADO, JMH e PORTO, MFS. Promoção da saúde e intersetorialidade: a experiência da vigilância em saúde do trabalhador na construção de redes.

Epidemiologia e Serviços de Saúde, 2003; 12(3): 121-130.

MCDONALD, JA e POTTER, NU. Lead's legacy? Early and late mortality of 454 lead-poisoned children. Arch Environ Health, 1996; 31(2): 116-121.

MERRIEN, FX. Governance and modern welfare states. International Social Science Journal 1998; 50(155): 57-67. 
[MES/SES] MINISTERE DE LÉMPLOI ET DE LA SOLIDARITE/SECRETARIE D'ETAT A LA SANTE. Paris, 1998. Communique de presse. Disponivel em: www. sante. gouv.fr/htm/actu/31 980409 htm. Acesso em 17/12/2003.

MEYER, I; HEINRICH, J; LIPPOLD, U. Factors affecting lead, cadmium, and arsenic levels in house dust in a smelter town in Eastern Germany. Environ Res 1999; Section A $81: 32-44$.

MINHOTO, LD e MARTINS, CE. As redes e o desenvolvimento social. Cadernos FUNDAP, $2001 ; 22: 81-101$.

MISOCZKY, MC. Redes e hierarquias: uma reflexão sobre arranjos de gestão na busca da eqüdade em saúde. RAP, 2003; 37(2): 335-354.

MONTESANTI, M; MORGANTINI, F; LANDUCCI, C; ROSSI, L; BIAGI, C; CASTELLI, S. Livelli ematici di piombo nei bambini della Piana di Lucca. Rilevazione del 1993. Minerva Pediatr, 1995; 47: 119-125.

MORISI, G; PATRIARCA, M; CARRIERI, MP; FONDI, G; TAGGI, F. Lead exposire: assessment of the risk for the general italian population. Ann Ist Super Sanitá, 1989; 25(3): 423-436.

NEEDLEMAN, HL; SCHELL, A; BELLINGER, D; LEVITON,A; ALLRED, EN. The long-term effects of exposure to low doses of lead in childhood. $\mathrm{Na} 11$-year follow-uo report. The New England Journal of Medicine, 1990; 322(2): 83-88.

NEEDLEMAN, HL; RIESS, JA; TOBIN, MJ; BIESECKER, GE; GREENHOUSE, JB. Bone lead levels and delinquent behavior. JAMA, 1996; 275(5): 363-369.

NEGRI, B. Concentração e desconcentração industrial em São Paulo (1880-1990). Editora da UNICAMP, Campinas, 1996.

NEVIN, R. How lead exposure relates to temporal changes in IQ, violent crime, and unwed pregnancy. Environ Res, 2000; Section A: 83: 1-22.

NOBRE, E.A.C. Impactos da globalização econômica no complexo metropolitano expandido de São Paulo: possibilidades de ação. FAU/USP, 2004. Disponível em: http://www usp.br/fau/docentes/depprojeto/c nobre/impactos.pdf. Acesso em 03/04/2004.

NRIAGU, JO; BLANKSON, ML; OCRAN, K. Childhood lead poisoning in Africa: a growing public health problem. Sci Total Environ, 1996; 181: 93-100.

NRIAGU, J; OLERU, NT; CUDJOE, C; CHINE, A. Lead poisoning of children in Africa, III. Kaduna, Nigeria. Sci Total Environ, 1997; 197: 13-19. 
OKADA, IA; SAKUMA, AM; MAIO, FD; DOVIDAUSKAS, S; ZENEBON, O . Avaliação dos niveis de chumbo e cadmio em leite em decorrência de contaminação ambiental na região do Vale do Paraíba, Sudeste do Brasil. Rev Saúde Pública, 1997; 31(2): 140-143.

[OPAS] ORGANIZACION PANAMERICANA DE LA SALUD. Carta Panamericana sobre salud y ambiente en el desarrollo humano sostenible. Washington-DC, 1995.

ORDONEZ, BR; ROMERO, LR; MORA, R. Investigacion epidemiológica sobre niveles de plomo en la populacion infantil y en el medio ambiente domiciliário de Ciudad Juarez, Chihuahua, en relacion com una fundicion de El Paso, Texas. Bol Oficina Sanit Panam, 1976; 80(4): 303-317.

PAGDEN, A. The genesis of "governance" and enlightenment conceptions of the cosmopolitan world order. International Social Science Journal 1998; 50(155): 7-15.

PAOLIELLO, MMB; GUTIERREZ, PR; TURINI, CA; MATSUO, T; MEZZAROBA, L; BARBOSA, DS; ALVARENGA, ALP et al. Valores de referência para plumbemia em população urbana. Rev Saúde Pública, 1997; 31(2): 144-148.

PAOLIELLO, M.M.B. e CHASIN, A.A.M. Ecotoxicologia do chumbo e seus compostos. In: Cadernos de Referência Ambiental v. 3. Salvador: Centro de Recursos Ambientais-CRA, 2001.

PAOLIELLO, M.M.B.; CAPITANI, E.M.; CUNHA, F.G.; MATSUO, T.; CARVALHO, M.F.; SAKUMA, A.; FIGUEIREDO, B.M. Exposure of children to lead and cadmium from mining area of Brazil. Environ. Res. 2002; A88: 120-128.

PAOLIELLO, MMB. Exposição humana ao chumbo em áreas de mineração, Vale do Ribeira, Brasil. Campinas, 2002. [Tese de Doutoramento - Faculdade de Ciências Médicas da Universidade Estadual de Campinas]

PAOLIELLO, MMB e CAPITANI, EM. Chumbo. In: Azevedo, FA e Chasin, AAM. Metais: gerenciamento e toxicidade. Editora Atheneu, 2003.

PIMENTA, CC. Novos modelos de gestão descentralizada e de parcerias para as administrações estaduais. RAP, i995; 29(3): 171-187.

PINHEIRO, MC; GUIMARÃES, GA; NAKANISHI, J; OIKAWA, T; VIEIRA, JL; QUARESMA, M et al. Avaliação da contaminação mercurial mediante análise do teor de $\mathrm{Hg}$ total em amostras de cabelo em comunidades ribeirinhas do Tapajós, Pará, Brasil. Rev Soc Bras Med Trop, 2000; 33(2): 181-184.

PIOMELLI, S; CORASH, L; CORASH, MB; SEAMAN, C; MUSHAR, P; GLOVER, B; GLOVER, B; PADGETT, R. Blood lead concentration in remote himalayan population. Science, 1980; 210: 1135-1137. 
PIRKCLE, JL; SCHWARTZ, J; LANDIS, R; HARLAN, WR. The relationship between blood lead levels and blood pressure and its cardiovascular risk implications. Am J Epidemiology, 1985; 121(2): 246-258.

PIRKLE, JL; BRODY, DJ; GUNTER, EW; KRAMER, RA; PASCHAL, DC; FLEGAL, KM; MATTE, TD. The decline in blood lead levels in the United States. The National Health and Nutrition Examination Surveys (NHANES). JAMA, 1994; 272(4): 284-291.

POCOCK, SJ; SMITH, M; BAGHURST, P. Environmental lead and childre's inteligence: a systematic review of the epidemiological evidence. BMJ, 1994; 309 : 1189-1197.

POISINDEX MANAGEMENTS. Lead. In Healthcare Series v. 112, 2002. MICROMEDEX ®.

PORTO, MF. Entre o sustentável, o saudável e o vulnerável: por uma ecologia política dos riscos. Boletim ECOECO 2002; 11 : 4-6.

PREFEITURA DE BAURU. Primeiros tempos de nossa Bauru. Disponível em: www bauru.sp.gov br. Acesso em 21/09/2003.

RAGHUNAT, R.; TRIPATHI, RM; KUMAR, AV; SATHE, AP; KHANDEKAR, RN; NAMBI, KSV. Assessment of $\mathrm{Pb}, \mathrm{Cd}, \mathrm{Cu}$ and $\mathrm{Zn}$ exposures of 6 to 10 year-old children in Mumbai. Environ Res, 1999; Section A 80: 215-221.

RANCIÉRE, J. O dissenso. In: Novaes, A, editores. A crise da razão. São Paulo. Ed. Companhia das Letras/Minc - FUNARTE, 1999.

RHODES, RAW. The new governance: governing without government. Political Studies, 1996; 44(4): 652-667.

RICE, C; FISCHBEIN, A; LILIS, R; SARKOZI, L; KON, S; SELIKOFF, I. Lead contamination in the homes of employees of secondary lead smelters. Environ Res $1978 ; 15: 375-380$.

ROELS, H.A.; BUCHET, J.P.; LAWERYS, R.R.; BRUAUX, P.; CLAEYSTHOREAU, C.; LAFONTAINE, A.; VERDUYN, G. Exposure to lead by the oral and the pulmonary routes of children living in the vicinity of a primary lead smelter. Environ Res, 1980; 22: 81-94.

ROMANO, J; GODINHO, R; ALONSO, CD; MARTINS, MHRB. Ethanol induced changes in the atmospheric lead in São Paulo Metropolitan Area - Brasil. IN $9^{\text {th }}$ WORLD CLEAN AIR CONGRESS. Montreal. Anais, september, 1992. 
ROMIEU, I; CARREON, T; LOPEZ, L; PALAZUELOS, E; RIOS, C; MANUEL, Y et al. Environmental urban lead exposure and blood lead levels in children of Mexico City. Environ Health Perspect 1995; 103(11): 1036-1040.

ROSCOE, RJ; GITTLEMAN, JL; DEDDENS, JÁ; PETERSEN, MR; HALPERIN, WE. Blood lead levels among children of lead-exposed workers: a meta-analysis. Am J Ind Med 1999; 36: 475-481.

ROSEN, JF. Adverse health effects of lead at low exposure levels: trends in the management of childhood lead poisoning. Toxicology, 1995; 97: 11-17.

ROTHENBERG, SJ; ARRIETA, LS; GUERRERO, IAP; CERVANTES, RH; MEDINA, SM; HERNÁNDEZ, EP. Factores relacionados com el nivel de plomo en el estudio prospectivo de plomo en la ciudad de México. Salud Pública de México 1993; 35(6): 592-598.

ROTHENBERG, SJ; SCHNAAS, L; PERRONI, E; HERNÁNDEZ, RM; KARCHMER, S. Secular trend in blood lead levels in a cohort of Mexico City children. Arch Environ Health, 1998; 53(3): 231-235.

ROTHENBERG, SJ; SCHNAAS, L; PERRONI, E; HERNÁNDEZ, RM; ORTEGA, JF. Blood lead secular trend in a cohort of children in Mexico City. II. 1990-1995. Arch Environ Health, 2000; 35(4): 243-249.

RUBIN, CH; ESTEBAN, E; REISSMAN, DB; DALEY, R; NOONAN, GP; KARPATI, A; GURVITCH, E. et al. Lead poisoning among young children in Russia: current evaluation of childhood lead exposure in Ekaterinburg, Krasnouralisk and Volgograd. Environ Health Perspect, 2002; 110(6): 559-562.

RUMMO, JH; ROUTH, DK; RUMMO, NJ.. Behavioral and neurological effects of symptomatic and asymptomatic lead exposure in children. Arch Environ Health, 1979; 34: 120-125.

SAKUMA, AM; SCORSAFAVA, MA; ZENEBOM, O; TIGLEA, P; FUKUMOTO, CJ. Hortaliças comercializadas em São Paulo: aspectos da contaminação por chumbo, cadmio e zinco. Rev. Inst. Adolfo Lutz, 1989; 49(1): 81-84.

SALKEVER, DS. Updated estimates of earnings benefits from reduced exposure of children to environment lead. Environ Res, 1995; 70: 1-6.

SÁNCHEZ, LE. A desativação de empreendimentos industriais: um estudo sobre o passivo ambiental. São Paulo, 1998. [Tese de Livre Docência - Departamento de Engenharia de Minas da Universidade de São Paulo]. 
SANTOS -FILHO, E.; SOUZA E SILVA, R.; BARRETTO, H.H.C.; INOMATA, ONK.; LEMES, V.R.R.; SAKUMA, A. M.; SCORSAFAVA, M.A. Concentrações sanguineas de metais pesados e praguicidas organoclorados em crianças de 1 a 10 anos. Rev. Saúde Pública, 1993; 27(1):59-67.

SANTOS, EC; CÂMARA, VM; BRABO, ES; LOUREIRO, EC; DE JESUS, IM; FAYAL, $\mathrm{K}$ et al. Avaliação dos niveis de exposição ao mercúrio entre os índios Pakaanóva, Amazônia, Brasil. Cad Saúde Pública, 2003; 19(1): 199-206.

SANTOS, L. Meio ambiente e saúde. Competências. Intersetorialidade. Mimeo. Brasilia. CGVAM/MS, 2002.

SÃO PAULO. Leis. Lei 898 (18/12/1975). Disciplina o uso do solo para proteção dos mananciais, cursos e reservatórios de água e demais recursos hídricos da região metropolitana da GSP. São Paulo, Diário Oficial do Estado, 1975.

SÃO PAULO. Leis. Lei 997 (31/05/1976). Dispõe sobre o controle da poluição do meio ambiente. Diário Oficial do Estado, 1976.

SÃO PAULO. Decretos. Decreto 8.468 (08/09/1976). Aprova o regulamento da Lei 997 de 31/05/1976. Diário Oficial do Estado, 1976.

SÃO PAULO. Resoluções. Resolução conjunta n 1 SMA/SS (23/04/97). Dispõe sobre estudos para identificar correlação entre poluição veicular e doenças e outros agravos à saúde dela decorrentes. Diário Oficial do Estado, 1997.

SÃO PAULO. Resoluções. Resolução conjunta n ${ }^{\circ}$ SS/SMA (01/06/2002). Define procedimentoss para ação conjunta das Secretarias de Estado da Saúde e Meio Ambiente no tocante a áreas contaminadas por substâncias perigosas. Diário Oficial do Estado, 07/06/2002.

SAYRE, JW; CHARNEY, E; VOSTAL, J; PLESS, IB; ROCHESTER, NY. House and hand dust as a potential source of childhood lead exposure. Am J Dis Child, 1974; 127 167-170.

SCHWARTZ, J. Low-level lead exposure and children's IQ: a meta-analysis and search for a threshold. Environ Res, 1994; 65: 42-55.

SCHWARTZ, J. Lead, blood pressure, and cardiovascular disease in men. Arch Environ Health, 1995; 50(1):31-37.

SCHWARTZ, J.; LANDRIGAN, PJ; BAKER, EL; ORENSTEIN, WA; LINDERN, IH. Lead-induced anemia: dose-response relationships and evidence for a threshold. AJPH, 1990; 80(2): 165-168.

[SEADE] FUNDAÇÃO SISTEMA ESTADUAL DE ANÁLISE DE DADOS. Municípios Paulistas. Disponivel em: www seade.sp.gov br. Acesso em 21/09/2003. 
[SEADE] FUNDAÇÃO SISTEMA ESTADUAL DE ANÁLISE DE DADOS. Pesquisa de condições de vida no estado de São Paulo, 1994. Disponivel em www.seade.gov.br. Acesso em 20/08/2004.

SEPÚLVEDA, A; VEJA, J; DELAGADO, I. Exposición severa a plomo ambiental en una población infantil de Antofogasta, Chile. Rev Med Chile, 2000; 128: 221-232.

SHARMA, K e REUTERGARDH, LB. Exposure of preschoolers to lead in the Makati area of Metro Manila, the Philippines. Environ Res, 2000; v. A 83: 322-332.

SHEN, X; ROSEN, JF; GUO, D; WU, S. Chidhood lead poisoning in China. Sci Total Environ, 1996; 181: 101-109.

SIBERGELD, EK; NASH, D; TREVANT, C; STRICKLAND, GT; DE SOUZA, JM; DA SILVA, RS. Mercury exposure and malaria prevalence among gold miners in Pará, Brazil. Rev Soc Bras Med Trop, 2002; 35(5): 421-429.

SILVA, B.C.E. Chumbo: Balanço Mineral Brasileiro, 2001. In: Departamento Nacional de Produção Mineral-DNPN. Disponivel em: wwww.dnpn.gov.br. Acesso em 14/09/2003.

SILVA, B.C.E. Chumbo: Sumário, 2002. In: Departamento Nacional de Produção Mineral-DNPN. Disponível em:

www.dnpn.gov.br/suma2002/chumbo \%20revisado.doc. Acesso em 14/09/2003.

SILVANY-NETO, A.M.; CARVALHO, F.M.; CHAVES, M.E.C.; BRANDÃO, A.M.; TAVARES, T.M. Repeated surveillance of lead poisoning among children. Sci. Total Environ, 1989; 78:179-186.

SILVANY-NETO, A.M.; CARVALHO, F.M.; TAVARES, T.M.; GUIMARÃES, G.C.; AMORIM, C.J.B.; PERES, M.F.T.; LOPES, R.S.; ROCHA, C.M.; RAÑA, M.C. Lead poisoning among children of Santo Amaro, Bahia, Brazil in 1980, 1985, and 1992.

Bulletin of PAHO, 1996; 30(1): 51-63.

SILVANY-NETO, AM; CARVALHO, FM; TAVARES, TM; GUIMARÃES, GC; AMORIM, CJB; PERES, MFT et al. Evolução da intoxicação por chumbo em crianças de Santo Amaro, Bahia - 1980, 1985 e 1992. Bol Oficina Sanit Panam 1996; 120(1): 11-23.

SIMÃO, A. Sindicato e estado: suas relações na formação de proletariado brasileiro. São Paulo, Editora Ática, 1981.

[SMA] SECRETARIA DO MEIO AMBIENTE DE SÃO PAULO. Tendências da industrialização do interior do estado de São Paulo. Série Documentos. São Paulo, 1989. 
[SMA] SECRETARIA DE ESTADO DO MEIO AMBIENTE. Agenda 21 em São Paulo. Propostas do estado de São Paulo - relatório final, 2001. Disponível em http://www.ambiente.sp.gov.br/agenda2lbras/pdfs/sao paulo.pdf. acesso em 18/04/2004.

SPINK, PK; CLEMENTE, R; KEPPKE, R. Governo local: o mito da descentralização e as novas práticas de governança. Revista de Administração, 1999; 34(1): 61-69.

STEENLAND, $\mathrm{K}$ e BOFFETTA, $\mathrm{P}$. Lead and cancer in humans: Where are we now? Am J Ind Med, 2000; 38(3): 295-299.

STOKER, G. Governance as theory: five propositions. International Social Science Journal 1998; 50(155): 17-28.

STOKES, L; LETZ, R; GERR, F; KOLCZAK, M; MCNEILL, FE; CHETTLE, DR; KAYE, WE. Neurotoxity in young adults 20 years after childhood exposure to lead: the Bunker Hill experience. Occup Environ Med, 1998; 55: 507-516.

SUPLIDO, ML e ONG, CN. Lead exposure among small-scale batery reciclers, automobile radiator mechanics, and their children in Manila, the Philippines. Environ Res, 2000; A82: 231-238.

TAMBELLINI, AT e CÂMARA, VM. A temática saúde e ambiente no processo de desenvolvimento do campo da saúde coletiva: aspectos históricos, conceituais e metodológicos. Ciência e Saúde Coletiva, 1998; 3(2): 47-59.

TAVARES, TM; BRANDÃO, AM; CHAVES, MEC; SILVANY-NETO, AM; CARVALHO, FM. Lead in hair of children exposed to gross environmental pollution. Intern J Environ Anal Chen, 1989; 36: 221-230.

TEIXEIRA, CF e PAIM, JS. Planejamento e programação de ações intersetoriais para a promoção da saúde e da qualidade de vida. RAP, 2000; 34(6): 63-80.

TEIXEIRA, PJ. Determinação de chumbo em amostras de água coletadas em escolas públicas do município de São Paulo, 2001. [Dissertação de Mestrado - Faculdade de Ciências Farmacêuticas da Universidade de São Paulo].

TOMITA, NE; PADULA, NAMR e GEPICCB. Intoxicação por chumbo em crianças de Bauru-SP: análise do discurso da imprensa. [Abstract]. Revista Brasileira de Epidemiologia 2004, Número especial . VI Congresso Brasileiro de Epidemiologia; 2004 jun 19-23; Recife, (BR). Associação Brasileira de Pós-Graduação em Saúde Coletiva. CD-ROM.

TONG, S; BAGHURST, PA; SAWYER, MG; BURNS, J; MCMICHAEL, AJ.

Declining blood lead levels and changes in cognitive function during childhood. The Port Pirie cohort study. JAMA, 1998; 280(22): 1915-1919. 
TREPKA, M.J.; HEINRICH, J.; KRAUSE, C.; SCHULZ, C.; LIPPOLD, U.; MEYER, E.; WICHMANN, H.E. The internal burden of lead among chindren in smelter town - a small area analysis. Environ Res, 1997; 72:118-130.

[UNDP] UNITED NATIONS DEVELOPMENT PROGRAME. Governance for sustainable human development. A UNDP policy document. 1997. Disponivel em http:/magnet.undp.org/policv/default htm. Acesso em 25/07/2004.

[USEPA] UNITED STATES ENVIRONMENTAL PROTECTION AGENCY. Review of the national ambient air quality standards for lead: exposure analysis methodology and validation. Office of Air Quality Planning and Standards. EPA-450/2-89-01 1, 1989.

[USEPA] UNITED STATES ENVIRONMENTAL PROTECTION AGENCY. Risk analysis to support standards for lead in paint, dust, and soil. Office of Pollution Prevention and Toxics. EPA 747-R-97-006, 1998.

[USEPA] UNITED STATES ENVIRONMENTAL PROTECTION AGENCY. Lead and copper rule minor revisions: fact sheet, 1999. Disponivel em:

http://epa.gov/safewater/standard/leadfs.html. Acesso em 04/02/2004.

[USEPA] UNITED STATES ENVIRONMENTAL PROTECTION AGENCY. National Ambient Air Quality Standards - NAAQS (2000). Disponivel em: http://www.epa.gov/air/criteria.html. Acesso em 14/12/2003.

[USEPA] UNITED STATES ENVIRONMENTAL PROTECTION AGENCY. Hazard Standards. Lead in Paint, dust and soil. TSCA Section 403 (2001). Disponivel em: http://www.epa.gov/opptintr/lead/leadhaz.htm. Acesso em 18/11/2004.

[USGS] UNITED STATES GEOLOGICAL SURVEY. Minerals information: lead. Disponivel em: http //minerals.usgs.gov/minerals/pubs/commodity/lead. Acesso em 14/09/2003.

USHIROBIRA, MFH; FALCÃO, ACMG; BARROS, JOO; ASSEFF, HMPA; BRAGA, MC; LEITE, AP et al. Investigação epidemiológica de população exposta a chumbo proveniente de empresa de recuperação de sucata no município de Jacarei/São Paulo, 2003. [Abstract]. Revista Brasileira de Epidemiologia 2004, Número especial VI Congresso Brasileiro de Epidemiologia; 2004, 19-23 jun; Recife, (BR). Associação Brasileira de Pós-Graduação em Saúde Coletiva. CD-ROM

[VIDÁGUA] INSTITUTO AMBIENTAL VIDAGUA. Bauru Ambiental. Disponivel em: www vidagua org. br/bauru ambiental/dadosgerais/bauru. shtm. Acesso em $21 / 09 / 2003$

VIVENDO BAURU. História: transformações de um areal da boca do sertão. Disponivel em: www vivendobauru com.br. Acesso em 21/09/2003. 
[VIGISUS] PROJETO VIGISUS. Estruturação do Sistema Nacional de Vigilância em Saúde. Brasilia: Ministério da Saúde. Fundação Nacional de Saúde, 1998.

VUPPUTURI, S.; HE, J.; MUNTNER, P.; BAZZANO, LA; WHELTON, PK; BATUMAN, V. Blood lead level is associated with elevated blood pressure in blacks. Hypertension, 2003; 41(3): 463-468.

WALGENBACH, W; MARTINS, RP; BARBOSA, FAR. Modos operativos de integração disciplinar na ciências ambientais. In: Philippi Jr, A; Tucci, CEM; Hogan, DJ; Navegantes, R. (Editores). Interdisciplinaridade em ciências ambientais. Editora Signus, 2000.

WEITZMAN, M; ASCHENGRAU, A; BELLINGER, D; JONES, R; HAMLIN, JS; BAISER, A. Lead-contaminated soil abatment and urban children's blood lead levels. JAMA 1993; 269(13); 1647-1654).

WILSON, D; ESTERMAN, A; LEWIS, M; RODER, D; CALDER, I. Chidren's blood lead levels in the lead smelting town of Port Pirie, South Australia. Arch Environ Health, 1986; 41(4): 245-250.

[WHO] WORLD HEALTH ORGANIZATION. IPCS. Environmental health criteria 165 - Inorganic lead. WHO, Geneva, 1995.

[WHO] WORLD HEALTH ORGANIZATION. IPCS. Guidelines for drinking water quality - Second Edition - Volume 2 - Health Criteria and other Suporting Information, 1996. Disponivel em: http://www.who.int/water sanitation healtl/dwq/gdwqzv $/ / \mathrm{en} / \mathrm{index}$ l.html. Acesso em 29/01/2004.

[WORLD BANK] WORLD BANK. Governance: The World Bank's experience. 1994. Disponível em http://www.worldbank.org. Acesso em 20/02/2002.

WU, T; BUCK, GM; MENDOLA, P. Blood lead levels and sexual maturation in U. S. girls: the Third National Health and Nutrition Examination Survey, 1988-1994.

Environ Health Perspect, 2003; 111 (5): 737-741.

YANG, T; WU, TN; HSU, SW; LAI, CH; KO, KN; LIOU, SH. Blood lead levels of primary-school children in Penghu Country, Taiwan: distribution and influencing factors. Int Arch Occup Environ Health, 2002; 75: 528-534. 
8 - Anexos 


\begin{abstract}
Anexo 1
Sumário da entrevista com o Dr. Affonso Viviani Junior, gestor regional do processo de investigação, Diretor da DIR X - Bauru em 02/07/2004. A entrevista foi acompanhada pela Diretora Técnica da Vigilância Epidemiológica da DIR X, Márcia Helena Simonetti.
\end{abstract}

Questão 1: A DIR $\mathrm{X}$ coordenou as atividades relativas à investigação da exposição da população a chumbo proveniente de empresa de acumuladores de baterias no município de Bauru. Gostaria que, como gestor regional, relatasse a experiência de gestão das diversas instituições, as articulações políticas para viabilizar o trabalho, os embates e encaminhamentos bem como a visão da DIR sobre o processo.

O conhecimento do problema:

Recebimento de oficio da CETESB em fevereiro de 2002, informando a interdição da empresa e solicitando inquérito epidemiológico. Um ofício frio, sem outras explicações sobre a gravidade do problema. $O$ fato foi encarado como algo inédito, que poderia ter desdobramentos para os quais a DIR não dispunha de experiência. As principais preocupações foram sobre a capacidade técnica para enfrentar o problema e o quê fazer.

Internamente ao setor saúde, o caso foi levado à Vigilância Epidemiológica - VE regional, ao município e se buscou orientação da VE no nível central.

Externamente ao setor saúde, a CETESB regional foi acionada por telefone e oficialmente para dar todas as informações sobre o fato e fornecer relatórios produzidos.

A CETESB enviou os relatórios e o CVE/DOMA orientou a realização de amostra preliminar de grupo exposto e não exposto para avaliar a necessidade de aprofundamento do estudo.

O gestor municipal - Secretário da Saúde - informou que não saberia como encaminhar o processo, que não tinha experiência e pessoal com conhecimento no momento. Sugeriu para a DIR a responsabilidade na condução. 
Neste primeiro momento não houve divulgação do problema para outros setores, portanto a imprensa, o Ministério Público e a VIDAGUA - Organização Não Governamental não tomaram conhecimento. $\mathrm{O}$ gestor regional considerou que se fazia necessário ter idéia mais precisa do problema e planejar as ações e estratégias.

Até este momento, segundo o Dr. Affonso, por falta de experiência ou por desconhecimento de sua abrangência, não houve angústia com relação ao tamanho e complexidade das ações que viriam a seguir.

Criou-se um grupo interno na DIR entre a direção, a VE, VS e assistentes técnicos de para discussão e encaminhamento das atividades.

A questão da assistência

Após análise dos dados do estudo-piloto e da decisão conjunta entre a VE regional e central e a Vigilância em Saúde do municipio de expandir a avaliação de crianças para o raio de mil metros da indústria, entendeu-se que, como Bauru é municipio em Gestão Plena de Atenção Básica, estaria responsável pela operacionalização do inquérito epidemiológico, sob orientação da VE regional e das avaliações sanitárias, orientadas pela VS regional, estas por sua vez com orientação de seus niveis hierárquicos superiores.

Os primeiros resultados das plumbemias das crianças começaram a ser conhecidos e se apresentavam acima do limite estabelecido pela OMS. O gestor regional passou a se preocupar com a assistência e a retaguarda especializada para tratamento e avaliações neurocomportamentais.

Quanto ao atendimento às crianças que necessitassem de tratamento, foi acertado que o município se encarregaria da atenção básica e que a DIR estruturaria a retaguarda especializada. Estas definições foram discutidas e acordadas com a gestora municipal.

A VE regional identificou dois centros especializados para o encaminhamento das crianças: a Santa Casa de Misericórdia de São Paulo e a Faculdade de Medicina de Botucatu. Registre-se que o diretor da DIR havia sido colega de o curso da área de neuropediatria da Faculdade de Medicina de Botucatu, Niura Aparecida 
de Moura Ribeiro Padula. Houve uma conversa telefônica, na qual o problema foi explicado e, como se tratava de um número pequeno de crianças, estas seriam encaminhadas ao serviço de neuropediatria de Botucatu para avaliação a título de retaguarda. Houve oficialização do fluxo. Quanto ao atendimento básico a dra. Niura informou ter um residente, funcionário do município de Bauru, que poderia dar assistência sob sua orientação. Em acerto com o município, o profissional foi deslocado para a função. Na ocasião estava se constituindo o Hospital Regional de Bauru, sob a retaguarda técnica da Faculdade de Medicina de Butucatu, o que facilitava a busca de referência no local.

A divulgação do problema

Em meados de março, os resultados de plumbemia das crianças começam a mostrar a gravidade da situação. A imprensa toma conhecimento destes e os divulga. Foram envolvidas tanto a mídia local como estadual e nacional. Segundo o diretor da DIR o processo foi tumultuado e esmagador. Além da imprensa, com entrevistas diárias, havia ONGs, polícia, Ministério Público, políticos e a sociedade local. Todos com interesses diversos. "A situação parecia estar fora de controle". Apesar de todos os passos serem acertados com o gestor municipal antes da divulgação, havia discordância política quanto ao encaminhamento. Esta só foi resolvida com o afastamento da secretária municipal de saúde para se candidatar a cargo eletivo. Havia conflitos de operacionalização também entre a VE e VS regionais e a Vigilância em Saúde do município. Com a posse da nova secretária municipal de saúde houve mudança significativa da situação. As questões passaram a ser discutidas tecnicamente. As discordâncias entre as vigilâncias de Estado e do município eram então discutidas e gerenciadas pelos respectivos gestores. Os esclarecimentos e reuniões com a comunidade afetada ficaram a cargo do município. O município como também a CETESB regional delegaram ao diretor da DIR o contato com a imprensa. Foram definidas reuniões freqüentes para cada passo a ser tomado tendo-se o cuidado de externalizar uma conduta coesa, mesmo se abrisse mão de uma opinião buscando unificar o processo. 
Neste momento, o número de crianças que necessitavam de avaliação especializada ultrapassavam em muito a capacidade da neuropediatria da Faculdade de Medicina de Botucatu. Tornou-se urgente a constituição de referência no nivel local. Passou-se a buscar profissionais em Bauru para fazer este atendimento. Foi solicitada a liberação da dra. Niura para orientar o processo. No momento de maior pressão por parte da imprensa, o "Centrinho" (Hospital de Reabilitação de Anomalias Crâneo-Faciais) de Bauru ofereceu profissionais e área física para a avaliação das crianças. Formou-se então equipe composta pelo Centrinho, Faculdade de Medicina de Botucatu, Faculdade de Psicologia de Bauru, Faculdade de Odontologia de Bauru, técnicos e outros profissionais da DIR e município, coordenados tecnicamente pela dra. Niura. Foram iniciados mutirões nos finais de semana para a avaliação dos menores. Este procedimento foi fundamental pois estas instituições têm grande credibilidade da população. Posteriormente estabeleceu-se a rotina de atendimento no Centro de Referência de Saúde do Trabalhador da prefeitura.

Relações com outros setores

\section{CETESB}

Após a iniciativa do gestor regional em procurar a CETESB, estabeleceu-se uma relação pessoal além de profissional entre o diretor da DIR e o diretor regional da CETESB. Este deixou a condução do processo com a DIR, mantendo discussões para esclarecimentos e acertos uniformes de condução. Havia inexperiência de ambas as partes quanto a um trabalho conjunto e os desencontros quanto a competências institucionais foram resolvidos por acordos. A CETESB participou de todas as reuniões públicas com a DIR e municipio para esclarecimento, encaminhamento e resolução de problemas.

Imprensa

Conforme acordado com todos os atores do caso, a responsabilidade de comunicação com a imprensa ficou a cargo do diretor da DIR. No auge do 
processo, as entrevistas eram diárias com as mídias local, regional e estadual. Sempre foram enfatizados todos os fatos e, sobretudo, foi dita a verdade, não deixando a possibilidade de que acontecessem furos jornalisticos e, dessa forma, construímos uma relação de confiança entre a comunicação com a imprensa e a população. Esclareceu-se desde o início que o trabalho seria demorado. $\mathrm{Na}$ medida em que se dava continuidade ao trabalho, a imprensa estadual se afastou, seguida depois pela regional. A imprensa local permaneceu noticiando o fato e o faz até hoje.

\section{Empresa}

Após a mídia começar a divulgar os fatos, a empresa procurou questionar as referências técnicas do trabalho, indo buscar apoio em políticos locais que, por sua vez, recorriam à DIR. Os fatos foram esclarecidos e, por isso, passaram a dar respaldo político ao gestor do processo.

De acordo com o gestor regional, a empresa cometeu erro estratégico quando foi para a imprensa questionando o estabelecimento do limite de intervenção, para niveis de plumbemia em crianças, de $10 \mu \mathrm{g} / \mathrm{dL}$. Argumentava que este limite servia para paises desenvolvidos. A resposta da DIR foi de que as crianças bauruenses tinham tanto direito à vida saudável quanto aquelas dos países referidos. A mídia passou a dar respaldo ao setor saúde. A avaliação da direção da DIR era de que o embate poderia levar ao confronto. Solicitou então reunião entre a empresa e a equipe técnica da Regional de Saúde. Nesta reunião foi colocado que cuidar da saúde das pessoas é uma função institucional e também foram explanados todo o plano de trabalho e suas razões. Ficou acordada a realização de reuniões periódicas entre a empresa e a equipe da DIR; a comunicação do que fosse planejado de ora em diante e o encaminhamento dos resultados dos exames de plumbemia das crianças, respeitando-se o sigilo médico. A empresa se comprometeu junto à DIR e ao município em garantir transporte das crianças para avaliação especializada, alimentação e em contribuir na aquisição de material para os testes psicológicos. A partir dai não houve mais questionamentos públicos, que passaram a ser feitos no campo juridico. 
No campo jurídico, a empresa questionou o limite de ação de $10 \mu \mathrm{g} / \mathrm{dL}$ para crianças argumentando que a legislação brasileira estabelece o nível de referência populacional em $40 \mu \mathrm{g} / \mathrm{dL}$, refutado tecnicamente pois este limite é para adultos. Ainda no campo jurídico a empresa entrou com recurso na Secretaria do Meio Ambiente do Estado para que pudesse voltar a funcionar. O gestor regional levantou os instrumentos juridicos do Setor Saúde para manter a empresa fechada e colocou publicamente que tinha estes instrumentos. A comunicação foi feita para a comunidade local reunida, para a imprensa e para o Ministério Público. Neste momento os ânimos da comunidade estavam acirrados quanto às repercussões sociais do fechamento da empresa. As razões de saúde para mantê-la fechada, de acordo com o diretor da DIR, podem ter servido para acalmá-los.

\section{Câmara dos Vereadores}

O rumor na cidade sobre as conseqüências sociais do fechamento da fábrica e da possível transferência dela para outro municipio levou a Câmara dos Vereadores a convocar uma audiência pública para discutir os riscos de fechar a empresa e do desemprego. Houve grande afluxo de pessoas que, de acordo com o gestor regional, buscavam entender a situação. Compareceram para a audiência o diretor da DIR, o diretor regional da CETESB, a secretária municipal de Saúde e um representante do Ministério do Trabalho. Foram explicados os motivos do fechamento da empresa e porque deveria continuar neste estado; a gravidade da situação de exposição e os cuidados que estavam sendo tomados com relação à saúde da população. A Câmara constituiu uma Comissão de Saúde que fez algumas reuniões com a população, trabalhadores e empresas locais. Em uma delas convidou especialistas em toxicologia que, também pertenciam ao grupo técnico assessor. Após alguns encontros este grupo feneceu. $\mathrm{O} d r$. Affonso opina que o esclarecimento do problema tornou o grupo dispensável.

\section{Sindicato de trabalhadores}

O sindicato de trabalhadores buscou mobilizar a população com discussões e passeata para reabrir a empresa diante da ameaça de desemprego. A DIR 
promoveu encontro com o sindicato para orientação quanto ao problema e suas conseqüências para a população do entorno. Após isto não houve mais indisposições entre as partes.

\section{ONG VIDÁGUA}

A primeira relação entre a VIDAGUA e o setor saúde foi de confronto. A VIDÁGUA colocou em seu site que a DIR estava omitindo informações. A DIR solicitou correção da informação. Tendo a primeira relação sido de embate, não houve estreitamento até o final do processo. A ONG manteve uma postura independente do setor saúde, sem agressões nem participação. Mantinha no entanto contato com a Secretaria Municipal de Meio Ambiente onde as informações eram disponibilizadas. Com relação a esclarecimentos por parte do Setor Saúde, houve encontro casual entre o diretor da DIR e um dos membros da ONG pelo qual foi esclarecida a situação (ambos moram no mesmo edificio).

A Ação Civil Pública impetrada pela VIDÁGUA contra a empresa não influenciou as ações de saúde.

\section{Delegacia de Polícia}

$\mathrm{O}$ delegado de dolícia convocou o diretor da DIR para esclarecimentos. $\mathrm{Na}$ reunião o delegado apresentou o Código Sanitário e perguntou se as funções de saúde estavam sendo cumpridas. Foi explicado ao delegado quais as funções da saúde constantes no Código Sanitário, o problema em si e o que estava sendo executado. Não houve outras convocações.

\section{Assistência versus pesquisa}

$\mathrm{O}$ grupo de profissionais que se envolveu na assistência às crianças, utilizando pessoal e área física do "Centrinho", tinha como meta garantir o atendimento emergencial especializado aos menores e colocar a questão da pesquisa como conseqüência deste atendimento. A direção do "Centrinho", que foi de extrema importância no primeiro momento, começou a apresentar demanda na área de pesquisa, com implicações sobre quem iria coordenar os estudos acadêmicos, 
publicações e apresentações de trabalhos. Nesta proposta afigurava-se o perigo de não garantia do acompanhamento das crianças após efetuado o diagnóstico. As discussões que giraram em torno deste problema levaram o "Centrinho" a colocar dificuldades para a continuidade da assistência no local. $\mathrm{O}$ acordado entre o diretor da DIR e o gestor municipal foi de que a assistência passaria a ser feita no Centro de Referência de Saúde do Trabalhador de Bauru, com os diversos profissionais já envolvidos, garantindo a continuidade. Os profissionais continuaram no atendimento das crianças sob a coordenação da dra. Niura e, a partir dai, ficando claro que pesquisas e publicações poderiam ser feitas desde que garantidos os cuidados futuros necessários.

$\mathrm{Na}$ medida em que se concluiu o estudo da exposição das crianças e se produziu um relatório pelo qual se indicava não ser necessária a expansão, naquele momento, da área de estudo; uma vez que a assistência às crianças estava garantida e que as que necessitavam de atendimento hospitalar estavam tratadas e as medidas de remediações tinham sido feitas, o diretor da DIR retomou a questão da relação entre pesquisa e assistência. Várias instituições solicitavam dados para publicações, uma vez que o campo era fértil. A idéia era dar oportunidade a quem no primeiro momento se dedicou ao trabalho. Estes deveriam conduzir o processo, embora sem se apropriar dele, evitando interesses outros que pudessem comprometer a questão assistencial. A primeira reunião entre o gestor regional e o grupo de assistência se deu no primeiro trimestre de 2003. Foi proposta a criação de um grupo de investigação e se buscou articulações para que a dra. Niura continuasse na coordenação dos trabalhos. Acertou-se que os dados seriam públicos e que as pesquisas seriam feitas, desde que respaldadas por comitês de ética. O grupo ganha corpo e afloram problemas éticos e técnicos. O diretor da DIR julgou que sua participação caracterizava uma postura institucional e se retirou do processo, deixando o grupo independente. Até o momento o grupo funciona mantendo reuniões periódicas, assistência e publicações. 
A relação com o Ministério Público e a remediação da área

O Ministério Público do Meio Ambiente encaminhou oficio para a DIR, em fevereiro de 2002, solicitando esclarecimentos sobre a população da área contaminada. O diretor da DIR fez contato com o promotor, apresentando a proposta de estreitamento dos laços para aclarar o caso. Em seguida houve reunião na qual estiveram presentes os promotores do Meio Ambiente, da Infância e da Adolescência e do Trabalho. Por parte dos atores do executivo regionais, a DIR, a CETESB e o gestor municipal. Cada órgão colocou seu posicionamento, detalhou seu plano de trabalho, quais as providências já tomadas e o que estava sendo executado. Ficou acertado o encaminhamento de todos os documentos produzidos no processo de trabalho para o Ministério Público. A DIR encaminhava os laudos de exames dentro de uma periodicidade acordada, mantendo sigilo sobre a identificação dos pacientes. Após esta primeira reunião, foram feitas mais algumas, sempre buscando discutir tecnicamente e fazer encaminhamentos. As reuniões entre o Ministério Público e empresa se davam em momentos diferenciados, sem a presença da DIR, e com enfoques juridicos. Não houve injuções juridicas contra o setor saúde.

Quando a DIR recebeu o relatório CVE/DOMA contendo a análise dos dados da investigação epidemiológica relativa á exposição a chumbo em crianças e à avaliação dos fatores relacionados aos níveis de plumbemia e às orientações de remediação proposta pelo grupo de suporte técnico, o gestor regional passou a se preocupar em como encaminhar as medidas de controle. Em discussão com a CETESB foi informado de que se houvesse o encaminhamento pelas vias formais judiciárias, o processo se arrastaria por anos. Na continuidade da discussão fícou acertado que o caso seria levado ao Ministério Público em reunião agendada. Seria feita a proposta de remediação capitaneada pelo municipio, sendo realizada e custeada pela empresa e supervisionada pela CETESB. Da reunião com o Ministério Público participaram a DIR, a CETESB e o gestor municipal. Foi decidido cobrar da administração municipal a responsabilidade pela condução das medidas de controle ambiental. A empresa foi acionada pela DIR e CETESB quando foi elaborada a lista de atividades a serem efetuadas. A decisão foi levada 
ao então prefeito de Bauru através do Ministério Público, da DIR e da CETESB. O prefeito entendeu a ação como prioritária e convocou todas as secretarias municipais envolvidas no assunto, no sentido de resolver o problema. $O$ município foi coordenador das ações e também executou várias atividades de remediação. Ao se encerrarem as atividades de saneamento ambiental (janeiro de 2003), a midia regional e estadual se retiraram do processo.

Questão 2. Como Vossa Senhoria avalia o papel do nível central?

Fragmentado. Parecia se tratar de várias secretarias. No início do processo o Instituto Adolfo Lutz colocava empecilhos à realização das avaliações de chumbo no sangue. Foram necessárias articulações com o diretor do Lutz. Depois o trabalho correu bem. Quanto às Vigilâncias (Epidemiológica e Sanitária) as discussões corriam em paralelo, o que dificultava o trabalho, embora não o tivesse impedido. Houve ocasiões em que as visitas à área por parte da Vigilância Sanitária foram feitas sem comunicação à DIR.

Quanto ao grupo de suporte técnico, as orientações ligadas à Vigilância Epidemiológica chegavam, mas as ligadas à Vigilância Sanitária não chegavam. Havia segurança nas orientações da Vigilância Epidemiológica.

Questão 3. Avaliando os processos das demais áreas contaminadas chegamos a pensar que Bauru foi um caso único, cuja liderança, por características próprias, possibilitou o encaminhamento a contento de todas as fases do trabalho. $\mathrm{O}$ que Vossa Senhoria acha disto?

Não acho que se trata de uma questão pessoal, durante o processo foram encontradas várias lideranças que tomaram o trabalho para si e o levaram adiante. O acaso também contribuiu. Às vezes penso que se não tivesse sido feito o acordo para remediar a área contaminada onde existem residências, talvez se conseguisse um processo mais abrangente. Outras questões na DIR se arrastam sem solução, o que reforça que as caracteristicas individuais não são as mais decisivas. No caso do chumbo em Bauru houve delegação completa por parte do nivel central para todas as articulações possíveis. Não é o que sinto em algumas outras áreas. A 
própria Secretaria precisa assumir que existem atores nos diversos niveis. Ter clareza das instâncias, de suas responsabilidades e saber delegar. Faz-se necessário investir no conhecimento técnico e gerencial para o enfrentamento de problemas como este. O Estado precisa começar a pensar estrategicamente e investir em pessoas agregadoras que possam assessorar quem está na linha de frente. 
Anexo 2

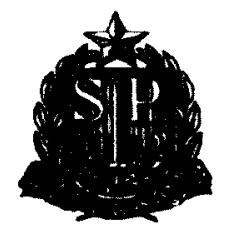

$$
\begin{gathered}
\text { SECRETARIA DE ESTADO DA SAÚDE } \\
\text { COORDENADORIA DE SAUUDE DO INTERIOR } \\
\text { DIREÇĀO REGIONAL DE SAÚDE DE BAURU - DIR X } \\
\text { Rua Quintino Bocaiúva, 5-45 Bauru/SP } \\
\text { Fone (0xx14) 235-0173 Fone/Fax (0xx14) 235-0172 } \\
\text { E-mail: gvedirx@adaptanet.com.br }
\end{gathered}
$$

D E C L A R AÇ Ã O

Eu,

R.G. $\mathbf{n}^{0}$ , residente

na cidade de Bauru, AUTORIZO os técnicos da Secretaria

Municipal de Bauru e do Instituto Adolfo Lutz - Bauru, a

coletarem sangue para análise de dosagem de chumbo, do meu

filho(a)

,nascido(a) em

Bauru/SP, de 2002.

Assinatura

\section{AUTORIZAÇÃO No.}




\section{Anexo 3}

Questionário de investigação aplicado na área.

\section{PESQUISA DE CHUMBO}

Tipo: INDIVIDUOS EXPOSTOS

N.:

Nome:

Data de nascimento:

1

Idade: (meses/anos)

Sexo: ( ) masculino ( ) feminino Raça:

Gestante: ( ) sim ( ) não Se sim, preencher:

Tempo de gestação:____(semanas/meses) Dt. Ültima menstruação:

Endereço:

Nome do pai/mãe e/ou responsável:

Telefone para contato: ( )

Distância da fonte: metros.

Há quanto tempo reside no local? anos.

Quantas pessoas residem na casa: De 0 a 12 anos:

13 anos e mais:

A criança tem algum problema de saúde? ( ) sim ( ) não

Se sim,especificar:

Tempo de permanência na residência, ao dia, em horas: horas.

Tempo de permanência na área, ao dia, em horas: horas.

Na residência tem horta? ( ) sim ( ) não

Na residência tem pomar? ( ) sim ( ) não

Come os alimentos produzidos horta/pomar? ( ) sim ( ) não

A água utilizada para beber/preparo de alimentos/banho e etc. é:

( ) rede pública

( ) poço

Toma leite industrializado? ( ) sim ( ) não

Se não, qual a fonte? 
Come terra? ( ) sim ( ) não

Brinca ou se banha em: ( ) lagoa ( ) rio ( ) racho

Em caso afirmativo onde (nome e local)?

Existência de outras fontes de contaminação: () $\operatorname{sim}($ ) não

Se sim, trabalhou ou faz uso de:

Cerâmica vitrificada artesanal para alimentos quentes ( ) sim （）não

Brinquedos importados chineses () sim ( ) nāo

Baterias de carros (local/redor) ( ) sim ( ) não

Zarcão nos portōes ou na casa ( ) sim ( ) não

Outros fatores (descrever)

Alguém da residência trabalha na empresa em questão? ( ) sim ( ) não

Se sim, especificar.

Há quanto tempo trabalha? (dias/meses/anos).

Qual o cargo/função?

Grau de parentesco com a criança:

Lava roupa da empresa em casa? ( ) sim ( ) não

Alguém da residência trabalha em empresa de:

$($ ) bateria () pigmentos () tintas () cerâmica

Se sim, especificar.

Exames laboratoriais:

Data da coleta: 1

Resultado:

Asfalto: $\operatorname{sim}($ ) não( )

Nome do pesquisador:

Data da pesquisa: 1

Nome do informante: 
Anexo 4

Análises de alimentos

Fevereiro de 2002

\begin{tabular}{|c|c|c|c|}
\hline Data & Tipo & Data & Resultado \\
\hline $15 / 02$ & 01 Coleta de água / Córrego da Vargem Limpa & $20 / 03$ & Satisfatório \\
\hline $15 / 02$ & 01 Coleta de água / Córrego da Vargem Limpa & $20 / 03$ & Satisfatório \\
\hline $20 / 02$ & 01 Coleta de água/poço DAE - N. José Regino & $20 / 03$ & Satisfatório \\
\hline $20 / 02$ & 01 Coleta de água/poço DAE - N. José Regino & $20 / 03$ & Satisfatório \\
\hline $26 / 02$ & 01 Coleta de água / poço Zoológico - 1 & $20 / 03$ & Satisfatório \\
\hline $26 / 02$ & 01 Coleta de água / poço Zoológico - 2 & $20 / 03$ & Satisfatório \\
\hline $26 / 02$ & 01 Coleta de água / poço Zoológico - 3 & $20 / 03$ & Satisfatório \\
\hline $26 / 02$ & 01 Coleta de água / poço Zoológico - 4 & $20 / 03$ & Satisfatório \\
\hline $26 / 02$ & 01 Coleta de água / poço Zoológico - 5 & $20 / 03$ & Satisfatório \\
\hline $26 / 02$ & 01 Coleta de água / poço Zoológico - 6 & $20 / 03$ & Satisfatório \\
\hline Totais & 10 amostras & & \\
\hline
\end{tabular}

Março de 2002

\begin{tabular}{|c|c|c|c|}
\hline Data & Tipo & Data & Resultado \\
\hline $01 / 03$ & 01 Coleta de leite in natura / chácaras vizinhas & $03 / 04$ & Insatisfatório \\
\hline $01 / 03$ & 01 Coleta de berinjela / chácaras vizinhas & $03 / 04$ & Satisfatório \\
\hline $01 / 03$ & 01 Coleta de hortelã / chácaras vizinhas & $03 / 04$ & Insatisfatório \\
\hline $01 / 03$ & 01 Coleta de ovos / chácaras vizinhas & $03 / 04$ & Insatisfatório \\
\hline $01 / 03$ & 01 Coleta de couve / chácaras vizinhas & $03 / 04$ & Satisfatório \\
\hline $01 / 03$ & 01 Coleta de laranja / chácaras vizinhas & $03 / 04$ & Satisfatório \\
\hline $01 / 03$ & 01 Coleta de abacate / chácaras vizinhas & $03 / 04$ & Satisfatório \\
\hline $01 / 03$ & 01 Coleta de mamão / chácaras vizinhas & $03 / 04$ & Satisfatório \\
\hline $11 / 03$ & 01 Coleta de água / chácara das Acácias & $20 / 03$ & Satisfatório \\
\hline $11 / 03$ & 01 Coleta de água / acumuladores Ajax & $20 / 03$ & Satisfatório \\
\hline $11 / 03$ & 01 Coleta de água / chácara Bighetti & $20 / 03$ & Satisfatório \\
\hline Totais & 11 amostras & & \\
\hline
\end{tabular}

Como se pode observar, em fevereiro de 2002, as análises de ovos, hortelã e leite in natura, segundo laudos do Instituto Adolfo Lutz de São Paulo, apresentaram concentrações de chumbo acima dos valores preconizados pela Agência de Vigilância Sanitária do Ministério da Saúde. 
Abril de 2002

\begin{tabular}{|c|l|c|c|}
\hline Data & \multicolumn{1}{|c|}{ Tipo } & Data & Resultado \\
\hline $23 / 04$ & 01 Coleta de Almeirão / R. Américo Oliva 8-7 & $20 / 05$ & Satisfatório \\
\hline $23 / 04$ & 01 Coleta de Almeirão/R. Naoki Shinohara 3-52 & $20 / 05$ & Insatisfatório \\
\hline $26 / 04$ & 01 Coleta de água / R. Américo Oliva 8-7 poço & $20 / 05$ & Satisfatório \\
\hline $26 / 04$ & 01 Coleta de água-mina/R. Natal Fornazari, 6-65. & $20 / 05$ & satisfatório \\
\hline $26 / 04$ & 01 Coleta de cebolinha / Natal Fornazari, 6-65 & $20 / 05$ & Satisfatório \\
\hline $26 / 04$ & 01 Coleta de Hortelã / R. Natal Fornazari, 6-65 & $20 / 05$ & Satisfatório \\
\hline $26 / 04$ & 01 Coleta de alface / R. Natal Fornazari, 6-65 & $20 / 05$ & Satisfatório \\
\hline $26 / 04$ & 01 Coleta de cebolinha/R. Ariovaldo Maciel Qd 05 & $20 / 05$ & Satisfatório \\
\hline $26 / 04$ & 01 Coleta de mandioca / chácara Bighetti & $20 / 05$ & Insatisfatório \\
\hline $26 / 04$ & 01 Coleta de mandioca / Carlos Teixeira Qd 10 & $20 / 05$ & Insatisfatório \\
\hline $26 / 04$ & 01 Coleta de Salsa / chácaras Bighetti & $20 / 05$ & Satisfatório \\
\hline $26 / 04$ & 01 Coleta de Ovos / chácaras Bighetti & $20 / 05$ & Satisfatório \\
\hline $26 / 04$ & 01 coleta de leite in natura / chácara 3 M & $20 / 05$ & Insatisfatório \\
\hline $26 / 04$ & 01 Coleta de cebolinha verde / chácara 3 M & $20 / 05$ & Satisfatório \\
\hline $26 / 04$ & 01 Coleta de Salsa / chácaras 3 M & $20 / 05$ & Satisfatório \\
\hline $26 / 04$ & 01 Coleta de mandioca / chácara 3 M & $20 / 05$ & Satisfatório \\
\hline Totais & & & \\
\hline
\end{tabular}

Em abril de 2002 novas coletas de almeirão, ovos, leite e mandioca também apresentaram niveis de chumbo acima do tolerado pela legislação.

Em 12 de abril de 2002, diante dos resultados dos laudos insatisfatórios de alimentos colhidos nas proximidades da empresa, houve a recomendação, dentre outras, que não fossem consumidos quaisquer alimentos produzidos na área até conclusão definitiva dos reais riscos à população da região

Setembro de 2002

\begin{tabular}{|c|c|c|c|}
\hline Data & \multicolumn{1}{|c|}{ Tipo } & Data & Resultado \\
\hline $18 / 09$ & 01 Coleta de leite in natura caprino/ chácara 3M & $28 / 10$ & Satisfatório \\
\hline $18 / 09$ & 01 Coleta de leite in natura caprino/ chácara 3M & $28 / 10$ & Insatisfatório \\
\hline $18 / 09$ & 01 Coleta de ovos/ chácara 3M & $28 / 10$ & Satisfatório \\
\hline
\end{tabular}




\section{Anexo 5}

Primeira reunião do grupo de suporte técnico

\section{RELATÓRIO DA $1^{a}$ OFICINA TÉCNICA PARA NORMATIZAÇÃO DOS NIVEIS POPULACIONAIS DE CHUMBO - SÃO PAULO/BRASIL - 21/05/2002}

Frente à contaminação por chumbo de crianças residentes no entorno da empresa Ajax Acumuladores na cidade de Bauru, o CVE, por meio da Divisão de Doenças Ocasionadas pelo Meio Ambiente e o CENEPI, por meio da Coordenação Geral de Vigilância Ambiental, promoveram uma reunião técnica denominada " 1 " Oficina Técnica para Normalização dos Níveis Populacionais de Chumbo" com especialistas na questão para discussão dos seguintes temas:

- a partir dos resultados obtidos até o momento de análises de plumbemia nas crianças, definir a conduta com relação à população.

- discussão de valores de referência de plumbemia para crianças.

- discussão de valores de referência de plumbemia para adultos.

- discussão de valores de referência de plumbemia para mulheres em idade fértil.

- discussão de valores de referência para nutrizes.

Devido à complexidade e extensão da pauta os organizadores estimam que serão necessárias outras reuniões do grupo na medida em que as decisões acordadas servirão para subsidiar a abordagem em outras áreas contaminadas no Estado. Ressalte-se que a discussão dos níveis referenciais de plumbemia para gestantes será efetuada em conjunto com o ECLAMC.

O grupo discutiu e decidiu consensualmente acerca dos temas propostos, tendo as seguintes recomendações:

1- Sobre a conduta frente à população:

1.1 - Retirada ou não da população da área:

O grupo discutiu e decidiu pela não retirada da população neste momento, levantando algumas condutas a serem tomadas:

- realizar medidas de saneamento do meio como asfaltar as ruas no raio de um $\mathrm{km}$ da empresa e colocar pisos e calçadas nas casas, para minimizar a exposição ao chumbo do solo;

- investigar outras possiveis fontes de contaminação no domicilio e peridomicilio baseado em listagem de fontes e exposição ao chumbo e visita ao local a ser efetuada em conjunto com dr. Eduardo Capittani;

- ter medidas de intervenção diferenciadas para as crianças com niveis muito elevados de chumbo no sangue. Seguindo os critérios de tratamento do CDC, as 
crianças tratadas não deveriam retornar para a área antes de serem tomadas as medidas de controle sugeridas, além das determinadas pela CETESB;

- realizar investigação mais aprofundada de outras fontes de exposição para a criança que apresentou plumbemia de $90 \mu \mathrm{g} / \mathrm{dL}$.

1.2 - Comunicação de risco:

- investir na formação de profissionais em comunicação de risco para a população e imprensa;

- orientação da população, individualmente e através de seus órgãos de representação, acerca dos cuidados preventivos para evitar contaminação por chumbo;

- envolvimento da população na investigação de outras possíveis fontes de chumbo na região.

\section{3 - Parceria com o Laboratório de Saúde Pública:}

- foi realizada discussão acerca da complexidade das análises de chumbo de sangue e urina, a sensibilidade do método e a dificuldade de se contar com laboratórios de boa qualidade para os exames. Todos foram unânimes em concluir que o Instituto Adolfo Lutz é um laboratório de excelência e que todos os esforços deveriam ser envidados para que continue a realizar as análises de diagnóstico e acompanhamento do caso. Para isto o grupo solicita do Senhor Secretário da Saúde e ao Ministério da Saúde o apoio ao IAL para que, como Laboratório de Saúde Pública, possa atender às demandas na área de Vigilância Ambiental e Saúde;

- algumas pessoas da comunidade, residentes fora do raio de um $\mathrm{km} \mathrm{da} \mathrm{Ajax,}$ realizaram análises laboratoriais de chumbo no sangue. Alguns desses resultados foram acima de $10 \mu / \mathrm{dl}$. O grupo discutiu e decidiu pela investigação destes casos buscando possíveis fontes de contaminação por chumbo e se for o caso repetição das análises no IAL;

- quanto à repetição das análises laboratoriais nas crianças com níveis de chumbo no sangue superiores ou iguais a $10 \mu \mathrm{g} / \mathrm{dL}$ o grupo recomenda continuar seguindo os critérios do CDC.

As crianças com niveis de chumbo no sangue menores que $20 \mu \mathrm{g} / \mathrm{dL}$ só repetirão as análises após seis meses.

1.4 - Tratamento com quelação das crianças:

- seguir protocolo do CDC para quelação e investigação da exposição caso a caso quando for indicado;

- manter contato com CDC para discussão de tratamento e acompanhamento; 
- testes de plumbúria devem ser realizados diariamente se o tratamento for realizado com EDTA e semanalmente se o tratamento for com o DMSA, sendo este preferencial em função de passar pela barreira hematoencefálica;

- as análises de pulmbemia devem ser realizadas 15 dias após o fim do tratamento.

1.5 - Diagnóstico de saúde da população

A avaliação das crianças com niveis de chumbo no sangue superiores a $10 \mu \mathrm{g} / \mathrm{dL}$ continuará sendo realizada pela equipe de neuropediatria da Faculdade de Medicina da UNESP/Botucatu, profissionais do Hospital de Reabilitação de Bauru - Centrinho - (composto por fonoaudiólogos, médico otorrinolaringologista, fisioterapeutas e eventualmente outras especialidades que se fizerem necessárias), da Faculdade de Psicologia da UNESP de Bauru (avaliação psicológica) e Faculdade de Odontologia de Bauru - FOB (avaliação odontológica).

\section{6 - Estudo de seguimento da população}

As crianças serão acompanhadas pela equipe de neuropediatria da Faculdade de Medicina da UNESP/Botucatu e demais profissionais envolvidos na avaliação.

2 - Níveis de referência de plumbemia para crianças:

- O grupo decidiu por continuar seguindo os critérios do CDC de $10 \mu \mathrm{g} / \mathrm{dL}$ para intervenção (necessidade de avaliação do estado de saúde na criança). Para exposição manter o critério de avaliação de plumbemia em população de referência.

3 - Valores de referência de plumbemia para adultos:

- para exposição: buscar referências de estudos populacionais no Brasil e no mundo para orientar e realizar avaliação de plumbemia em população de referência residente no município de Bauru;

- para intervenção: $40 \mu \mathrm{g} / \mathrm{dL}$ - investigação de possiveis efeitos na saúde.

4 - Níveis de referência de plumbemia para mulheres em idade fértil:

- o grupo discutiu a necessidade de se trabalhar com niveis menores que aqueles estabelecidos para o sexo masculino, na medida em que há mobilização do chumbo ósseo durante a gravidez e passagem para o feto pela placenta.

Faz-se necessária maior discussão.

5 - Níveis de referência de plumbemia para nutrizes:

Também não se chegou a um consenso, mas recomendou-se não suspender amamentação enquanto não se dispuser de análises do leite materno 
6 - Outros encaminhamentos:

6.1- Formação de uma comissão de profissionais especializados em toxicologia e epidemiologia em conjunto com os órgãos da Secretaria de Saúde do Estado e município para informação ao Ministério Público acerca das limitações e pertinência referentes aos seguintes temas:

- embasamento dos níveis de referência populacionais de chumbo.

- embasamento das ações de diagnóstico e controle de saúde.

- discussão da necessidade de realizar exames de plumbemia de toda a população e discussão de possíveis alternativas.

6.2 - O grupo discutiu a viabilidade de realizar tratamento homeopático em crianças com niveis de chumbo no sangue abaixo de 20 ou $25 \mu \mathrm{g} / \mathrm{dl}$; portanto aquelas que não receberão tratamento com quelantes, proposto pelo município de Bauru. Devido à não existência de estudos terapêtuticos em crianças, concluiu-se que trata-se de um ensaio clínico e deve seguir todos os protocolos relativos a este tipo de estudo. Discutiu-se que devido à grande sobrecarga de exames laboratoriais para a realização do ensaio clínico, caso se decidisse por fazê-lo, dever-se-ia buscar recursos de outras fontes.

7- Encaminhamentos:

- fazem-se necessárias novas discussões com as seguintes finalidades:

- continuidade da discussão dos níveis de referência;

- ceavaliação das condutas relativas à população a partir da existência de dados de contaminação ambiental a serem cedidos pela CETESB bem como os demais resultados dos exames na população exposta;

- cs resultados das discussões serão encaminhados aos níveis decisórios.

A próxima reunião será agendada em prazo de um mês, na dependência do laudo ambiental da CETESB. 
Anexo 6

Segunda reunião do grupo de suporte técnico

\section{RELATÓRIO DA $2^{a}$ OFICINA TÉCNICA PARA NORMATIZAÇÃO DOS NIVEIS POPULACIONAIS DE CHUMBO - SÃO PAULO/BRASIL - 23/07/2002}

Frente à contaminação por chumbo de crianças residentes no entorno da empresa Ajax Acumuladores na cidade de Bauru, o CVE, por meio da Divisão de Doenças Ocasionadas pelo Meio Ambiente e o CENEPI por meio da Coordenação Geral de Vigilância Ambiental, promoveram a segunda reunião técnica denominada " 2 a Oficina Técnica para Normatização dos Niveis Populacionais de Chumbo" com especialistas na questão para discussão dos seguintes temas:

- a partir dos resultados obtidos até o momento de análises ambientais e das avaliações de plumbemia nas crianças, definir a conduta com relação à população.

- discussão de relatório da avaliação de exposição para a imprensa.

- discussão da necessidade de estudo de exposição em adultos.

- discussão de proposta de normatização de procedimentos frente a episódios semelhantes no Estado.

O grupo discutiu e decidiu consensualmente acerca dos temas propostos, tendo as seguintes recomendações:

1- Conduta frente aos dados de avaliação ambiental e de exposição:

1.1- Em relação ao relatório ambiental:

$\mathrm{Na}$ primeira avaliação efetuada pela CETESB no solo da área foi retirado material com profundidade de 0 a $20 \mathrm{~cm}$, os níveis de chumbo foram abaixo dos valores de intervenção genéricos estabelecidos para solos no Estado de São Paulo. Após análise conjunta dos dados de saúde e ambiente, selecionou-se outras áreas de investigação e optou-se por analisar solo mais superficial. Foi colhido material com profundidade de 0 a $2 \mathrm{~cm}$. Em área mais próxima da empresa (raio aproximado de $200 \mathrm{~m}$ ) o solo se apresenta extremamente contaminado fazendo-se necessário a retirada de sua camada superficial. Em pontos localizados entre 200 e $400 \mathrm{~m}$ de distância aproximada da fonte, o solo também se mostrou impactado, porém a níveis mais baixos que a faixa próxima à indústria. Os níveis de chumbo no quintal da casa da criança que apresentou plumbemia de $90 \mu \mathrm{g} / \mathrm{dl}$ encontram-se também muito elevados. A investigação epidemiológica efetuada no local constatou que o morador anterior lavava baterias velhas na residência. Com relação à continuidade da investigação o grupo discutiu a necessidade de colher solo mais superficial e nos quintais das casas para análise, pois é a poeira que está mais disponivel para respiração e 
contato com as mãos das crianças. Foi recomendado colher poeira peridomiciliar da área e em local controle.

De acordo com os dados analisados até o momento pode-se supor que a contaminação do solo é superficial, por deposição da fonte de poluição atmosférica.

Ainda se aguardam os resultados das análises de poeira no interior das casas efetuadas pelo dr. Capitani.

\section{2 - Com relação à conduta a ser tomada}

O grupo discutiu que os dados de meio ambiente e saúde colhidos até o momento já dão subsídios suficientes para se produzir documento ao Ministério Público solicitando medidas de remediação ambiental com vistas a reduzir a exposição das crianças. Inicialmente serão produzidos laudos da CETESB e da Secretaria da Saúde. Uma comissão composta pelo dr. Tarcísio Buschinelli, dr. Eduardo Capitani, DIR Bauru, Município de Bauru e CVE se encarregarão de redigir um sumário executivo, fundamentando com bibliografia produzida a respeito, no qual devem constar a situação de exposição e as medidas a serem tomadas. Várias destas medidas já foram discutidas na primeira Oficina e incluem:

- realizar medidas de saneamento do meio como asfaltar as ruas no raio de um $\mathrm{km}$ da Empresa;

- colocar pisos nas casas de chão batido;

- colocar calçadas ao redor das casas;

- colocar grama nos quintais;

- limpar a poeira das casas.

2 - Com relação ao comunicado para a imprensa

O material produzido para o Ministério Público seria também encaminhado para a imprensa.

3 - Tratamento das crianças

Solicitou-se ao Ministério da Saúde urgência na compra da medicação para tratamento.

4 - Conduta com relação aos adultos

$\mathrm{Na}$ medida em que as plumbemias nas gestantes e nutrizes estão com níveis baixos, supõe-se que a via principal de absorção do chumbo das crianças seja pelos seus hábitos mão/boca. Espera-se que os niveis nos adultos em geral sejam baixos. Estabeleceu-se o limite para exposição em adultos de $25 \mu \mathrm{g} / \mathrm{dl}$.

Para avaliar a necessidade de estudo ampliado na população adulta, foi definido estudo preliminar com a população de maior risco composta de todas as mulheres cujas residências tenham crianças com plumbemias iguais ou superiores a $25 \mu \mathrm{g} / \mathrm{dl}$. Caso esta amostra de mulheres apresente níveis de chumbo no sangue elevados, se ampliará o estudo para os demais adultos. 
5 - Normatização de conduta frente a outros casos semelhantes no Estado Foi apresentada proposta inicial para discussão. Várias modificações foram sugeridas. O CVE responsabilizou-se por realizar as modificações e encaminhar aos participantes por email. Outras sugestões posteriormente incluídas estarão na pauta de discussão da próxima Oficina. 
Anexo 7. Distribuição das crianças e percentual de perdas entre os grupos segundo

realização dos exames de plumbemia antes e após medidas de remediação. Bauru, 2004.

\begin{tabular}{|c|c|c|c|c|c|}
\hline \multirow[b]{2}{*}{ Variável } & \multirow[b]{2}{*}{ Tatal } & \multicolumn{2}{|c|}{ Fizeram $2^{\circ}$ exame } & \multirow[b]{2}{*}{$\%$ de perdas } & \multirow[b]{2}{*}{ Valor de $p$} \\
\hline & & Sim & Não & & \\
\hline Sexo masculino ${ }^{1}$ & 171 & 137 & 34 & 19,9 & \\
\hline Sexo feminino & 140 & 104 & 36 & 25,7 & 0,22 \\
\hline Plumbemia de 10 a $14 \mathrm{ug} / \mathrm{dL}^{2}$ & 161 & 118 & 43 & 26,7 & 0,43 \\
\hline Plumbemia de 15 a $19 \mathrm{ug} / \mathrm{dL}^{2}$ & 80 & 65 & 15 & 18,8 & 0,83 \\
\hline Plumbemia de 20 a $39 u g / \mathrm{dL}^{2}$ & 67 & 55 & 12 & 17,9 & 0,61 \\
\hline Plumbemia de 40 e mais & 3 & 3 & 0 & 0,0 & \\
\hline Criança menor de 1 ano & 13 & 10 & 3 & 23,1 & \\
\hline Criança de 1 a 5 anos & 165 & 128 & 37 & 22,4 & \\
\hline Criança de 6 a 12 anos $^{1}$ & 133 & 103 & 30 & 22,6 & 0,99 \\
\hline
\end{tabular}

1 Teste do Chi-Quadrado

${ }^{2}$ Calculada diferença entre as médias de plumbemia no primeiro exame. 